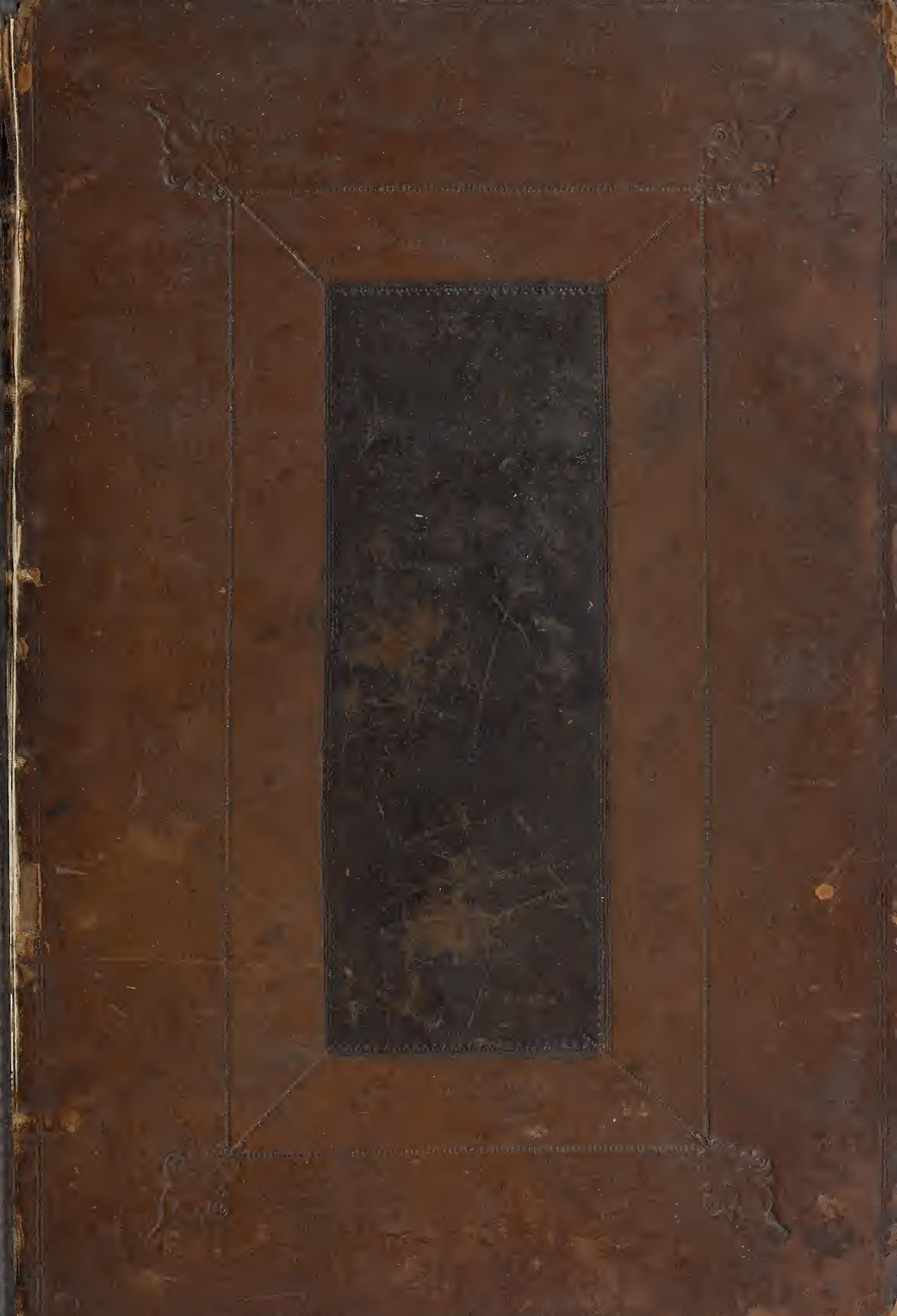




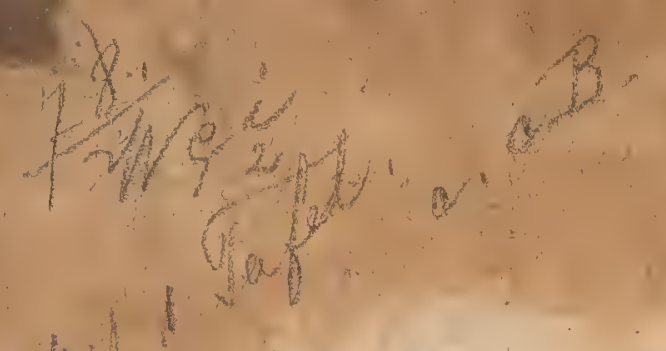


$\left(\begin{array}{c}1 \\ 1\end{array}\right.$

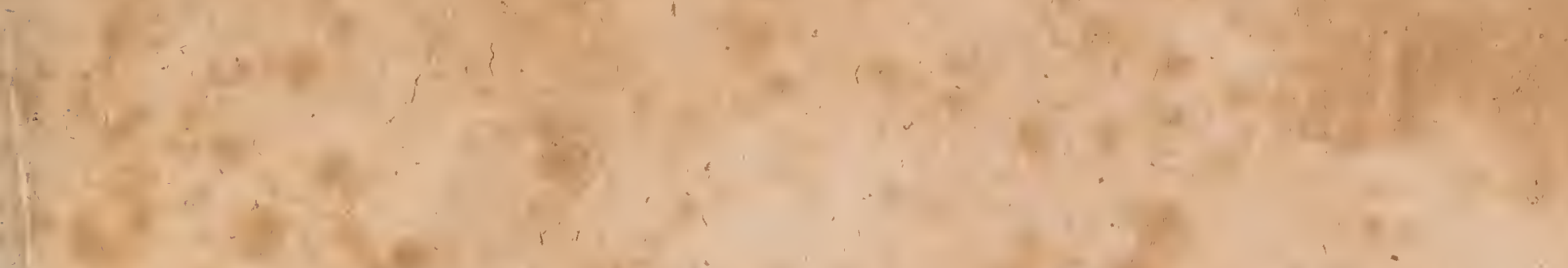

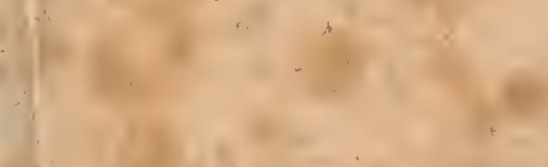

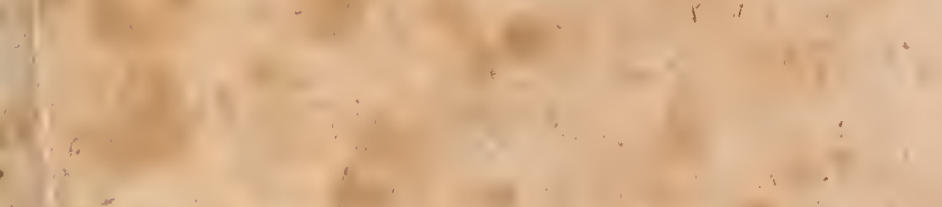

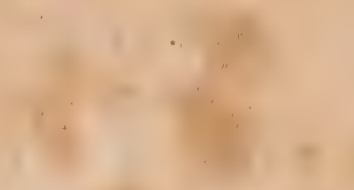
.
$3+\frac{1}{3}$

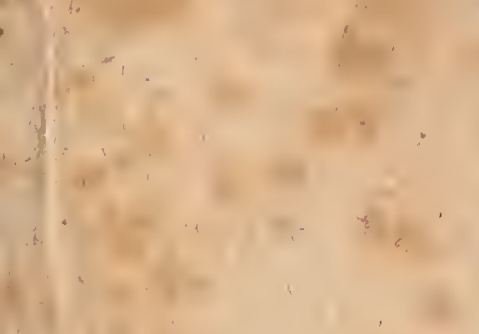

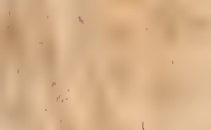

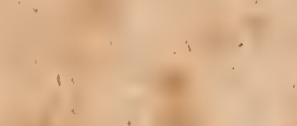

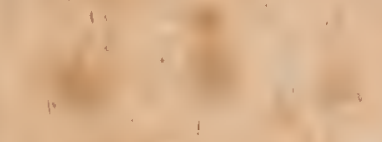
$+2$
,

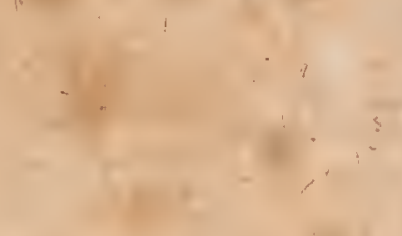

W:

,

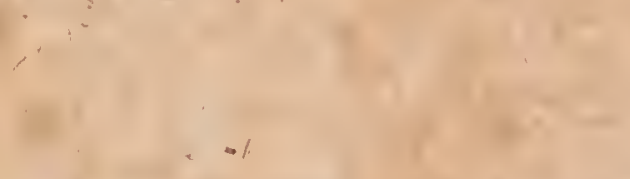

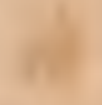

8.14

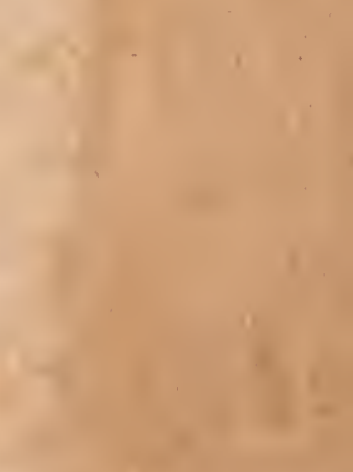

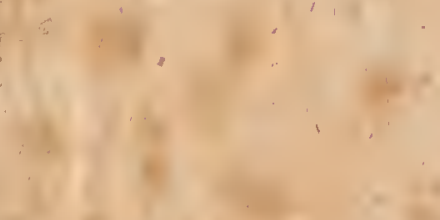

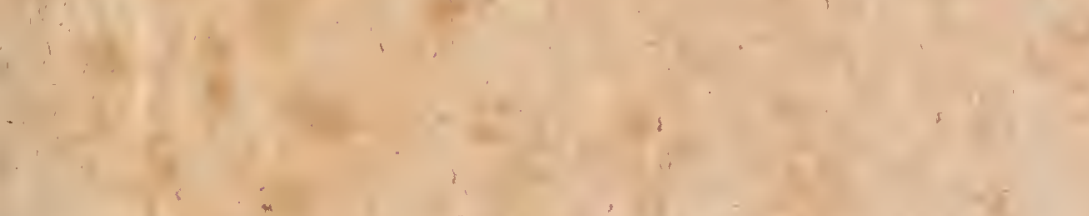

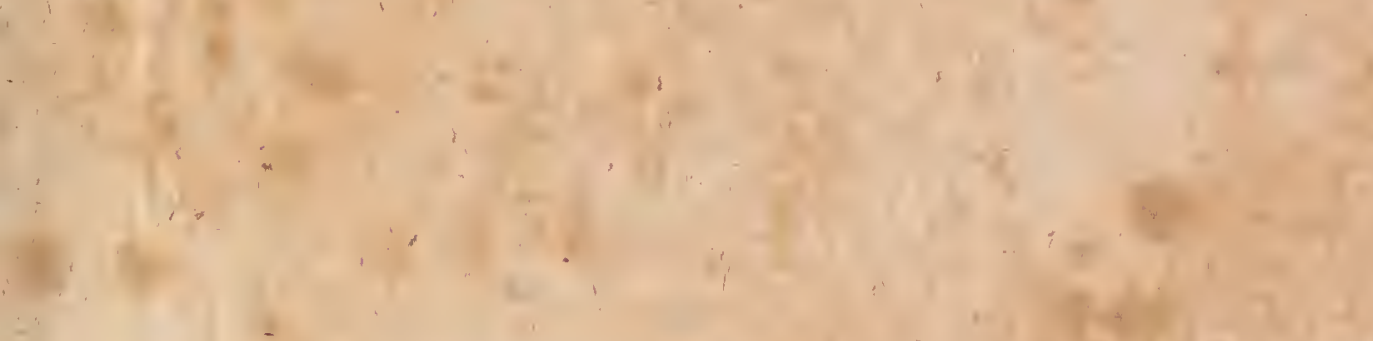

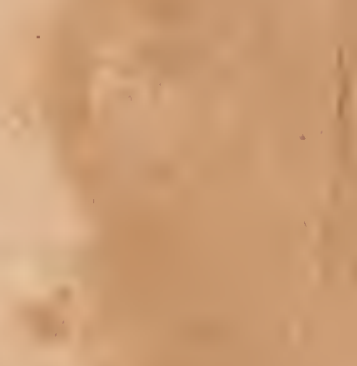

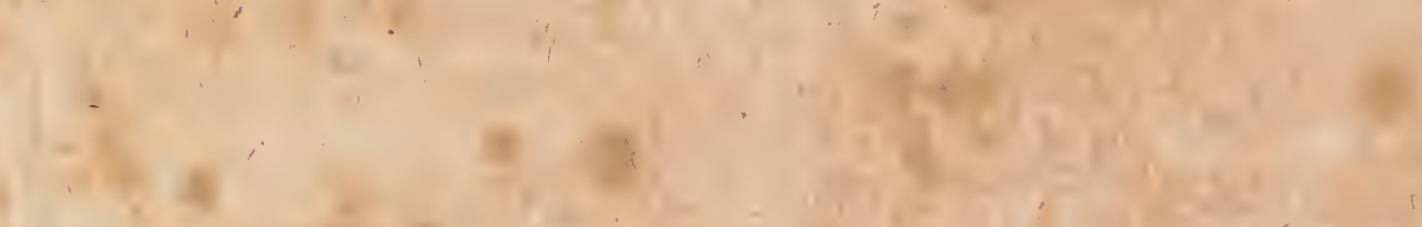

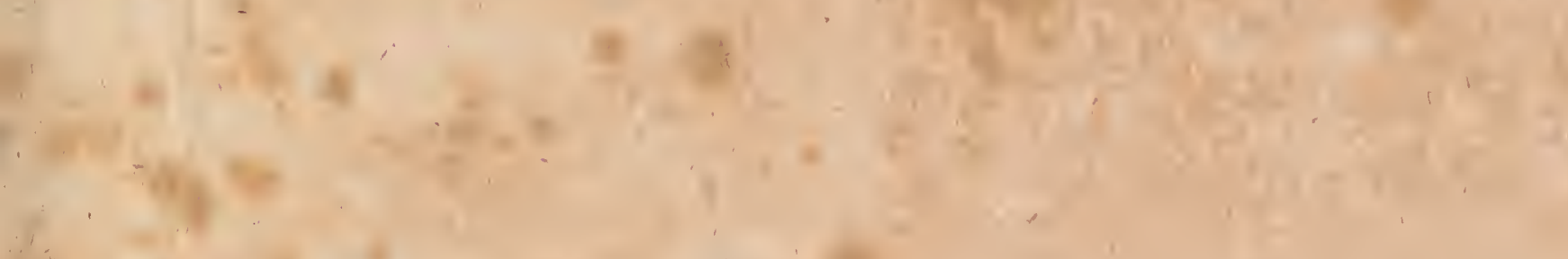

$14+4$

$x^{4}+y^{2}+y^{4}$

$\tan _{\mathrm{i}} \mathrm{k}$

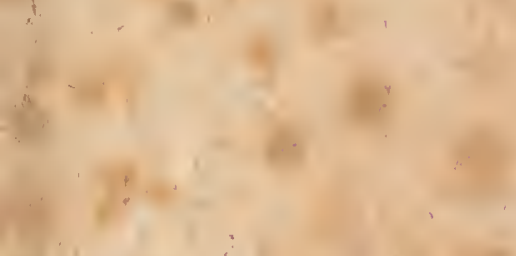

H.

6

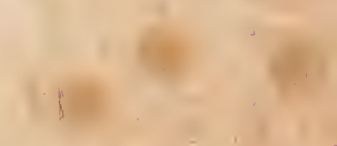

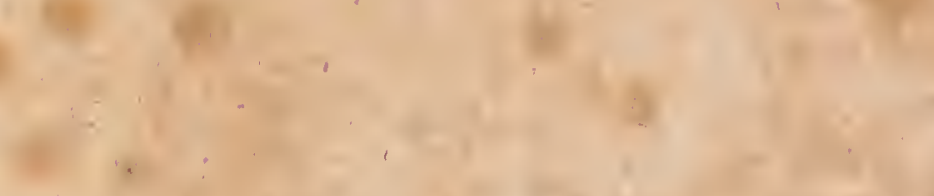

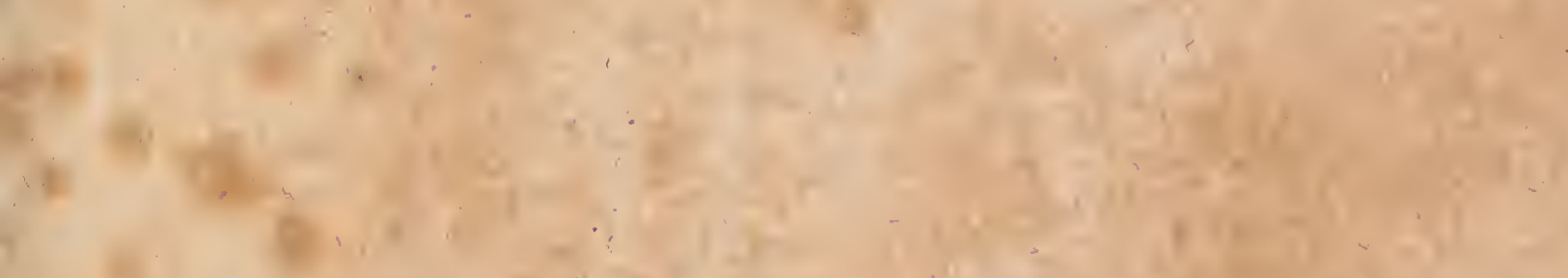

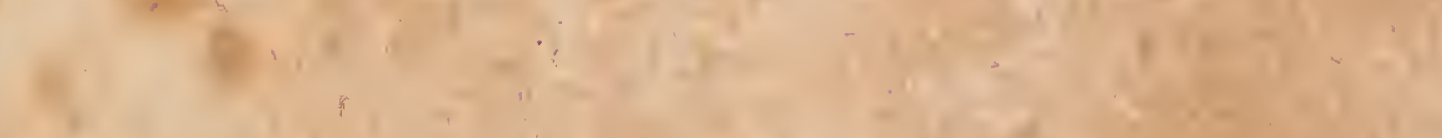

a

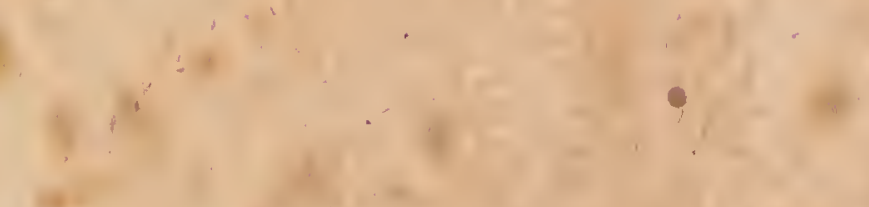

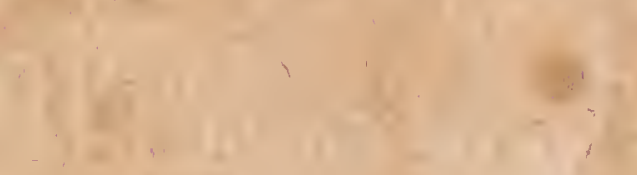

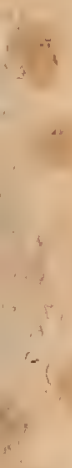

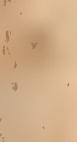

$+$

$e^{2}$

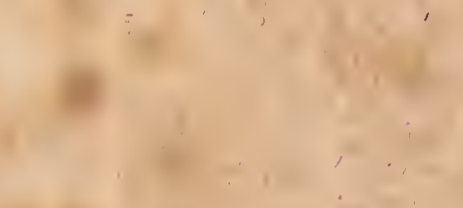

08

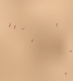

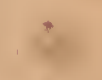

18

(1) $-1+2+2$

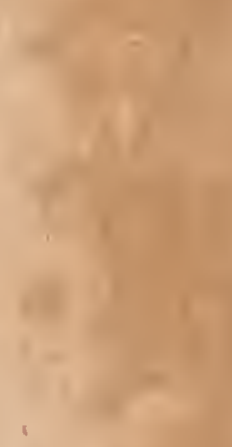

- 12

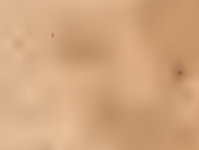<smiles>C1CC1</smiles>

,

i

1. 1.6

(y)

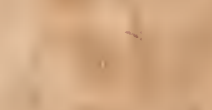

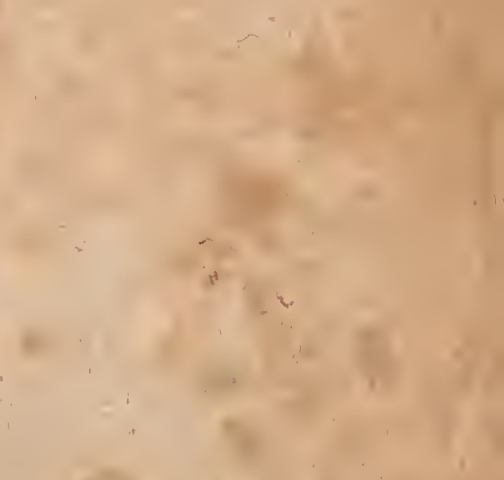

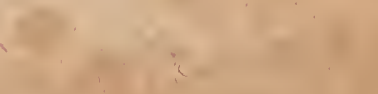




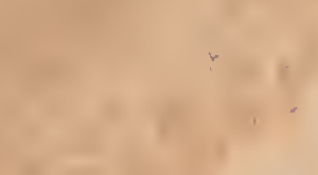

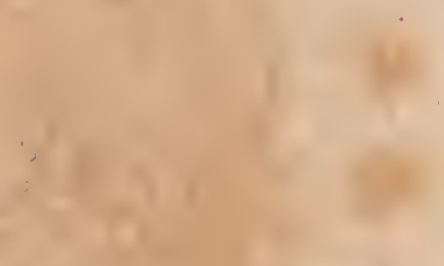

$+2+1+2$

1

z.

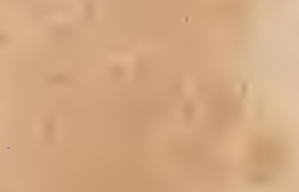
ton

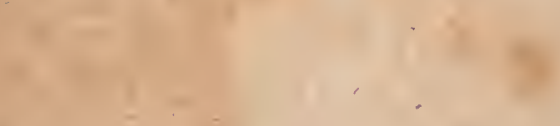

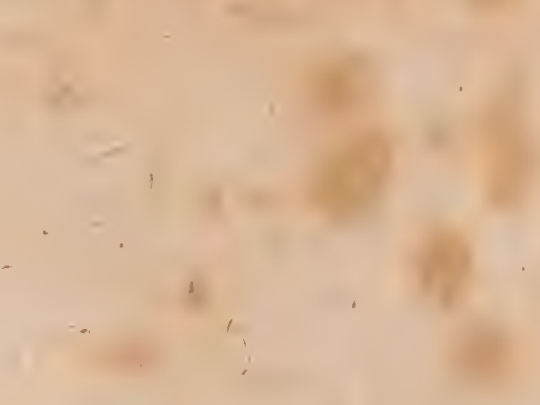

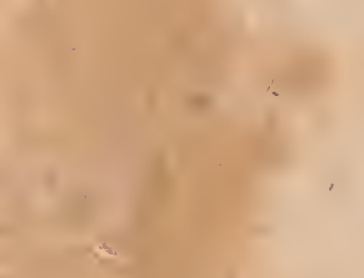

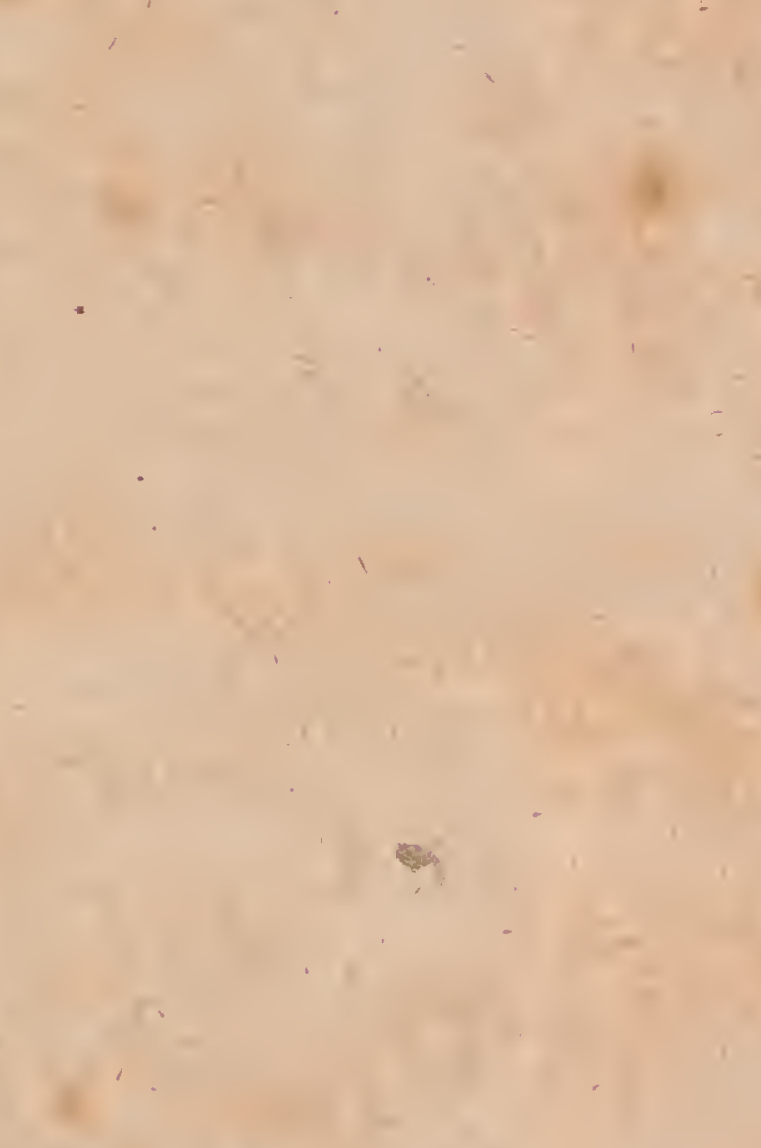

s.

4.

8

$x^{4}+2$

3

$$
\text { (1) }
$$

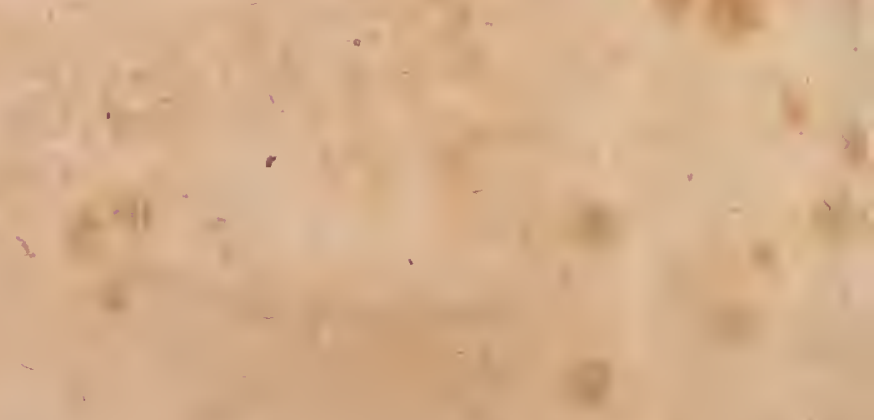

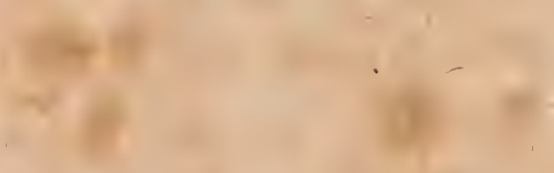$$
-
$$ 



\section{H R IST I A N I \\ H V G E N I I}

ZVLICHEMII, CONST. F.

HOR OLOGIVM OSCILLATORIVM.

S I V E

DE MOTV PENDVLORVM AD HOROLOGIA APTATO

DEMONSTRATIONES.

GE O M E T R I E

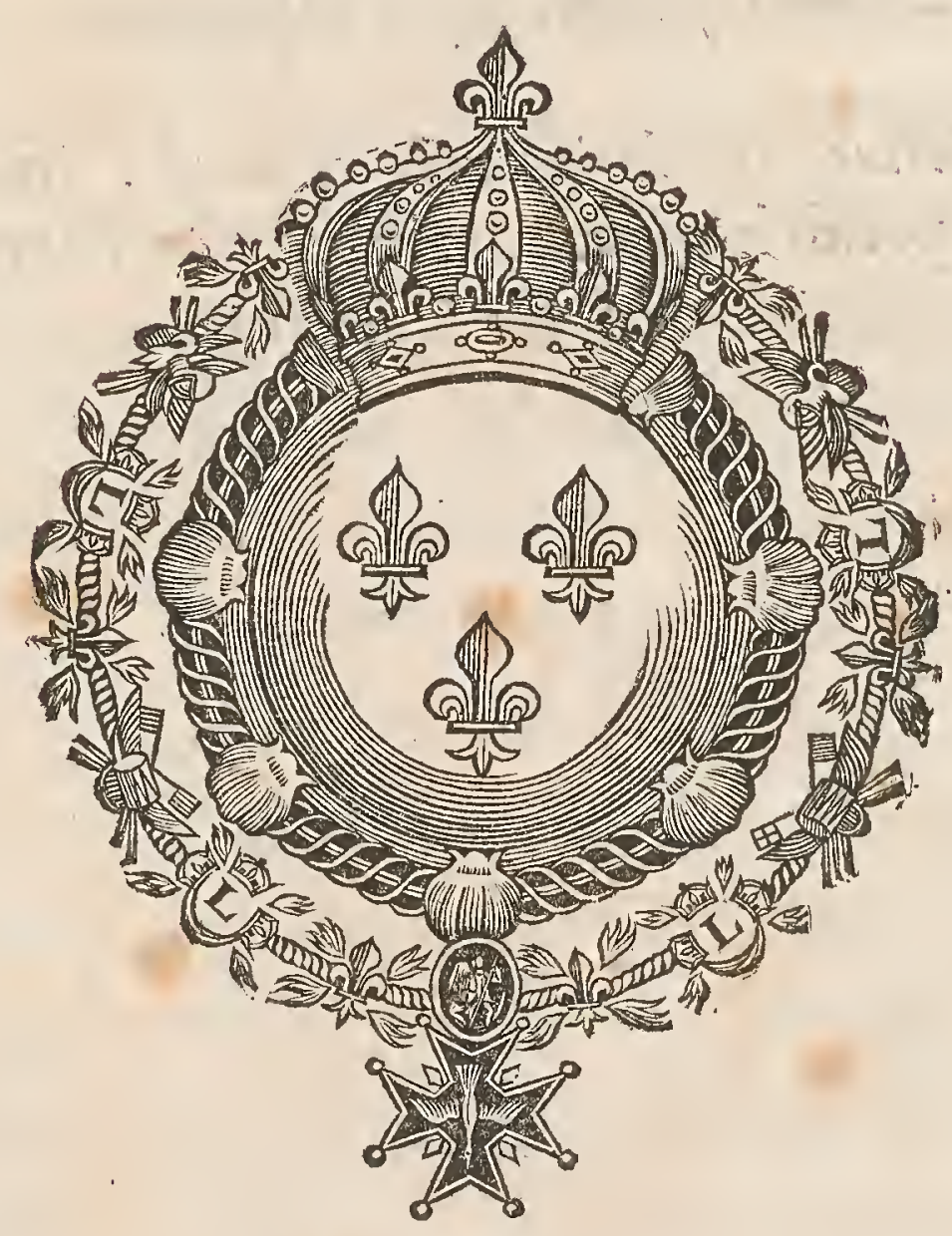

P A R I S I S,

Apud F. Muguet, Regis \& Illuftriffimi Archiepifcopi Typographum, viâ Citharæ, ad infigne trium Regum.

M D C L X X I I I.

CVM PRIVILEGIO REGIS 


\section{Dividitur liber hic in partes quinque, quarum}

Prima Defcriptionem HOR OL OG II OS CILLATORI I continet.

Secunda agit de Defcenfu gravium, \& motu corum in Cycloide.

Tertia de Evolutione er Dimenfione linearum curvarum.

Quarta de Centro Ofcillationis fen Agitationis.

Quinta alterius Horologii confructionem, in quo circularis eft penduli motus, exhibet, \& Theoremata de $V i$ Centrifuga. 


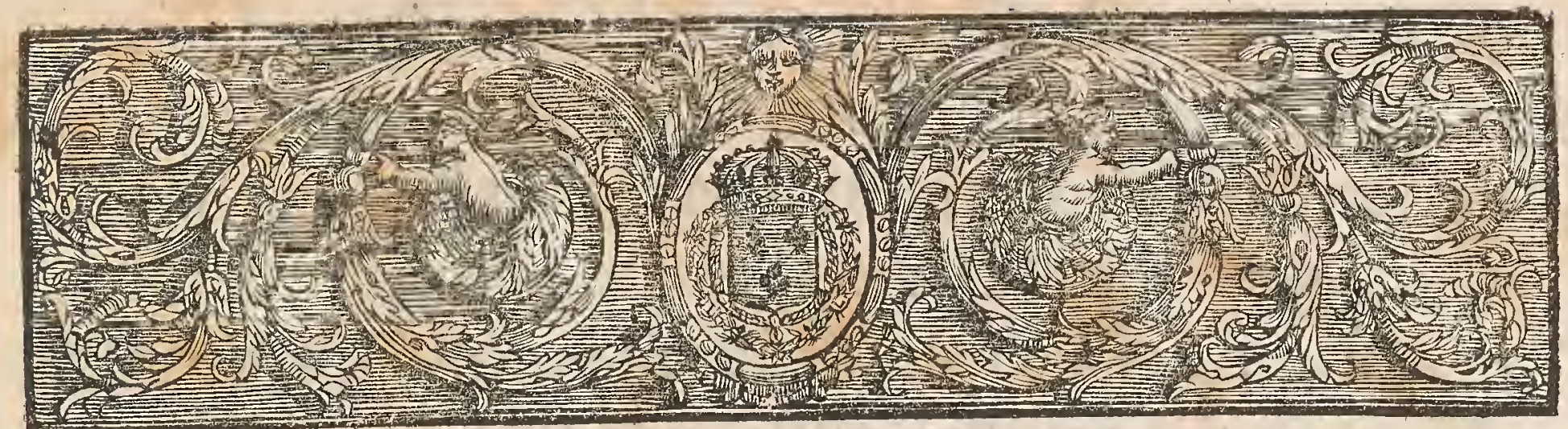

\section{LVDOVICO XIV,}

\section{FRANCIÆ ET NAVARRÆ REGI I NCL Y T O.}

2Ne A (5) ftitutamque hoc freculo Geometriam, Galliæ præcipue debemus. Hinc enim orti, qui magna me. liorique fui parte deperditam, ac veluti fepultam, inftaurarunt pri$\mathrm{mi}, \&$ in lucem reduxerunt. Quorum veftigiis infiftentes, ita eam deinde, per totam Europam, excoluere viri fubtiliffimi, ut pauca jam pofterorum induftrix ab his relicta videantur; veterum vero inventa longiffime prætervecti fint. Inh ac fcientia, quam femper admiratus fum $\&$ amavi plurimum, quandocunque ad eam animum applicui, illa mihi pre cæeteris propofui inveftiganda, qua vel ad vitæ commoda, vel ad Natura cognitionem, reperta prodeffe poffent. Tunc verò optimè o peram me collocaffe exiftimavi, cum in ea incidiffem, in quibus utilitas cum inveniendi difficultate, ac fubtilitate ali- 
qua, conjuncta foret. Quod fi commendationis nonnihil accerfere muneri noftro permittitur, ne prorfus indignum tua magnitudine appareat; non alias felicius, quam in hoc Horologii invento, utrumque illud me confecutum effe profiteor. Etenim, cum ex parte mechanicum fit inventum; ex parte altera, eaque multò præcipua, geometricis principiis conftet; id quod ad pofteriorem hanc attinet, non levi conamine, ex intimis artis receflibus petendum fuit: adeo quidem, ut inter omnia, quæ impenfiore ftudio hactenus pertractaverim, haud dubie primum huic fpeculationi locum tribuam. Quænam vero in his fit utilitas, non eft quod multis, Rex potentiflime, oftendere tibi laborem. Non folum enim diutinâ experientiâ compertum habes, ex quo regiæ tuæ penetralibus recipi meruere Automata noftra, quantum, æquabili horarum demonftratione, cæteris hujufmodi machinationibus excellant: fed \& potiores ufus eorum, quibufque jam inde à principio mihi deftinata fuere, non ignoras. Illos fcilicet, quos \& in Caleftium obfervationibus, \& in Longitudinibus locorum inter navigandum dimetiendis, praftare apta funt. Tuo enim juffu, non femel, per mare vecta fuere Horologia noftra. Tuis aufpiciis eadem nec pauca, Aftronomiæ ufibus dicata, vifuntur in præclara illa Vraniæ arce, quam infigni nuper magnificentia, quantaque antehac regum nemo, exædificandam curafti. Quæ quoties mecum reputo, toties de fortuna hu- 
jus inventi, quod in tua tempora inciderit, non parum mihi gratulari foleo. Nec jam requiret quifquam, opinor, qui quantum tibi illud debeat intelliget, cur lucubrationes has, quibus rationem ejus omnem defcriptionemque explicui, augutto Nomini tuo infcribendas duxerim. Ac minus etiam id mirabitur, qui mihi, ad hæc atque alia meditanda, tranquillum otium benignitate tua contigiffe didicerit. Namque \& hujus, ut mihi aliquatenus apud te ratio confta. ret, adnitendum erat; \& quoquo modo conandum, ut, multis continuifque à te beneficiis affectus, nonnulla grati animi fignificatione defungerer. Scio equidem, rebus maximis, negotiifque is intento, quæ in illo rerum fattigio pofitum agitare convenit, haudquaquam tibi liberum effe, ut ad hujufmodi contemplationes animum, alioqui rerum omnium capacem, advertas. Sed non ideo minus grata hæc fore, minufve tibi probatum iri arbitror, Rex auguftiffime; cui illa maximè placere videmus, quæ plurimum publicè profunt; neque aliud magis curæe effe, quam ut nova incrementa fumant optimæ difciplinæ, novifque illuftrentur inventis. Hoc enim fatis declarat eximia illa tua, ac fingularis, tum in ipfis promovendis, tum in his qui cognitione earum præminent remunerandis, liberalitas. Quam non immenfex, ac folito majores, bellorum impenfæ quidquam imminuunt : non Galliæe tuæ fines circunfcribunt. Vt plane te hoc ágere appareat, quò non folum fub 
imperio tuo viventes, fed \& Orbis univerfus, quacunque beneficio tuo dignus eft, te regnante, eruditior, ornatior, felicior evadat. Cui veriffimæ præclariffimæque gloriæ tuæ, ita aliquid fortaffe etiam hæc literaria monumenta conducent; ut, fi viguiffe hoc tempore ftudia ifta, artefque, pofteris teftari poffint, fimul illos edoceant, tuæ hoc virtuti, atque animi magnicudini, ante omnia acceptum ferendum effe. Lutetiæ Parifiorum; xxv. Mart. A. CIOIJCLXXIII.

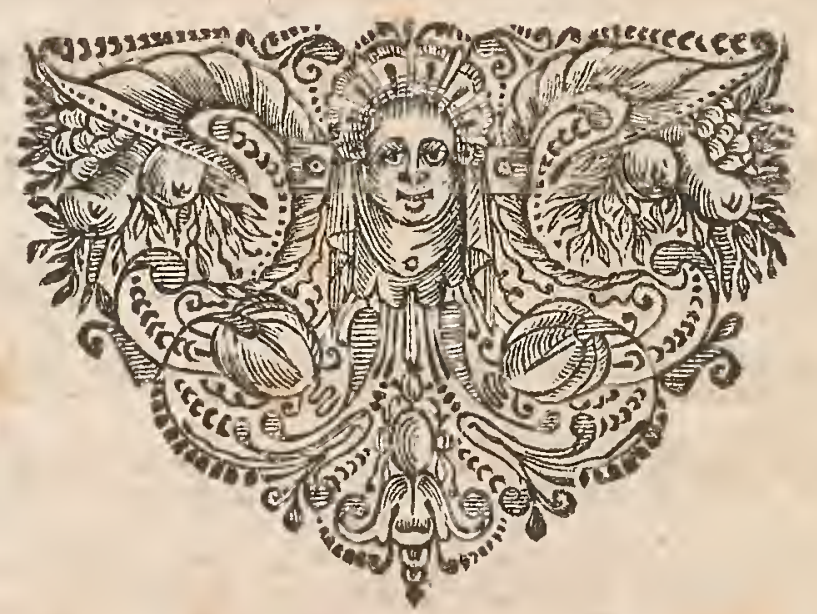




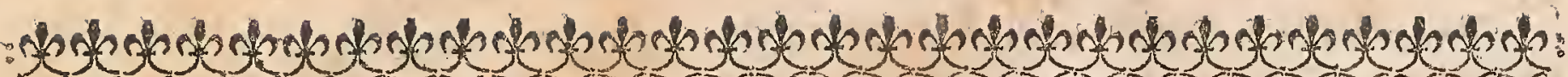

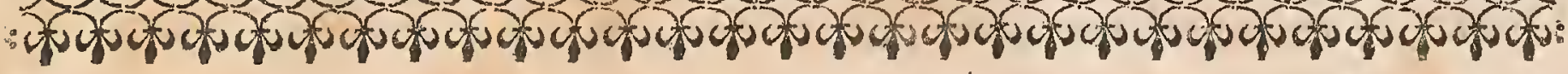

\section{HADRIANI VALLII \\ D A P H I S. \\ E C L O G A.}

Ad Cbriftianum Hugenium Zulichemium,

Confantini $F$.

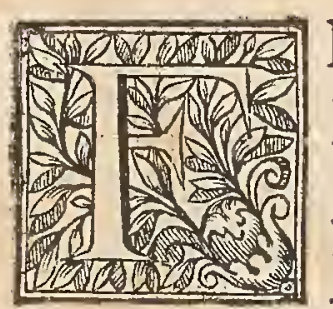

I N I T I M u m turela, fimul jucunda volupras,

Dilectæ Phobo, Sceverinides * Oceaninæ;

Hunc quoque Pierium mihi fortunate laborem:

Pervigilem noctem quo carmine duxerit Ancon

Navita, dicemus: veftro fic gurgite numquam

Pan lavet, aut turpes inceftent æquora Fauni.

Te, quem Fama vehit fuper aurea fidera curru,

Ne pigeat nobis aurem prabere faventem,

HU GENIDE, decus Hugenidum, fratrumque patrifque:

Haud indigna tuo ferimus donaria fenfu,

Sicelifin aptata modis à vate Batavo

Mixta Palæphatio commenta Solenfia verfu,

Teque intertextum tuaque præclara reperta.

Iam caput Occano, Atipata minoribus aftris,

Extulerat radiis fraternis æmula Phœbe,

Cum reditum molirentur paftoria pubes,

Sidere quam pleno conchas legiffe marinas

Iuverat, hærentefque vadis captare paguros.

In celfo tamen advertunt Ancona morantem

Colle, reum toties promiffi carminis. ipfum

Theftylis \& Corydon, quos cætera curba fecuti,

A tergo circumveniunt, cinguntque corona.

Ecquid agat, rogitant blandè : tum faufta precantur;

Et damnant voti, promiffaque carmina pofcunt.

Contra ille; O Pueri, quid portet craftinus Eos,

Sedi explorator: turmales agmine mergi, Solivaga aut cornix, aut alcyones defertæ

* Sgeverina, Pagus apud Batavos, mari adjacens. 


\section{DAPHNIS ECLOGA.}

Si qua darent mihi figna. maris cras æquor arandum. Detinuit nunc ufque Iovis clementia fudi,

Et picturatus tot circum animalibus ærher.

Qux nos in vitreo miramur monftra profundo,

Fert radians $x$ ther, vultus formafque natantum.

Cancer ibi eft, delphinque; eft grandi corpore cerus.

Ad Boream pifces, \& contemplere fub Auftro

Pifces; nuper ubi numero creviffe feruntur.

Sunt urna, Alviufque, \& apluftris comra carina

Illic. quin operis fimulamina plurima veftri,

Luminaque in colo pecori debentia nomen.

Sunt hódi parvæque fues, materque capella.

Et fufe fparfo qux candet femita lacte.

Veftibulum fervant, elucens vellere fulvo

Dux aries, ingenfque auratus cornua taurus.

Bini cernunturque canes, pernoxque bubulcus;

Plauftraque; quique auriga fuis excuffus habenis.

Stellatum volat alatus per inane caballus:

Ac præfepe fuum juxta ftabulantur afelli.

Illic virgo, manum Cereali inluftris arifta,

Et, tranfmutatus faciem, Pan ipfe renidet;

Daphinin amans veftrum, fecretæ rupis in umbra,

Vranie velut edocuit: me fingula Daphnis.

Singula qux (carmen quia pófciris) ordine pandam.

Extemplo tentat vocem: numerofque modofque

Perpendens mulcet variis concentibus auras.

Tum venti pofuere. jacet fine fluctibus æquor;

Factaque funt terris, funt facta filentia ponto.

Mox interfarur: Quod profperer; ab love magno

Ordiar: ordiri confuerunt $a b$ love vates.

Vos, nec enim rerum brevis hic mihi nafcitur ordo,

Nocturnum chorea defendite corpore frigus.

Inde Iovis magni cunas, veterifque celebrat

Saturni juffum crudele, dolumque Cybelles;

Ortaque Diotæis Corybantia facra latebris:

$V t$ puero nutrix fit olentis lecta mariti

Vxor; \& ipfa recens hædos enixa gemellos;

Queis comitata polum modo lucida ftella frequenter,

Quæ prius Oleniis balavit beftia campis;

$\mathrm{sub}$ pedibufque terat formof limen Olympi. 


\section{DAPHNIS ECLOGA.}

Tantus amor lovis, \& percepti gratia lactis.

Nec tamen hoc niveum manaffe fuore nirorem,

In duo fecta vias, oculis manifefta videntum,

Semita quo candet ducens ad tecta Tonantis;

Tergeminam fed nootem productumque canebat

Alciden mundo; deus immortalis haberi

Haud pote qui fuerat, fopitæ parvula mammis

Labra pater gnati nifi conjugis admoviffet:

Quæ, fimul experrecta, fimul conterrita, furgens

Vvidulas tenero mammas fubtraxerit ori;

Indignata. pavimentum tabulataque cœli

Deciduus maculis ut tunc infecerit albis

Per convexa ruens in fe revolubilis humor:

Orbita cycneo nunc unde bifurca colore,

Ducta per æquales medio difcrimine partes,

Cæruleum velut argento ferruminet axem:

Axem, cervices qui quum laffaret Atlantis,

Haud gravis Herculeo requierit farcina collo;

Atque tor ærumnas quem polt, manefque fubactos;

Ipfe fuis ornet jam porrio magna triumphis;

Hefperidum contra cultodem divitis horti

Infurgens Anguem pede nixus; apertaque retro

Terribili rictu nil currans ora Leonis;

Lernexque audacem Hydræ fuccurrere Cancrum;

Monftra novercales teftantia jugiter iras

Et fruftra bacchatum odium Iunonis iniqux.

Hinc aliam memorat graffatam fraude novercam;

Et tranfmittendi pavidam nimis æquoris Hellen:

In thalamos fit ut illa tuos, Neptune, recepta:

Phryxeumque pecus, foetamque heroibus Argo

Phafidos ad fluctus deducit \& $x$ thera cantu.

Nec filet Europæ vectoris præmia; vel te,

Bigarum Pelopis perjuri, Myrtile, rector.

Myrtoum pelagus fignaras ante caduco

Funere; fublimem nunc tollunt cornua Tauri.

Haud procul his Hyades notat exardefcere: fed, qux

Sunt Hyades Graiis, Suculas dixiffe Latinos;

Atque duas feptem mutaffe Trionibus Arctos;

Arctophylaca pigro, fua plauftra fequente, Bubulco;

Quando bovem prifco vocitabant more trionem, 
DAPHNIS ECLOGA.

Quod tereret duro profciffam vomere terram.

Hanc adeo fortem miferans, fufpiria ducir;

Buceriumque genus queftu compellat inani;

Ah pecus infelix, armentum! frcla fuerunt,

Pondere quum duro neque vos gemeretis aratri,

Navita nec veftro vocitaret nomine Atellas.

Tunc neque fidus erat terris pia Virgo relictis,

Qux Cereale manu fpicum gerit ; Icariotis

Sive fit Erigone, cui fida Canicula patrem

Quærenti indigna moñltravir cæde peremtum;

A tque, comes domin $x$, domino comitem Oarioni

Aftra minor focium majorem repperit inter:

Seu magis Aftræi fit fanguine creta, perenne

De genitore fuo quæ nomen contulit aftris:

Sive fit antiqux Themidis juftiflima proles,

Averfata jugo vos afpectare gravari,

Tempora dum, pulfis melioribus, ærea furgunt:

Sive fit alma Ceres; horrens fugitiva videre

Vos quoque mactari; nil pejor linquit inaufum

Ferrea dum foboles, ipforum inimica Deorum:

Quos, quafi de terra (nam Dii coluiftis \& illam)

Sit pepuliffe parum, tentavit pellere colo.

Tum deteftatur fuffultos angue Gigantas;

Porphyriona, Atatu terrentem cuncta minaci;

Rhæcumque; immanemque Gygen, validumque Mimanta;

Enceladumque; manufque rotantem Ægeona centum;

Et, cui par nemo feritate, Typhöea dirum,

Aufos invafiffe. Deos tellure fugatos,

Ac totum magno colum compleffe tumultu,

Vndique divulfas jaculantes torviter ornos

De tumulis cumulorum montibus ex aggeftis.

Terrigenam ut pubem, Divûm penetralia fancta

Rimantem, Superi mentito fallere vultu

Quxfierint, addit; difpertitofque pavore:

Donec apud latè ftagnantis flumina Nili

Horrifican faciem Pan fumferit Ægocerocis;

Ambiguoque fono Superos animarit ad arma,

Anguipedefque metu dare terga coëgerit omnes:

Coelo donandos Afinos auxiffe timorem

Congerie vocum, perterricrepoque fragore: 


\section{DAPHNIS ECLOGA.}

Illa calicolis nam tempeftate fuiffe

Auxilio Satyros, Silenorumque phalangem,

Evantes in afellis cum Bacchæo ululatu,

Thyrfis armatos, tectos colocynthide parma.

Parvus ut interea volucer cum matre Cupido

Venerit Affyrii fugiens Euphratis ad undam;

Induerintque gregis (Syriæ poft numina genti)

Squammigerum formas, gemini nunc aurea Pifces

Lumina, figniferum Capricorno juncta per orbem,

Ni fufa medius fecernat Aquarius Vrna;

Deucalioneos neque non edifferit imbres,

Nectaris aut quanti Ganymedes pocula verfet;

Sive fic is Cecrops, peplo præfignis Athenæ;

Paftor Ariftrus feu plena alvearia geftet,

Qux fubter voliteris apes examine denfo.

Qualiter \& pandus vectarit Ariona Delphin,

Ac aliter vectum Danaeium Perfed narrat;

Cepheaque, Andromedenque, \& mortam Caniepeiam,

Infercumque polo vaftum Piftricis hiatum:

Quem Phaëthonteus longo finuamine propter

Fulgeat Eridanus declivi proximus Auftro:

Nuper ad occulti Batavos ubi verticis axem

Intuitos nova fquammigerum fimulacra micare:

Sollertes Batavos, imo leu gurgite pifcem

Venari fit opus, vel in alto fidera colo.

Tum canit, ut Daphnis facra fub rupe docenten

Viderit Vranien: argutas carmina filvas,

Et repetita cavos edifcere carmina montes:

Vt Chaldæa vetus, mira dulcedine capti,

Stent auditores circum, \& Babylonia rurba;

Dein quos Graia tulit, quos aut Nilorica tellus,

Itala quos, ac pulchra fuo cum Cafare Roma;

Poft Arabum de ftirpe viri \& regnator lberus;

Ac tandem quos confultos Germania mifit

Aftrorum colique, fuæ qui fidera terræ;

Inferior nullis ut item neque Gallia defit;

Gallia magnanimi Regis fplendore fuperba,

Borbonios ignes cui parturit arduus ærher:

Tum Dea quo Daphnin, Divam quo Daphnis amore Complexus, quanri non confcia Larmia faxa: 


\section{DAPHNIS EGLOGA.}

Vtque Conon juveni radium donarit, utrimque Multo infignem auro, \& pellucidulis cryftallis; Per quas quod fpectes, prope fiat; \& augmina fumat: Dixerit \&: Sollers, en, primus quale Batavus Munus adornarit; fed Etrufci quo decus Arni Eft Antenorea fenior Tyrrhenus in urbe Regna Iovis princeps metatus, ab xthere vobis Nunquam nota prius miracula nuntia portans; Lunai montes; vultus tibi, Phofphore, ternos; Quove fatellitio fubluftri nocte vagetur

Stella Deûm regis per cærula templa fuperne? Hoc quoque tu non nota prius miracula prodes: Hujus erat tibi fervatus follertior ufus; Arcanumque Chroni mortalibus omne recludes. Accipe fruftra olim nobis optabile donum.

Daphnidis ad gratum nomen pernice chorea

Exfultant alacres Pueri: neque fegnius ipfe Profequitur; Geminas imitantia lumina falces Hactenus ut vanè Saturni credita fidus Oblongo ram diverfa fub imagine difco Fingere, quando globum teretem teres annulus extra Splendet, \& ambo nigror fpatii difterminat intus; Exiguo circum quos erret ftellula gyro: Omnia divino qux fretus munere Daphnis Extulerit, non ante novam vulgata per artem: Adjungitque; quod his meritis permulfus, eundem In fua magna Chronus fit adire facraria paffus: Heic oculis luftrarit ut omnia; promferit atque Inventum fubtile fecandi temporis illinc; Partes quo minimas ac momina dividat horæ, Ofcilla ex tenui fufpendens mollia filo: Id labyrintheos curfus qui dirigat alni, Ignarumque viæ ratis haud finat effe magiftrum: Cui neque quotidie tam certus fpondeat auctor, Oceano quantum Titan altiffimus exfter; Ac quibus emergat, queis tunc fimal occidat oris, Daphnidos egregio norint conamine docti.

Ille canit: chorus in numerum fua brachia quaffant, Alternoque folum pede pulíant. at freta faltu Librabant hilares fefe fuper humida thynni. 
DAPHNIS ECLOGA

Auritus leporum populus tunc creditur ultro

Iliceas liquiffe domos, carafque quietes

Vicini nemoris: nulloque frequentior unquam

Caricis arrofor prodiiffe cuniculus antris

Tempore narratur; narrent fi vera puellx

Littorex, quæ ficcandis cultodia paffim

Retibus ad ventos expanfis forte fedebant.

Pectore Nerëides nudo, lafciva carerva,

Vifa per incertam Lunam, vifæve putantur,

Et Triton, Glaucufque, procul fub luce maligna;

Tuque, cubans juxta ftratas prope littora phocas,

Neptuninarum pecudum fidifime cultos:

Neu quifquam feræ meminit decedere nooti.

Interea tenebræ denfantur; \& abdita nimbo

Cynthia dum latitar, coli de parte ferena

Cinctum non folitis proceflit crinibus altrum,

Prolixumque trahens albore notabile fyrma.

Mirantur chorus attoniti. miratur \& ipfe;

Præfertim tantum capiti cum demfit honorem,

Ornatumque fequacem omnem mox reddita Luna.

Infit \&: Ad fua quifque mapalia tendite nota,

Prodigio nil folliciti, curamve foventes.

Infuetos alias tales cantabimus ignes,

Et trepidantem nequicquam formidine vulgum.

Hæc Ancon: mihi vila tibi qux digna referri,

H U G E I DE, decus Hugenidum, cui fidera curr;

Nec Phobum ac Pimpla fas eft contemnere Divas,

Queis tua tota domus, fratres, genitorque dicati.

Sic neque te facies peregrini terreat aftri,

Idemve anne alius vario fulgore cometes.

A. CIO IOC LXV. 


\section{PRIVILEGE DU ROY.}

T OUIS par la grace de Dieu Roy de France \& de Navarre; A nos amez \& feaux Conteillers, les Gens tenans nos Cours de Parlement, Maitres des Requeftes ordinaires de noftre Hoftel, Baillifs, Senefchaux, Prevofts, leurs Lieutenans, \& tous autres Jufticiers \& Officiers qu'il appartiendra, Salut. Noftre cher \& bien amé F R A N ç O I S M u G u E T noftre Imprimeur ordinaire, Nous a tres-humblement fait remontrer qu'il luy auroit efté mis és mains un Livre intitulé, Chriftiani Hugenii Zulichemii Conft. F. Horologium Ofcillatorium, feu de motu Pendulorum ad horologia aptato demonfirationes Geometrice, qu'il defireroit donner au public s'il nous plaifoit luy en accorder la permiffion, humblement requerant icelle. A CES C A U S ES voulant favorablement traiter l'Expofant, Nous luy avons permis \& accordé, permetrons \& accordons par ces prefentes d'imprimer ou faire imprimer ledit Livre en telle forme, caractere, volume, \& autant de fois que bon luy femblera, durant le temps de fix années entieres \& confecutives, à commencer dujour qu'il fera achevé d'imprimer pour la premiere fois, faifant tres-expreffes défenfes à toutes perfonnes de quelque qualité \& condition qu'elles foient, de l'imprimer ou faire imprimer, vendre ny débiter durant ledit temps en aucun lieu de noftre Royaume, fans le confentement de l'Expofant, ou de ceux qui auront droit de luy, fous quelque pretexte que ce foit, à peine de quinze cens livres d'amende applicable, un tiers à Nous, un tiers à l'Hôpital General de noftre ville de Paris, \& l'autre tiers à l'Expofant, de confifcation des exemplaires contrefaits, \& de tous dépens, dommages \& interefts, à la charge qu'il en fera mis deux exemplaires en noftre Biblioreque ordinaire, un en celle du cabinet de noftre Louvre, \& un autre en celle de noftre amé \& feal Garde des Sceaux le fieur Daligre. S I vous mandoris que du contenu en ces prefentes vous faffiez joüir $\&$ ufer l'Expofant, \& ceux qui auront droit de luy pleinement \& paifiblement, ceffant \& faifant ceffer tous troubles \& empêchemens au contraire, voulans qu'en inferant ces prefentes ou extrait d'icelles en chacun des exemplaires, elles foient tenuës pour bien $\&$ deuëment fignifiées; Commandons au premier noftre Huiffer ou Sergene fur ce requis, faire pour l'execution des prefentes tous exploits à ce neceffaires. C A R tel eft noftre plaifir. D O N N E' à Verfailles le dernier jour de Septembrel'an de grace mil fix cens foixante-douze. Er de noftre Regne le trentiéme. Signé, L O U IS. Par le Roy, C O L b e R T.

Regifté Jur le Livre de la Communauté des Marchands Libraires \& Imprimeurs de Paris, le 4. Novembre 1672. fuivant l'Arref du Parlement du 8. Avrib 7653 . \& celuy du Confeil Privé du Roy du 27 . Fevrier mil fax cens foixante-cinq. Signé, D. TH I E R Y, Syndic.

Achevé d'imprimer pour la premiere fois le premier jour d'Avril 1673.

Les Exempläires ont effé fournis. 


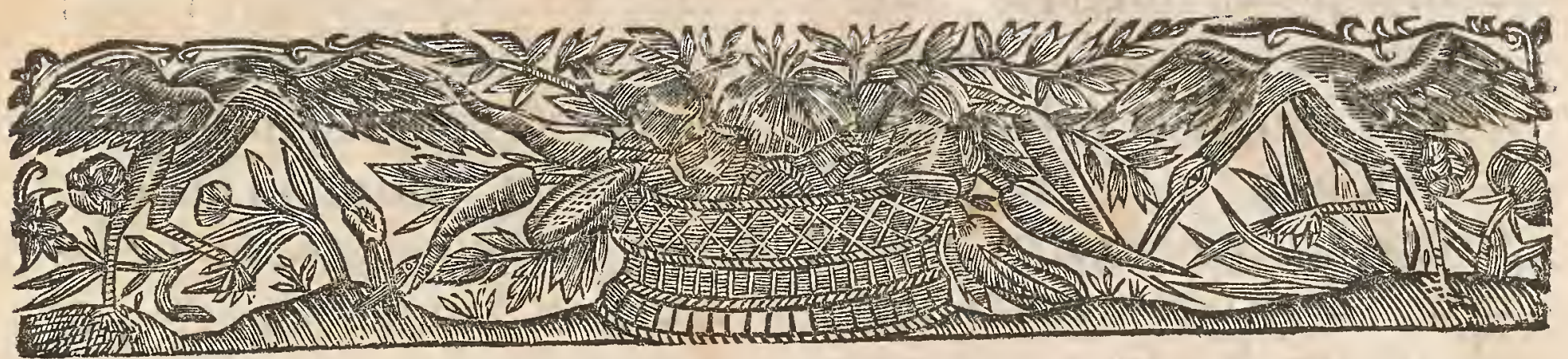

\title{
CHRISTIANI HVGENII
}

\author{
Z V L ICHEMII, C ONST. F.
}

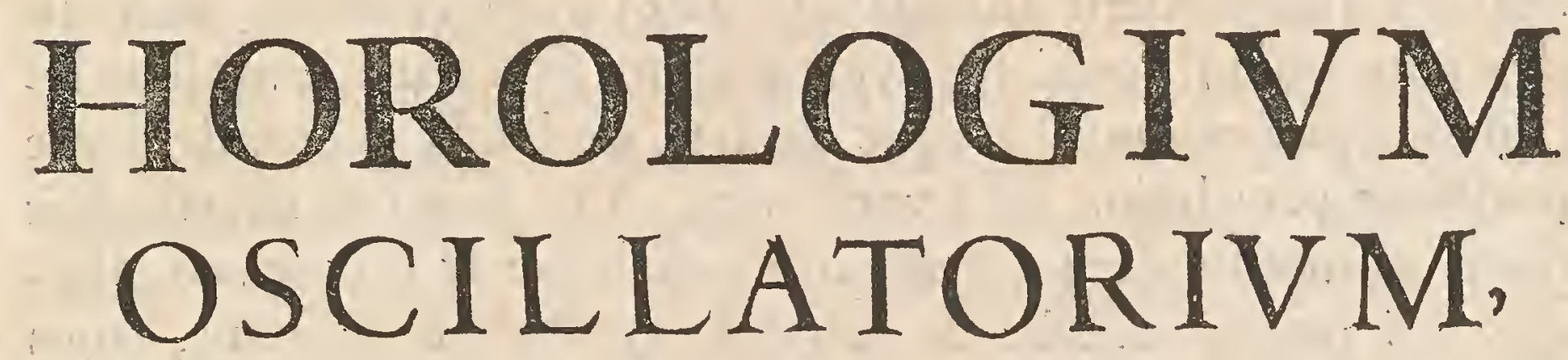

S I V E

DE MOTV PENDVLORVM

\author{
A. D H OROLOGIA A P T TO
}

Demonftrationes Geometricæ.

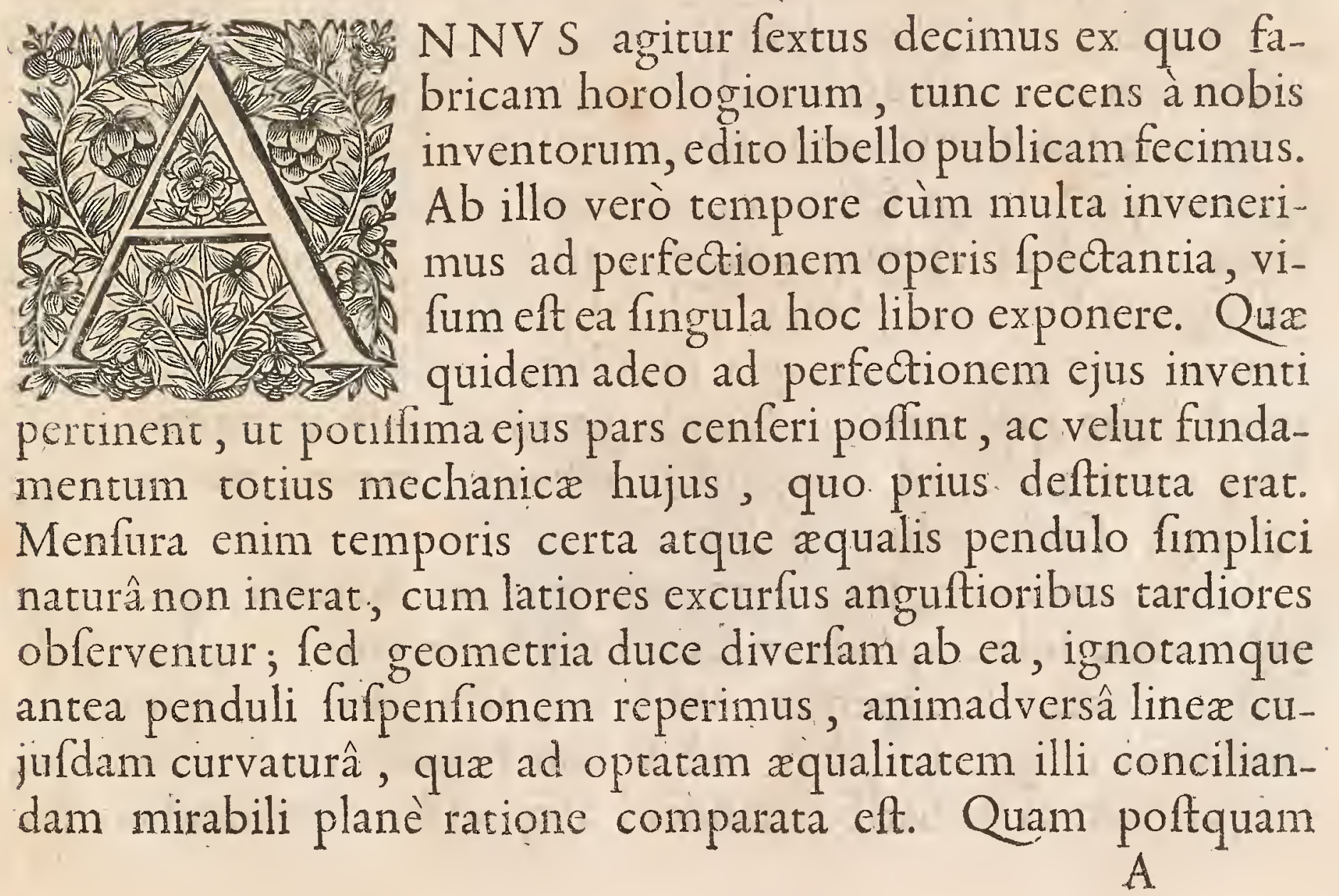


horologijs adhibuimus, tam conftans certufque eorum motus evafit, ut poft crebra experimenta terra marique capta, manifeftum jam fit \& Aftronomiæ ftudijs \& arti Nauticæ plurimùm in ijs effe præfidij. Hæc ea eft linea quam defixus in circumferentia currentis rotæ clavus, continua circumvolutione, in aëre defignat; à Geometris noftri ævi cycloidis nomine donata, \& ob alias multas fui proprietates diligenter expenfa ; à nobis vero propter eam quam diximus menfurandi temporis facultatem, quam nihil tale fufpicantes, ac tantùm artis veftigiis infiftentes, ineffe ipfi comperimus. Hanc cum jam pridem amicis horum intelligentibus notam fecerimus (nam non multo poft primam horologij editionem animadverfa fuit) nunc eandem, demonfratione quàm potuimus accuratiflima firmatam, omnibus legendam proponimus. Itaque in hac tradenda demonftratione potiffima pars hujus libri verfabitur. Vbi primùm neceffe fuit novis nonnullis demonftrationibus ftabilire \& promovere ulterius viri maximi Galilei de defcenfu gravium doctrinam, cujus fructus defideratiffimus, atque apex veluti fummus, hæc ipfa quam. invenimus cycloidis eft proprietas.

Qux porro ut ad pendulorum ufum aptari poffet, nova curvarum linearum confideratio adhibenda fuit, earum fcilicet qux fui evolutione alias curvas generant. Vnde comparatio inter fe longitudinis curvarum cum rectis nafcitur, quam ulterius etiam quam præfens neceflitas poftulabat profecutus fum, propter theorix, ut mihi vifum eft, elegantiam \& novitatem.

Cæterùm ad explicandam Penduli Compofiti naturam, cujus utilitatem in conftructione horum automatôn demonftro, adjungenda fuit Centrorum Of cillationis contemplatio, à pluribus quidem, fed minus feliciter, hactenus tentata ; in qua theoremata complura animadverfione, ni fallor, digna reperientur, ad figuras lineares, planas, folidafque pertinentia. Ante hæc omnia vero præmittitur ipfa horologij mechanica conftructio, pendulique applicatio, eâ formâ qux ad ufus aftronomicos aptif́ fuma reperta eft, ad cujus inftar reliqux omnes, mutatis qux opus eft, facile ordinari poffint.

Quia vero contigit egregio hujus inventi fucceffu, quod fieri plerumque folet, quodque futurum prædixeram, ut plures fefe ejus auctores effe cuperent, aut fi non fibi ipfis, fux tamen nationis alicui potius quàm nobis eum honorem tribui vellent, iniquis eorum conatibus tandem aliquando occurrendum hic 
HOROLOG. OS CILLATOR.

arbitror. Nec fanè aliud fere opponere ijs neceffe fuerit præterquam id unum, nempe ante annos fexdecim, cum nec dicto nec frripto cujufquam de horologijs hujufmodi mentio facta effet, aur rumor ullus omnino ferretur (loquor autem de penduli fimplicis ufu ad horologia tranflato, nam de Cycloidis additione nemo credo controverfram movebit) conftructionem corum propria meditatione me adinveniffe \& perficiendam curaffe. Infequenti anno, qui nempe hujus fxculi quinquagefimus octavus fuir, delineationem automati defcriptionemque typis vulgaffe; exemplaria, tum operis ipfus, cum libelli, quaquaverfum dimifffe. Nam cum hæc ita omnibus nota fint, ut nec teftimoniis eruditorum, nec Batavix Ordinum actis, quibus poffent, confirmari opus habeant, facile apparet quid de illis exiftimandum fir, qui feptem poft annis eandem conftructionem, quafi à fe fuifve amicis pro fectam, libris fuis venditarunt. Qui vero Galileo primas hic deferre conantur, fi tentaffe eum, non vero perfeciffe inventum dicant, illius magis quam mex laudi detrahere videntur, quippe qui rem eandem, meliore quam ille eventu, inveftigaverim. Cum autem vel ab ipfo Galileo, velà filio ejủs, quod nuper voluit vir quidam eruditus, ad exitum perductum fuiffe contendunt, horologiaque ejufmodi re ipsâ exhibita, nefcio quomodo fibi creditum iri fperent, cum vix verifimile fit adeo utile inventum ignoratum manere poruiffe annis totis octo, donec à me in lựcem ederetur. Quod fi dedirâ operâ celatum fuiffe dicant, idem hoc intelligunt à quolibet alio poffe obtendi, qui fibi originem in venti arrogare cupiat. Itaque probandum quidem id foret, neque eo magis ad me tamen quicquam pertineret, nifi unà quoque oftendatur, id quod omnes latebat, mihi foli innotuiffe. Et hæc quidem neceffariæ defenfionis caufa dicenda fuere. Nunc ad ipfus automari conftructionem pergamus.

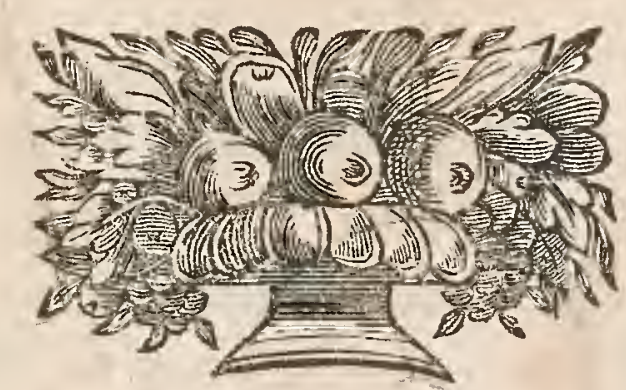


FIG.I.

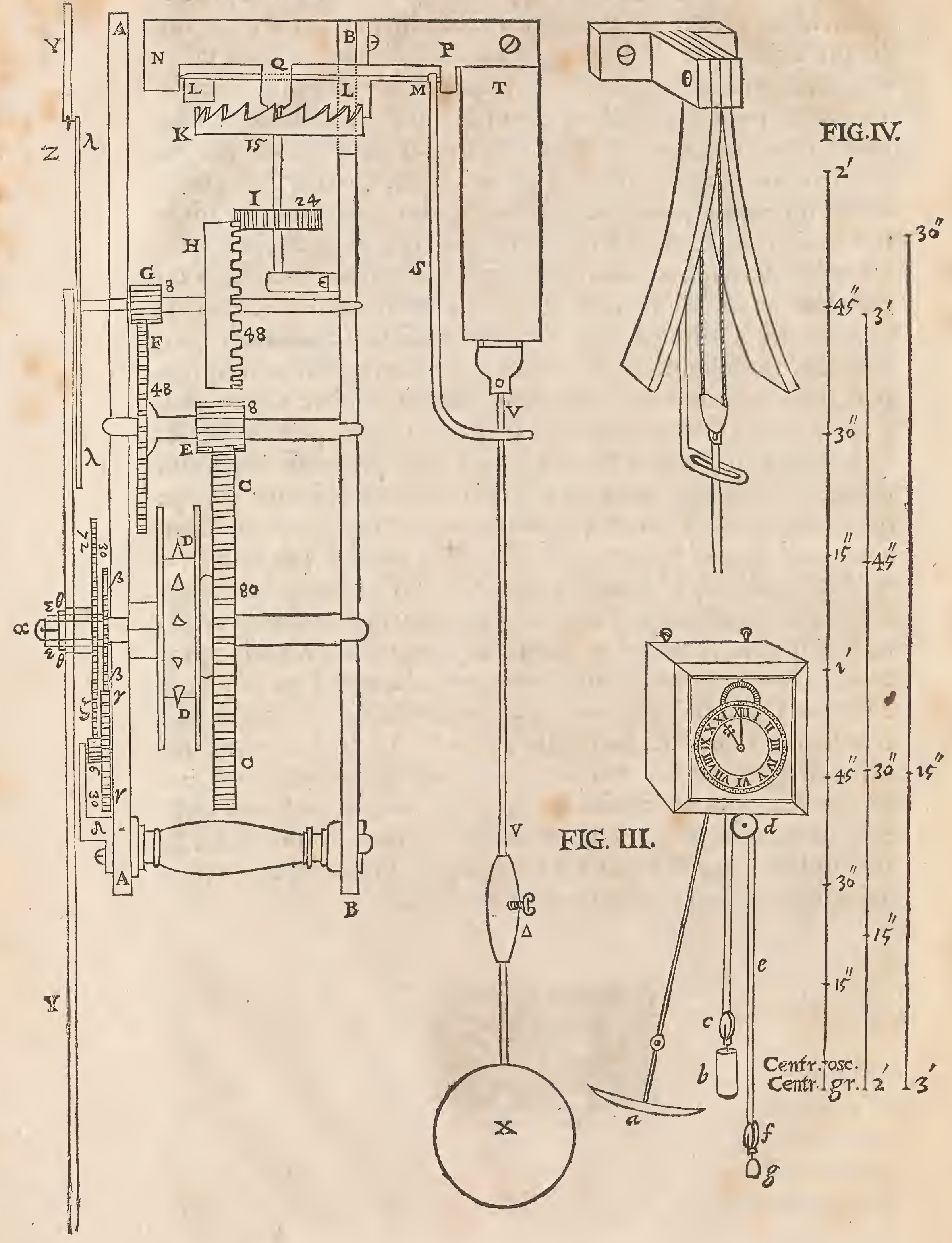

FIG.II. 


\section{HOROLOGII OSCILLATORII.}

\section{$P A R S P R I M A$,}

\section{Defcriptionem ejus continens.}

TI I V RA adfcripta horologium à latere infpiciendum pra- 1 bet, ubi primum laminæ binæ funt A A, B B , femipedali aut paulo ultra longitudine, latæ pollices duo \& femis, quarum anguli quatuor columellis coaptantur, ut fefquipollice inter fe diftent. His laminis rotarum præcipuarum axes utrinque inferuntur. Prima atque infima eft qux notatur $\mathrm{C}$, dentibus 80 incifa, cujus axi orbiculus quoque $\mathrm{D}$ affixus eft, aculeis ferreis afper, ut funem cum appenfis ponderibus contineat, qux qua ratione ordinentur poftea dicetur. Ponderis itaque vi rota $\mathrm{C}$ vertitur; hæc movet proximum tympanum $\mathrm{E}$ dentium octo, unáque rotam $\mathrm{F}$ codem axe hrentem, cui dentes 48. Hanc excipit tympanum aliud $G, \&$ in eodem axe rota $\mathrm{H}$, quibus dentium numerus idem qui tympano rotæque præcedenti. Sed hæc rota ejus eft generis quas à forma coronarias vocant artifices noftri. Hujus dentibus agitatur tympanum $\mathrm{I}$ fimulque rota $\mathrm{K}$, qux eodem axe tenetur, ad perpendiculum erecto. Tympano dentes 24 ; rotæ Is, atque hi ad inftar ferræ dentium incifl. Supra mediam rotam $\mathrm{K}$ tranfverfus jacet axis pinnatus $\mathrm{L} \mathrm{M}$, cujus extrema fuftinent hinc inde gnomones $\mathrm{N} \& \mathrm{P}$, feorfim affixi laminæ B B. Notanda vero in gnomone $N$ e pars deorfum prominens $Q$, quæ oblongo foramine patens tranfmittic axem $L \mathrm{M}$, fimulque retinet eum quem. rotæ $\mathrm{k}$ tympanoque $\mathrm{x}$ communem effe diximus, inferiori fui parte gnomoni $\mathrm{N}$ innitentem. In lamina $\mathrm{B}$ B foramen amplum excavatum eft, quo ultra ipfam extendatur axis pinnatus $L M$, qui fubtili cufpide infertus gnomoni $\mathrm{p}$, liberius ita movetur quam fiabipfalamina в в fuftineretur fimulque ultra cam promineret, debet enim prominere neceffario ut affigi poffit clavula $s$, quix fimul cum eo verfationes faciat. Eft autem hic motus reciprocus, nunc in hanc nunc in illam partem, quum dentes rotæ. $\mathrm{K}$ alternatim occurrant pinnulis $\mathrm{L} L$, notâ vulgुo ratione, quæque proinde diligentiori explicatione non indiget. 
Porro clavula s, ima fui parte reflexa ac foramine oblongo terebrata, penduli virgam ferream, cui plumbum $\mathrm{x}$ affixum eft, amplectitur. Hæc vero virga fupernè duplici filo fufpenfa eft inter geminas lamellas, quarum una $\mathrm{T}$ hic tantum cernitur; ita que alteram figuram juxta defcripfimus, qux utriufque formam flexumque \& totam hanc fufpendendi penduli rationem exprimeret. Quanquam de vera laminarum iftarum curvatura pluribus poftea agendum erit.

Nunc autem ut de motu horologij dicamus, nam reliquas figuræ partes poftea exequemur, facile equidem apparet \& vi rotarum, à pondere rractarum, perpendiculi $\vee$ x motum fultentari, poftquam femel manu incitatum fuerit; \& frmul perpendiculi ftatos recurfus rokis univerfis, totique adeo horologio movendi legem normamque præf cribere. Clavula enim, quantumvis levi rotarum impulfu acta, non tantum obfequitur trahenti perpendiculo, fed \&z fingulis recurfibus paulifper ejus notum adjuvat, atque ita perennem reddit, qui alioqui fua fponte, vel verius occurfu aëris, deficeret paulatim, vergeretque ad quietem. Rurfus vero, quum ejufmodi fit natura penduli ut eodem femper tenore feratur, neque $a b$ eo ulla ratione præterquam mutata longitudine dimoveri poflit utique poftquam flexu lamellarum, inter quas fufpenfum èt, æqualitatem illam confequuti fuimus; nequaquam permittitur rotæ $\mathrm{K}$, ut nunc citius nunc tardius incedat, etfr fæpe, ut in vulgaribus horologiis, id facere conetur; fed neceffario finguli dentes ejus coguntur æqualibus tranfire temporibus. Hinc vero manifeftum eft, \& reliquarum quæ præcedunt rotarum, \& denique etiam indicum xquabiles converfiones effici, cum omnia proportionaliter moveantur. Quamobrem fiquid in fabrica virij fuerit, vel, ob aëris mutatam temperiem, difficilius rotarum axes volvantur; dummodo non eo ufque ur omnis horologij motus interrumpatur; nulla propter hæc inæqualitas aut motus retardatio timenda erit, femperque aut rectè tempus metietur aut omnino non metictur.

Indices porro hoc pacto circumaguntur atque ordinantur. Tertia lamina prioribus parallela eft $\mathrm{Y} Y$, pollicis quarta parte diftans ab ea quæ notatur $A$ A. In ea circuli horarij defcripti funt centro codem $x$ quo protenditur axis rotæ c. Quorum circulorum interior duodecim horarum divifionem habet, alter fcrupulorum 60 . Axi vero rotæ $\mathrm{C}$ aptacur, ultra laminam $\mathrm{A} A$, rota $\beta$, tubulo coherens qui ufque ad E continuatur trans laminam $Y \mathrm{X}$; atque ita 
infidet axi illi, ut una cum illo circumferatur; fine illo tamen, ubi DEscRaptso opus fuerit, converti poflit. Ad $\mathrm{E}$ index imponitur, horæ fpatio Horologrr. circuirurus atque ita fcrupula prima, feu fexagefimas horarum, demonftraturus. $R$ ota vero quam diximus $\beta$, aliam rotam, totidem quot ipfa habet dentium, impellit, atque una affixum ei tympanum cui dentes $f e x$, axiculo eorum communi hinc laminâ $A$, inde gnomone $\delta$ fuffulto. Hoc tandem tympano rota $\zeta$ movetur, dentes habens 72 , tubulumque affixum qui $\&$ ipfe ultra laminam $\mathrm{Y}$ ad $\theta$ porrigitur, paulo citra quam definit tubulus rotæ $\beta$; quem intra fe complectirur. Parce extrema $\theta$ apponitur horarius index; brevior aliquanto illo quem fcrupula prima fignare diximus, cum interiore gyro ferri debeat. Secunda vero fcrupula ur abfque errore demonftrentur, imponitur axi rotæ $\mathrm{H}$, ufque ad laminam $y$ producto, orbis $\lambda$, cui circulus in fexaginta partes divifus infcribitur, incifoque in laminâ y foramine ad $\mathrm{z}$, ex divifiones, cufpide in fummo foramine defixâ, prætereuntes notantur. Hæc vero tota indicum circulorumque horariorum difpofitio ex figura minori clarius perfpicitur, exreriorem horologij formam referente.

Cæterum penduli longitudinem, rotis quemadmodum diximus ordinatis, eam effe oportet ut frupula fecunda fingulis recurfibus metiatur, qux longitudo tripedalis eft, cumque commodè in fchemate exhiberi nequiret, ejus quintam partem à fufpenfione fumma, ubi incipit flexus laminæ $\mathrm{T}$, ad ufque centrum ponderis $\mathrm{x}$ expreffimus. Tripedalem dico, non alicujus refpectu pedis qui apud Europx gentem hanc illamve in ufu fit, fed certo æternoque pedis modulo ab ipfa hujus penduli longitudine defumpto, quem PEDEM HORARIU in pofterum appellare liceat, ad illam enim omnium aliorum pedum menfuræ referri debent quas incorruptas polteris tradere voluerimus. Neque enim, verbi gratiâ, ignorabitur unquam venturis freculis Parifini pedis modus, dum conftabit eum ad Pedem Horarium effe ut 864 ad 88i. Sed de hujus menfuræ exactiffima conftitutione pluribüs agemus in iis qux de Centro Ofcillationis. nunc tempora converfionum in fingulis rotis indicibufque obiter defignabimus, ut rectè omnia ad dentium füpra defcriprorum numerum quadrare intelligantur.

Ergo una quidem converfione rotæ $\dot{c}$, decies circumire apparet rotam $\mathrm{F}$, fexagies vero rotam $\mathrm{H}, \&$ centies vicies fupremam $\mathrm{M} \mathrm{K}$ : cui quum dentes fint quindecim, iifque alternatim pulfentur pin- 
nulæ L L, una converfione rotæ $\mathrm{K}$ numerabuntur ictus 30 , quibus refpondent totidem itus reditufque penduli $\mathrm{v} x$. ideoque converfionibus 120 , refpondebunt of cillationes fimplices 3600 , qui numerus eft fcrupulorum fecundorum unam horam efficientium. I taque horæ tempore femel circumit rota $\mathrm{C}$, cumque e fimul index ad $\mathrm{E}$ impofitus, qui fcrupula prima demonftrat. Et quoniam codem temporis fpatio etiam rota $\beta$, \& per eam $\gamma$, convertitur, cum tympanidio fuo dentium fex, ad quem numerum duodecuplus eft numerus dentium rotæ $\zeta$, apparet duodecim demum horis hanc circumduci, totidemque indicem illi conjunctum in $\theta$. Denique cum rotæ $\mathrm{H}$ fexaginta converfiones refpondere oftenderimus fingulis converfionibus rotæ $\mathrm{C}$, hinc illa, una cum affixo orbe $\lambda$, fexagies in fingulas horas circumferetur, hoc eft, femel unius fcrupuli primi tempore, ideoque partes fexagefimæ orbiculi $\lambda$ fecunda fcrupula tranfitu fuo oftendent : atque ita omnia rectè fe habere manifeftum erit. Pondus $\mathrm{x}$ in imo perpendiculo trilibre eft, plumbeum totum, vel ænea fuperficie plumbum continente. Nec tantum metalli gravitate fed \& figurâ infuper profpiciendum (plurimi enim refert) ut quam minimum occurfu aëris impedimentum fentiat. Eoque in cylindri jacentis oblongi \& utrinque præacuri formam fingitur, qualis cernitur ad a fchemate horologij minore. Quanquam in his qux ad navigationem parantur, forma lentis erectx aptior vifa eft.

Porro eodem fchemate $\&$ ponderis alterius $b$, quo motus horologij continuatur, fufpendendi ratio expreffa eft, quam, incognitam prius, inveftigare nobis neceffe fuit, ne interim dum furfum retrahitur pondus iftud, ceffaret vel impediretur aliquatenus horologij curfus, quod hic omnino cavendum erat. Paratur itaque funis continuus atque in fe rediens, extremitatibus apte inter fe connexis. Is primum orbiculum rotæ infimæ conjunctum, qui in fchemate majori notatus eft $\mathrm{D}$, amplectitur ; inde defcendens, altera fui parte trochleam $c$, cui pondus $b$ appenfum eft, fubit. Hinc fuper orbiculum $d$ afcendit, extrinfecus horologio affixum, qui ferreos per circumferentiam aculeos habet, atque infuper ferratis dentibus ita eft aptatus ut volvatur tracto fune $e$; nequaquam vero in partem contrariam revolvi poffit. $\mathrm{Ab}$ hoc orbiculo defcendit funis ad alteram trochleam $f$, cui pondus exiguum $g$. appenditur, quantum fufficit continendo majori $b$, ne alirer quam revoluto orbiculo defcendat. Namque à trochlea $f$ rurfus ad ipfum orbiculum $d$, unde defcenderat, funis revertitur. Quibus ita 
fe habentibus, manifeftum eft femper pondus $b$ dimidia fui gra-Descripria vitate conari ut rotas horologij circumagat, nec tunc quidem HoRososis. ceffare cum manu funem $e$ trahente afcendere cogitur; adeoque horologij motum nufquam interrumpi, nec momentum temporis deperdi.

Gravitatis modus in pondere $b$ definiri certo non poteft, fed quo minor confervando motui fuffeceric, co melius accuratiufque fabrefactum automaton arguet. In noftris, qux optima hactenus habemus, ad fex libras redactum eft, pofita nimirum orbiculi $\mathrm{D}$ diametro pollicarifere, uti exhibita fuit; item perpendiculi pondere trilibri, ac totidem pedum longitudine. Quæ longitudo, ut hoc etiam admoneamus, trans capfam horologij dependet, oblongo foramine perviam, quantum of cillationibus peragendis neceffe eft. Ipfum vero horologium, ad hominis alticudinem fufpenfum, horis 30 moveri perfeverat.

Supereft nunc forma lamellarum defcribenda inter quas per. pendiculum affigi diximus, quarumque ad xquabilem horologio motum præltandum vel præcipua eft opera. Abfque his enim Penduli fimplicis of cillationes ( etfi nonnullis aliter vifum eft) non erunt $x$ que diuturnæ , fed brevioris temporis ex quæ per mi. nores arcus incedent; idque primùm experimento hujufmodi facile deprehenditur. Si enim fila accipiantur ejufdem longitudinis duo, paribufque in parte ima ponderibus religatis, utrumque feorfim fufpendatur, tumque alterum eorum procul à linéa perpendiculari, alterum parumper duntaxat extrahatur, fimulque è manu dimitrantur; non diu utrumque fimul in partes eafdem ferri videbitur, fed prævertet illud cujus exiliores erunt recurfus. Sed \& temporum per quollibet arcus rationes numeris definiri poffunt, certâ fcientiấ nixis, \& vero quam libuerit propinquis, veluti quod tempus defcenfus per totum circuli quadrantem eft ad tempus per arcum minimum fere ut 34 ad 29. Adeo ut nequaquam refiftentix aëris ea diverfitas imputanda fit, ut quidam. voluere, fed ex ipfa motus natura circulique proprietate nafca. tur. Quod alio quoque argumento concludi pollit ex ipfa Penduli ifochroni conftruetione, ubi à circulari linea haud parum receditur, uti mox patebit.

Sed videatur forfan in noftris horologiis hifce, ubi eadem femper eft of cillationum latitudo, nullius momenti futura quam diximus inæqualitas, adeoque nec correctione ulla perpendiculi opus fore. Quod fane ita effet fi latitudo omnium planè eadem 

flatur, idque ita effe reipfa atque experimentis evincitur. Etfi enim eadem femper fit ponderis vis, rotæ fibi proximæ refpectu, tamen per tot alias tranfdita, quantâcunque curâ limatæ fuerint, non femper eadem ad perpendiculum ufque pervenit. Præterquam quod frigore quoque difficilior motus rotarum efficitur; item que evanefcente aut fordefcente quod illis additur oleo. Sed præcipue inæquales fiunt of cillationes horologiis quæ mari vehuntur, ob jactationem navis continuam, adeo ut omnibus quidem in univerfum, fed his maxime omnium remedio opus fit, quo reciprocationum Penduli latiorum anguftiorumque tempora æqua. lia evadant.

Ad definiendam ergo lamellarum formam in quibus pofitum eft remedium iftud, in primis Penduli longitudinem ftatuiffe oportet, qux facile ex eo habetur, quod fint inter fe longitudines perpendiculorum, ficut temporum qux in fingulos recurfus impenduntur quadrata. Adeo ut cum tribus pedibus definiverimus longitudinem perpendiculi quod fcrupula fecunda metitur, ejus quarta pars, five unciæ novem debeantur ei quod femifecunda notaturum fit. Item fi Penduli longitudo quæratur, cujus recurfus fimplices 10000 horæ fpatio peragantur, hoc modo ratio inibitur. Penduli nempe tripedalis feimus 3600 recurfus in horas fingulas numerari : ergo hujus recurfuum tempora fingula, majora funt temporibus Penduli quxfiti, proportione roooo ad 3600 , five 25 ad 9 . Quare ut quadratum numeri 25 ad quadratum 9 , hoc eft, ut 625 ad 81 , ita erit longitudo pedum 3 ad eam quæ quærebatur, nempe unciarum 4 cum $\frac{66}{100}$.

Pofita ergo lohgitudine perpendiculi, puta pedum trium in horologio à nobis propofito, inde Cyclois linea, qux curvaturam laminarum $T$ datura eft, hoc modo defcribetur.

Super tabula plana affigatur regula A B, femidigiti craffitudine. Deinde fiat cylindrus C D E eadem illa altitudine, diametrum vero bafeos, dimidiæ perpendiculi longitudini, æqualem habens; fitque $\mathrm{F}$ G $\mathrm{H}$ fafciola, feu potius bractea tenuis, affixa regulæ in $F$, cylindro verò in circumferentiæ puncto áliquo $E$, ita ut parcim huic circumvoluta fic, partim extendatur juxta latus regulæ A. B. Cylindro autem infixa fir ferrea cufpis D I, pauxillum ultra bafin inferiorem prominens, atque ita ut circumferentiz ejus exacte refpondeat. 
HOROLOG. OSCILLATOR.

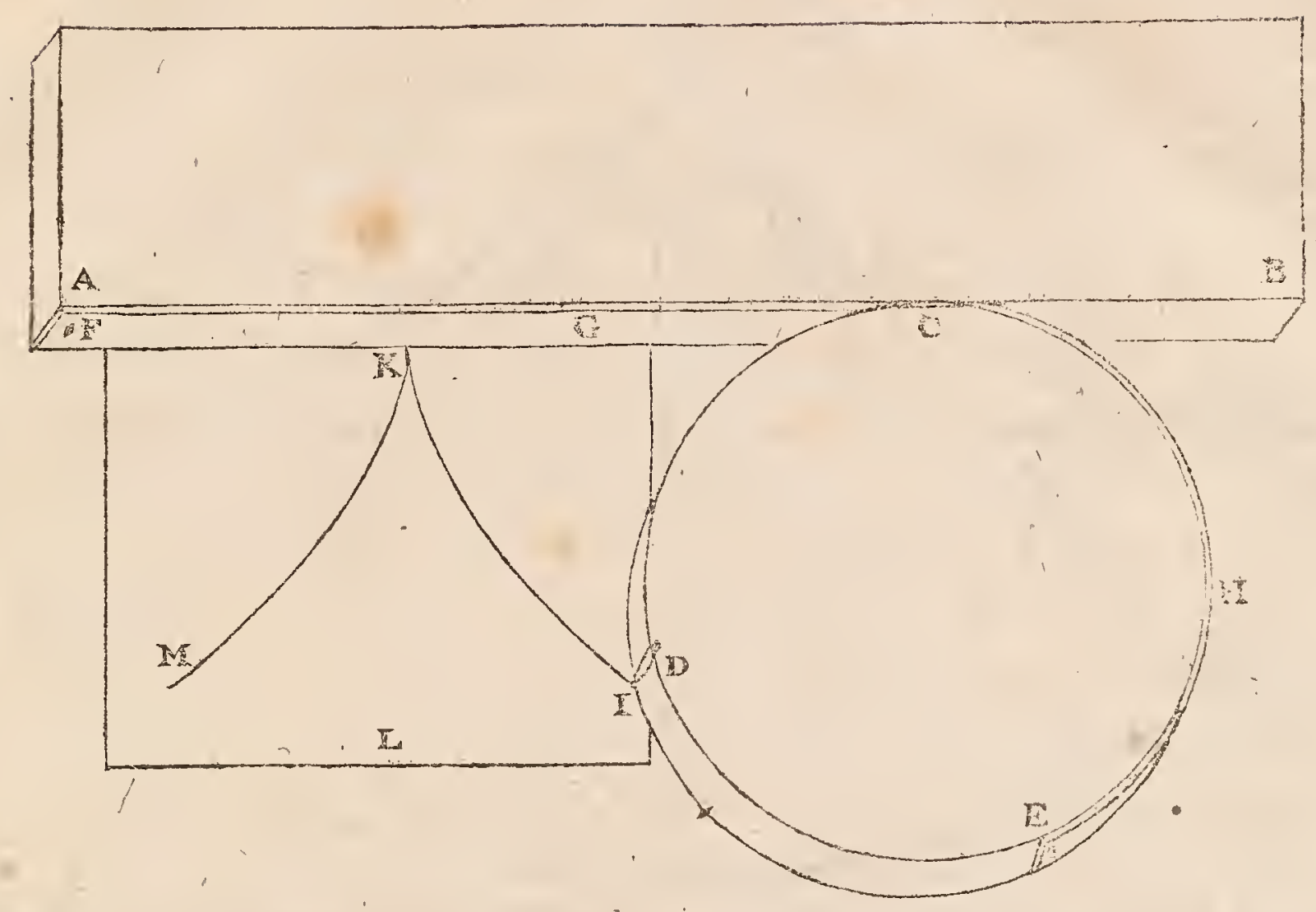

DESCRIPTIO

His ita fe habentibus, fi cylindrus fecundum regulam a B volvatur, bracteolæx tantum $\mathrm{F}$ G craffitudine intercedente, eâque $\mathrm{fem}$ perquantum poteft extensâ, defcribet cufpis I in fubjecto tabulæ plano lineam curvam $\mathrm{K}$ I, quæ Cyclois vocatur. Circulus vero genitor erit C D E , cylindri adhibiri bafis. Quod fi jam laminam $\mathrm{K} \mathrm{L}$ ad regulam A B applicuerimus; exaratâ primum in ea cycloidis portione $\mathrm{K} I$, invertemus deinde ipfam, $\&$ in fuperficie adverfa fimilem lineam $\mathrm{K} \mathrm{M}$, ab eodem puncto $\mathrm{k}$ egredientem, incidemus. Tum figuram M K I, accurate fecundum lineas iftas, efformabimus, cui figuræ lamellarum interftitium aptarioportet, inter quas perpendiculum fufpenditur. Sufficiunt autem ad horologiorum ufum portiones exigux arcuum $\mathrm{KM}, \mathrm{K} \mathbf{I}$; reliquo flexu inutili futuro, ad quem perpendiculi filum accedere non poteft.

Verum, ut mirabilis lineæ natura atque effectus plenius intelligantur, integras femicycloides $\mathrm{KM}, \mathrm{KI}$, alio fchemate hic exprimere vifum fuit, inter quas fufpenfum agitatumque Pendulum KN P, diamerri circuligenitoris duplum, cujufcunque amplitudinis ofcillationes, ufque ad maximam omnium perarcum M P I, iifdem temporibus confecturum fit : atque ita, ut appenf fpheræ $\mathrm{p}$ centrum, in linea M $\mathrm{PI}$, quæ \& ipfa cyclois integra eft, femper verfetur. Qux proprietas infignis, nefcio an alii piater hanc lineæ data fit, ut nempe fe ipfam fui evolutione defcribat. Hac autem quæ dicta funt, in fequentibus, ubi de defcenfu gravium, deque evolutione curvarum agemus, fingula demonftrabuntur. 


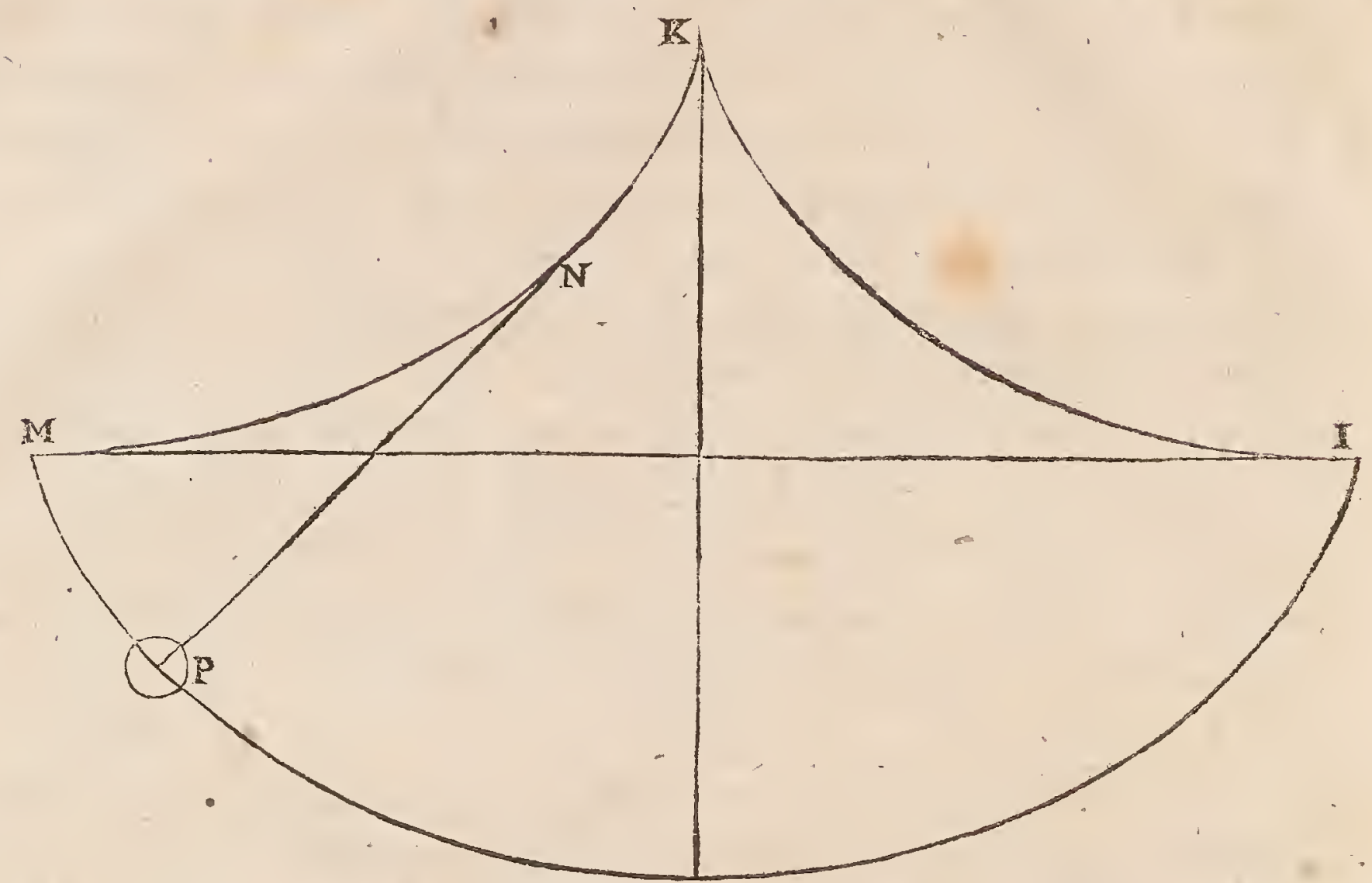

Licebit aurem aliter quoque, per inventa puncta, cycloidem defignare. Defcribatur circulus diametro A B, qux dimidiæ longitudini perpendiculi æqualis fit. In cujus circumferentia fumptis partibus æqualibus quotliber, $A C, C D, D E, E F, A G, G H, H I$, $\mathrm{I} \mathrm{K}$, jungantur $\mathrm{G} \mathrm{C}, \mathrm{H} \mathrm{D}, \mathrm{IE}, \mathrm{K} \mathrm{F}$, quæerunt inter fe parallelæ. Deinde arcui $A \mathrm{~F}$ fumatur $x$ qualis linea recta $\mathrm{L} M$, eaque in partes xquales totidem dividatur quot funt in arcu $\mathrm{A} F$, earumque partium uni æquales ponantur fingulæ $C_{N}, G$ in recta $C G$, duabus vero partibus rectæ $L_{\mathrm{M}}, \mathfrak{x}$ quales fiant fingulæ $\mathrm{D} \dot{\mathrm{P}}, \mathrm{H}$ Q in recta $D$ H. Tribus vero, fingulæ E $R$, I s in recta $\mathrm{E}$; atque ita porro fi partes plures fuerint acceptæ; ac tandem toti $L$. $x$ xuales fiant fingulæ $\mathrm{F} T, \mathrm{~K} V$ in linea extrema $\mathrm{F}$ K. Iam fi curvæ dêfcribantur per puncta $A O Q S V, A N P R T$, hær rurfus quxfitæ cycloidis partes erunt, inter quas perpendiculum affigi oportet.

Recta autem $\mathrm{L} M$ $æ$ qualis arcui $\mathrm{A}$ invenitur, fi primum duabus rectis, quæ femiffibus arcus $\mathrm{A} F$ fubtenduntur, $æ$ qualis ponatur $\mathrm{X} Y$; totius vero arcus fubtenf $x \mathrm{~A} x$ qualis ab eodem termino accipiatur $\mathrm{x} z$, differentixque $\mathrm{y} z$ triens $\mathrm{z} \Delta$ ad totam $\mathrm{x} z$ adponatur. Nam tota $\mathrm{X} \Delta$ toti arcui $\mathrm{A} \mathrm{F}$ tam prope $x$ qualis erit, ut licet fextans fuerit circumferentix; (neque major hic unquam requiritur) non una fexies millefima parte fuæ longitudinis deficiat; uti in his, qux de Circuli Magnitudine antehac fcripfimus, demonftratum eft.

Explicitis qux ad horologii fabricam attinent, nunc quoque illud declarandum eft, quo pacto ad veram horarum menfuram componi debeat. Ergo primum, an recte fe habeat motus ejus, hoc modo examinabitur. 


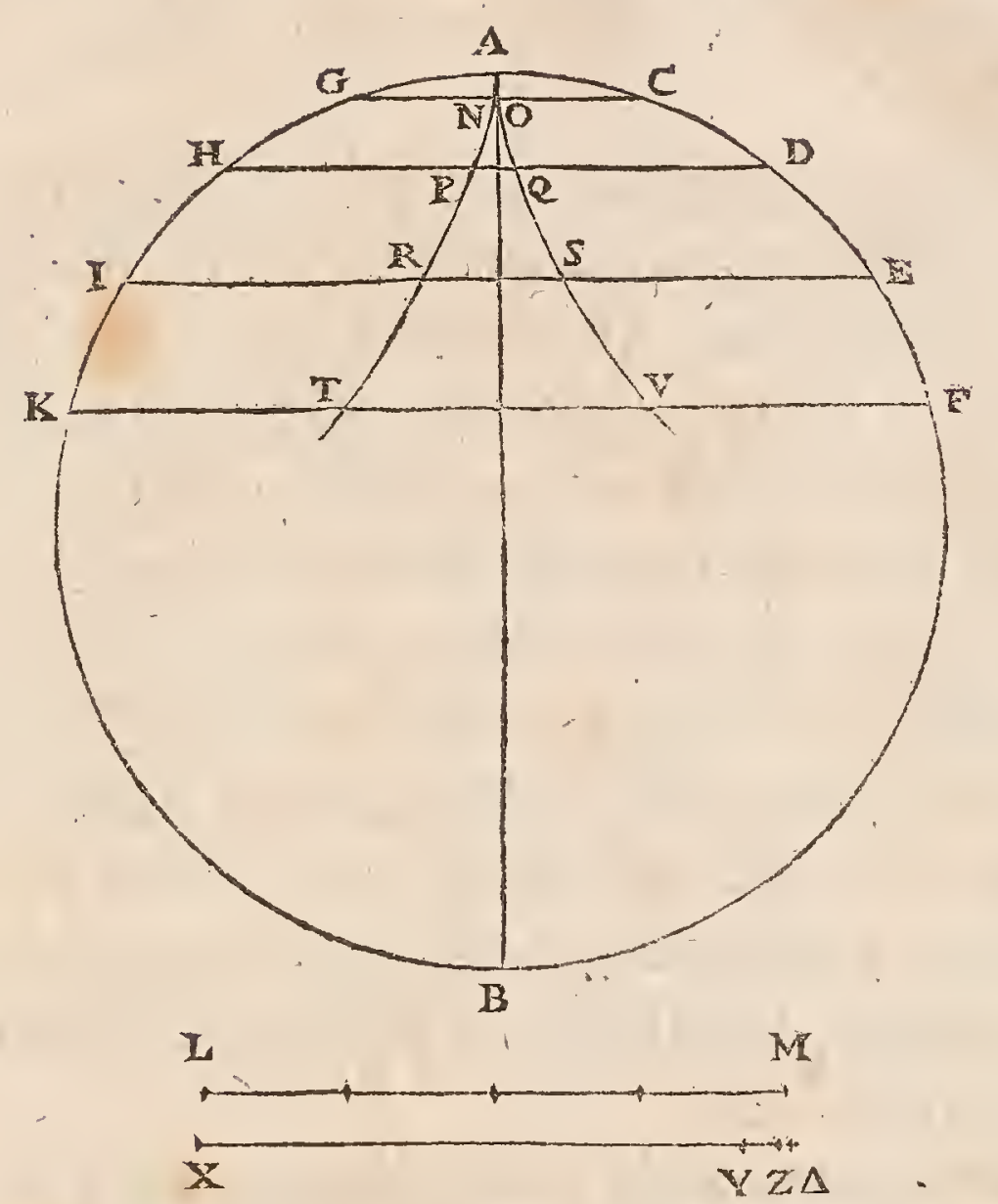

Oculo obfervatoris certus eligatur locus, unde fidera defpici poffint, fimulque tecta parietefve vicinarum ædium, fic pofita, ut, cum eò appulerint ftellæ quædam è fixarum numero, fimul videri definant. Eo loco foramen, ad pupillæ magnitudinem, conftitua tur, ut fequentibus diebus, abfque errore, oculus ad idem punctum reponi poffit. Iam ad momentum ipfum, cum ftellarum aliqua è confpectu abit, notetur tempus horologio indicatum. Arque idem poftero die, vel potius aliquot diebus intermiffis, fiat. Quod fi tantum unius dieifpatium duabus obfervationibus intercefferit, oportet in poftrema obfervatione tempus horologii deficere $a b$ illo, quod prima obfervatione annotacum fuerat, frupulis primis 3 , fecundis 56.1 ta enim rectè fe habere perpendiculi longitudinem conftabit; quum tanto fuperetur qualibet fiderum fixorum revolutio à die folari mediocri. Mediocri dico, quoniam dies folares, de medie ad meridiem, non omnes inter fe rquales funt, ut mox amplius exponetur. Si vero poft plures demum dies obfervario repetatur, in fingulos tantundem differentix caufa computandum erit. Sit, exempligratiâ, in prima obfervatione, ad momentum evanefcentis ftellæ, adnotata horologii hora 9, cum fcrupulis primis 30 , fecundis 18 ; deinde, feptimo poft die, eâdem diffarente ftellâ, indicet horam 8 , cum fcrupulis pr. 50 , fec. 24 . Hæc hora deficit à priorefcrupulis pr. 39 , fecundis 54 . Quæ, in feptem divifa, dant retardationem diurnam fcrupulorum $5^{\prime} .42$ ". Debebat autem effe fcrupulorum $3^{\prime} \cdot 56^{\prime \prime}$. quæ illâ minor eft fcrupulis $\Sigma^{\prime} \cdot 46^{\prime \prime}$ 
Descriptro Itaque tantundem quotidie deficit horologiumà vera, feu, media. dierum menfura.

Cæterum alio quoque modo, ad folem, horologii motum examinare licebit. Sed hic jam inæqualitatis dierum naturalium ratio habenda erit. Sunt enim, ut jam dixi, non omnes ejufmodi dies inter fe æquales; \& quanquam exiguum fit difcrimen, tamen plurium dierum incervallo fxpe co ufque excrefcit, ut haudquaquam contemni poffit. Erenim fi \& folarium quam perfectiflime delcriptum habeatur, \& horologii automati motus ad veriffimam dierum menfuram exactus fit, neque ab ea recedat; eveniet tamen neceffario ut, certis anni temporibus, fape horæ quadrante, aut etiam femihora, inter \e difcrepent, ac rurfus ftatis temporibus ultro concordent. Hoc enim ita effe, ex tabula temporis æquaroria quam fubjicimus, intelligetur; poftquam ufum ejus oftenderimus, qui eft hujufmodi.

Accipiarur æquatio tabulæ, affignata diei qua primum cum fole, five cum fciotherico, horologium ut conveniret fecimus. I temque rquatio diei, qua quæritur quam bene ad dierum menfuram temperatum fit. Quod fijam prior aquatio major fuerit fequente, fuperare debebit hora automati horam gnomonis eo, quo inter fe xquariones ift $x$ differunt. At fi pofterioris diei æquario major inveniatur, erit excelfus penes horam gnomonis, five eam qua ex fole obfervatur. Vtfl, exempligratia, die s Martii in eandem horam conveniant fciothericum horologium atque automaton, cujus diei æquatio invenitur, in tabula, fcrupulorum primorum 3 , fecundorum.r. lubeatque fcire ejufdem menfis die 20 , an automaton horas xquales rectè metiatur necne: invenietur die pofteriori adfcripta æquatio fcrupulorum primorum 7, fecundorum 27. qux quia fuperat præcedentem fcrupulis primis 4 , fecundis 16 , debebit tanto ferior effe hora fciotherici, quam quæ automato indicatur. Vnde, fi diverfum reperiatur, facile inde colligetur, quantum in dies.fingulos exuperer automaton, aut retardet.

In computanda tabula hac duplicem caufamadhibui, utramque Aftronomis notam, Eclipticæ nimirum obliquitarem, \& folaris motus anomaliam. Quod cum ratio poftulat, tum experientia quoque, his ipfis horologiis fuperftructa, quxque fine his nequaquam haberi poterat, evincit; quandoquidem, cum xquatione hic propofita, obfervationes folis, quas fæe per complures menfes, quotidie ad momentum quo meridianum circulum fol occuparet, inftituimus, planiffime confencire inventa funt. 


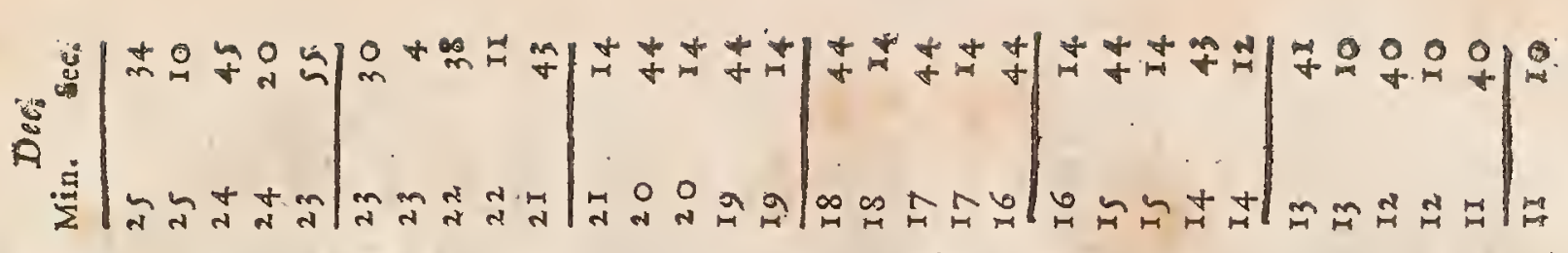

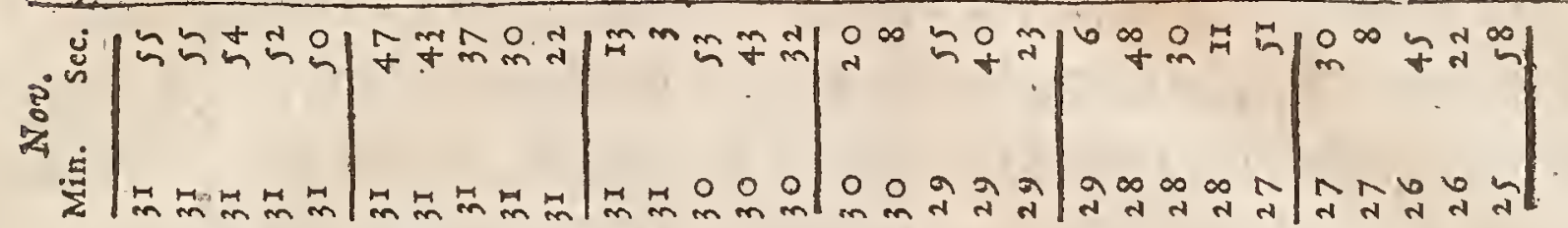

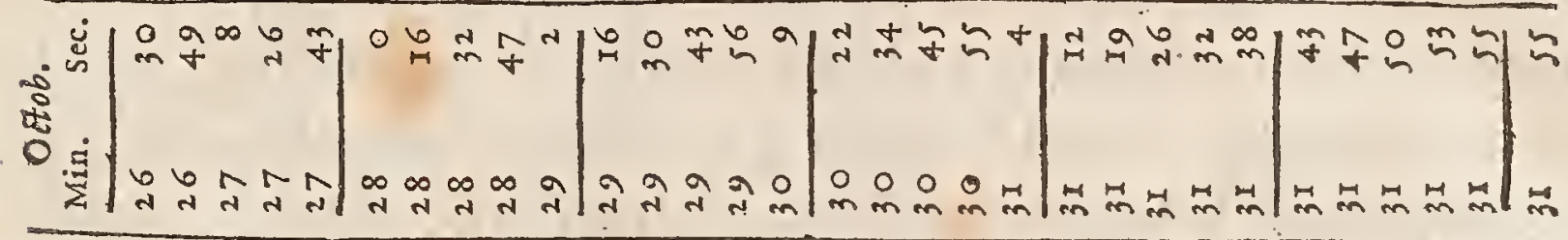

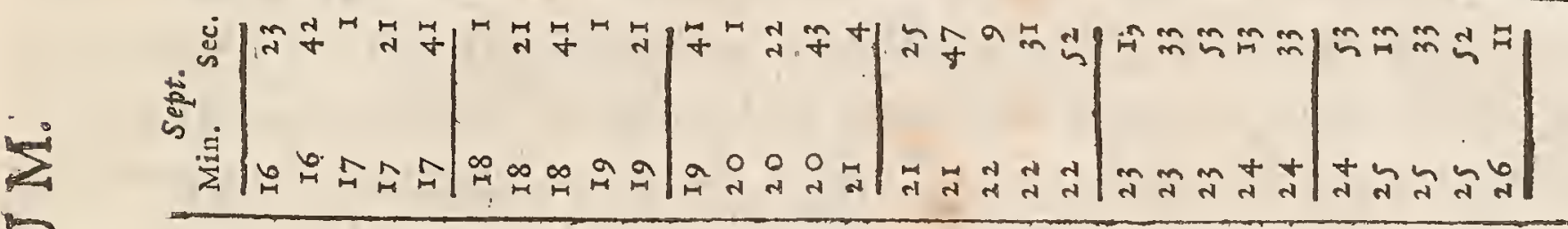

戛| 竞|

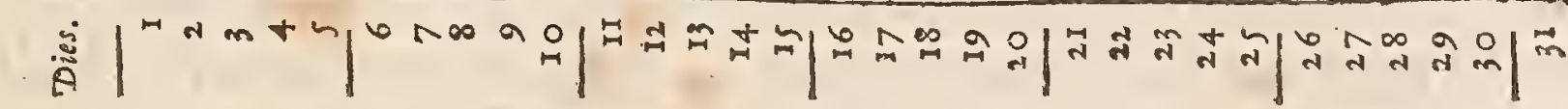

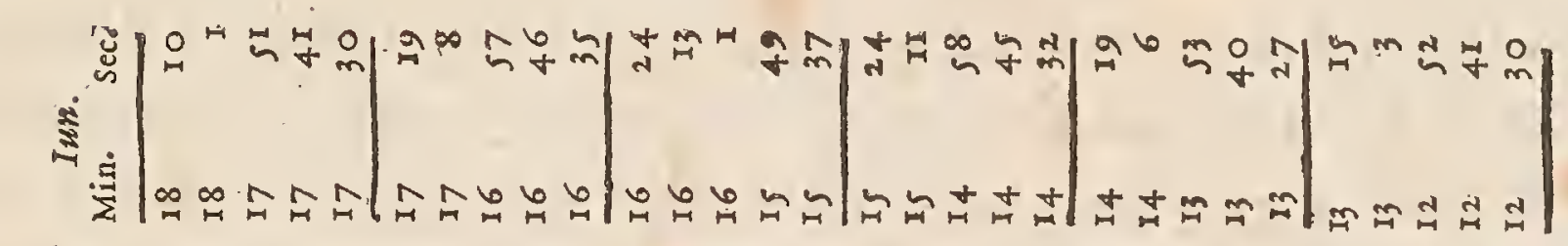

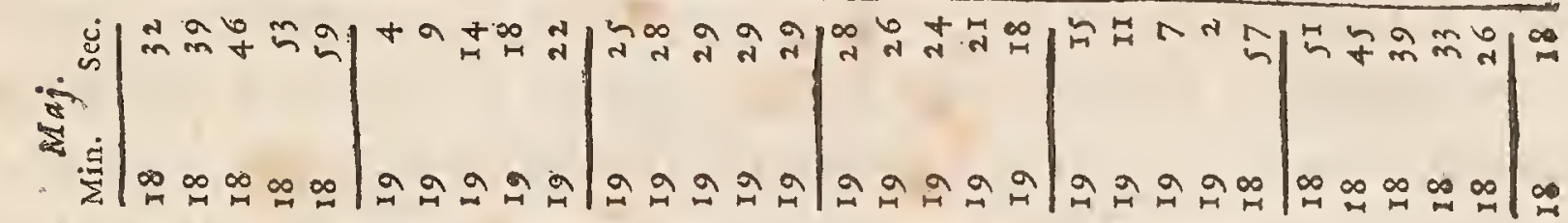

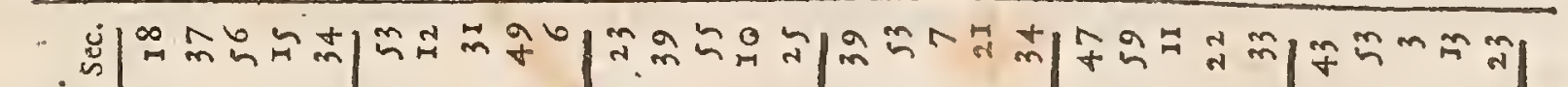
竞|

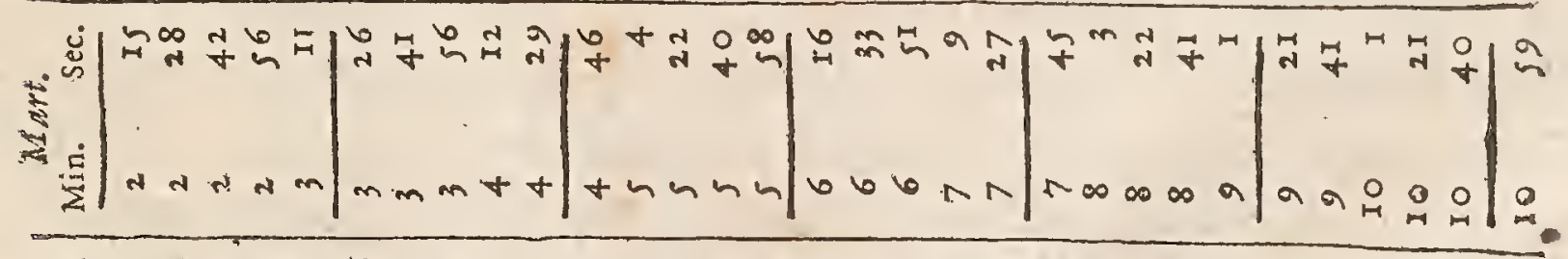

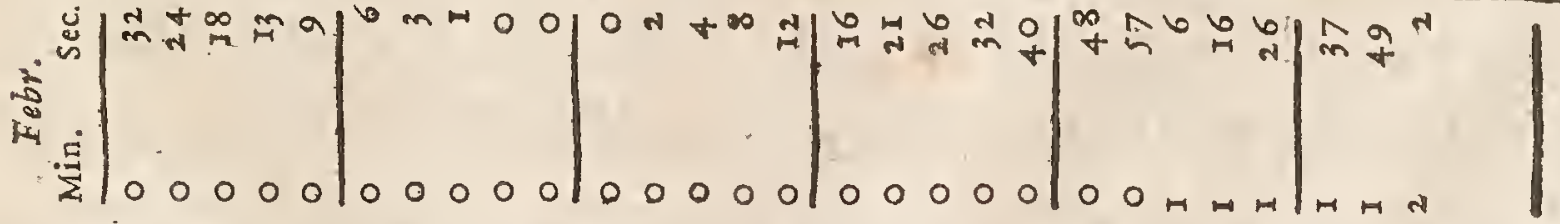

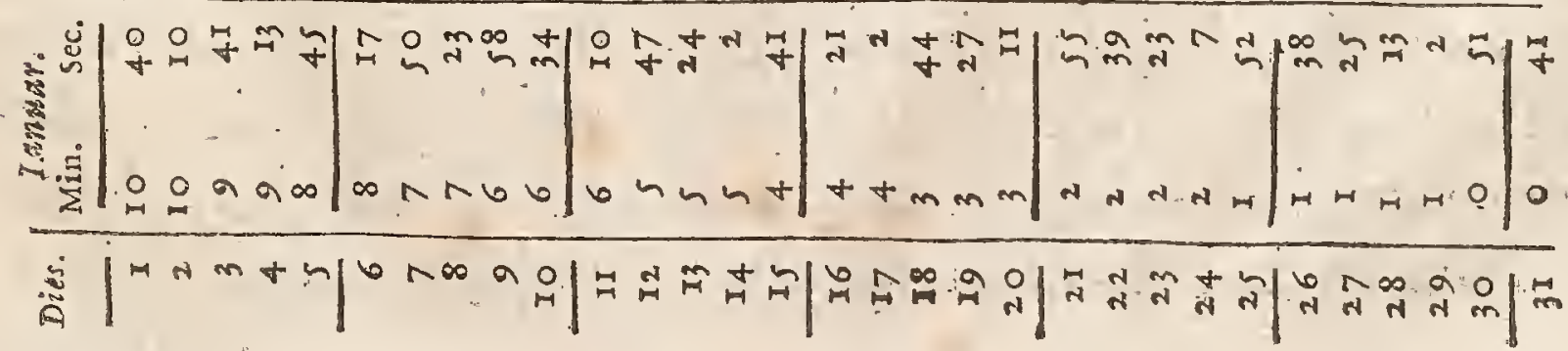


Iam poftquam utrovis modo eorum quos diximus, fed priore potius, "examen infticutum fuerit, fi multum aberrare à media dierum longitudine horologium reperiatur, adeo ut differentia ul tra rria quatuorve prima fcrupula afcendat, remedium adhibebitur aucta aut diminuta ipfrus penduli longitudine. Vbi hæc tenenda eft regula, tot crupulis primis, in fingulos dies, motum horologij acceleratum aut retardatum iri, quot $\frac{7}{10}$ unius liner auferentur pendulo aut addentur. Cumque ad veram menfuram hoc pacto jam prope reductum erit, reliqua correctio tranfpofitione exigui ponderis $\Delta$, virgæ $\mathrm{v} v$ adhærentis, commode peragetur. Id pondus lentis formam habet, cujus fectionem fecundum axem in figura I expreffimus. Et quia tantum vicefimam tricefimamye partem $x$ quat ponderis $x$, hinc fit ut fat magnis fpatiis è priore loco difcedens, haud multum tamen perpendiculi motum afficiat, accelerando nempe quoties verfus mediam virgæ longitudinem attrahitur, retardando cum inde furfum atu deorfum movetur. Ne vero diu punctum illud quærendum fit quo veriffimam daturum fit dierum menfuram, divifimus certa ratione, ex motus legibus petita, inferiorem virgæ medietatem, pofito nimirum pondere $\Delta$ parte quinquagefima ponderis $\mathrm{x}$, parique gravitate ipfus virgæ $\mathrm{v} v$. Quæ quidem divifiones figura IV exhibentur, ubi penduli porrio inferior in tres partes fecta cernitur, quarum, qux infimo loco ponenda, eft A B. Punctum A eft centrum gravitatis ponderis $\mathrm{x}$, à puncto autem $\mathrm{C}$, partes fingulx, quindecim fcrupulorum primorum differentiam diurnam efficiunt, ubi tali intervallo mota fuerit lens $\Delta$. Demonftratio autem divifionumque inventio, dabitur in iis qux de Centro Ofcillationis.

Cxterumillorum quoque qux mari vehuntur, longitudinum inveftigandarum gratiâ, formam hic defcriberemus, fi quænam maxime ad hunc ufum accommodata fit, xque ac in præcedentibus, exploratum determinatumque haberemus; etfi quidem jam nunc co res deducta fit, ut parum deeffe videatur ad perficiendum tantæ utilitatis inventum. Quid autem \& qua fortuna hic tentatum fuerit, quidve deinceps tentandum reftet, exponere non pigebir.

Prima duo hujufmodi horologia Britannica navi vecta fuere anno 1664 , qux vir nobilis è Scotia nobifque amicus ad noftrorum exemplum fabricari curaverat. $\mathrm{Hxc}$ ponderis loco laminam chalybeam habebant in fpiram convolutam, cujus vi rotx circumagerentur, 
HOROLO G. OSCILLATOR.

cumagerentur, quemadmodum in exiguis illis quæ circumferri DESCRADTXO folent automatis adhiberi folent. Vt autem jactationem navis Horozogix perferre poffent, è chalybea pila, cylindro æneo inclufa, horologia fufpenderat, clavulamque qux penduli motum continuat (erat autem femipedali longitudine pendulum, deorfum productam geminaverat, ut literæ $\mathrm{F}$ inverix formam referrer; ne videlicet in gyrum evagari poffet penduli motus, unde ceflationis periculum. Navis hæc, cum tribus aliis quas icineris focias habuerat, poftquam in Britanniam reverfa eft, Præfectus claflis hæc retu17. Se nempe, cum a Guinex littore folviffer, atque ad infulam, fancti Thomæ dictam, perveniffer, qux xquinoctiali circulo fubjace compofitis hic ad folem horologiis, occidentem verfus curfum inftituiffe, atque ad feptingenta circiter milliaria continuo rramite progreffum, tum rurfus vento favente Libonoto ad Afric $x$ littora declinaviffe. Cum autem ad ducenta trecentave mil: liaria eo curfum tenuiffet, magiftros aliarum navium, veritos ne prịfquam Africam atrigiffent aquâ ad potum deficerentur, fuafiffe ur ad infulas Americanas, Barbatorum dictas, aquandi gratiâ deflecteret. Tum fefe concilio nauclerorum habito, juflifque ut Ephemeridas ac fupputationes finguli fuas proferrent, reperiffe cxterorum calculos a fuis diverfos abire, unius quidem 80 milliaribus, alterius centenis, tertii amplius etiam. Iplum vero, cum ex horologiorum indicio collegiffer non amplius quam triginta circiter milliaribus abeffe infulam del Fuego dictam, qux una eft earum, non procul ab Africa diftantium, qux àv iridi promontorio nomen habent, eamque poftero die teneri poffe; confifum pendulis fuis eò curfum dirigi imperaffe, ac die infequenti fub meridiem eam ipfam in confpectum veniffe infulam, paucifque poft horis navibus ftationem præbuiffe. Et hæc quidem ex Præfecti illius relatu.

A b eo vero tempore aliquoties tum Batavorum tum Gallorum opera, idque Regis Sereniffimi juffu, repetita fuere experimenta, vario eventu, fed ita ut fæpius negligentia eorum quibus horologia commiffa erant quam ipfamet automata culpari poffent. Op. timus vero fucceffus fuit in Mediterraneo mari, expeditione inCreram infulam, quò illuftriffimus Dux Belfortius, Candiæ à Turcis obfeffr auxilium laturus, cum Gallorum copiis miffus erat, ubi $\&$ in prælio occubuit. Is in ea qua vehebatur navi, horologia hujufce experimenti gratiâ habebat, virumque Aftronomix peritum iis præfecerat, è cujus obfervationibus, in fingulos dies habitis, longitudines locorum ad quæ in ea profectione aut appulerunt na- 
Descristio ves, aut qux pratervecti dignofcere oculis potuerant, horologio. Hororogri. rum operâ exacte dimenfas fuiffe comperimus, atque ita ut Geo.. graphicis defcriptionibus quæ melioris notæ habentur eædemmet longitudinum differentix defignatæ reperiantur. Namque inter Toloni portum Candiamque oppidum differentia hor. 1. fcrup. 22 reperta fuit, hoc eft graduum longitudinis 20 . fcrup. 30 . ac rurfus à Candia Tolonum revertencibus differentia proxime eadem. qui confenfus certiflimum veritatis eft indicium.

Inter eundem Toloni portum \& infulam quandam cui $M$ are timo nomen eft, prope promontorium Sicilix quod Occidentem fpectat, Lilybxum olim vocatum, differentia horaria obfervata eft fcrup. prim. 25 , fec. 20 , quibus refpondent gradus longitudinis 6, fcrup. 20'. Item à Tolono ad infulam Sapienza dictam, qux juxta Peloponnefum eft Occidentem verfus, hora 1 , fcrup :prima s', fec. $45^{\prime \prime}$, quibus relpondent longitudinis gradus 16, fcrup. 26.

Horologia ad folem examinata fuerant, mane ad Orientem, vefpere ad Occidentem, fupputato ex data poli altitudine utroque temporis momento. Atque hæc ratio cum naves in anchoris thant omnium optima videtur, quod, abfque inftrumentorum ope, folis oculis ex obfervationes peragantur.

Pendulum vero unciarum novem longitudine inerat horologiis hifce, pondere femiflis. Rotx ponderum attractu circumagebantur, eademque cum illis theca inclufx erant quaternum pedum longitudine. In ima theca plumbum infuper centum atque amplius librarum additum erat, quo melius perpendicularem fitum fufpenfa in navi machina fervaret.

Quanquam autem æquabilis admodum fibique conftans automari motus per hæc experimenta comperiebatur, tamen alia quoque ratione ulterius illud perficere aggrefli fumus, quæ erat hujufmodi. Rotæ illi quæ ferratos dentes habet, penduloque proxima. eft, pondus exiguum ex catenula affabre confructa appendimus, quo fola ipfa moveretur, reliqua omni machina nihilaliud agente quam ut fingulis femifcrupulis horariis plumbum illud exiguum ad priorem altitudinem reftitueret; eadem fere ratione atque in conftructione horologii fuperius expofita videre eft, ubi pondus altero fune atcollitur, dum altero gravitarem fuam horologii mo. tui impertic. Quibus ita conftructis, cum velutiad unicam rotam omnia effent redacta, major adhuc quam antea apparuit horologiorum xqualitas, illudque accidit memoratu dignum, quod cum duo ad hanc formam confructa ex eodem rigno fufpendiffemus, tignum vero fulcris duobus impofitum effet; motus pendul: 
HOROLOG. OSCILLA T OR:

utriufque ita ictibus adverfis inter fe confenfere, ut nunquam in- DESCRIPTYO de vel minimum recederent, fed utriufque fonus una femper exHOROLOGII. audiretur: imo fi data opera perturbaretur concordia illa, femetipfam brevi tempore reduceret. Miratus aliquandiu rem adeo infolitam, inveni denique, inftituto diligenti examine, à motu tigni ipfius, licet haudquaquam fenfibili, caufam petendam effe. Nempe pendulorum reciprocationes horologiis, quantolibet pondere gravatis, motum aliquem communicare; hunc vero motum, tigno ipfi impreffum, neceffario efficere ut fi aliter quam contrariis ad unguem ictibus pendulum utrumque movearur, co tamen neceffario tandem deveniant, ac tum demum tigni motum penitus interquiefcere: Qux tamen caufa non fatis efficacix haberet, nifi \& horologiorum motus aliunde æquabiliffimus foret atque inter fe confentiens.

Cærterum experimentis in Oceani navigatione habitis, ac præfertim procella vehementiore aquas agitante, compertum fuit primam ac præcipuam curam de motu horologiorum abfque interruptione confervando habendam effe, quod jactationem navis tantam ægrè tunc perferre illa animadverfum fit. Quamobrem nova denique ratione \& penduli formam immutavimus, \& aliter horologia ipfa fufpendimus. Pendulum trianguli formam habet, in

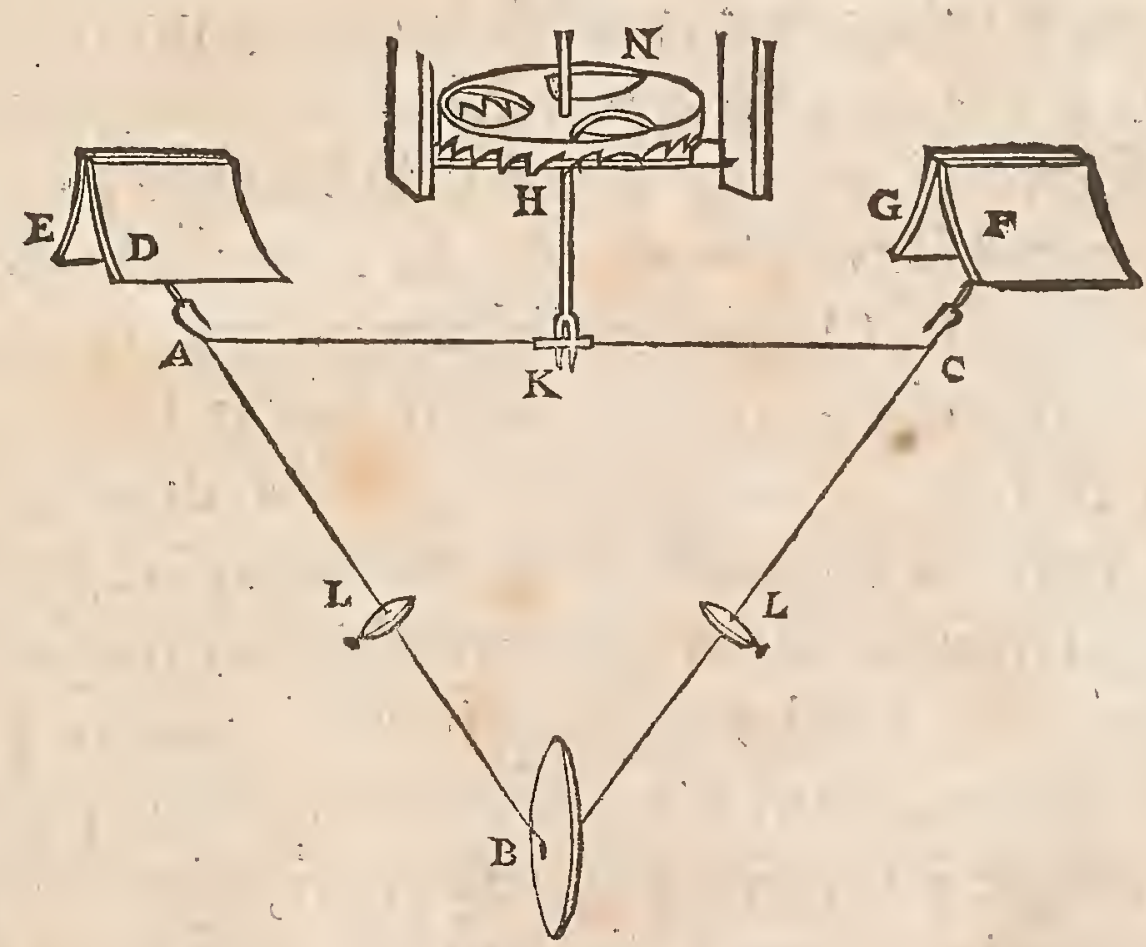

cujus vertice deorfum fpectante plumbea lens affixa eft. Anguli utrique reliqui filis inter laminas cycloidales fufpenfi funt. Bafis clavulam bifurcatam puncto fui medio recipir ab eaque movetur, illa vero ab rota ferrata horizonti parallela motum accipit. Motus rotarum omnium non à ponderefed à chalybea lamina, tympano inclufa, principium habet. In figura adjecta pendulum triangulare eft A B C; lens plumbea B; laminæ cycloidales $\mathrm{E} D, \mathrm{~F}$ G. Clavula 
Descriptro bifurcata $\mathrm{H} \dot{\mathrm{K}}$; rota ferratis dentibus $\mathrm{N}$, quæ cæreris horologii ro.

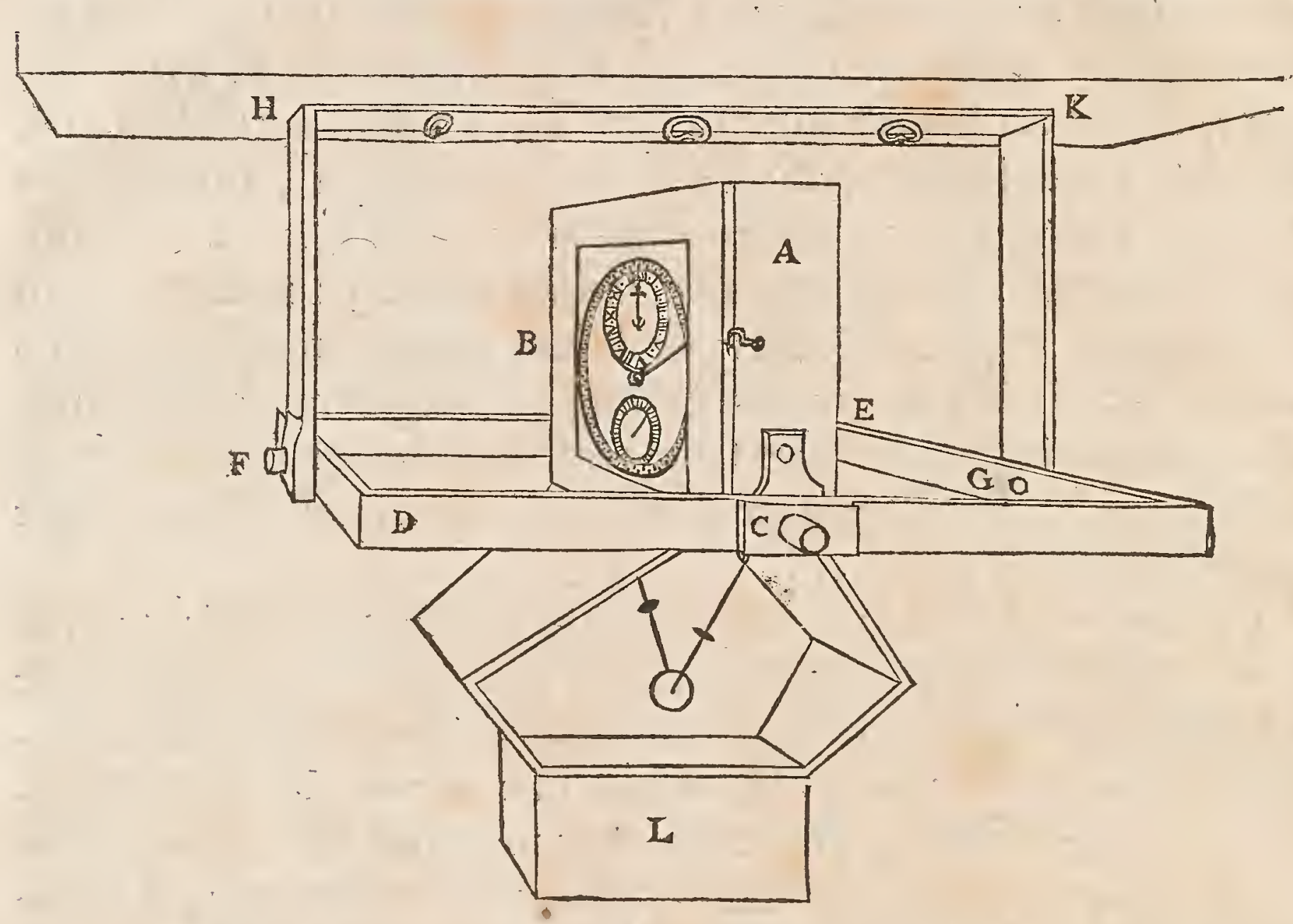

Sufpenfionis modum altera hæc figura exhibet; ubi theca $A$ axibus primum duobus, quorum alter $C$ tantum apparet, rectangulo ferreo $\mathrm{D}$ E inferta eft; quod deinde rectangulum rurfus axibus fuis $\mathrm{F} \mathrm{G}$ ferreo gnomone $\mathrm{F} \mathrm{H} \mathrm{K} \mathrm{G} \mathrm{fuftinetur,} \mathrm{qui} \mathrm{contigna-}$ tioni navis immobiliter affixus eft. in ima theca pondus so librarum appenfum eft. Quibus ita fe habentibus, quacunque navis inclinatione perpendicularem pofitum fervat horologium. Axis autem c, cum fibi oppofito, ita collocati funt, ut ad rectam lineam refpondeant punctis fúpenfionum penduli ejus quod diximus: quo fit ut motus ipfius of cillatorius machinam nequaquam commovere poffic, quo nihil eft alioqui quod magis penduli motum deftruar. Porro axium C C, \& F G craffitudo, qux pollicem xquat, gravitafque plumbi inferius appenfi, nimiam movendi libertatem horologio adimunt, faciuntque ut fi forte fuccuffu navis graviore commotum fuerit, continuo ad quietem perpendicu-. lumque fuum revertatur.

Et hæc quidem ita adaptata machina ut in mare deducarur experientiæque committatur fupereft, qux \& certam pene fucceffus fpem præber, quod iis quæ hactenus inftituere licuit experimentis, multo melius quam priores illæ omnem motus diverfitatem perferre reperca fit. 


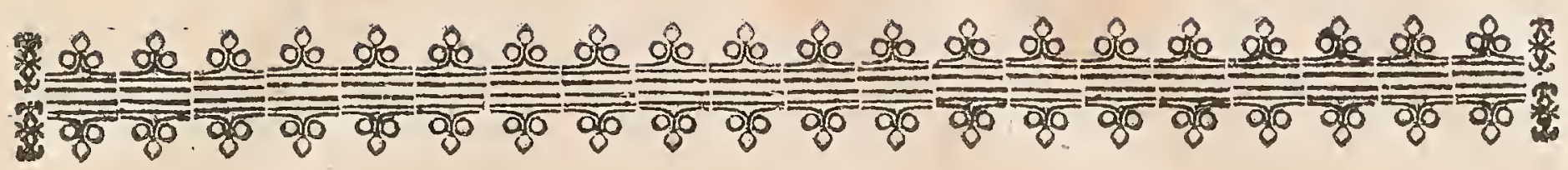

\section{HOROLOGII OSCILLATORII}

$$
P A R S \text { SECVNDA. }
$$

De defcenfu Gravium E' motu eorum in Cycloide.

\section{H Y POT H E ES.}

I.

I I gravitas non effet, neque aër motwi corporum officeret, unum quodque corum, acceptum femel motum continuaturum velocitate aquabili, fecundum lineam rectam.

\section{I.}

Nunc vero fieri gravitatis actione, undecunque illa oriatur ut moveantur motu compofito, ex aquabili quem habent in banc vel illam partem, Ev ex motu deorfum à gravitate profecto.

\section{I I.}

Et borum utrumque feorfim confiderari poffe, neque alterum ab altero impediri.

Ponatur grave $\mathrm{c}$ è quiete dimiffum, certo tempore, quod dicatur F, vi gravitatis tranfire fpatium C B: Ac rurfus intelligatur idem grave accepiffe alicunde motum quo, fi nulla effet gravitas, tranfiret pari tempore F motu æquabili lineam rectam C D. Accedente ergo vi gravitatis non perveniet grave ex $\mathrm{C}$ in $\mathrm{D}$, dicto rempore $F$, fed ad punctum aliquod $\mathrm{x}$, recta fub $\mathrm{D}$ fitum, ita ut $\mathrm{fpa}$ tium D E femper æquetur fpatio C $B$, ira enim, \& motus æquabilis, $\&$ is qui à gravitate oritur fuas partes peragent, altero alterum non impediente. Quamnam vero lineam, compofito illo motu; grave percurrat, cum motus æquabilis non recta furfum aut deorfum fed in obliquum tendit, è fequentibus definiri poterit. Cum vero deorfum in perpendiculari contingit motus æquabilis $C D$,

$$
\text { C iij }
$$




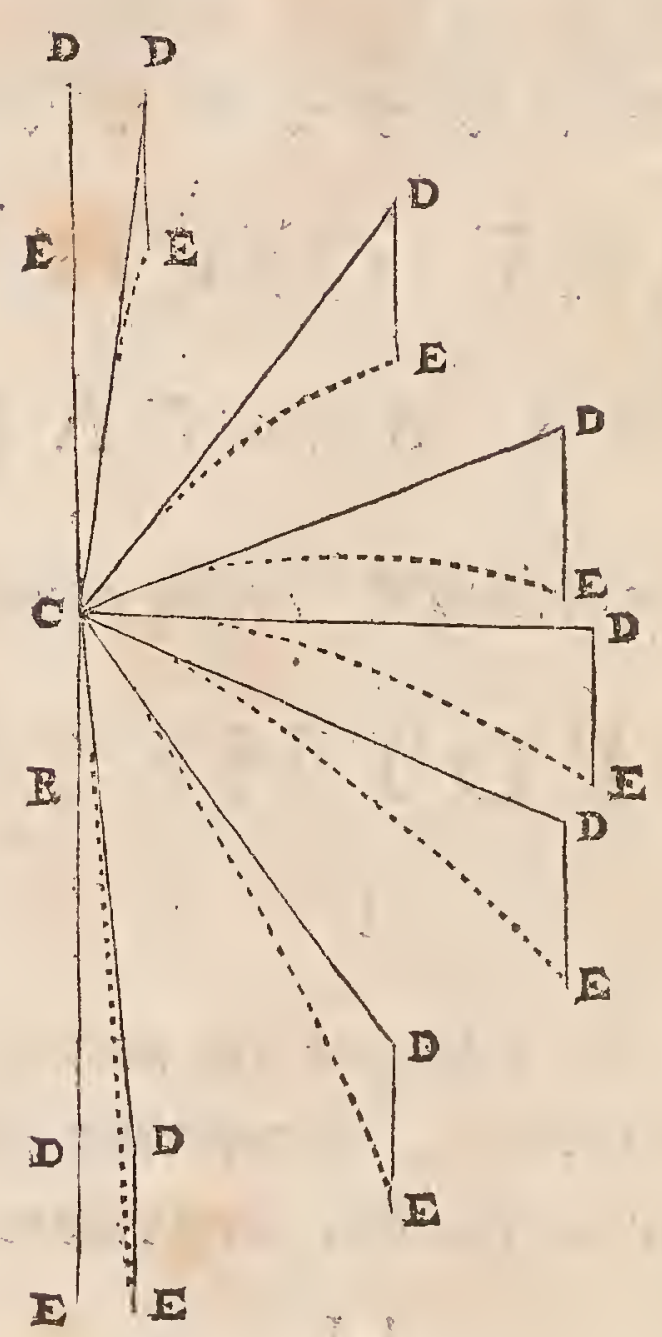

apparer lineam C D, accedente motu ex gravitate, augeri recta $D$ E. Item, cum furfum tendit motus æquabilis $C D$, ipfam $C D$ diminui recta $D E$, ut nempe, peracto tempore $F$, grave inveniatur femper in puncto E. Quod fi, utroque hoc cafu, feorfim, uti diximus, duos motus confideremus, alterumque ab altero nullo modo impediri cogitemus, hinc jam accelerationis gravium cadentium caufam legefque reperire licebit. Et primum quidem duo ifta finul oftendemus,

\section{P R D POS I T IO I.}

\section{Qualibus temporibus aquales celeritatis partes gravi} $1 \mathrm{C}$ cadenti accre fcere, $\xi \sigma$ patia equalibus temporibus ab initio defcenfus emenfa, augeri continue aquali excef]u.

Ponatur grave aliquod, ex quiete in $A$, primo tempore lapfum effe perfpatium A B, atque ubi pervenit in $B$, acquifiviffe celeritatem qua deinceps, tempore fecundo, motu æquabili, percurrere poffet fpatium quoddam B D. Scimus ergo fparium fecundo tempore peragendum majus fore fpatio $B D$, quia vel ceffante in $B$ omni gravitatis actione fpatium B D percurreretur. Feretur vero motu compofito ex æquabili quo percurfurum effet fpatium B.D, \& ex motu gravium cadentium, quo deprimi neceffe eft per fpa- 
tium ipfi A B xquale. Quare ad B D addita D E, xquali A B, fCi- De descénsu mus tempore fecundo grave perventurum ad $\mathrm{E}$.

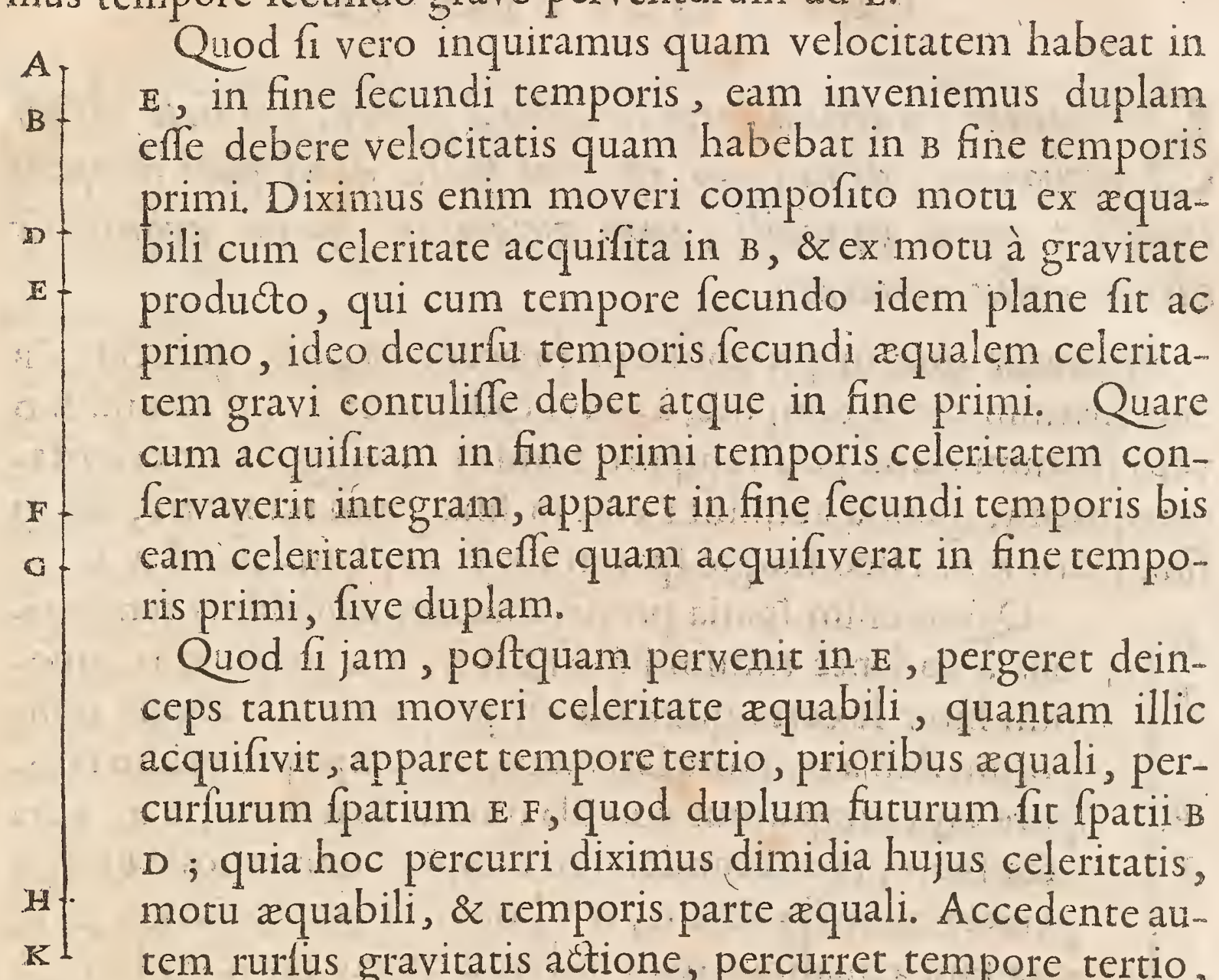
præter fpatium E E, etiam fpatium F G, ipf A B vel D e æquale. Itaque in fine tertii temporis grave invenietur in G., Velocitatem vero hic habebit triplam jam ejus quam habebat in $B$, in fine primi temporis: quia præter celeritatem acquifitam in $\mathrm{E}$, quam diximus duplam effe acquifitæ in B, vis gravitatis, temporis tertii decurfu, æqualem rurfus atque in fine primi celeritarem conrulit. Quamobrem utraque celeritas, in fine temporis tertii, triplam celeritatem conftituet ejus qux fuerat in fine temporis primi.

Eodem modo oftendetur tempore quarto peragi debere \& $\mathrm{fpa}$ tium G.H triplum fpatii B D, \& fpatium н K ipf A в xquale: velocitatemque in $\mathrm{x}$, in fine quarti temporis, fore quadruplam ejus qux fuerat in $B$, in fine temporis primi. A tque ita fpatia quotliber deinceps confiderata, qux xqualibus temporibus peracta fuerint, xquali exceflu, qui ipfi B D xqualis fit, crefcere manifeftum eft; fimulque eriam velocitates per æqualia tempora æqualicer augeri. 


\section{PROPOSITIO II.}

Tatium peractum certo tempore à gravi, è quiete cafom $\checkmark$ inchoante, dimidium ef ejus patii quod pari tempore tranfiret motu aquabili, cum velocitate quam acquifioit ultimo cafus momento.

Ponantur qux in propofitione præcedenti, ubi quidem $A B$ erat fparium certo tempore, à gravi cadente ex $A$, peractum. $B$ D vero fparium quod pari tempore tranfiri intelligebatur celeritate æquabili, quanta acquifita erat in fine primi temporis, feu in fine Ppatii A B. Dico itaque fpatium B D duplum effe ad A B.

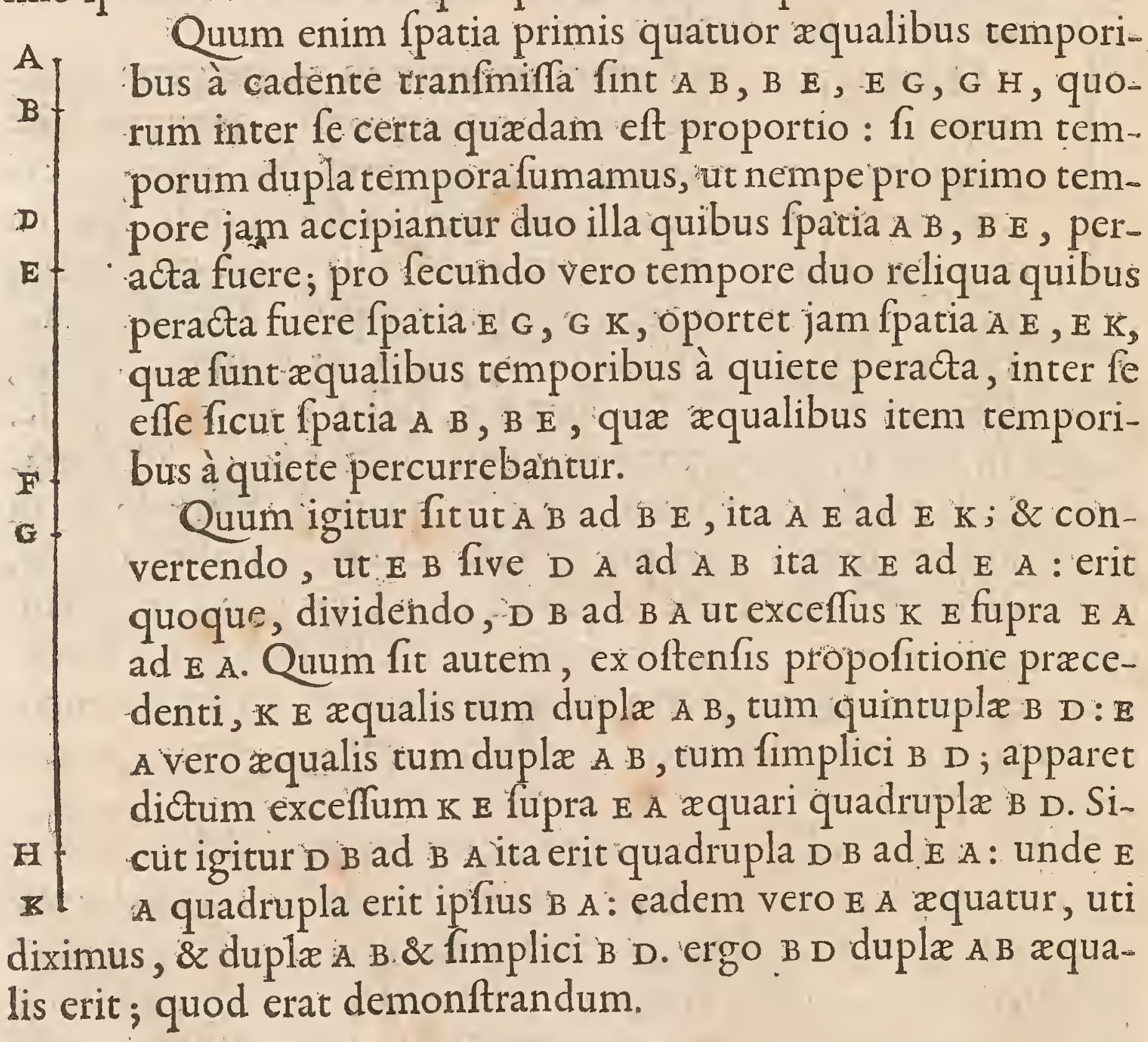

PROPOS. 
S Patia duo, à gravicadente quibuflibet temporibustranf$\checkmark$ miffa, quorum utrumque ab initio defcenfus accipiatur. funt inter fe in ratione duplicata corundem temporum, five ut temporum quadrata, five etiam ut quairata celeritatum in fine cuingque temporis acquifitarum.

Quum enim oftenfum fit propofitione antecedenti fpatia A B, B E, E G, G K, quotcunque fuerint, æqualibus temporibus à cadente peracta, crefcere æquali exceffu, qui exceffus fir ipfi в D xqualis: Patet nunc, quoniam $\mathrm{B} D$ eft dupla $\mathrm{A} B$, fpatium $\mathrm{B} \mathrm{E}$ fore triplum $A B ; E$ G quintuplum ejufdem $A$ B; $G$ K fcptuplum; aliaque deinceps auctum iri fecundum progreffionem numerorum imparium ab unitate, $\mathrm{I}, 3,5,7,9$, \&c. cumque quotlibet horum numerorum, fefe confequentium, fumma faciat quadratum, cujus latus eft ipfa adfumptorum numerorum multitudo (velut fi tres primi addantur, facient novem, fi quatuor fexdecim) fequitur hinc fparia, à gravi cadente tranfmiffa, quorum utrumque à principio cafus inchoetur, effe inter fe in ratione duplicata temporum quibus cafus duravit, fi nempe tempora commenfurabilia fumantur.

Facile autem \& ad tempora incommenfurabilia demonftratio extendetur. Sint enim tempora hujufmodi, quorum inter fe ratio ea qux linearum A B , C D. fpatiaque temporibus his tranfmiffa fint $E, \& F$, utraque nimirum ab initio defcenfus adfumpta. Dico effe, ut quadratum $A$ B ad quadratum $C D$, ita fpatium $E$ ad $F$.

Si enim negetur; habeat primo, fi poteft, fpatium E ad $\mathrm{F}$ majorem rationem quam quadratum $A$ B ad quadratum $C D$, nempe eam quam quadratum $A B$ ad quadratum $C G$, fumta $C$ G minore quam C D \& à C D auferatur pars $D H$, minor quam D G exceffus $C D$ fupra $C G$, atque ita ut reliqua $\mathrm{H} C$ commenfurabilis fit ipfi $A B$; hoc enim fieri poffe conftat. Erit ergo $C$ H major quam C G. Atqui ut quadratum temporis $\mathrm{A}$ B ad quadratum temporis $\mathrm{C}$ H, ita fpatium E, quod tempore A B peractum eft ad fpatium peractum tempore $\mathrm{CH}$, per fuperiùs oftenfa. Hoc vero fpatio majus eft illud quod tempore $C D$ percurritur, nempe fpatium $F$. ergo fpatii $\mathrm{E}$ ad fpatium $\mathrm{F}$ minor eft ratio quam quadrati $\mathrm{A}$ B ad. quadratum $\mathrm{C}$ H. Sicut autem fpatium $\mathrm{E}$ ad $\mathrm{F}$, ita ponebatur effe quadratum $A$ B ad quadratum $C$ G; ergo minor quoque erit ra- 

DEDESCNSu tio quadrati A B ad quadratum C G, quam quadrati $A$ B ad qua-

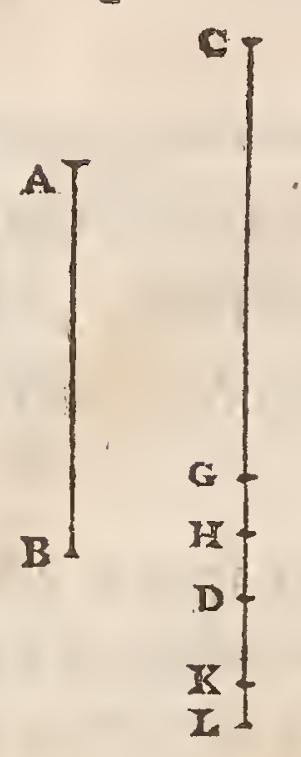
dratum $\mathrm{CH}$, ac proinde quadracum $\mathrm{C}$ G majus quadratum $\mathrm{C} \mathrm{H}$; quod eft abfurdum, quum $\mathrm{C} \mathrm{H}$ major dicta fit quam c G. Non habet igitur fpatium $\mathrm{E}$ ad $\mathrm{F}$ majorem rationem quam quadratum $A$ B ad quadratum C D.

Habeat jam, fi poteft, minorem; fitque ratio fparii $\mathrm{E}$ ad $\mathrm{F}$ eadem quæ quadrati $\mathrm{A}$ B ad quadratum CL, fumptâ C I majore quam C D, \& à C L auferatur $L \mathrm{~K}$ minor exceffu L D, quo $\mathrm{C} D$ fuperaturà $C \mathrm{~L}$; atque ita ut reliqua $\mathrm{K} \mathrm{C}$ fit commenfurabilis A B. Quia ergo ut quadratum remporis A B ad quadratum temporis $\mathrm{C} K$, ita eft fpatium $E$, peractum tempore $\mathbb{A} \mathrm{B}$, ad fpatium peractum rempore $\mathrm{C}$. Hoc vero fpatio minus eft fparium peractum tem. pore $C D$, nempe fpatium $F$. erit proinde fpatii $\mathrm{E}$ ad $\mathrm{F}$ major ratio quam quadrati $\mathrm{A} B$ ad quadratum C K. Sicut autem fpatium E ad F, ita ponebatur effe quadratum A B ad quadratum C L. Ergo major erit ratio quadrati A B ad quadratum C L quam ejufdem quadrati A B ad quadratum $\mathrm{C} \mathrm{K}$, ideoque quadratum C L minus erit quam qu. C K. quod eft ab. furdum, quum $\mathrm{c}$ I major fit quam $\mathrm{c} \mathrm{K}$. Ergo neque minorem rationem habet fparium ead f quam quadratum $A$ B ad quadratum $C D$. quare neceffe eft ut eandem habeat. Porro cum celeritates in fine remporum A B , C D acquifitæ fint inter fe ficut ipfamet tempora; apparet rationem fpatiorum $\mathrm{E}$ ad $\mathrm{F}$ eandem quoque effe quæ quadratorum temporum $\mathrm{A} B, \mathrm{CD}$, quibus tranfmiffa funt. Itaque conftat propofitum.

\section{P R O P O S I T I O I V.}

I grave celeritate ea quam in fine defcenfus acquifruit $\checkmark$ Jurfum tendere caperit, fiet ut paribus temporis partibus, spatia que prius furfum, eadem deorfum tranfeat, adeoque ad eandem unde de cenderat altitudinem a fcendat. Item ut aqualibus temporis partibus aqualia amittat celeritatis momenta.

Sunto enim ut in propofitione 2 , fpatia quot libet, xqualibus 

tium compofitum, ex E F, duplo ipfius B D, \& ex F G, eidem $A$ B æquali; quartum compofitum ex G H, triplo ipfius B. D, \& ex H $\mathrm{K}$ ipfi itidem A в xquali, atque eadem ratione porro crefcenA tia, fi plura fuerint. Dico totidem xqualibus temporibus A eadem fpatia K G, G E, E B, B A, fingula fingulis peragenda effe à gravi furfum tendente, atque incipiente cum celeritate in fine defcenfus $\mathrm{k}$ acquifita.

- Brevitatis autem gratia celeritas quaque defignetur deE- inceps longitudine fpatii quod grave motu æquabili, cum celeritate illa, atque temporis parte una, quales in defcenfu confideravimus, tranfmiffurum effet.

Itaque ex oftenfis dicta propofitione, cum in $\mathrm{K}$ grave F- pervenerit, habet celeritatem $G H$ auctam celeritate $B D$, hoc eft celeritatem $\mathrm{K} F$, quia $\mathrm{K}$ F 2 quatur ipfis $\mathrm{H} \mathrm{G}, \mathrm{B} \mathrm{D}$, funt enim partes fingulæ $\mathrm{H} \mathrm{K}_{\mathrm{K}}, \mathrm{F} \mathrm{G}$, æquales ipf $\mathrm{A} B$, ac proinde utraque fimul ipfi $B D$, quam effe duplam $A B$ oftendimus propolitione 2 . Itaque celeritarem in fine defcenfus $\mathrm{K}$ acquifitam furfum convertendo, $f_{1}$ grave $x q u a-$ bili motu ferretur, conficeret una temporis parte fpatiun K F. Atqui, gravitatis actione accedente, diminuetur H. afcenfus $\mathrm{K}$ F fpatio $\mathrm{F}$ G ipfi A в xquali, ut patet ex dictis ad ₹ hypothefin initio fumptam. Ergo parte prima temporis afcendet grave tantum per $\mathrm{K} \mathrm{G}$, quo eodein fpatio parte temporis noviffima defcenderat. Simul vero \& celeritati tantum deceffiffe neceffe eft, quantum acquiritur temporis parte una deorfum cadendo, hoc eft celeritatem B D. Itaque grave, ubiad G afcenderit, habet celeritatem reliquam $\mathrm{H} G$, cum initio afcenfus habuerit celeritatem $\mathrm{H} G$ una cum celeritate $B D$. Eft autem ipf $\mathrm{H} G$ $æ$ qualis G D ; quum æquetur ipfi $\mathrm{F}$ E una cum $\mathrm{D} B$, hoc eft una cum dupla A B, hoc eft una cum duabus $\mathrm{F} G$ \& E D ; Ergo fi ex G, cum celeritate xquabili, quantam illic habet, furfum pergeret, conficeret una parte temporis fpatium $\mathrm{G} D$. Accedente autem gravitatis actione, diminuetur afcenfus ifte fpatio D E, ipfl a в æquali. Ergo, hac fecunda parte temporis, afcendet per fparium G.E, quod fimili temporis parte etiam cadendo tranfierat. Simul autem celeritati tantum deceffiffe denuo debet quantum temporis parte una ex cafu acquiritur, nempe celeritas B D. Itaque ubiufque ad 
DE DESCENSU $E$ afcenderit, habet duntaxat celeritatem $F E$, quæ nimirum re-

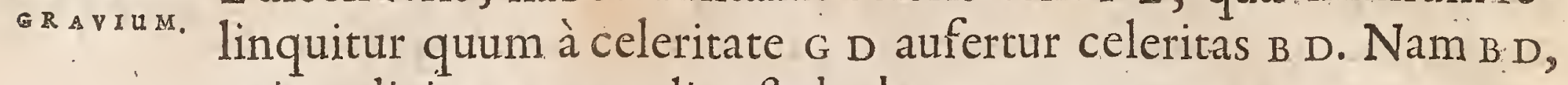
u

Eft aurem ipfi $\mathrm{F}$ E $x$ qualis $\mathrm{E} A$, quum $\mathrm{F}$ E $x$ quetur ipf $\mathrm{B} \mathrm{D}$ bis fumptæ, hoc eft ipfi B $\mathrm{D}$ una cum dupla $\mathrm{A} \mathrm{B}$, hoc eft una cum duabus A B , D E. Ergo fi ex E cum celeritate aquabili, quantam illic habet, furfum pergeret, confecturum effet una temporis parte fpatium EA. Sed accedente actione gravitatis, diminuetur alcenfus ifte ipfo fpatio A B. Proinde hac parte temporis per fpatium E B tantum afcendet, quod fimili parce remporis defcendendo quoque tranfierat. Hic vero rurfus celeritati tantum deceffiffe neceffe eft quantum una temporis parte cadendo deorfum acquiritur, hoc eft celeritatem B D. Itaque grave, ubiufque ad B afcenderit, habet celeritatem ipfam B D reliquam, cum in $\mathrm{E}$ habuerit celeritatem F E ipfrus B D duplam. Si ergo ex B cum celeritate æquabili, quantam illic habet, furfum pergeret, confecturum effet parte una temporis fpatium æquale ipf $D$. B, hoc eft duplum A B. Sed accedente gravitatis actione, diminuitur afcenfus ifte fpatio quod ipfi a B æquale fit. Igitur hac parte temporis afcendet tantummodo per fpatium B A, quod etiam primo defcenfus tempore tranfierat. Atque in fine quidem extremi remporis hujus neceffario grave in A puncto reperietur. Sed dicetur forfan altius afcendiffe quam ad $A$, atque inde eo relapfum effe. At hoc abfurdum effet, cum non poflit, motu à gravitate profecto, altius quam unde decidit afcendere. Porro quum celericati quam in B habebat rurfus decefferit celeritas B D, patet jam gravi in A conftituto nullam celeritatem fupereffe, ac proinde non altius excurfurum. Itaque oftenfum eft ad eandem unde decidit altitudinem perveniffe, \& fingula fpatia, quæ xqualibus defcenfus temporibus tranfmiferat, eadem totidem afcenfus temporibus remenfum effe : fed $\&$ xqualibus temporibus æqualia ipfi deceffiffe celeritatis momenta apparuit. Ergo conftat propofitum.

Quia vero in demonftratione propofitionis fecundx, ex qua. pendet præcedens, adfumptum fuit certam quandam effe proportionem fpatiorum qux continuis xqualibus temporibus à gravi cadente tranfeuntur, quæque eadem fit, quæcunque æqualia tempora accipiantur; quod quidem \& ex reinatura ita fe habere neceffe eft, \& fi negetur, fatendum fruftra proportionem iftorum fpatiorum inveftigari. Tamen, quia propoficum etiam abfque hoc demonftrari potelt, Galilei methodum fequendo, 
HOROLOG. OS CILLA TOR. 29: operæ pretium erit demonftrationem, abillo minus perfecte tra- DR DESCENSR ditam, hic accuratius confcribere. itaque rurfum hic demonAtrabimus,

\section{PROPOSITIO V.}

C Patium peractum certo tempore, à gravi è quiete calum D inchoante, dimidium efje ejus fpatii quod pari tempore tranfiret motu aquabili, cum celeritate quam acquifioit ultimo cafus momento.

Sit tempus defcenfus totius A $\mathrm{H}$, quo tempore mobile peregerit fpatium quoddam cujus quantitas defignetur plano P. ducta-
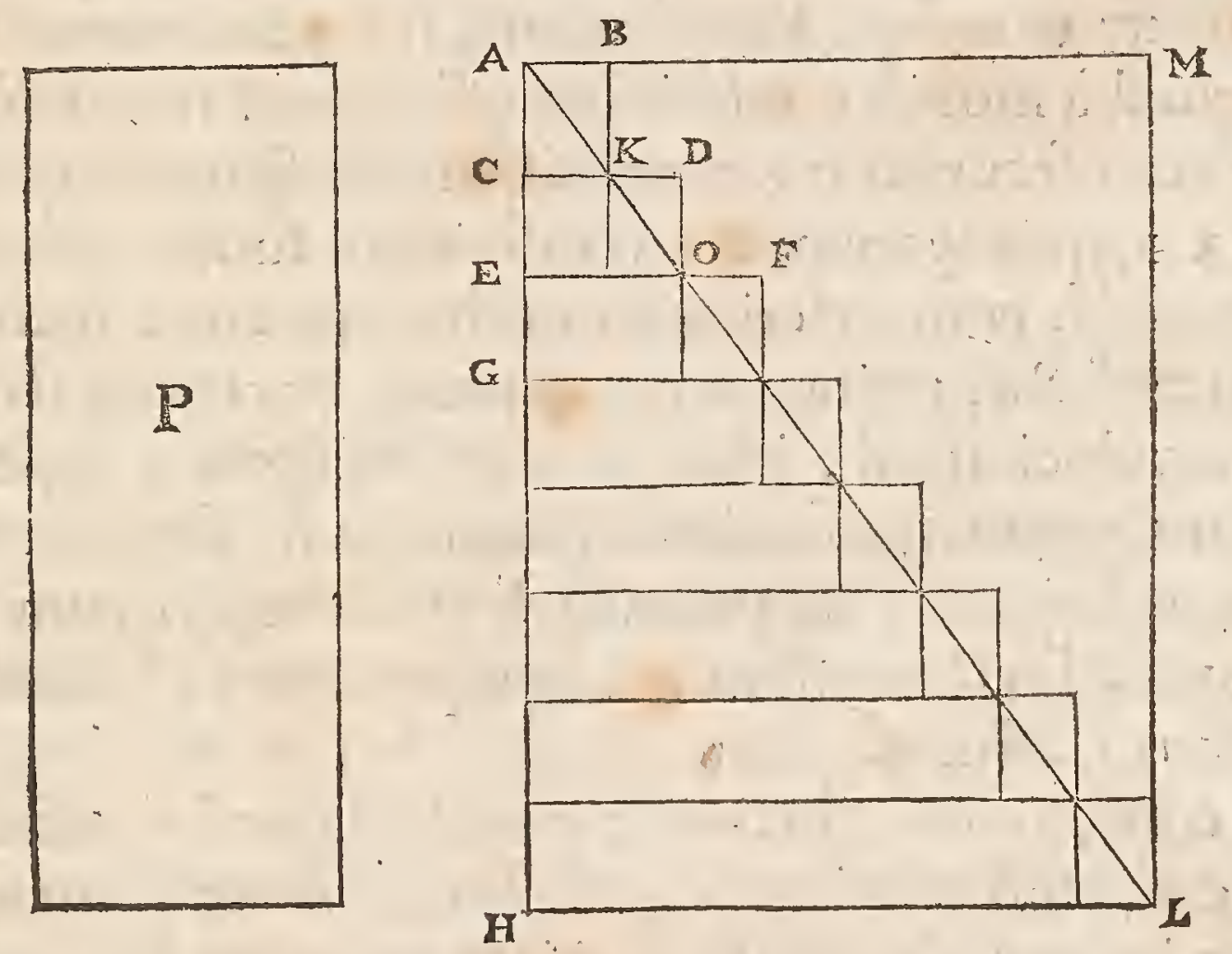

que $\mathrm{H}$ L perpendiculari ad $\AA \mathrm{H}$, longitudinis cujuflibet, referar illa celeritarem in fine cafus acquifitam. Deinde completo rectangulo A H L M, intelligatur eo notari quantitas fpatii quod percurreretur tempore $\mathrm{A} H$, cum celeritate $\mathrm{H}$ L. Oftendendum eft igitur planum $\mathrm{p}$ dimidium effe rectanguli $\mathrm{M} \mathrm{H}$, hoc eft; ducta diagonali A $\mathrm{L}$, æquale triangulo A H L.

Si planum $\mathrm{P}$ non eft xquale triangulo A $\mathrm{H} \mathrm{L}$, ergo aut minus co erit, aut majus. Sit primo, fi fieri poteft, planum p minus triangulo $\mathrm{A} \mathrm{H}$ L. dividatur autem $\mathrm{A} \mathrm{H}$ in tot partes xquales $\mathrm{AC}, \mathrm{CE}$, E G \&C. ut, circumfcriptâ triangulo A H L figurâ è rectangulis quorum altitudo fingulis divifionum ipfius $\mathrm{A}$. $\mathrm{H}$ partibus æquecur, ut funt rectangula B C, D E, F G, alterâque eidem triangulo infcriptâ, ex rectangulis ejufdem altitudinis, ut funt $\mathrm{K} \mathrm{E}, \mathrm{O} \mathrm{G} \& \mathrm{C}$. ut, inquam, exceflus illius figurx fupra hanc, minor fit exceffu 
De DESCENSU trianguli A $\mathrm{H}$ L fupra planum $\mathrm{P}$. hoc enim fieri poffe perfpicuum.

- RAVIUM. eft, cum totus exceffus figurx circumfcriptæ fuper infcriptam xquetur rectangulo infimo, bafin habenti $\mathrm{H}$ L. erit itaque omnino exceffus ipfus trianguli $\mathrm{A} H \mathrm{~L}$ fupra figuram infcriptam minor quam fupra planum $\mathrm{p}$, ac proinde figura triangulo infcripta major plano p. Porro autem, quum recta A H tempus totius defcenfus referat, ejus partes æquales $\AA$ C, C E, E G, æquales temporis illius partes referent. Cumque celeritates mobilis cadentis crefcant ea-

* Prop.r. huj. dem proportione qua tempora defcenfus *; fitque celeritas in fine totius temporis acquifita $\mathrm{H}$; erit ea, qux in fine primæ partis temporis A C acquiretur, $C \mathrm{~K}$; quia ut A Had A C, ita $\mathrm{H} \mathrm{Lad} \mathrm{C} \mathrm{K}$. Similiter qux in fine partis temporis fecundæ $\mathrm{C}$ E acquiritur, eric E $O$, atque ita deinceps. Patet autem, tempore primo A C, f patium aliquod à mobili tranfmiffum effe, quod majus fit nihilo; tempore vero fecundo $\mathrm{C}$ E tranfmiffum effe fpatium quod majus fit quam $\mathrm{K} E$, quia fpatium $\mathrm{K} \mathrm{E}$ tranfmiffum fuiffer tempore $\mathrm{C} E$, motu xquabili, cum celeritate $\mathrm{C}$ K. habent enim fpatia, motu æquabili tranfacta, rationem compofitam ex ratione temporum, \& ratione velocitatum, ideoque cum tempore $\AA \mathrm{H}$, celeritate æquabili $\mathrm{H}$ L percurri pofuerimus fpatium $\mathrm{M} \mathrm{H}$, fequitur tempore $C E$, cum celeritate $C K$, percurri fpatium $K E$, quum ratio rectanguli $\mathrm{M} \mathrm{H}$ ad rectangulum $\mathrm{K} \mathrm{E}$ componatur ex racionibus $\mathrm{A} H$ ad C E, \& H L ad E O.

Quum ergo, ut dixi, fpatium $\mathrm{k}$ E fit illud quod tranfmitteretur tempore C E, cum celeritate æquabili $\mathrm{CK}$, mobile autem feratur tempore C E motu accelerato, qui jam principio hujus temporis habet celeritatem $\mathrm{C} \mathrm{K}$; manifeftum eft ifto accelerato motu, tempore C E, majus fpatium quam $\mathrm{K}$ E confecturum. Eadem ratione, tempore tertio E G, majus fpatium conficier quam o $G$, quia nempe hoc confecturum effet tempore eodem $\mathrm{E} G$, cum celeritate æquabili E O. Atque ita deinceps, fingulis temporis A H partibus, à mobili majora fpatia quam funt rectangula figuræ infcri. ptæ, ipfis partibus adjacentia, peragentur. Quare totum fpatium motu accelerato peractum majus erit ipfa figura infcripta. Spatium vero illud æquale pofitum fuit plano $p$. Itaque figura infcripta minor erit fpatio p. quod eft abfurdum; eodem enim fpatio major oftenfa fuit. Non eft igitur planum $\mathrm{P}$ minus triangulo $\mathrm{A} H$ L. At neque majus effe oftendetur.

Sit enim, fr poteft; \& dividatur $\mathbb{A}$ H in partes $x q u a l e s$, atque ad earum altitudinem, infcripta circunfcriptaque rurfus, 

teram excedat minori exceffu quam quo planum $\mathrm{p}$ fuperat trian, gulum A H L, erit igitur necelfario figura circumferipta minor plano $\mathrm{p}$. Conftat jam, prima temporis parte $\AA \mathrm{C}$, minus fpatium à mobili tranfmitti quam fit B $\mathrm{C}$, quia hoc percurreretur eodem tempore A $\mathrm{C}$ cum celeritate $x q u a b i l i c \mathrm{~K}$, quam demum in fine remporis A $\mathrm{C}$ mobile adeptum eft. Similiter fecunda parte tenporis C.E, minus fpatium motu accelerato tranfmittetur quam fit $D E$, quia hoc percurreretur eodem tempore $\mathrm{CE}$, cum celeritate xquabili E $\mathrm{O}$, quam demum in fine temporis C E mobile affequitur. Atque ita deinceps, fingulis partibus temporis $\mathrm{A} H$, minora fpatia à mobili trajicientur quam funt rectangula figuræ circumfcriptæ, ipfis partibus adjacentia. Quare totum fpatium motu accelerato peractum, minus erit ipfa figura circumfcripta. Spatium vero illud $x$ quale pofitum fuir plano $\mathrm{P}$; ergo planum $\mathrm{P}$ minus quoque erit figura circumfcripta. quod eft abfurdum, cum figura hæc plano p minor oftenfa fuerit. Ergo planum p non majus eft triangulo A H L, fed nec minus effe jam oftenfum fuit. Ergo xquale fit neceffe eft; quod erat demonftrandum.

Et hæc quidem omnia qux hactenus demonftrata funt, gravibus per plana inclinata defcendentibus atque afcendentibus æque ac perpendiculariter motis convenire fciendum eft : cum, qux de effectu gravitatis pofita fuerunt, eadem ratione utrobique fint admitrenda.

Hinc vero non difficile jam erit demonftrare propofitionem fequentem quam concedi fibi, ut quodammodo per fe manifefram, Galileus poftulavit. nam demonftratio illa quam poftea adferre conatus eft, quxque in pofteriori operum ejus editione extat, parum firma meo quidem judicio videtur. Eft autem propofitio hujufmodi.

\section{PROPOSITIO VI.}

\section{Cleritates gravium, Super diverges planorum inclina- tionibus defcendendo acquifits, equales funt, fi plano- rum elevationes fuerint aquales.}

Elevationem plani vocamus altitudinem ejus fecundum perpendiculum.

Sunto itaque plana inclinata, quorum fectiones factr planoad horizontem erecto, $A B, C B$; quorumque elevationes $A$ E, $C D$ 


\section{2 CHR IS T I A I HVGEN II}

Da DESCENSU fint æquales; \& cadat grave ex A per planum $\AA$ B,$\&$ rurfus ex $C$ gravius. per planum C B. dico utroque cafu eundem gradum velocitatis in puncto $B$ acquifiturum.

Si enim per $\mathrm{C}$ в cadens minorem velocitatem acquirere dicatur quam cadens per A B, habeat ergo, per C B cadens, eam duntaxat quam per $\mathrm{F}$ B acquireret, pofita nimirum $\mathrm{F}$ B minore quam A B. Acquiret autem per C B cadens eam velocitatem qua rurfus * Prop, 4. huj. per totam B C poflit afcendere.* Ergo \& per F B acquiret eam

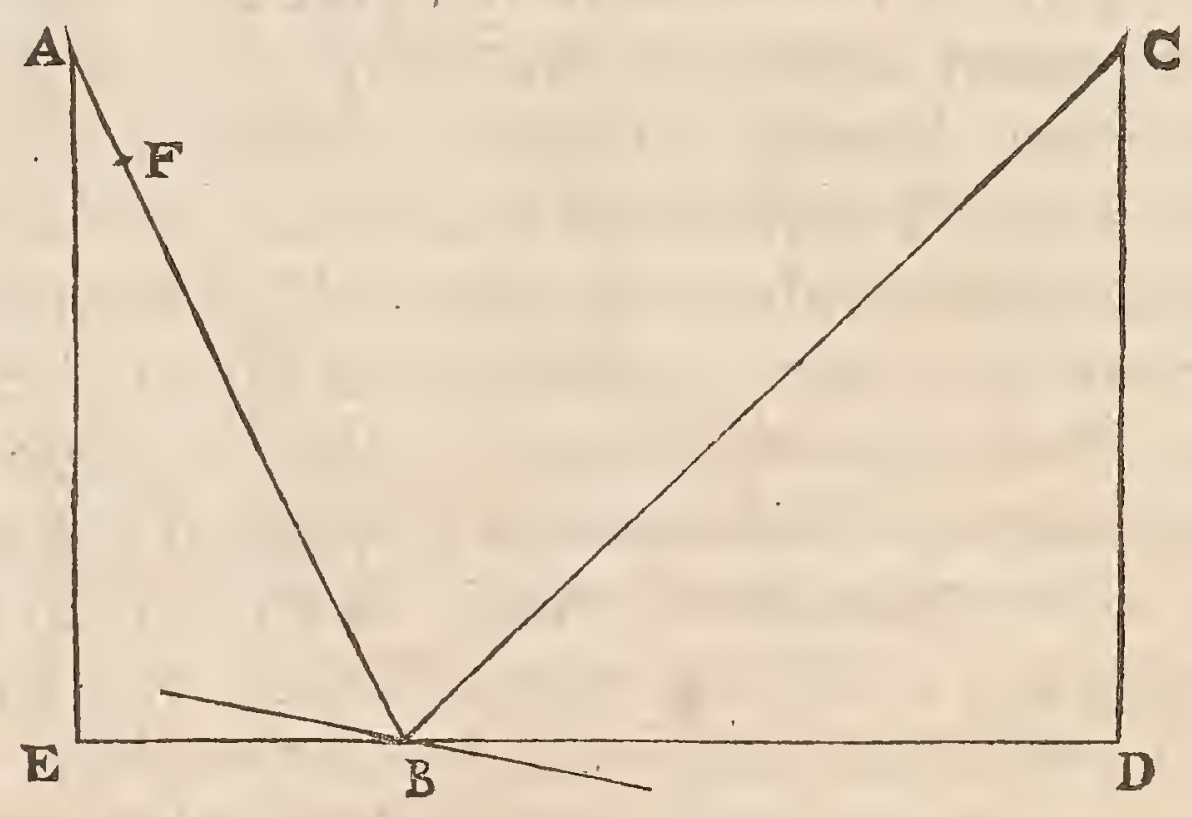

velocitatem qua poffit afcendere per totam B C. Ideoque cadens ex $\mathrm{F}$ in $\mathrm{B}$, ficontinuet porro motum per B C; quod repercuffu ad fuperficieñ obliquam fieri poteft; alcendet ufque in $\mathrm{C}$, hoc eft, altius quam unde decidit, quod eft abfurdum.

Eodern mojo oftendetur neque per planum A B decidenti minorem velocitatem acquiri quam per С B. Ergo per utraque plana eadem velocitas acquiritur, quod erat demonftrandum.

Quod fi vero, pro plano alterutro, fumatur perpendiculum ipfum planorum elevationi æquale, per quod decidere mobile ponatur, fic quoque eandem quam per plana inclinata velocitatem eiacquiri conftat; eadem namque eft demonftratio.

Porro hinc jam recte quoque procedet demonftratio alterius theorematis Galileani, cui reliqua omnia, quæ de defcenfu fuper planis inclinatis tradidit, fuperftruuntur. Nempe

$$
\text { PROPOSITIO VII. }
$$

TW Empora defcenfuum fuper planis diverfimode incli2. natis, fed quorum eadem eff elevatio, effe inter fe ut planorum longitudines.

Sint plana inclinata $A$ C, A D quorum eadem elevatio A B. dico 

tempus defcenfus per planum $A$ C ad tempus defcenfus per $A$ D Dé Daserast

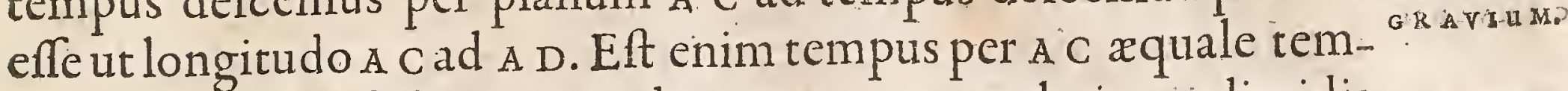
pori motus æquabilis per eandem A C, cum celeritate dimidia ejus qux acquiritur calu per $\mathrm{A} \mathrm{C}^{*}$. Similiter tempus per A D eft * Prop 2 .huj. æquale tempori motus æquabilis per ipfam $\mathrm{A} D$, cum dimidia ce.

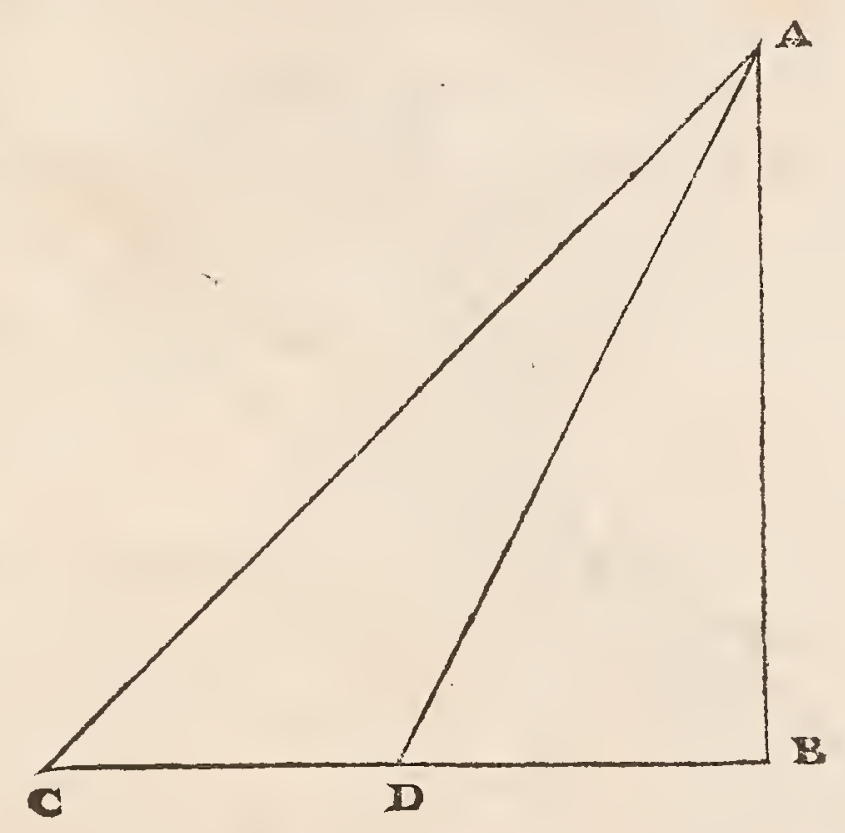

leritate ejus quæ acquiritur cafu per A D. Eft autem hæc dimidia celeritas illi dimidix celeritati æqualis *, ideoque dictum tempus * ${ }^{*}$ rop. pracew. motus æquabilis per A $C$, ad tempus motus æquabilis per $A D$, erit ut A C ad A D. Ergo \& tempora fingulis iftis æqualia, nimirum tempus defcenfus per $\mathrm{A} C$, ad tempus defcenfus per $\mathrm{A} D$, eandem rationem habebunt, nempe quam $A C$ ad $A$ D. quod erat demonAtrandum.

Eodem modo oftendetur \& tempus defcenfus per a C, ad tempus cafus per A B perpendicularem, effe ut A C ad A B longitudine.

\section{PROPOSITIO VIII.}

I ex altitudine eadem defcendat mobile continuato motu D per quotlibet ac quelibet plana contigua, utcunque inclinata; femper eandem in fine velocitatem acquiret, que nimirum aqualis erit ei quam acquireret cadendo perpendiculariter ex pari altitudine.

Sint plana contigua A B , B C, C. D, quorum terminus A, fupra horizontalem lineam $D$ F per infimum terminum $D$ ductam, altitudinem habeat quanta eft perpendicularis $\mathrm{E} F$. defcendatque mobile per plana illa ab a ufque in $\mathrm{D}$. Dico in $\mathrm{D}$ eam velocitatem habiturum quam, ex $\mathrm{E}$ cadens, haberet in $\mathrm{F}$.

Producta enim С в occurrat rect $\mathrm{A}$ E in G. Itemque $\mathrm{D}$ C producta 


\section{4.}

DE DEseensu OCcurrat eidem $A E$ in $E$. Quoniam itaque per $A$ B defcendens eandem acquirit velocitatem in termino $B$, atque defcendens * Prop. 6. huj. per G. B*; manifeftum eft, cum flexus ad B nihil obftare motui ponatur, tantam velocitatem habiturum ubi in $\mathrm{C}$ pervenerit, quantam fi per a c planum defcendiffer; hoc eft, quantam ha-

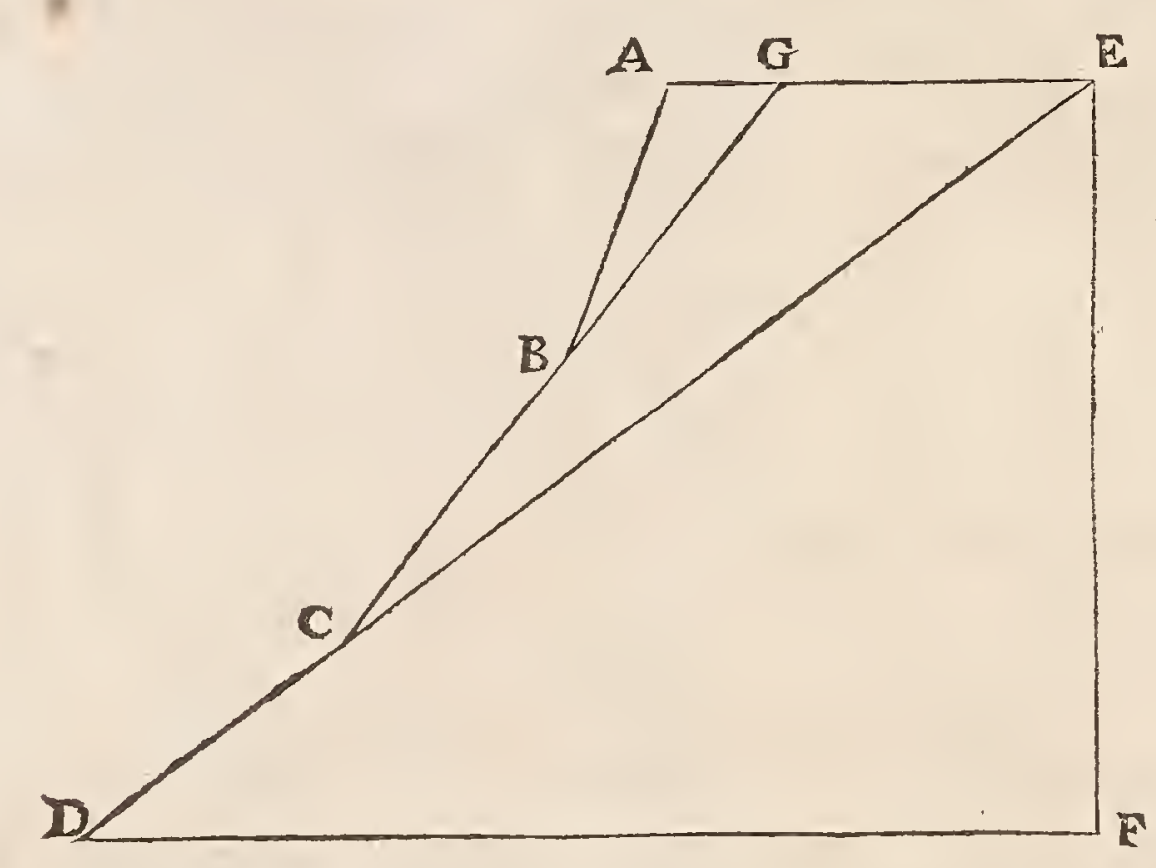

beret ex defcenfu per. B C. Quare \& reliquum planum C D eodem modo rranfibit ac fi per $\mathrm{E} C$ adveniffet, ac proinde in $\mathrm{D}$ denique parem velocitatem habebit, ac fi defcendiffet per planum $E D$, hoc elt, eandem quam ex cafi perpendiculari per $\mathrm{E} F$. quod erat demonftrandum:

Hinc liquet etiam per circuli circumferentiam, vel per curvam quamlibet lineam defcendente mobili (nam curvas tanquam ex infinitis rectis compofitx effent hic confiderare licet) femper eandem illi velocitarem acquiri $f_{1}$ ab xquali altitudine defcenderit: tantamque eam effe velocitatem, quantam cafu perpendiculari ex eadem altitudine adipifceretur.

\section{PROPOSITIO IX.}

S I grave, à defcenfu, furfum convertat motum fuum, $\checkmark$ afcendet ad eandem unde venit altitudinem, per quafcunque planas fuperficies contiguas, ES quomodocunque inclinatas, incefferit.

Cadar grave ex altitudine $\bar{A} B$, \& ex puncto $B$ inclinata fint furfum plana B C, C D, D. E, quorum extremitas E fit eademaltitudine cum puncto A. Dico fi mobile, polt cafum per A B, convertat motum ur pergat moveri per dicta plana inclinata, perventutum ufque in $\mathrm{E}$. 
Dicatur enim, fi fieri poteft, tantum ad G perventurum. Pro- DE DESCENG ducantur B C \& C D, donec occurrant horizontali G F in F \& $\mathrm{H}$. Cum igitur mobile, fuperatis planis B C, C D, habeat tantum eam velocitatem quâ poflit afcendere per $D G$, vel per $D \mathrm{H}$; nam ad hæc utraque eadem velocitare opus effe conftat ex propofitione

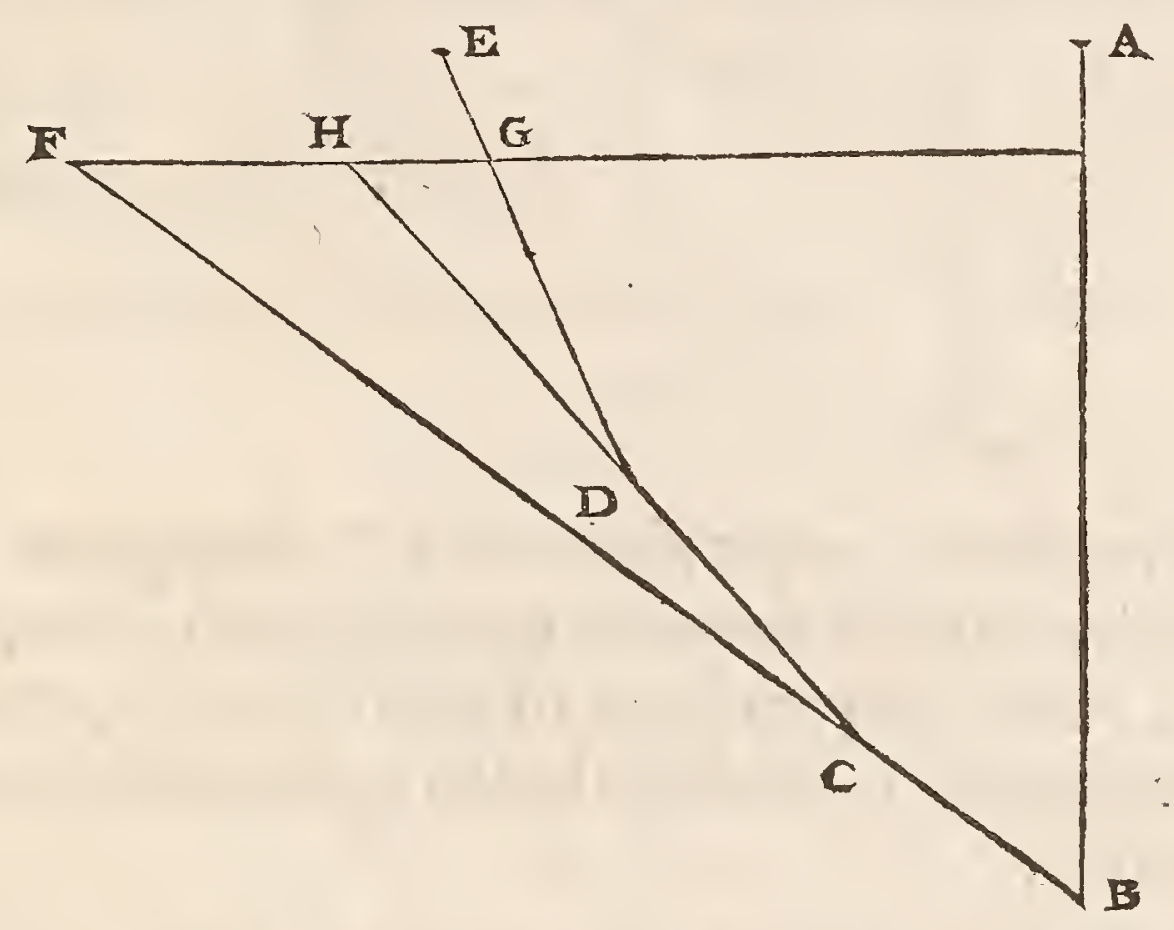

6; Ergo, fuperato plano в C, eam duntaxat habebat qua po: tuiffet affendere per $\mathrm{C} H$, vel per $\mathrm{C}$. Ergo in B duntaxat eam qua potuiffet afcendere per $B \mathrm{~F}$, hoc eft, eandem quam acquireret defcendendo per F B. Atqui in в habet velocitatem qua poteft afcendere ufque in $A$. Ergo illa velocitate quam acquirit grave defcendendo per $F B$, poffer afcendere per B A, hoc eft, altius quam unde difcefferat, quod fieri non poteft.

Eft autem eadem prorfus demonftratio quotcunque plana fuerint per quæ mobile afcendar. Vnde \& $\mathrm{fi}$ infinita fuerit planorum multitudo, hoc eft, fi fuperficies aliqua curva ponatur, per hanc quoque ad eam ex qua venit altitudinem mobile affurget.

\section{PROPOSITIO X.}

S Imobile cadat perpendiculariter, vel per quamlibet fu$\checkmark$ perficiem defcendat, ac rur uns impetu concepto per quamlibet aliam feratur fur urm, habebit afcendendo ac defcenpendo in puncitis aque altis eandem femper velocitatem.

$\mathrm{Vt}$ fi mobile ex alcitudine A B decidens, motum deinde continuet per fuperficiem $B C D$, in qua punctum $C$ fit pari altitudine atque in $\mathrm{A} B$ eft punctum $\mathrm{E}$. Dico in $\mathrm{C}$ eandem velocitatem ineffe mobili atque in $\mathrm{E}$ fuerat. 


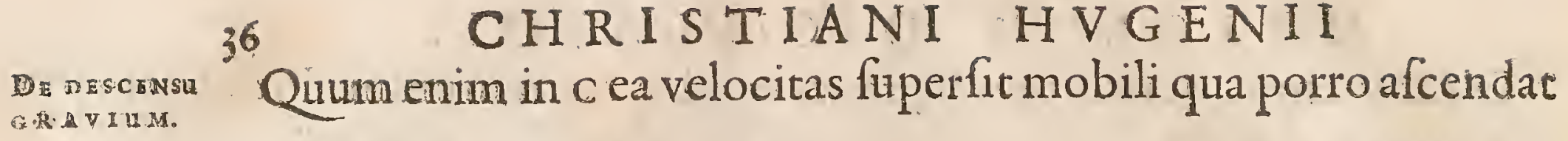

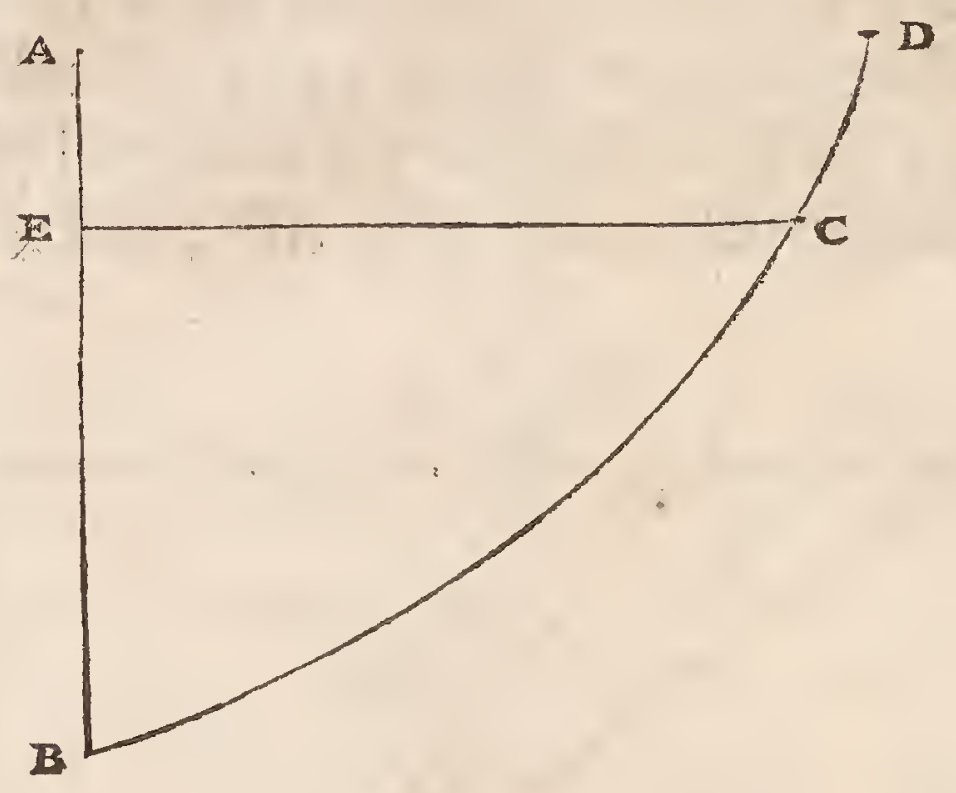

${ }^{*}$ prop. praced. ufque ad D punctum, xque altum ac $A *$ : cumque \& ex defcenfu per A $\mathrm{E}$ velocitatem eam acquirat qua, converfo motu, afcenfurum

* Prop.praced. fit per C D*; Patet cum pervenit ad c afcendendo, eandem ipfum habere velocitatem, quam habebat in $\mathrm{E}$ defcendendo; quod erat demonftrandum.

\section{PROPOSITIO XI.}

I mobile per fuperficiem aliquam deorfum tendat, ac 1 deinde converfo motu furfum per eandem fuperficiem vel aliam fimilem finilitergue pofitam feratur; aqualibus cemporibus per idem jpatium defcendet atque afcendet.

Velut fi per fuperficiem A B defcendat mobile, atque, ubiad B

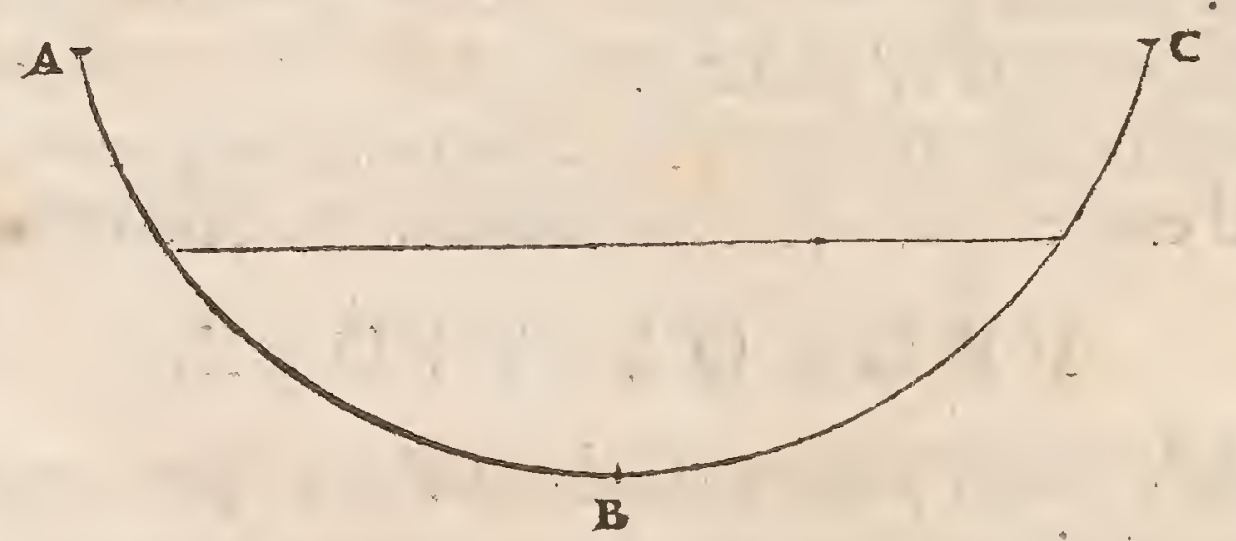

pervenerit, converfo motu füfum per eandem $A B$, vel ei fimilem \& refpectu plani horizontalis fimiliter pofitam B C, afcendat, conftat ex ante demonftratis, perventurum ad eandem ex qua venit altitudinem. Cum autem perpetuo, in punctis quorum

* prop.praced. eadem altitudo, eandem velocitatem habeat afcendendo ac defcendendo*; apparer eandem lineam bis eadem velocitate fingulis fui partibus percurri: unde \& tempora utriufque motus æqualia effe neceffe eft; quod erat demonftrandum. 


\section{PROPOSITIO XII.}

TI Sto circulus A B C, diametro A C, cui ad angulos rectos fit $F G$; buic vero occurrat à termino diametri $\mathrm{A}$ educt a A F extra circulum, que quidem neceffario fecabit circumferentiam, pute in $\mathrm{B}$. Dico arcum $\mathrm{BD}$, lineis $\mathrm{GF}$, A $\mathrm{F}$ interceptum, minorem effe recta D F.

Iungatur enim в C, \& ducarur ex B puncto tangens circumfe-

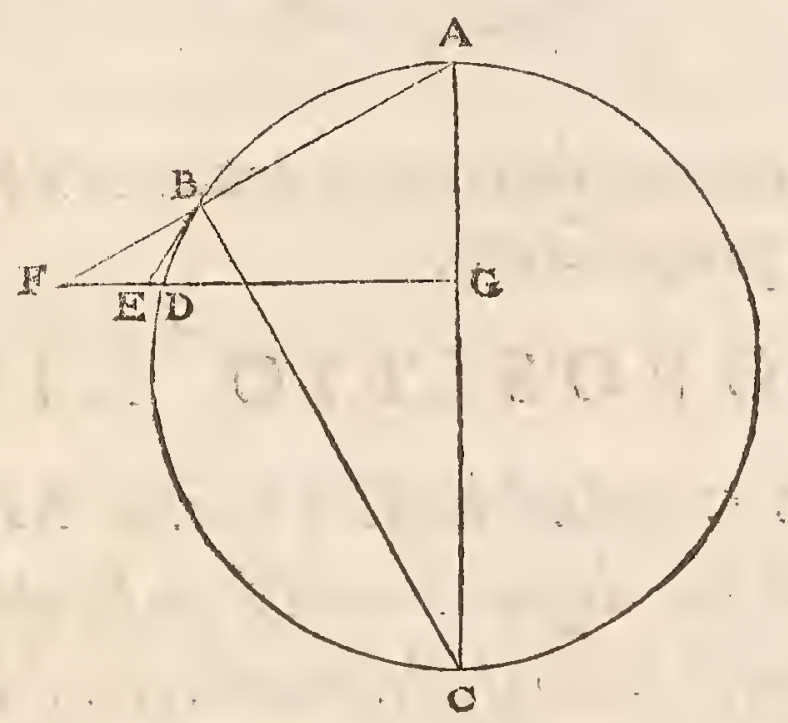

rentiam recta $\mathrm{B} \mathrm{E}, \mathrm{qu}$ neceffario occurret rectæ $\mathrm{F} G$ inter $\mathrm{F} \& \mathrm{D}$. Eft igiturangulus B A C in circulo æqualis angulo $\mathrm{E} \mathrm{B} \mathrm{C} *$. quare \& angulus $\mathrm{F}$ B E, qui una cum $\mathrm{E}$ B $\mathrm{C}$ conftituit angulum rectum F B C , erit æqualis B C A. Quia autem fimilia funt triangula $A B$ $C, A$ G F, erit $\&$ angulus $\mathrm{F} æ$ qualis angulo $\mathrm{A} C \mathrm{C}$. Ergo idem angulus $\mathrm{F} x$ qualis angulo $\mathrm{F} \mathrm{B} \mathrm{E}$. Itaque ifofceles eft triangulus $\mathrm{F} \mathrm{E}$ $B$, habens crura æqualia $\mathrm{F}$ E, E B. Addita ergo utrique eorum recta $\mathrm{E} D$, fiet $\mathrm{F} D$, xqualis duabus $\mathrm{B} E, \mathrm{E} \mathrm{D}$. Hafce vero duas majores effe conftat arcu B D, iifdem terminis intercepto, \& in eandem partem cavo. Ergo \& F D eodem arcu B D major erit: quare conftat propofitum.

\section{PROPOSITIO XIII.}

TIdempofitis, se recta A B occurrat ip $/ \mathrm{D}$ G intra circulum; 1 Dico arcum B D, rectis $\mathrm{G} D$, A B interceptum, majorem effe recta $D$ F.

Iungazur enim D C \& ducatur arcui D B fubtenfa D B. Quo niam ergo angulus $A B D$ $x$ qualis $A C D$, hoc eft, angulo $A D$ $G$; angulus autem $D$ F B major angulo A D F, five A D G; erit 
DE DEsensu idem D F B etiam major D B F. Ergo in triangulo D F B larus D B

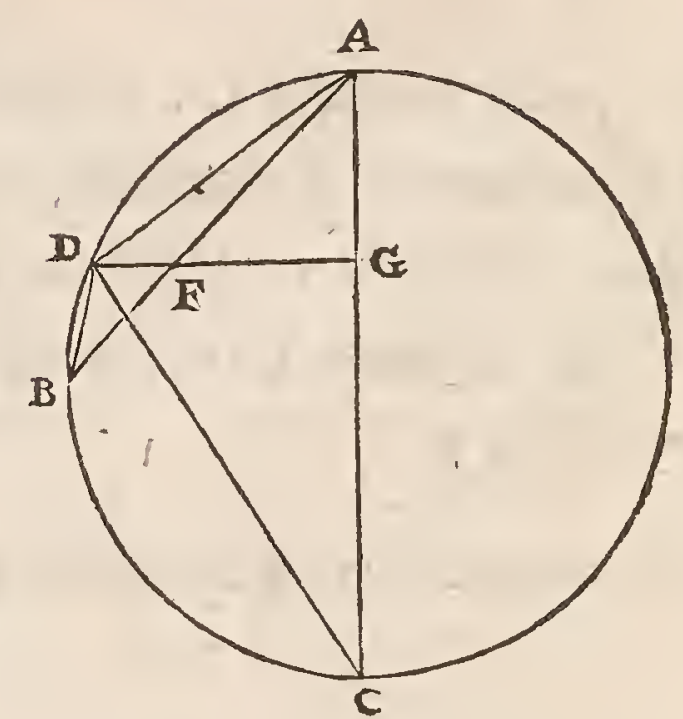

majus latere D F; unde multo magis arcus $\mathrm{D}$ B fuperabit eandem D F. Quare conftar propofitum.

\section{PROPOSITIO XIV.}

O It cyclois A B c cujus bafis A c axis B D. Quomodo au$\checkmark$ tem generetur ex definitione $E^{\circ}$ defcriptione mechanica superius traditis fatis manifefum arbitror. Et circa axem B $D$, circulus de criptus fit BGD, ES à quolibet puncto $\mathrm{E}$ in cycloide Jumpto agatur E F bafi A C parallela, qua occurrat axi $\mathrm{B} D$ in $\mathrm{F}$, fecetgue circumferentiam B G D in G, Dico rectiam G $\mathrm{E}$ arcui $\mathrm{G} B$ aqualem eße.

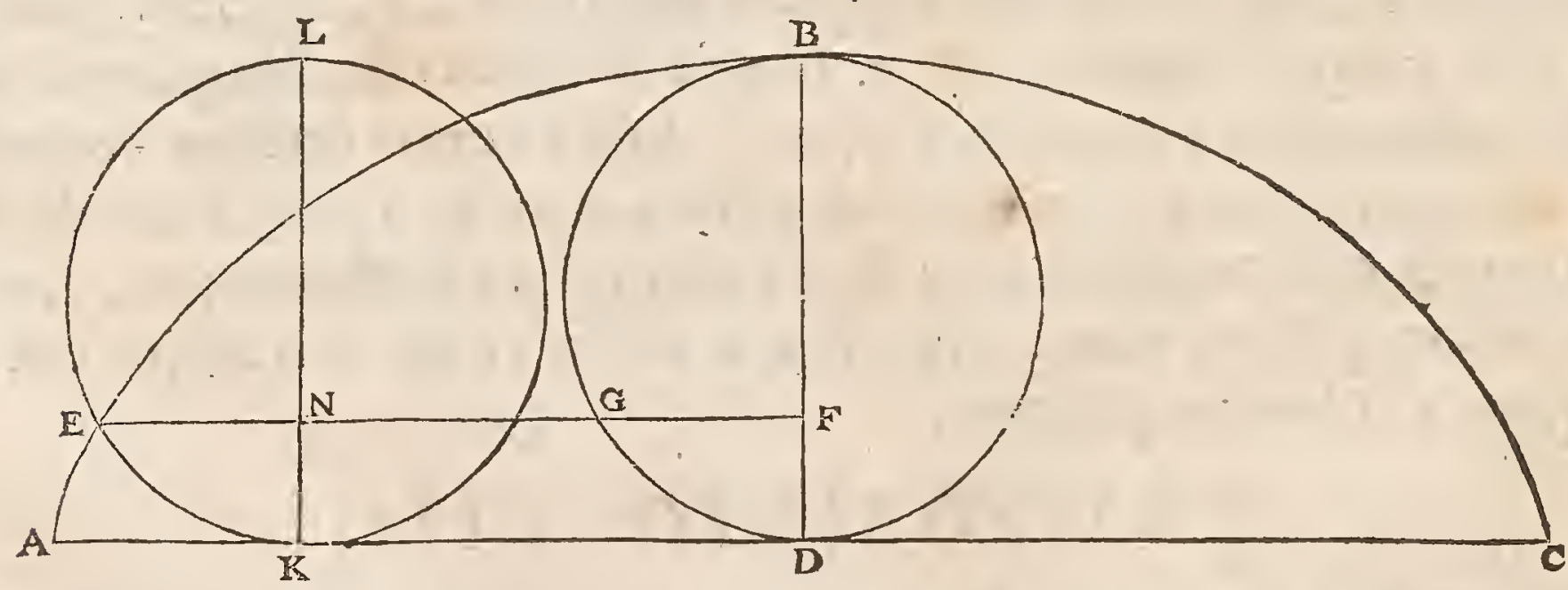

Defcribatur enim per $E$ punctum circulus $I E$ ipfi B G $D$ xqualis, quique tangat bafin cycloidis in $\mathrm{K}$, \& ducatur diameter $K \mathrm{~L}$. Eft igitur recta $\mathrm{A} K$ arcui $\mathrm{E} K x q u a l i s ;$ fed tora $\mathrm{A} \mathrm{D} x q u a l i s$ femicircumferentiæ $\mathrm{K} E \mathrm{~L}$; ergo $\mathrm{KD}$ æqualis arcui $\mathrm{E} \mathrm{L}$ five $\mathrm{G} \mathrm{B}$. Eft

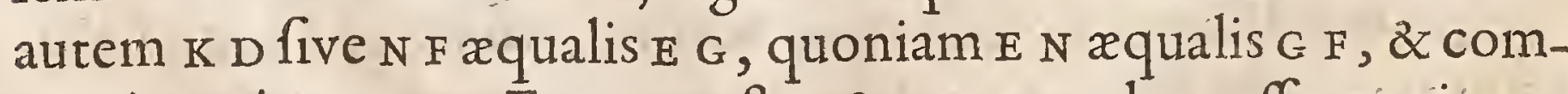
munis utrique N G. Ergo conftat \& G E xqualem effe arcui G B. 
Sir cyclois A B C, \& punctum in ea datum B, per quod tangen. tem ducere oporteat.

Circa axem cyćloidis A D defcribatur circulus genitor A E D, \& ducatur B E parallela bafi cycloidis, qux dicto circulo occurrat in E, \& jungatur A E, cui denique parallela per в agatur H B N. Diço hane cycloidem in B contingere.

Sumatur enim in ea punctum quodlibet, à B diverfum, ac pri-

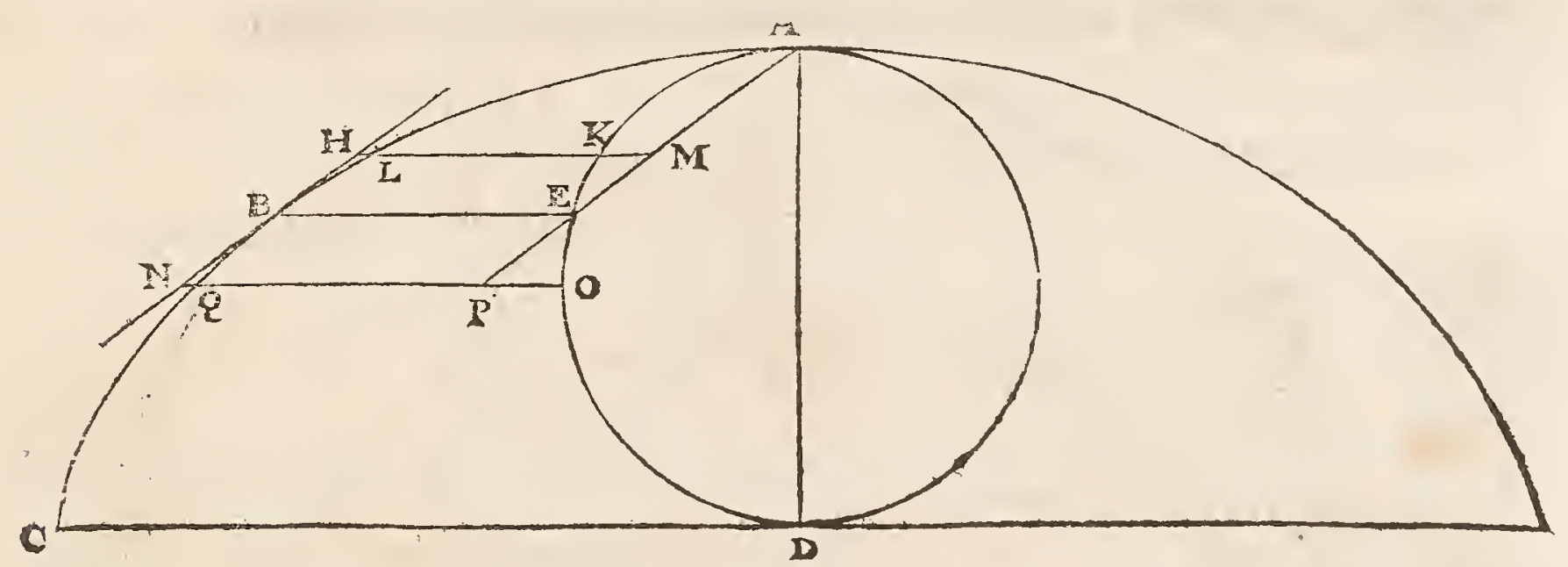

mo verfus fuperiora velut $\mathrm{H}$, \& per $\mathrm{H}$ ducatur recta bafi cycloi dis parallela, qux occurrat cycloidi in $L$, circulo $A \mathrm{E} D$ in $\mathrm{K}$, rect $x \mathrm{~A} E$ in $\mathrm{M}$. Quia ergo $\mathrm{K} \mathrm{L}$ eft $x$ qualis arcui $\mathrm{K} \mathrm{A}$, recta aurem $\mathrm{K}$ $M$ minor arcu $K E$, erit recta $M L$ minor arcu $A E$, hoc eft, rectâ $E \mathrm{~B}$, five $\mathrm{M} \mathrm{H}$; unde apparet punctum $\mathrm{H}$ effe extra cycloidem.

Deinde in recta $\mathrm{H} N$ fumatur punctum $\mathrm{N}$ inferius $\mathrm{B}, \&$ per $\mathrm{N}$ agatur, ut ante, bafi parallela, qux occurrat cycloidi in $Q$, circulo $A E D$ in $O$, rect $x$ A product $x$ in $P$. Quia ergo $O Q Q$, xqualis eft arcui $O A ; O P$ autem major arcu $O E$; erit $P$ R minor arcu $E A$, hoc eft, rectâ $\mathrm{E} B$, five $\mathrm{P} N$. Vnde apparet rurfus punctum $\mathrm{N}$ effe extra cycloidem. Cum igitur quodlibet punctum preter $B$, in recta $\mathrm{H}$ B N fumptum, fit extra cycloidem, conftat illam in puncto B cycloidem contingere; quod erat demonftrandum.

Huic demonftrationi an locum fuum hic relinquerem dubitavi, quod non multum ei abfimilem à clariffimo VVrennio editam inveniam in libro VVallifij de Cycloide. Poteft autem \& univerfali conftructione propofitum abfolvi, quæ non cycloidi tantum. fed \& aliis curvis, ex cujuflibet figuræ circumvolutione genitis, conveniat; dummodo fit figura in eandem partem cava, \& ex iis qux geometricx vocantur. 


\section{CHR IS T I N I H GEN I}

DE DESCENSU Sit enim curva $N$ A B , orta ex circumvolutione figuræ o I fuper regula $\mathrm{L} D$; defcribente nempe puncto $\mathrm{N}$, in circumferentia figurx o L fumpto. Et oporteat ad punctum curvæ $A$ tangente ducere. Ducatur recta C A à puncto $C$, übi figura regulam tangebat cum punctum defcribens effet in $\mathrm{A}$ : quod punctum contactus femper inveniri poteft, fiquidem eo reducitur problema ut duæ rectæ inter fe parallelæ ducendx fint, quarum altera tran. feat per punctum defcribens in figuræ ambitudatum, altera figuram tangar, quæque inter fe diftent quantum diftat punctum datum $A$ ab regula $L$ D: dico ipfam $C A$ occurrere curvæ ad angulos rectos, five circumferentiam $\mathrm{M}$ A $\mathrm{F}$ defcriptam centro $\mathrm{C}$ radio $C_{A}$, tangere curvam in puncto $A$, unde perpendicularis ad A $C$ per punctum $A$ ducta curvam ibidem continget.

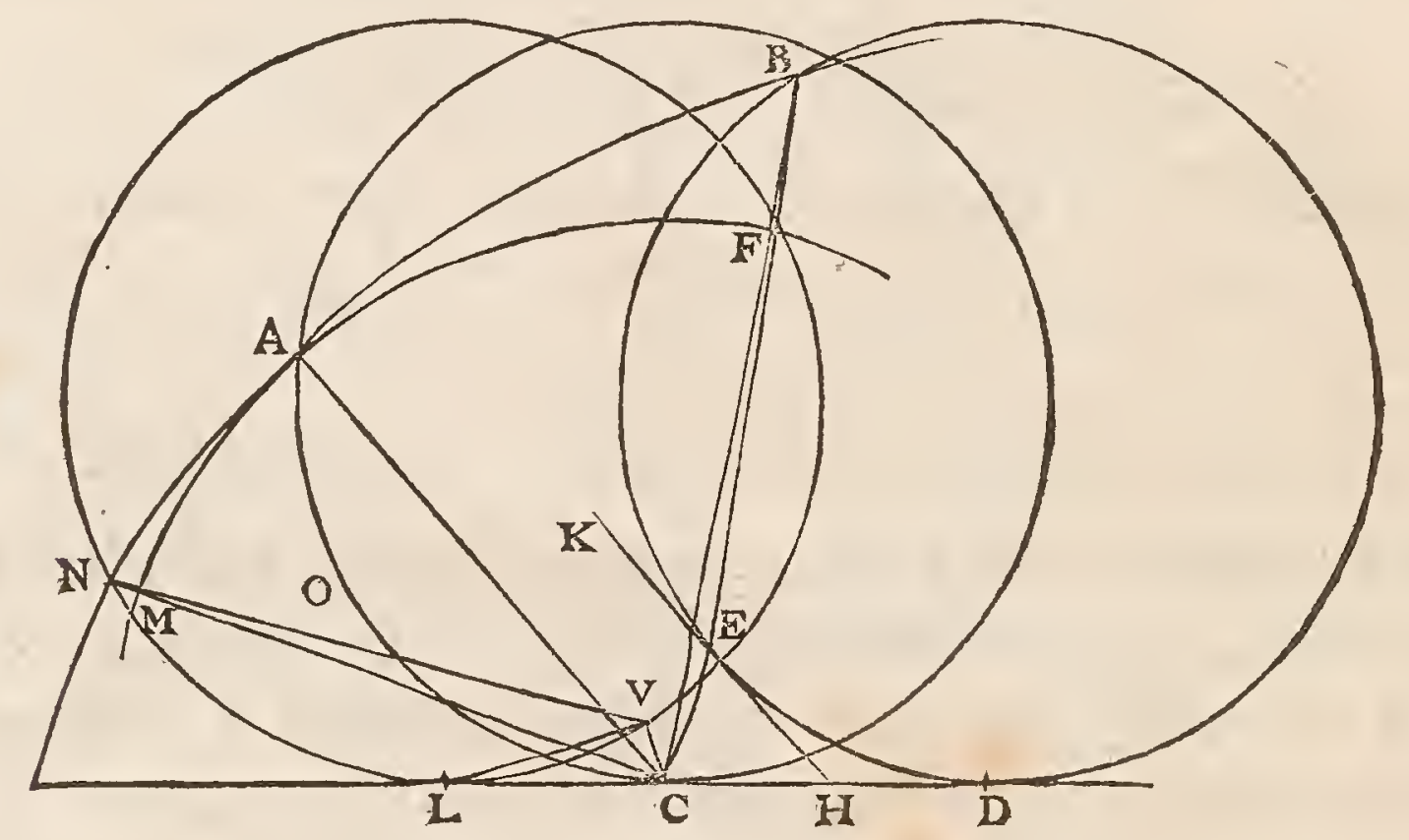

Ducatur enim C B primum ad punctum curvæ B, quod difter ultra punctum $A$ ab regula $L D$, intelligaturque figuræ pofitus in $B E D$, cum punctum defcribens effet in $B$, contactus regulæ in D. \& punctum curvæ quod erat in C, cum punctum defcribens effet in $A$, hic jam fublatum fir in $E$; \& jungantur $\mathrm{E} C, \mathrm{E} B$, tangarque figuram in $\mathrm{E}$ recta $\mathrm{KH}$, occurrens regula in $\mathrm{H}$.

Quia ergo recta C D $æ$ qualis eft curvæ E $D$; eadem vero curva major eft utraque fimul E $\mathrm{H}, \mathrm{H} \mathrm{D}$; erit E H major quam $\mathrm{C} \mathrm{H}$. Vnde angulus $\mathrm{E} C \mathrm{C}$ major quam $\mathrm{CE} H, \&$ proinde $\mathrm{E} C \mathrm{~L}$ minor quam. C E K. Atquiaddendo angulum K E B, qui æqualis eft L C A, ad K

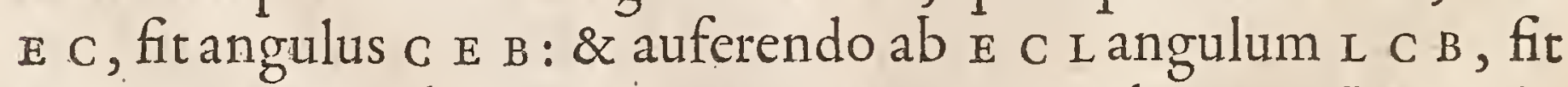
E C B. Ergo angulus $C$ E B major omnino angulo E C B. Itaque in triangulo $C_{\text {. }} \mathrm{B}$, latus $\mathrm{C}$ B majus erit quam $\mathrm{E}$ B. fed $\mathrm{E} B$ $x$ quale pater effe $C A$, cum fit idemmet ipfum unà cum figura tranfpofi- 
HOROLOG. OSCILLATOR. tum. Ergo C в eriam major quam $C A$, hoc eft, quam C F. unde Dr Descensus conftar punctum B effe extra circumferentiam $M \cdot A$.

Sit rurfus punctum $\mathrm{N}$ in curva fumprum inter regulam $\mathrm{L} D \&$ punctum $A$. Cumque punctum defcribens effet in $\mathrm{N}$, ponatur fitus figuræ fuiffe in $v \mathrm{~L}$, punctumque contactus $\mathrm{L}$, punctum verò quod tangebat prius regulam in $\mathrm{C}$, fir jam fublatum in $\mathrm{V}$ : \& jungantur C $\mathbf{N}, \mathbf{N}$ V, V C, V L. Erit ergo $\mathrm{V}$ N æqualis C A; imo erit ipfa C 'A tranflata in $\mathrm{V} N$. I Iam quia recta $\mathrm{L} C \mathfrak{C}$ quatur curvæ $\mathrm{L} V$, ac proinde major eft recta $\mathrm{L} v$, erit in triangulo $\mathrm{C} \mathrm{L} V$ angulus $\mathrm{L} V \mathrm{C}$ major quam $L C$ V. Quare addico infuper angulo $L V N$ ad $L V C$, fiet totus $\mathrm{N} V \mathrm{C}$ major utique quam $\mathrm{I} \mathrm{C} V$, ac proinde omnino major angulo $\mathrm{N} \mathrm{C} \mathrm{V}$, qui pars eft $\mathrm{L} \mathrm{C}$ V. Ergo in triangulo $\mathrm{C} \mathrm{V} N$ latus $\mathrm{C} N$ majus erit latere $v \mathrm{~N}$, cui æquatur $\mathrm{C} A$, ideoque $\mathrm{C} N$ major quoque quam $\mathrm{C}_{\mathrm{A}}$, hoc eft quam $\mathrm{C}$ M. Vnde apparet punctum $\mathrm{N}$ cadere extra circulum $M A F$, qui proinde tanget curvam in puncto $\AA$. quod erat demonftrandum.

Eft autem eadem quoque tum conftructio tum demonftratio, fi curva genita fic à puncto defcribente, vel intra vel extra ambitum figuræ circumvolutx fumpto. Nifi quod, hoc pofteriori cafu, pars quædam curvæ infra regulam defcendit, unde nonnulla in demonftratione oritur diverfitas.

Sit enim punctum $A$, per quod tangens ducenda eft, datum in

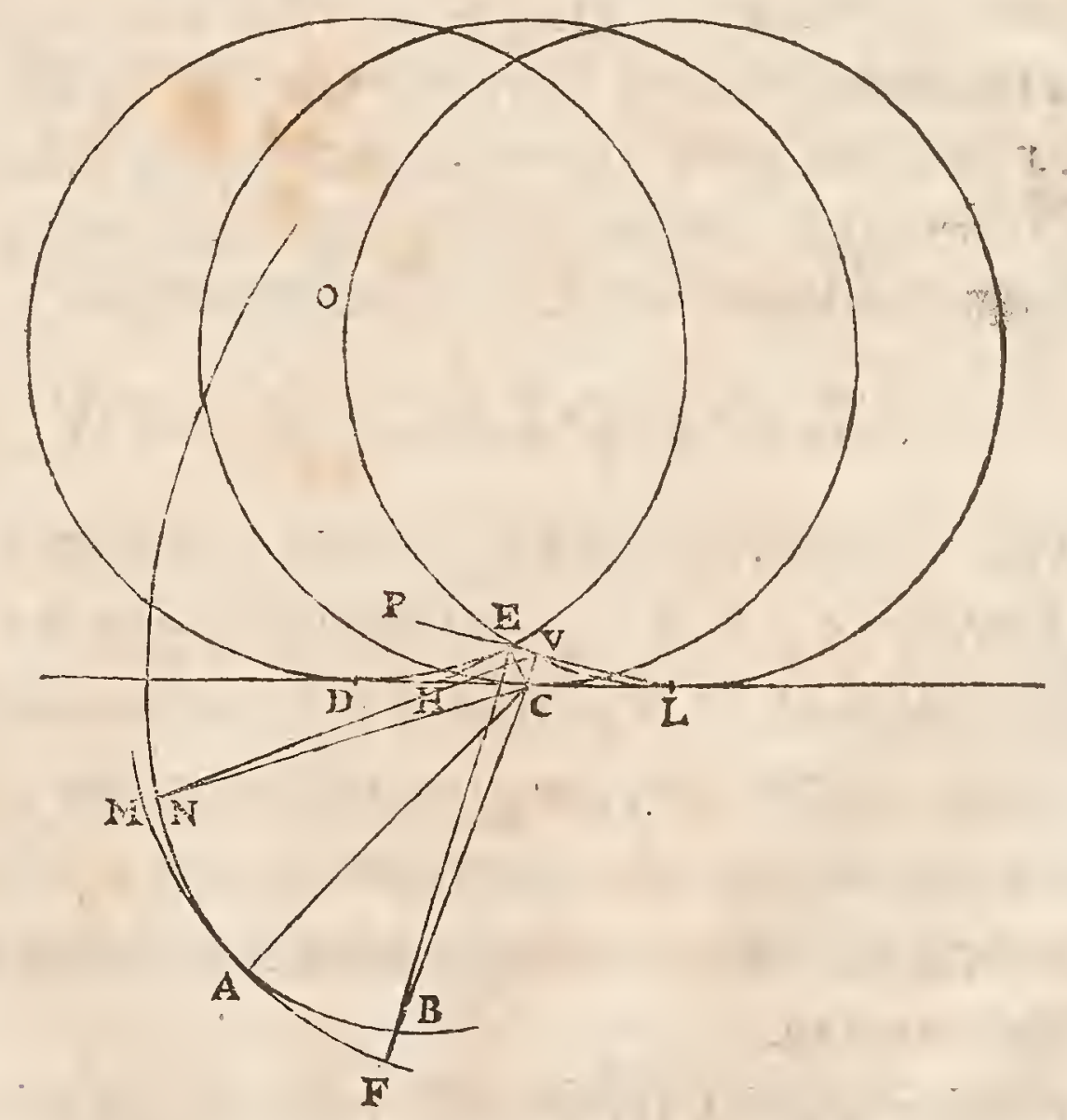

parte curvæ $\mathbb{N} \AA$ B, qux infra regulam C L defcendit, defcripta nimirum à puncto N extra figuram revolutam fumpto, fed certam 


\section{CHRISTINI HVGENII}

$\overrightarrow{D E}_{\text {DEsCENSU }}$ Ofitionem in eodem ipfius plano habente. Invento igitur punGRAIUM. Cto $C$, ubi figura revoluta tangit regulam $C D$ quum punctum deféribens effet in $A$, ducatur recta $C A$. Dico hanc curvæ NA B occurrere ad réctos angulos, five circumferentiam radio $\mathrm{C} A$ centro $C$ defcriptam tangere curvam $\mathrm{N} A \mathrm{~B}$ in puncto $\mathrm{A}$. Oftendetur autem exterius ipfam contingere, cum in curvæ parte fuprä regulam $C D$ pofita interius contingat.

Pofitis enim \& defcriptis iifdem omnibus qux pritis, often. ditur rurfus angulús $\mathrm{E} C \mathrm{H}$ major quam $\mathrm{C} E$ H. atqui ad $\mathrm{E} C \mathrm{C}$ addito $\mathrm{H}$ C B fit angulus E C B xqualis eft $D C A$; fit angulús $C E$ B. Ergo E $C$ B major omnino quam $C$ E $B$ : unde in triangulo E C B latus E B majus quam C B. fed.

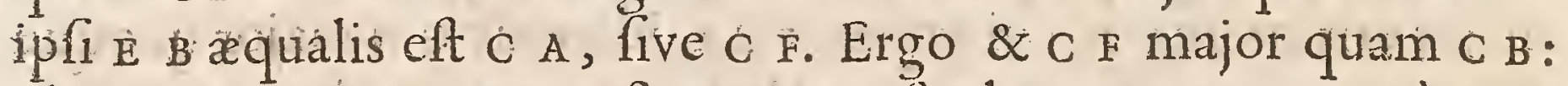
ideoque punctum circumferentix f eft ultra curvam $N \mathrm{~A}$ B à centro renotum.

Item rurfus oftenditur angulus $\mathrm{L} \mathrm{V} \mathrm{C}$ major $\mathrm{L} \mathrm{C} \mathrm{V}$. Quare $\mathrm{C} \mathrm{V} \mathrm{P}$,

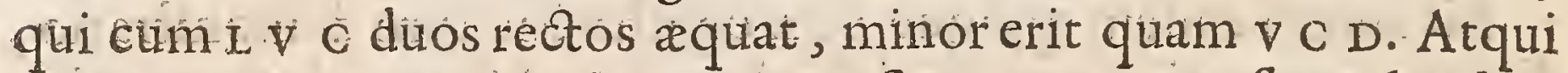
adderido ad $\vee C D$ angulam $D C N$, fit $v \mathrm{C} \mathrm{N} ; \& z$ auferendo $a b C$ $\checkmark v$ angulum $\mathrm{P} V \mathrm{~N}$, fit $\mathrm{C} V \mathrm{~N}$. Ergo angulus $\mathrm{V} C \mathrm{~N}$ omnino major quám $\mathrm{C} V \mathrm{~N}$. In triangulo itaque $\mathrm{C} V \mathrm{~N}$, latus $\mathrm{V} N$ majus erit quam C.N. Eft aurem ipfí v N xqualis C A five C M. Ergo \& C M major quari $C N$, ideoqute punctum circunferentix $M$ erit ultra curvam $N A$ B à centro $C$ remotum. I taque conftat circumferentiam $M A F$ tangere curvam in puncto A. quod erat demonftrandum.

Quod fi punctum curvx per quod tangens ducenda eft, fit illud ipfum ubi regula curvam fecat, erit tangens quæfita femper regulæ perpendicularis; ut facile effet oftendere.

\section{PROPOSITIO X VI.}

DE MOTU IN CYCLOIDE.

I circulicircumferentiam, cujus centrum E, fecent recta
duse parallele A F, B G, quarum utraque ad eandem partem centri tranfeat, vel altera A F per centrum ip fum: E⿱ $\sigma^{2}$ punct.o A, quo centro propior circumferentiam fecat, ducatur recta ip (am contingens: dico partem bujus $\mathrm{A}$ is, à parallela utraque interceptam, minorem effe arcu A C, ab utraque eadem parallela intercepto.

Ducatur enim arcui A c fubtenfa recta A C. Quia ergo angulus B A $\mathrm{F}$ eft $æ$ qualis ei quem capit portio circuli $\mathrm{A} H \mathrm{~F}$, quæ vel major eft femicirculo vel femicirculus, erit proinde angulus B A F, 
HOROLOG. OS CILLATOR.

vel minor recto vel rectus; ideoque angulus $A$ B $C$ vel major re- $D_{E}$ Moru int

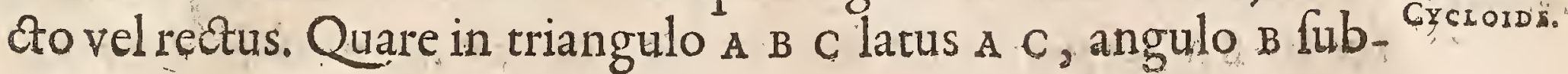

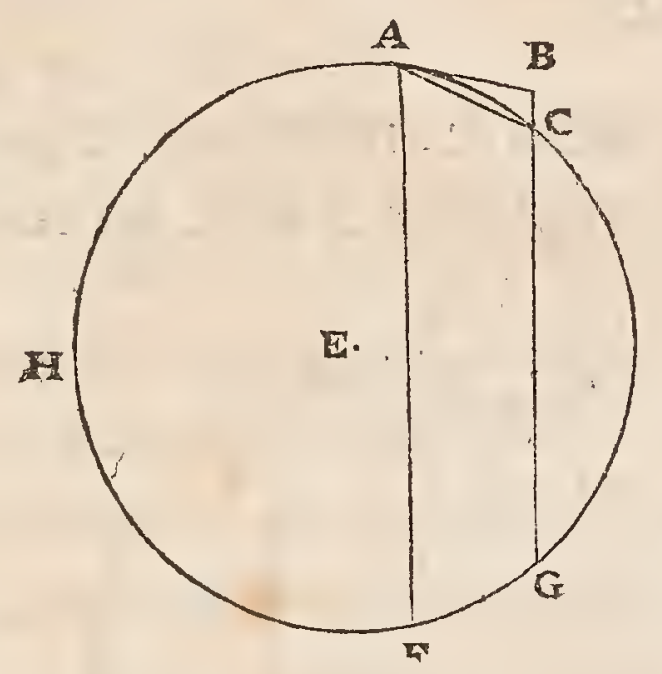

tenfum, majus erit latere A B. fed idem latus A C minus eft arcu A C. Ergo omnino \& A B arcu A C minor erit.

\section{PRO POS I T IO X V I I.}

7 Ifdem pofitis, fi tertia recta prioribus parallela $\mathrm{D} \mathrm{K}$, cir 1 culum fecuerit, qua ab ea qua centro propior eft A F, tantumdem diftet quantum bac à reliqua B $\mathrm{G}$ : dico partem tan. gentis in $\mathrm{A}$, à parallela ultimo adjecta, $\sigma$ media interceptam, nempe A D, arcu A C à primis duabus parallelis intercepto minorem effe.

Hoc enim patet quum $\triangle \mathrm{D}$ ipf $\mathrm{A}$ B $x$ qualis fit, quam antea oftendimus arcu a $\mathrm{C}$ minorem effe.

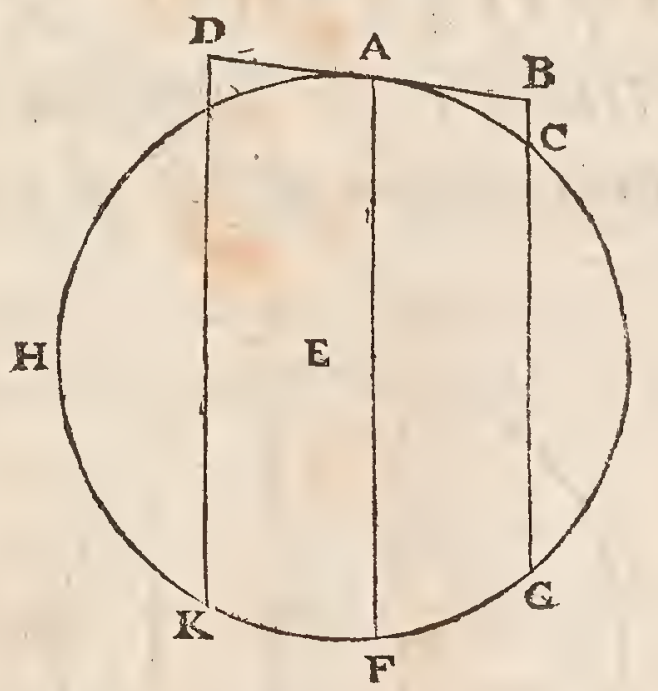

\section{PROPOSITIO XVIII.}

CI circulum, cujus centrum $\mathrm{E}$, dua recta parallela fecue$\checkmark$ rint AF, BG; Et à puncto $\mathrm{B}$, ubi que à centro remotior eft, vel tantundem atque altera diftat, circumferentia 06- 
44 CHR IS I I N I HVENII

Di woтu IN currit, ducatur recta circumferentiam tangens: erit pars CYсго一⿻ bujus BA, ì parallelis intercepta, major arcu ab iifdem parallelis intercepto $\mathrm{B} C$.

Ducatur enim in puncto C, recta M C L circumferentiam tangens, qux occurrat tangenti $\mathrm{B}$ in $\mathrm{L}$. In triangulo igitur $\mathrm{A} C \mathrm{C}$,

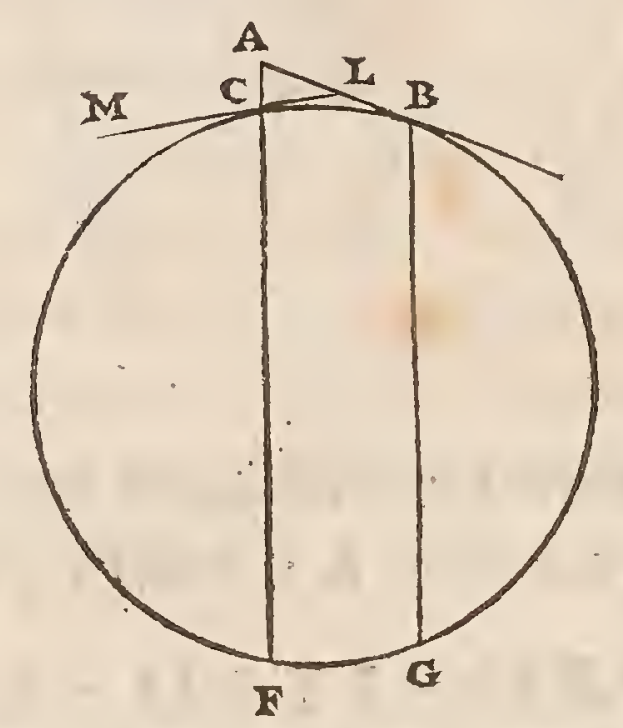

angulus C æqualis eft angulo M C F, hoc eft, ei quem capit portio circuli C B F. angulus autem A xquatur angulo quem capit portio circuli B C G, qux portio quum fit major vel æqualis portioni C B F, quippe quum B G vel ulterius diftet à centro quam $C$ $F$, vel tantundem : erit proinde trianguli $A, C$ L angulus $A$ minor vel æqualis angulo $\mathrm{C}$ : \& confequenter latus $\mathrm{C} L$ vel minus vel æquale lateri A L. Atqui C $\mathrm{L}$ una cum $\mathrm{L}$ в majores funt arcu C B.' Ergo \& A L. una cum $x$ b, hoc eft, tangens A B, eodem arcu C B major erit. quod erat demonftrandum.

PROPOSITIO XIX.

T Ifdem pofitis, futertia recta prioribus parallela $\mathrm{D} \mathrm{K}$ circu1 lum fecet, que tantundem diftet ab ea que remotior eft ì

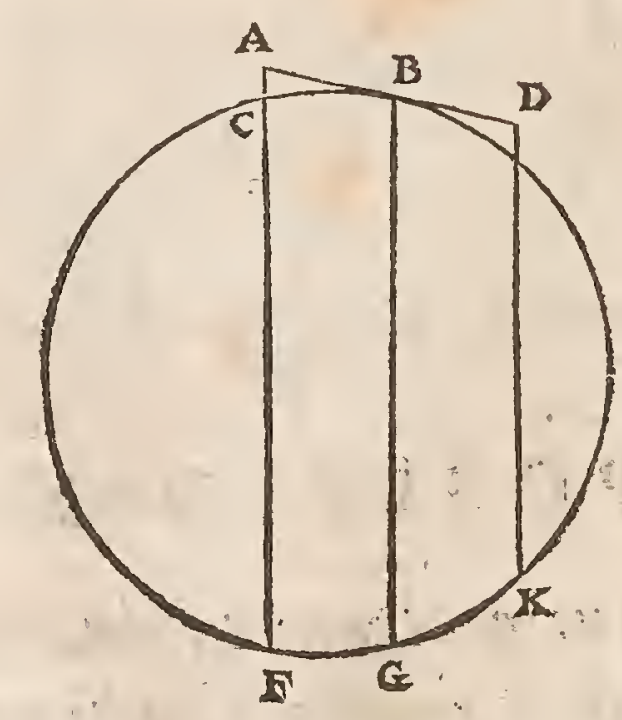

centro quantum bac à reliqua A F : Erit pars tangentis in $\mathrm{B}$, 

à parallela media, É ultimo addita $\mathrm{DK}$, intercepta; nimi- $\mathrm{DE}$ MотU rum B D, major arcu B C.

Hoc enim manifeftum eft cum B D fiat ipfi в A æqualis, quam oftendimus arcu B C majorem effe.

\section{P R O POS I T I O X X.}

I arcus circuli, femicircumferentia minor, $A B$, in partes 1 quotlibet fecetur line is rectis parallelis, que $G$ inter $\int e$, 65. cum rectis fibi parallelis per terminos arcus ductis, aqualia intervalla confituant, quales funt $\mathrm{CD}, \mathrm{E}, \mathrm{GH}, \mathrm{K} \mathrm{L} \boldsymbol{G}^{2} \mathrm{c}$. ducanturque ad terminum arcus alterutrum $\mathrm{A}$, \&) ad reliqua ornia fectionum puncta recte circumferentiam tangentes, omnes in eandem partem, ES ut unaquaque occurrat proxime dictarum parallelarum; cujufmodi funt tangentes $\mathrm{A} C, \mathrm{D}$ E, F G., H K EGc. Dico has tangentes, dempta prima A C, Jimul fumptas, minores effe arcu propofito A B. Eafdem vero omnes, non omiffa $\mathrm{AC}$, majores effe arcu $\mathrm{A} B$ diminuto parte extrema $\mathrm{NB}$, boc eft, majores arcu A N.

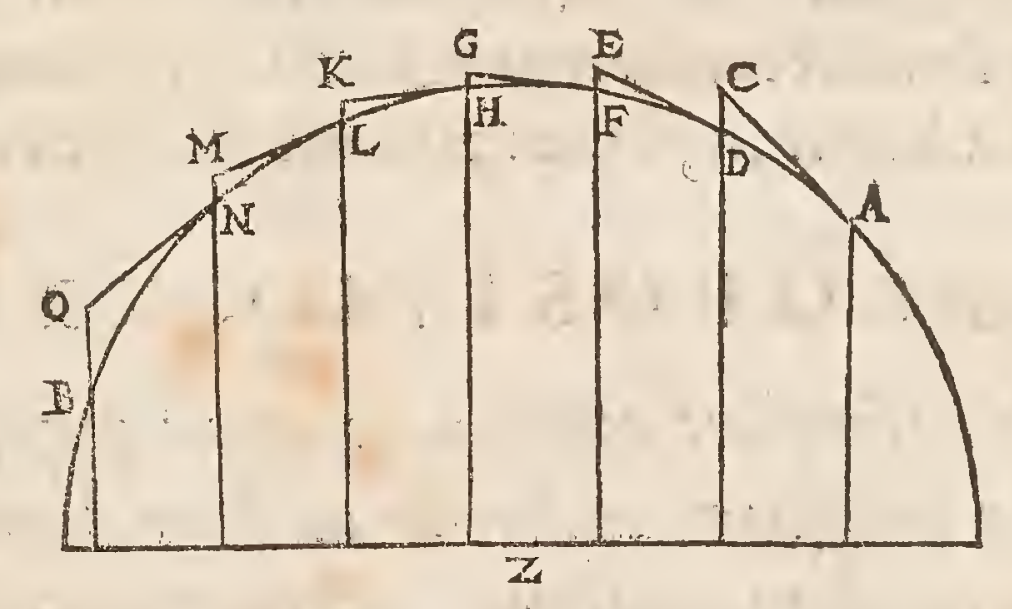

Ponamus enim primo parallelarum aliquas tranfire ab utraque parte centri $\mathrm{z}, \&$ fit $\mathrm{G} \mathrm{H}$, earum qux funt à parte $\mathrm{B}$, centro proxima, vel per ipfum centrum tranfeat. Itaque tangentes omnes inter $\mathrm{G} \mathrm{H} \& \mathrm{~B}$ O comprehenfæ, ut $\mathrm{H} \mathrm{K}, \mathrm{L} \mathrm{M}, \mathrm{N} O$, fingulæ fuis arcubus minores funt $*$. Porro autem $\&$ tangens $G \mathrm{~F}$, arcu $\mathrm{fe}_{-} * \mathrm{P}_{\mathrm{rop} .16}$. huj.

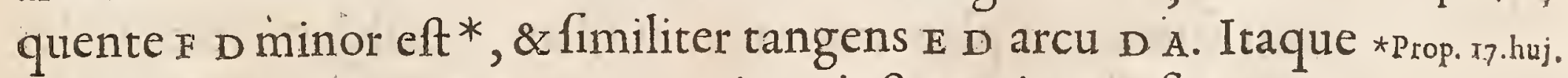
tangentes omnes inter $\mathrm{B} O \mathrm{O} \& \mathrm{C} \mathrm{D}$ interjectæ, minores funt arcubus $B$ H \& F A, ac proinde omnino minores arcubus $B-H, H$, five arcu B A, quod erat primo oftendendum.

Porro jam demonftrabimus tangentes omnes inter $\mathrm{B}$ O \& $\mathrm{A}$ majores effe arcu A N. Enimvero parallela $\mathrm{G} H$, vel propius centrum $z$ tranfit quam parallela $E F$, quam pono proximam effe 
D\& Moru in earum qux à parte $A$ tranfeunt, vel erit remotior, vel æque diCYeLOIDE. ftabit.

Quod fi E F longius à centro vel æque remota eft ac $\mathrm{G} \mathrm{H}$, erit tangens $\mathrm{F} G$ major arcu fuo $\mathrm{F} H$, \& reliquæ tangentes verfus $A$, $*$ Prop.rs huj. nimirum E D , C A majores fingulæarcubus fuis *; adeo ut omnes fimul G F, E D, C A majores fint arcu H A. fed \& arcu H L major

* Prop.ro.huj. erit tangens $L M *, \&$ arcu $L N$ tangens $N O$; itaque tangentes omnes, præter $\mathrm{HK}$, majores fimul erunt arcu $\mathrm{A} N$; multoque' magis, accedente ipfa $\mathrm{H} \mathrm{K}$, tangentes omnes inter A \& B comprehenfæarcu eodem A.N majores erunt.

Si vero $\mathrm{G} H$ à centro longius diftat quam $\mathrm{E} F$, eric tangens $\mathrm{K} \mathrm{H}$ * Propas.huj. major arcu $\mathrm{H} \mathrm{F}^{*}, \&$ tangens $\mathrm{M} \mathrm{L}$ ut ante major arcu L H, \& tangens $\mathrm{O} N$ major arcu N L \& omnes proinde tangentes $\mathrm{O} N, \mathrm{MI}$, $\mathrm{K} \mathrm{H}$ majores arcu $\mathrm{N} \mathrm{F}$. Sed \& tangens $\mathrm{E} D$ major eft arcu fuo $\mathrm{F}$ * Prop, x8,huj. $\mathrm{D}$ *, \& tangens $\mathrm{C}$ A major fimiliter arcu fuo D A. Itaque tangentes omnes inter $\mathrm{B} O \& \mathrm{~A}$, præter $\mathrm{G} F$, majores erunt arcu $\mathrm{N} A$; multoque magis tangentes exdem, accedente $\mathrm{G} F$, hoc eft; omnes qua inter B O \& A interjiciuntur, codem arcu N A majores erunt.

Ex his vero etiam demonftratio manifefta eft in cafibus aliis, qualifcunque femicircumferentix arcus accipiatur, quippe cum vel eadem fit ubique, vel pars tantum præcedentis demontrationis.

\section{P R O P O I T I O X X I.}

I mobile defendat continuato motu per qualibet plana Sinclinata contigua, ac rurfus ex pari altitudine defcendatper plana totidem contigua, ita comparata ut fingula altitudine refpondeant fingulis priorum planorum. fed majori quam illa fint inclinatione. Dico tempus defenfus per minus inclinata, brevius effe tempore defcenfus per magis inclinata.

Sint feries dux planorum inter eafdem parallelas horizontales comprehenfæ A B C D E , F G H K L, atque ita ut bina quæque fibi correfpondentia plana utriufque feriei iifdem parallelis horizonralibus includantur; unumquodque vero feriei $\mathrm{F} \mathrm{G} \mathrm{H} \mathrm{K} \mathrm{H}$ magis inclinatum fit ad horizontem quam planum fibi altitudine refpondens feriei A B CD E. Dico breviori tempore abfolvi defcenfum per A B C D E, quam per F G H K L. 


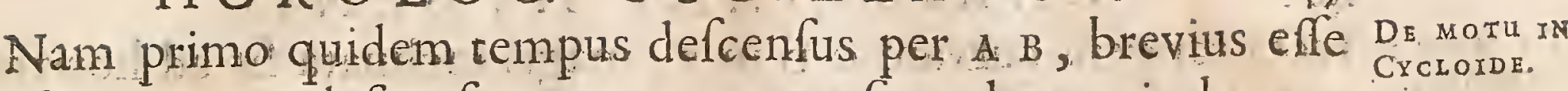
conftat empore defcenfus per $F G$, quim fit eadem ratio horum temporum qux rectarum A B ad E G *, fitque A B minor quam $\mathrm{FG}$, * Prop. 7 huj. propter minorem inclinationem. Producantur jam furfum rectx $C B, H G$, occurrantque horizontali $A F$ in $M \& N$. Itaque tempus per B C poft A B, æquale eft tempori per eandem B C polt $M B$,

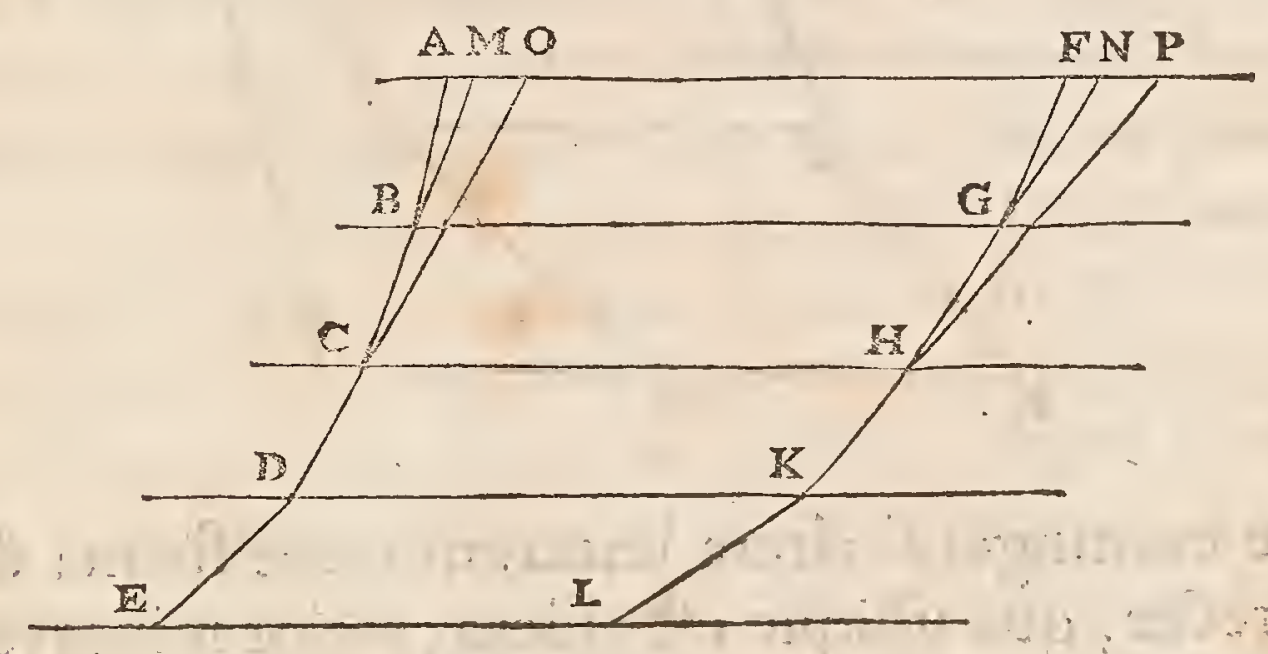

cum in puncto $B$ eadem celeritas contingar, five per $A B$, five per M в defcendenti*. fimiliterque tempus per $\mathrm{G}$ H poft $\mathrm{F}$ G, æquale $\star$ Prop. 6 . huj. erit tempori per eandem $\mathrm{G}$ H polt $\mathrm{N}$ G. Eft autem tempus per $\mathrm{B} C$ poft $M B$ ad tempus per $G H$ polt $N G$, ut $B C$ ad $G$ H longitudine, five ut $\mathrm{C} M$ ad H N , cum hanc rationem habeant \& tempora per totas $\mathrm{M} \mathrm{C}, \mathrm{N} \mathrm{H}, \&$ per partes $\mathrm{M} \mathrm{B}, \mathrm{N} \mathrm{G}^{*}$, ideoque etiam tempora $*$ Prop. 7 . huj. reliqua. Eftque $\mathrm{B} C$, minor quam $\mathrm{G}$ H propter minorem inclinationem. Patet igitur tempus per B C polt $M$ B five poft A B, brevius effe tempore per G H poft N G five polt F G.

Similiter oftendetur, productis D C, K H furfum, doneç occurrant horizontali A $F$ in $O \& P$, tempus per C D poft A B C, five poft o $\mathrm{C}$, brevius effe tempore per $\mathrm{H} \mathrm{K}$ polt $\mathrm{FG}$ H five poft $\mathrm{P} \mathrm{H}$. Ac denique tempus per $D$ E poft $A B C D$, brevius effe tempore per KL poft $\mathrm{F}$ G H K. Quare totum tempus defcenfus per A B C D E, brevius erit tempore per F GHKL. quod erat demonftrandum.

Hinc vero manifeftum eft, confiderando curvas lineas tanquam ex innumeris rectis compofitas, $f_{1}$ fuerint duæ fuperficies, fecundum lineas curvas ejufdem altitudinis inclinatæ, quarum in punctis quibuflibet æque altis major femper fit inclinatio unius quam reliqux, etiam tempore breviori per minus inclinatam gra. ve defcenfurum quam per magis inclinatam.

Velut fi fine duæ fuperficies inclinatx fecundum curvas A B, $C D$, xqualis altitudinis, quarumque in punctis xque altis quibuflibet E, $F$, major fit inclinatio ipfius $C D$ quam $A$, hoc eft; ut 

DE MOTU IN recta tangens curvam $C D$ in $F$, magis inclinata fit ad horizontem, quam qux curvam $A$ B tangit in puncto $E_{\text {. }}$ erit tempus defcenfus per $A$ B brevius quam per $C D$.

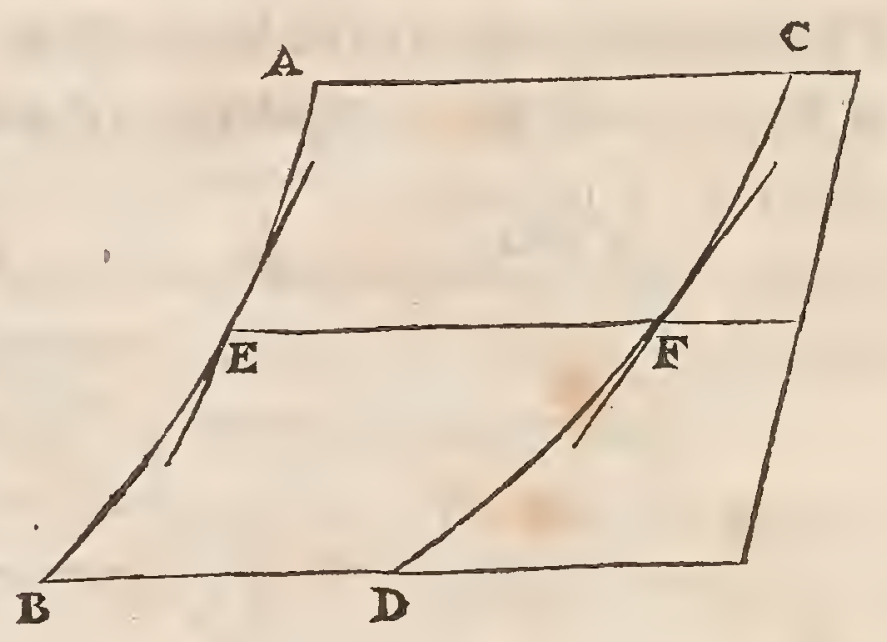

Idemque continget fi altera linearum rectx fuerit: dummodo inclinatio rectx, qux ubique eft eadem, major minorve fuerit inclinatione curvæ in quolibet fui puncto.

\section{P R O P O S I T IO X X II.}

I in Cycloide cujus axis ad perpendiculum erectus ftat. $\checkmark$ vertice deorfum spectante, dua portiones curva aqualis altitudinis accipiantur, fed quarum alter a propior fit vertici; erit tempus defcenfus per fuperiorem, brevius tempore per inferiorem.

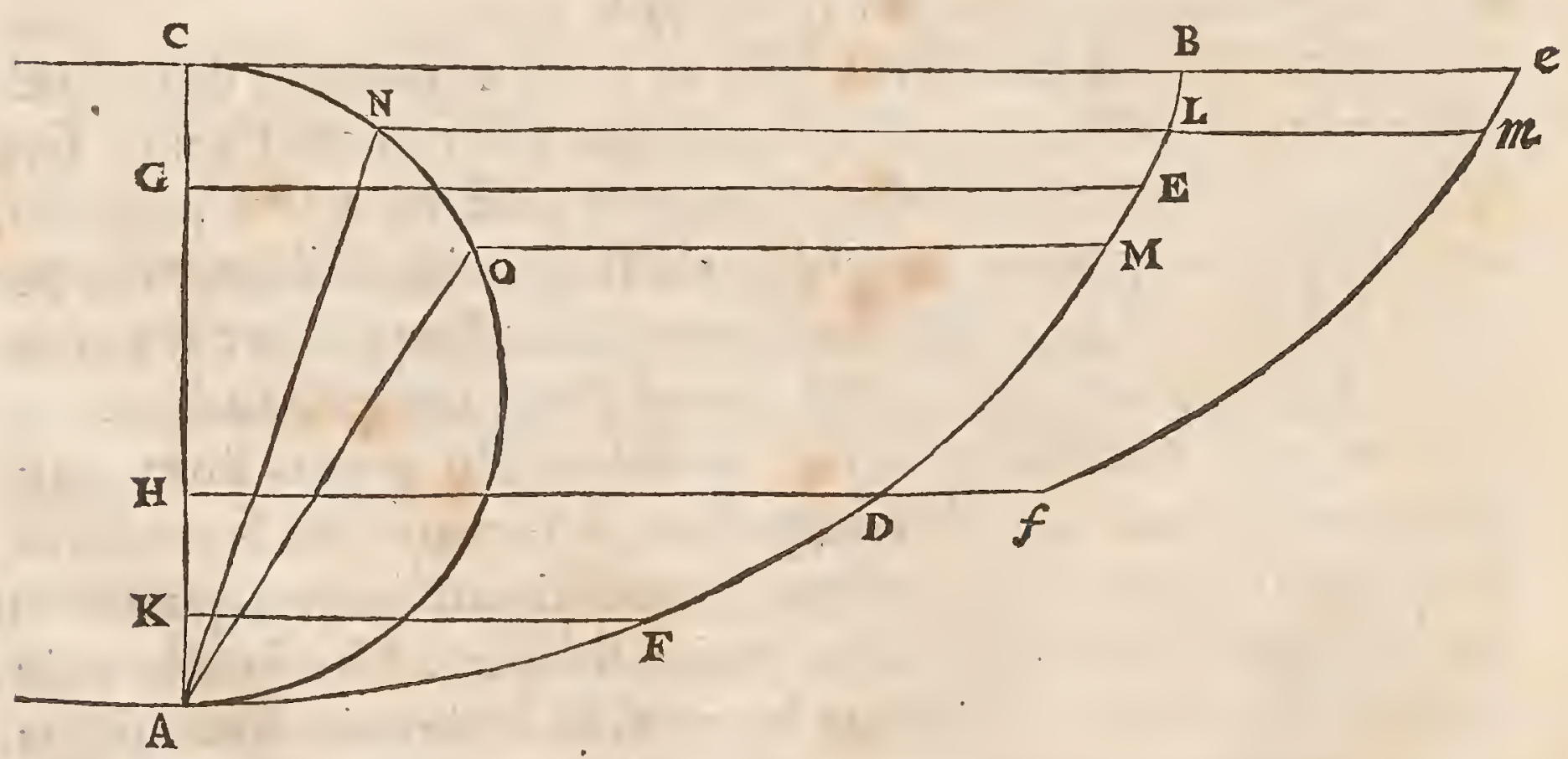

Sit Cyclois A B, cujus axis A C ad perpendiculum erectus, vertex A deorfum fpectet; \& accipiantur in ea portiones B D \& E $F$, xqualis altitudinis, hoc eft, ejufmodi ut parallelæ horizontales $B$ C, D H, qux fuperiorem portionem $B$ D includunt, æque inter 
HOROLOG. OSCILLATOR.

fe diftent $\mathrm{ac} \mathrm{E} \mathrm{G}, \mathrm{F} \mathrm{K}$, inferiorem portionem $\mathrm{E} \mathrm{F}$ includentes. Dico tempus defcenfus per curvam $B$ D brevius fore tempore per $E$ E.

Sumatur enim in B D punctum quodlibet $L$, \& in E F punctum $M$, ita ut eadem fit altitudo e fupra $M$ quæ в fupra $L$. Et defcripto fuper axe $\mathrm{A} C$ femicirculo, occurrant ei rectæ horizontales $L N, M O$, in $N \& O$, \& jungantur $N A, O A$. I taque quum punctum $\mathrm{N}$ fit altius puncto $\mathrm{O}$, manifeftum eft rectam $\mathrm{N}$ A minus ad horizontem inclinari quam o A. Eft autem ipfi N A parallela tangens curvæ in L puncto*, \&ipfi o A parallela tangens curvæ in M. Ergo curva $B D$ in puncto $L$ minus inclinata eft quam curva $E \mathrm{~F}$ in puncto M. Quod fi igitur portio E F, invariata inclinatione, altius extolli intelligatur: velut in $e f$, ita ut inter eafdem parallelas cum portione в $\mathrm{D}$ comprehendarur, invenietur punctum $\mathrm{M}$ in $m$, xquali altitudine cum puncto $\mathrm{L}$. eritque etiam inclinatio curvæe $f$ in puncto $m$, qux eadem eft inclinationi curvæ $\mathrm{E} F$ in $\mathrm{M}$, major inclinatione curvæ B D in L. Similiter vero, $\&$ in quolibet alio puncto curvæ $e f$, major oftendetur inclinatio quam curvæ $\mathrm{B} D$ in puncto xque alto. Itaque tempus defcenfus per B D brevius erit tempore per $e f^{*}$, five, quod idem eft, per E F. quod erat demon- $*$ prop praced. ftrandum.

\section{E M M.}

$\mathrm{E}$

Sto circulus diametro A C, quem fecet ad angulos rectos $\mathrm{DE}, E$ à termino diametri A educta recta A B occurrat circumferentia in $\mathrm{B}$, ipfs vero D E in $\mathrm{F}$. Dicotres ha fce, $\mathrm{A} B$, $A D, A F$, proportionales effe.

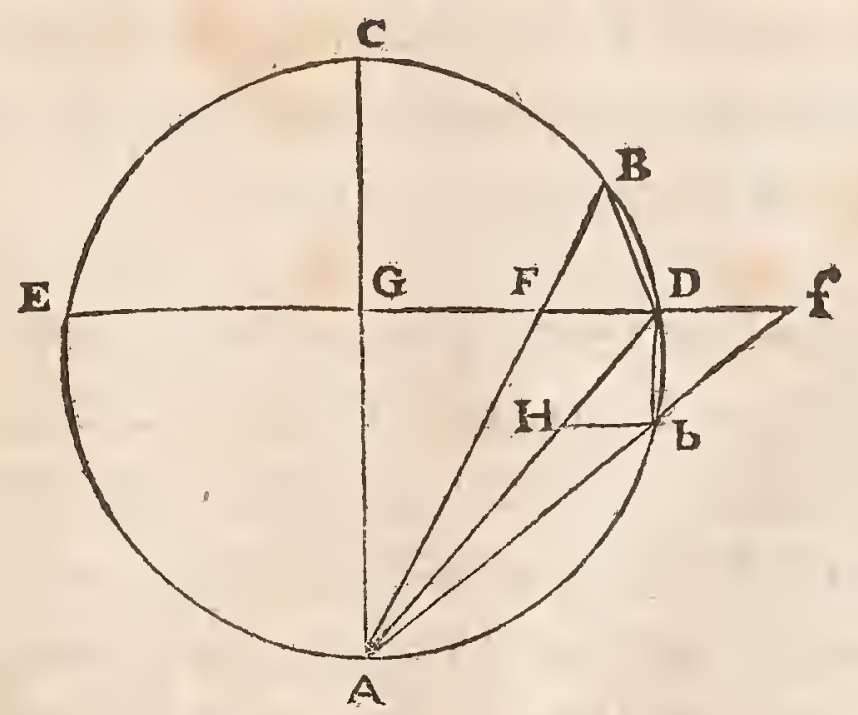

Sit enim primo interfectio $\mathrm{F}$ intra circulum; \& arcui B D recta fubtenfa ducatur. Quia igitur arcus $x$ quates funt $A E, A D$, erunt anguliad circumferentiam iplis infiftentes, $E$ D A, A B D rqua- 
$D_{E}$ моти IN les. Itaque in triangulis $A B D, A D F$, rquales anguli $A$ B D, A D Crcroide. F. Communis autem utrique eft angulus ad A. Ergo dicti trianguli fimiles erunt, ideoque $B A$ ad $A D$ ut $A D$ ad $A$.

Sit jam punctum interfectionis $f$ extra circulum, \& ducatur $b \mathrm{H}$ parallela $D E$, qux occurrat rect $A$ D in $\mathrm{H}$. Itaque fecundum jam demonftrata erit ut $D$ A ad $A b$, ita $A b$ ad $A H$, hoc eft, ita $A$ fad. A D: Ideoque rurfus proportionales erunt $A f, A D, A b$. Quare conftat propofitum.

\section{PROPOSITIO. XXIII.}

C It Cyclois A B C, cuins vertex A deorfum convergus fit, 1 axe A D ad perpendiculum erecto; umptoque in ea quolibet puncto B, ducatur inde deorfum recta B I que Cycloidem tingai, termineturque recta borizontali $\mathrm{A} I$. recta vero $\mathrm{B} F$ ad axem perpendicularis agatur, EG divifa bifariam $\mathrm{F} \mathrm{A}$ in $\mathrm{X}$, superea de cribatur femicirculus F H A. Duct $\hat{A}$ deinde per punctum quodlibet $\mathrm{G}$ in curva B A fumptum, recta. $\Sigma$ G parallela $\mathrm{B} F$, qua circumferentic $\mathrm{F} H \mathrm{~A}$ occurrat in $\mathrm{H}$, ax $\mathrm{A} \mathrm{D}$ in $\Sigma$, intelliganturper puncta $\mathrm{G}$ ES $\mathrm{H}$ recte tangentes utriug que curva, earumque tangentium partes iifdem duabus borizontalibus $\mathrm{MS}, \mathrm{N} \mathrm{T}$ intercepte fint $\mathrm{M} \mathrm{N}, \mathrm{S} \mathrm{T}$. Jifdemque rectis $\mathrm{M} \mathrm{S}, \mathrm{N}, \mathrm{T}$ includantur tangentis $\mathrm{B}$ I pars $\mathrm{O} P, \sigma \sigma_{\text {axis }} \mathrm{D}$ A pars $Q R$.

Quibus ita fe habentibus, dico tempus quo grave percur. ret rectarn $\mathrm{M}$, celeritate aquabili quanta acquiritur defeendendo per arcum Cycloidis B G, fore ad tempus quo percurretur recta o P, celeritate equabili dimidia ejus que acquiritur defcendendo per totam tangentem $\mathrm{B} I$, ficut eft tangens $S \mathrm{~T}$ ad partem axis $\mathrm{QR}$.

Defcribatur enim fuper axe A D femicirculus D $V$ A fecans rectam $B \mathrm{~F}$ in $\mathrm{V}, \& \Sigma \mathrm{G}$ in $\Phi, \&$ jungatur $\mathrm{A} v$ fecans rectas $O \mathrm{Q}, \mathrm{P} \mathrm{R}$, $\mathrm{G} \Sigma$ in $\mathrm{EK} \& \Lambda$. Iungantur item $\mathrm{H} \mathrm{F}, \mathrm{HA}, \mathrm{HX} \& A \Phi ;$ qux poltrema fecet rectas $O Q, P R$ in punctis $\Delta \& \Pi$.

Habet ergo dictum tempus per $\mathrm{M} N$ ad tempus per o $\mathrm{P}$, ratio nem eam qux componitur ex ratione ipfarum linearum $M N$ ad o P, \& ex ratione celeritatum quibus ip $æ$ percurruntur, contrarie *Prop.s.Galil. fumpta*, hoc eft, \& ex ratione dimidix celericatis ex B I five ex.

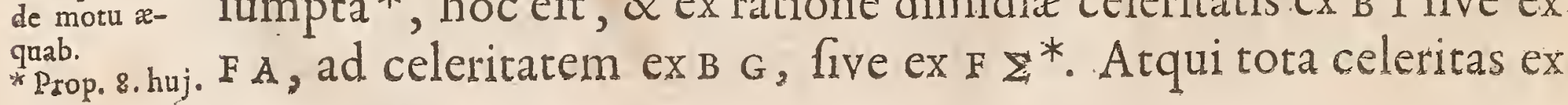


$F A$ ad celeritatem ex $F \Sigma$, eft in fubduplicata ratione longitu- $D_{\Sigma}$ моти го dinum $\mathrm{F}$ A ad $\mathrm{F} \mathrm{\Sigma}^{*}$, ac proinde eadem quæ $\mathrm{F}$ A ad $\mathrm{F}$ H. Ergo di-Crczorde. midia celeritas ex $\mathrm{F} A$ ad celeritatem ex $\mathrm{F} \mathrm{\Sigma}_{\mathrm{L}}$ erit ut $\mathrm{F} \mathrm{X}$ ad $\mathrm{F} \mathrm{H}$. Itaque tempus dictum per $M N$ ad tempus per o $P$ habebit rationem compofitam ex rationibus $M N$, ad $O P, \& F$ X ad $F$ H. Harumvero prior ratio, nempe $\mathrm{M} N \mathrm{~N}$ ad $\mathrm{O}$, eadem oftendetur qux F H ad $\mathrm{H} \Sigma$.

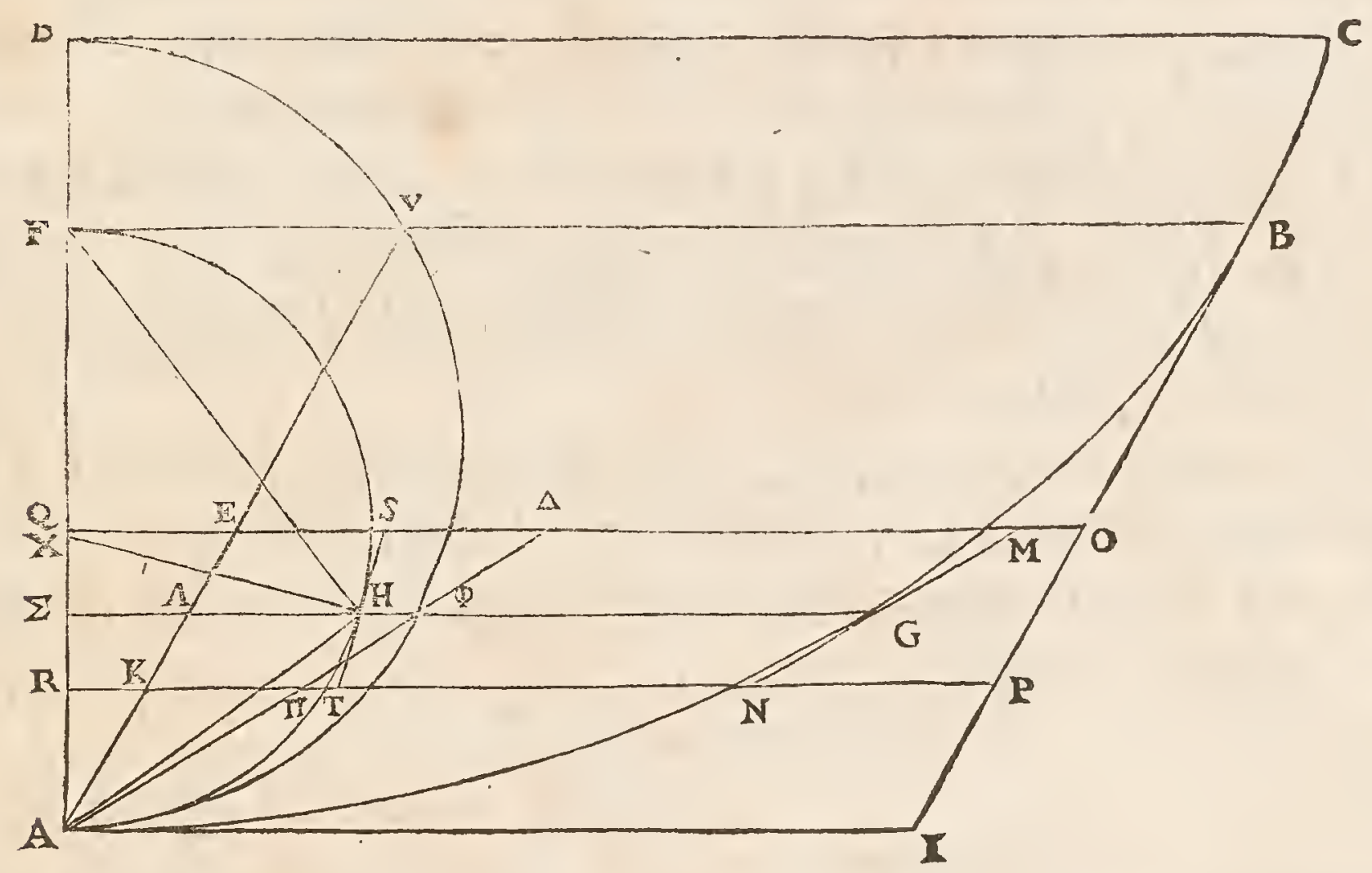

Eft enim tangens Cycloidis B I parallela rectx $v \mathbb{A}$, fimiliterque tangens $M G N$ parallela rectx $\Phi A$; ac proinde recta $M N$ æqualis $\Delta \Pi, \&$ O P æqualis $\mathrm{E} K$. Ergo dicta ratio rectæ $\mathrm{M} N$ ad $O P$ eadem eft qux $\Delta \Pi$ ad $E \mathrm{~K}$; hoc eft, $\Delta A$ àd $\mathrm{E} A$; hoc eft,

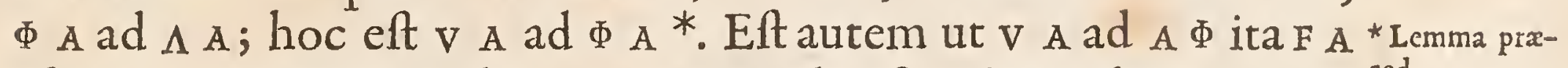
$\operatorname{ad} \mathrm{A} H$; nam quia quadratum $\mathrm{V}$ A $x$ quale eft rectangulo $\mathrm{D} A \mathrm{~F}, \& \mathrm{C}^{\mathrm{ced} .}$ quadratum $\mathrm{A} \Phi$ xquale rectangulo $\mathrm{D}$ \& $\Sigma$, qux rectangula funt inter fe ut $\mathrm{F} A$ ad $\Sigma A$, hoc eft ut quadratum $\mathrm{F} A$ ad quadracum $A \mathrm{H}$, crit proinde \& quadratum $v$ A ad quadratum $\Phi$ A ut quadratum F $A$ ad quadratum $\mathbb{A}$; atque eriam $V \mathbb{A}$ ad $A \Phi$ longitudine, ut $F A$ ad $A$ H. Ratio itaque $M N_{\text {ad }} O \mathrm{P}$, eadem erit quæ $\mathrm{FA}$ ad $A \mathrm{H}$, hoc eft, propter triangula fimilia $\mathrm{F} \mathrm{A} \mathrm{H}, \mathrm{F} \mathrm{H} \Sigma$, eadem quæ $\mathrm{F} \mathrm{H}$ ad $\mathrm{H}$ $\Sigma$, ut dictum fuit. Itaque dicta ratio temporis per $\mathrm{M} N$ ad tempus per O P, componitur ex rationibus F X ad F H \& F H ad H $\Sigma$, ideoque eadem erit quæ $\mathrm{F} X$ five $X \mathrm{H}$ ad $\mathrm{H} \Sigma$. Sicut autem radius $\mathrm{X} H$ ad $\mathrm{H} \Sigma$, ita eft tangens $\mathrm{s} T$ ad rectam $Q \mathrm{R}$; hoc enim facile perfpicitur. Igitur tempus motus qualem diximus per $\mathrm{M} N$, ad tempus per o P conftat effe ficut $\mathrm{S} T$ ad $Q \mathrm{R}$. quod erat demonftrandum. 


\section{PROPOSITIO XXIV.}

S It murgus ut in precedenii propofitione Cyclois A B C, $\checkmark$ cujus vertex A deorfum pectet, axis $\mathrm{A} \mathrm{D}$ ad horizontem erectus fit; $E$ fumpto in ea quovis puncto $\mathrm{B}$, ducatur inde deorfum recta $\mathrm{B} \Theta$ que Cycloidem tangat, occurratgue recta borizontali $\mathrm{A} \Theta$ in $\Theta$ : recta vero $\mathrm{B} \mathrm{F}$ ad axem perpendicularis agatur, ES Juper F A de fribatur femicirculus F H A. Deinde alia rect $\mathrm{G} \mathrm{E}$, parallela $\mathrm{F} \mathrm{B}$, fecet $C$ ycloidem in $\mathrm{E}$, rectam $\mathrm{B} \odot$ in $\mathrm{I}$, circumferentiam $\mathrm{FH}$ A in $\mathrm{H}, \mathrm{ES}^{2}$ denique axem $\mathrm{DA}$ in $\mathrm{G}$.

Dico tempus defcenfus per arcum Cycloidis B E, effe ad tempus per tangentem $\mathrm{B}$ I cum celeritate dimidia ex $\mathrm{B} \Theta$, ficut arcus $\mathrm{FH}$ ad rectam $\mathrm{F} \mathrm{G}$.

Si enim hoc verum non eft, habebit tempus per arcum $\mathrm{B} E$ ad dictum tempus per B $I$, vel majorem rationem quam arcus $\mathrm{F} \mathrm{H}$ ad rectam $\mathrm{F}$ G vel minorem. Habeat primo, fi fieri poteft, majorem.

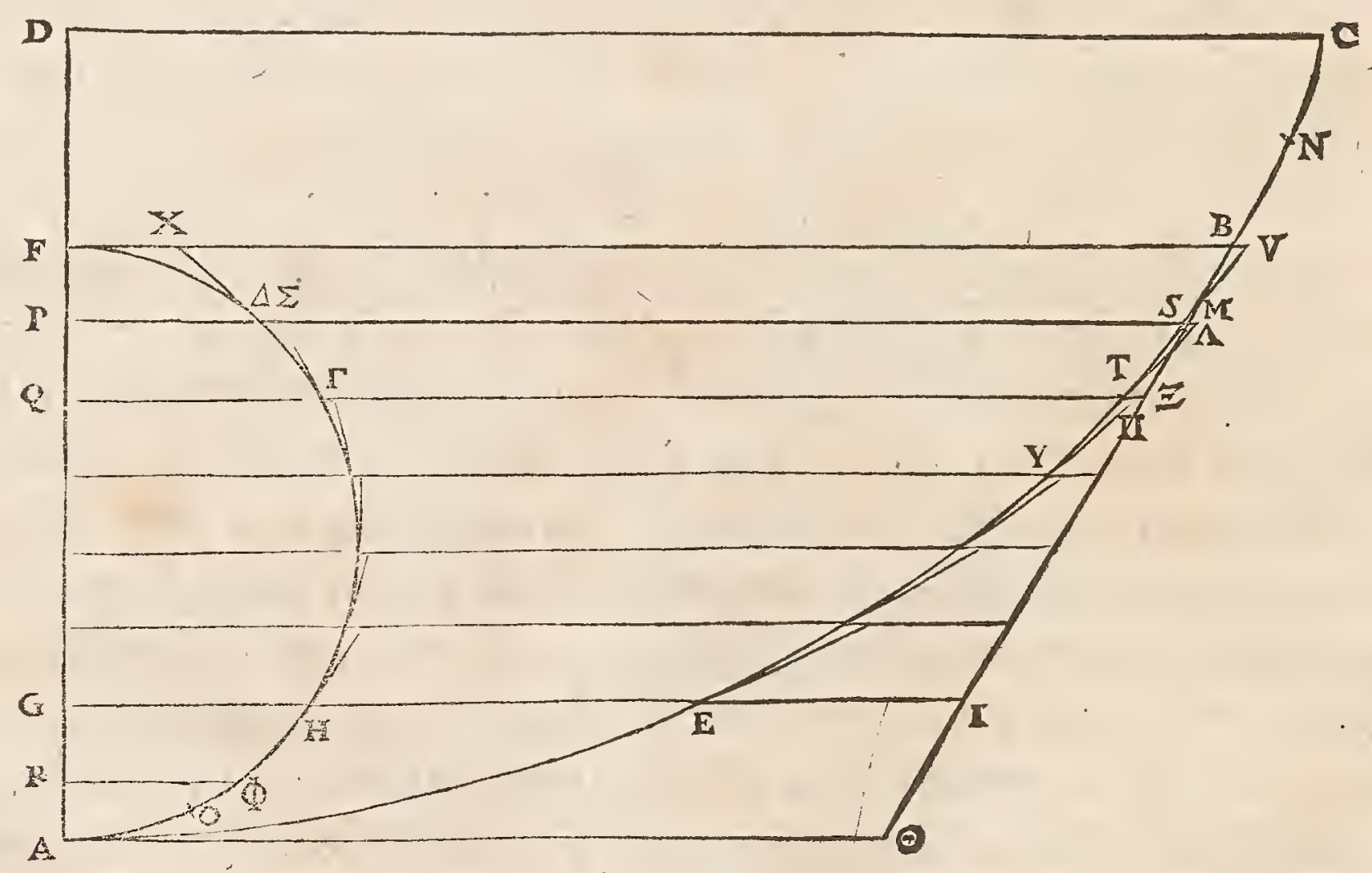

Itaque tempus aliquod brevius tempore per B E (fit hoc tempus z) erit ad dictum tempus per B I ut arcus F H ad rectam F G. Quod fi jam in Cycloide fupra punctum в fumatur punctum aliud $N$, erit tempus per B E poft $N$ B, brevius tempore per B E. Manifeftum eft autem punctum $N$ tam propinquum fumi polfe ipfi $B$, ut differentia eorum temporum fit quamlibet exigua, ac proinde ut minor fit ea qua tempus z fuperatur à tempore per B E. Sit itaque 

punctum $N$ ita fumptum. unde quidem tempus per $B E$ poft $N$ B DE Moru iN majus erit tempore $\mathrm{z}$, majoremque proinde rationem habebit ad rempus dictum per B I cum dimidia celeritate ex $\mathrm{B} \Theta$, quam arcus $\mathrm{F} H \mathrm{H}$ ad rectam $\mathrm{F}$ G. Habeat itaque eam quam arcus $\mathrm{F}$ H $\mathrm{O}$ ad rectam $\mathrm{F}$ G.

Dividatur $F \mathrm{G}$ in partes æquales F P, P Q, \&c. quarum unaquxque minor fit altitudine linex $\mathrm{N} \mathrm{B}$, atque item altitudine arcus HO; hoc enim ficri poffe manifeftum eft; $\&$ à punctis divifionum agantur rect $x$, bafi D c parallel $x, \&$ ad tangentem B $\Theta$ terminat $\mathrm{P} \Lambda, Q \nexists, \& \mathrm{c}$. Quibufque in punctis hæ fecant circumferentiam $\mathrm{FH}, \mathrm{ab}$ is, itemque à puncto $\mathrm{H}$, tangentes furfum ducantur ufque ad proximam quxque parallelam, velut $\Delta \mathrm{x}, \Gamma \Sigma \approx \mathrm{c}$. Similiter vero \& à punctis, in quibus dictæ parallelæ Cycloidi occurrunt, tangentes furfum ducantur velut $\mathrm{S}, \mathrm{V}, \mathrm{T} \mathrm{M} \& \mathrm{C}$. addicâ vero ad rectam $\mathrm{F}$ G parte una $\mathrm{G} R$ æqualiiis quæ ex divifione, ductâque $\mathrm{R} \Phi$ parallelâ fimiliter ipfi $\mathrm{D} C$, paret eam occurrere circumferen. tiæ $F$ H A inter $\mathrm{H} \& \mathrm{O}$, quia G R minor eft altitudine puncti $\mathrm{H}$ fupra o. Iam vero fic porro argumentabimur.

Tempus per tangentem v s cum celeritate æquabili quæ acquireretur ex B s, majus eft tempore motus continue accelerati perarcum B s polt N B. Nam celeritas ex B $S$ minor eft celeritate ex N.B , propterea quod minor altitudo B $S$ quam N B. At celeritas ex B $\mathrm{s}$ æquabiliter continuari ponitur per tangentem $\mathrm{v}$ s, cum celeritas acquifita ex N B continue porro acceleretur per arcum B $s$, qui arcus minor infuper eft tangente $v s$, omnibufque partibus fuis magis erectus quam ulla pars tangentis v s. Adeo ut omnino majus fit futurum tempus per tangentem v s cum celeritate ex B s, tempore per arcum B s poft $N$ B. Similiter tempus per tangentem $M T$, cum celeritate ex $B \mathrm{~T}$, majus erit tempore per arcum $\mathrm{T}$ poft $\mathrm{N}$ s, \& tempus poft tangentem $\Pi$ y cum celeritate $\mathrm{x}$ $B \mathrm{Y}$, majus tempore per arcum $\mathrm{T}$ Y polt $\mathrm{N} T$. A tque ita tempora mo. tuum æquabilium per tangentes omnes ufque ad infimam quæ tangit cycloidem in $\mathrm{E}$, cum celeritatibus per fingulas quant $x$ acquiruntur cadendo ex $\mathrm{B}$ adufque punctum ipfarum contactus, majora fimul erunt tempore per arcum B E poft N B. Eadern vero \& minora effent, ut nunc oftendemus.

Confiderentur enim denuo tempora eadem motuum xquabilium per tangentes cycloidis. Et eft quidem tempus per tangentem $\mathrm{V}$ scum celeritate ex B $\mathrm{s}$, ad tempus per rectam $\mathrm{B} \Lambda$ cum celeritate dimidia ex $\mathrm{FA}$, ut tangens circumferentix $\Delta \mathrm{x}$ ad partem 
54 CHRIS TIANI HVGENII

DB moтu IN axis $F P^{*}$. Similiterque tempus per tangentem $M T$, cum celeritate CYCLO1DE. * Prop. praced. ex B $T$, ad tempus per rectam $\Lambda$. cum eadem dimidia celeritate ex $\vec{F} \mathbb{A}$, ut tangens $\Gamma \Sigma$ ad rectam $\mathrm{P} Q$. Atque ita deinceps fingula tempora per tangentes cycloidis, qux funt eadem fupradictis, erunt ad tempora motus æquabilis per partes fibi refpondentes rectæ B I cum celeritate dimidia ex B $\Theta$, ficut tangentes circumferentix $\mathrm{F} H$, iifdem parallelis comprehenf $x$, ad partes rectæ $\mathrm{F} G$ ipfis refpondentes.

Sunt igitur quantitates quædam rectæ F P, P Q \& \& . \& totidem alix, tempora fcilicet quibus percurruntur $\operatorname{rectæ} B \Lambda, \Lambda \Xi \&$, motu xquabili cum celeritate dimidia ex $B \Theta$; Et unaquæque quantitas in prioribus ad fequentem eadem proportione refertur, qua unaquxque pofteriorum ad fuam fequentem; funt enim utrobique inter fe æquales. Quibus autem proportionibus priores quantitates ad alias quafdam, nempe ad tangentes circuli $\Delta \mathrm{x}$, $\Gamma \Sigma, \& c$, referuntur, iifdem proportionibus \& eodem ordine pofteriores quoque referuntur ad alias quafdam, nempe ad tempora motus qualem diximus per tangentes cycloidis v s, M T \&c. Ergo, ficut fe habent omnes fimul priores ad omnes eas ad quas ipfære feruntur, hoc eft, ficut tota $\mathrm{F} G$ ad tangentes omnes $\mathrm{x} \Delta, \Gamma \Sigma_{\text {, }}$ \&c. ita tempus quo percurritur tota B I cum celeritate dimidia ex $B \Theta$, ad tempora omnia motuum quales diximus per tangentes

* Prop. 2. Archimedis de Sphroid. \& Conoid.

$\star$ Prop. 20 huj. cycloidis V S, M T, \& ${ }^{*}$. Et invertendo itaque, tempora motuum dictorum per tangentes cycloidis, ad tempus per rectam в I cum celeritate dimidia ex $\mathrm{B} \Theta$, eandem rationem habebunt quam dićx tangentes omnes circumferentix $\mathrm{F} H$ ad réctam $\mathrm{F} \mathrm{G}$; ac minorem proinde quam arcus $\mathrm{F} O$ ad rectam eandem $\mathrm{F} G$; quia arcus $\mathrm{F} \Phi$, ideoque omnino \& arcus $\mathrm{F}$ o major eft dictis omnibus arcus F $\mathrm{H}$ tangentibus *. A tqui tempus per B E poft $\mathrm{N} \mathrm{B}$, ad tempus per B. I cum celeritate dimidia ex B $\Theta$, pofuimus effe ut arcus F o ad rectam F G. Ergo dicta tempora omnia per tangentes cycloidis minora fimul erunt tempore per B E poft $\mathrm{N} \mathrm{B}$, cum antea majora. effe oftenfum fit; quod eft abfurdum. Itaque tempus per arcum cycloidis B E, ad tempus per tangentem B I, cum celeritate dimidia ex $\mathrm{B} \Theta$ vel ex $\mathrm{FA}$, non habet majorem rationem quam arcus circumferentix $\mathrm{F} \mathrm{H}$ ad rectam $\mathrm{F}$ G.

Habeat jam, fi poteft, minorem. Ergo tempus aliquod majus tempore perarcum B E, ( fic hoc tempus $\mathrm{z}$ ) erit ad tempus dictum per $B I$, ut arcus $F H$ ad rectam $F$ G.

Quod fi jam fumatur arcus $\mathrm{N}$ м æqualis altitudine cum arcu B 

pus perarcum N M majus tempore per arcum B E*. Manifeftum * * rop. 22.huj. autem quod punctum $\mathrm{N}$ tam propinquum fumi poteft puncto $\mathrm{B}$, $\mathrm{Ut}$ differentia dictorum temporum fit quamlibet exigua, ac proinde minor ea qua tempus z fuperat tempus per arcum B $\mathrm{E}$. Sit itaque punctum $N$ ita fumptum. Vnde quidem tempus per $N$ M minus erit tempore $\mathrm{z}$, habebitque proinde ad dictum tempus per B I,cum dimidia celeritare ex $\mathrm{B} \Theta$, minorem rationem quam arcus $\mathrm{F} \mathrm{H}$ ad rectam $F$. G. Habeat ergo eam quam arcus $L$. $H$ ad rectam $F$ G.

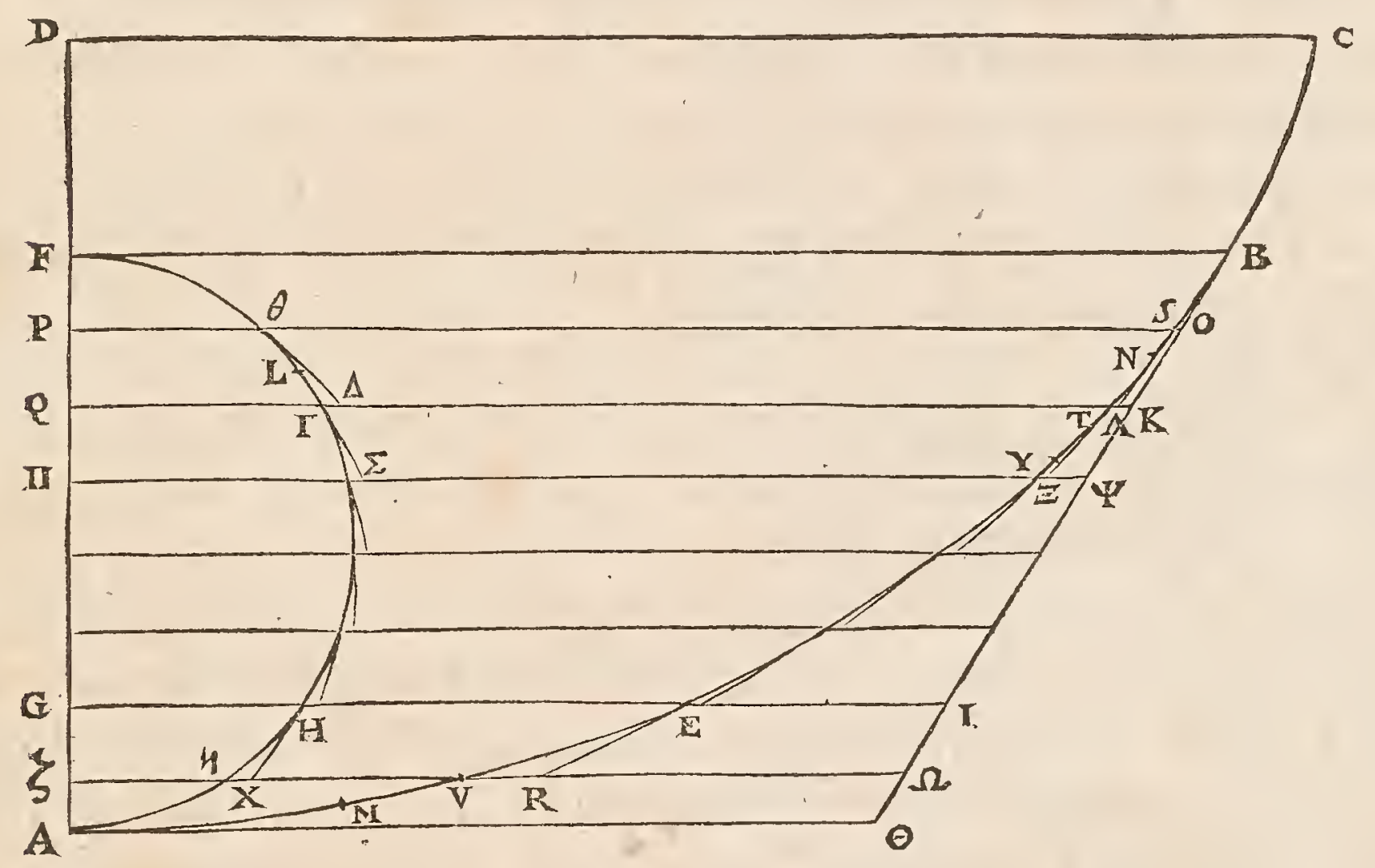

Dividatur jam F G in partes æquales F P, P Q; \&c. quarum unaquæque minor fit arcus cycloidis B $N$ altitudine, itemque minor altitudine arcus circumferentix F L; \& additâ ad F G unâ earum partium $\mathrm{G} \zeta$, ducantur à punctis divifionum rectx bafi $\mathrm{D}$ C parallelæ, \& ad tangentem в $\Theta$ terminatæ, P O , Q K , \&c; itemque à puncto $\zeta$ recta $\zeta \Omega$ qua fecet cycloidem in $\mathrm{v}$, circumferentiam in $n$, quibufque in punctis ductx parallelæ fecant circumferentiam F $\mathrm{H}, \mathrm{ab}$ iis tangentes deorfum ducantur ufquead proximam qux que parallelam, velur $\theta \Delta, \Gamma \Sigma$ : Quarum infima à puncto $\mathrm{H}$ ducta occurrat rectæ $\zeta \Omega$ in $x$. Similiter vero \& à punctis, in quibus dictæ paralielæ occurrunt cycloidi, ducantur totidem tangentes deorfum, velut $s \Lambda, T z, \& c$. quarum infima, tangens nempe à puncto $\mathrm{E}$ ducta, occurrat rect $\zeta \Omega$ in $\mathrm{R}$.

Quia igitur $\mathrm{P} \zeta æ q u a l i s$ eft $\mathrm{F}$ G alcitudini arcus B E, cui æqualis eft ex conftructione altitudo arcus N.M, erit \& P $\zeta x q u a l i s$ altitudini arcus $\mathrm{N}$ M. Eft autem recta $\mathrm{P}^{\prime} \mathrm{O}$ ex conftructione fuperior ter- 


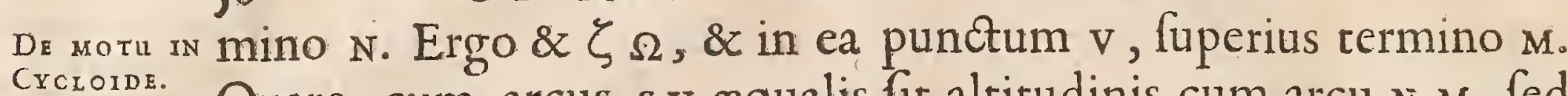
Quare, cum arcus $s \mathrm{v} æ$ qualis fit altitudinis cum arcu $N \mathrm{M}$, fed termino $s$ fublimiore quam $\mathrm{N}$, erit tempus per $\mathrm{s}, \mathrm{v}$ brevius tem*Prop.zz huj. pore per $\mathrm{N} \mathrm{M}^{*}$.

Atqui tempus per tangentem $s \Lambda$, cum celeritate æquabili ex B $s$, brevius eft tempore defcenfus accelerati per arcum $S \mathrm{~T}$, incipientis in $s$. Nam celeritas ex $B s$, qua tota $s \Lambda$ tranfmiffa poni*. Próp 8. huj. tur, xqualis eft celeritati.ex $\mathrm{S} \mathrm{T}^{*}$, qux motui per arcum $\mathrm{S} T$ in fine demum acquiritur; ipfaque s $\Lambda$ minor eft quam s $\mathrm{T}$. Similiter tempus per tangentem $\mathrm{T}$, cum celeritate æquabili ex B $\mathrm{T}$, brevius eft tempore defcenfus accelerati per arcum $\mathrm{T}$ Y poft $\mathrm{S} T$; quum celeritas ex B $T$, qua tota $T$. tranfmiffa ponitur, fir $x$ qualis celeritati ex $\mathrm{Y}$, qux in fine demum acquiritur morui dicto per arcum $T$ Y poft $s$ T; ipfaque $\mathrm{T} g$ minor fit arcu $T$ Y. Atque ita tempora omnia motuum æquabilium per tangentes cycloidis, cum celeritatibus per fingulas quantæ acquiruntur defcendendo ex в ufque ad punctum ipfarum contactus, breviora fimul erunt tempore defcenfus accelerati per arcum $s \mathrm{v}$. Eadem vero \& longiora effent, ut nunc oftendemus.

Eft enim tempus dictum per tangentem $s \Lambda$, cum celeritate æquabili ex B $s$, ad tempus per rectam o k cum celeritate æquabili dimidia ex $\mathrm{B} \Theta$, ficut tangens femicirculi $\theta \Delta$ ad rectam $\mathrm{P} Q^{*}$. fimiliterque tempus per tangentem $T \Xi$, cum celeritate $x$ quabili ex $B \mathrm{~T}$, eft ad tempus per rectam $\mathrm{K} \psi$ cum celeritate $x$ quabili dimidia ex $\mathrm{B} \Theta$, ut tangens $\Gamma \Sigma$ ad rectam $Q \Pi$. Atque ita deinceps fingula tempora per tangentes cycloidis, qux funt eadem fupra dictis, erunt ad tempora motus æquabilis per partes fibi refpondentes rectx o $\Omega$, cum celeritate dimidia ex $B \Theta$, ut tangentes circumferentix $\theta n$, iifdem parallelis inclufx, ad partes rectx $\mathrm{p} \zeta$ ipfis refpondentes. Vnde, ut in priori parte demonftrationis, concludetur omnes fimul rectas $P \mathrm{Q}, \mathrm{Q} \Pi$ \& $\mathrm{c}$. hoc eft, totam $\mathrm{P} \zeta$ effe ad. omnes fimul tangentes $\theta \Delta, \Gamma \Sigma, \& c$. ficut tempus quo percurritur tota $\mathrm{O} \Omega$, cum celeritate dimidia ex $\mathrm{B} \Theta$, adtempora omnia motuum quales diximus per tangentes cycloidis $\mathrm{o} \Lambda, \mathrm{T} \equiv, \& \mathrm{c}$. Quare \& convertendo, tempora omnia per tangentes cycloidis, eam rationem habebunt ad tempus dictum motus æquabilis per rectam o $\Omega$, five per B I, quam dictx tangentes omnes arcus $\theta$ a ad rectam $\mathrm{P} \zeta$ vel F G, ac proinde majorem quam arcus $L \mathrm{H}$ ad. rectam F G; eft enim arcus $\theta \mathrm{H}$, adeoque etiam omnino arcus $L F$, *prop io.huj, minor dictis tangentibus arcus $\theta_{n} *$. Sed tempus per N M pofui- 

mus ab initio ad idem tempus per $B$ I fe habere ut arcus $L$ H ad DE MOT́ IN rectam $\mathrm{E}$ G. Ergo rempus per $\mathrm{N} \mathrm{M}$, multoque magis tempus per $s v$, minus erit tempore per tangentes cycloidis. Quod eft abfurdum, cum hoc tempus, illo per arcum's $\mathrm{v}$, antea minus oftenfum fuerit. Patet igitur tempus per arcum cycloidis B E ad tempus per tangentem в I cum celeritate æquabili dimidia ex $\mathrm{B} \Theta$, non minorem rationem habere quam arcus $F \mathrm{H}$ ad rectam $\mathrm{F}$. Sed nec majorem habere oftenfum fuit. Ergo eandem habeat neceffe eft. quod erar demonftrandum.

\section{PROPOSITIO XXV.}

I

NCycloide cujus axis ad perpendiculum erectus eft, ver. tice deorfum pectante, tempora defcenfus quibus mobile, à quocunque in ea puncto dimiffum, ad punctum imum verticis pervenit, funt inter $\int e$ aqualia; habentque ad tempus cafus perpendicularis per totum axem cycloidis eam rationem, quam femicircumferentia circuli ad diametrum.

Efto cyclois A B C cujus vertex A deorfum fpectet, axis vero $A \mathrm{D}$ ad perpendiculum erectus fit, \& à puncto quovis in cycloide fumpto, velut B, defcendat mobile impetu naturali per arcum B A, five per fuperficiem ita inflexam. Dico tempus defcenfus hujus effe ad tempus cafus per axem D A, ficut femicircumferentia circuli ad diametrum. Quo demonftrato, etiam tempora defcenfus, per quoflibet cycloidis arcus ad A terminatos, inter fe æqualia effe conftabit.

Defcribatur fuper axe D A femicirculus, cujus circumferentiam fecet réta B F, bafi D c parallela, in E; junctâque $\mathrm{E} A$, ducatur ei parallela B G, quæ quidem cycloidem tanget in B. Eadem vero occurrat rectx horizontali per $A$ duct $x$ in $G$ : fitque etiam fuper F A defcriptus femicirculus F H A.

Eft igitur, per præcedentem, tempus defcenfus per arcum cycloidis B A, ad tempus motus æquabilis per rectam B G cum celeritate dimidia ex $\mathrm{B}$ G, ficur arcus femicirculi $F \mathrm{H}$ A ad rectam F A. Tempus vero dicti motus xquabilis per B G, æquatur tempori defcenfus naturaliter accelerati per eandem B G, five per E A, quæ ipfi parallela eft \& xqualis, hoc eft, tempori defcenfus accelerati per axem $D A^{*}$. Itaque tempus per arcum $B A$, erit * Prop.6.G2quoque ad tempus defcenfus per axem D A, ur femicirculi cir-Accel. cumferentía F H A ad diametrum F A. quod erat demonftrandum. 
DE MOYu Quod fi tota cycloidis cavitas perfecta ponatur, conftat mobiCrciorde. le, poftquam per arcum B A defcenderit, inde continuato motu. * Prop. 9 . huj. per alcerum ipfi æqualem arcum afcenfurum *, atque in eo tan* Prop.rishuj. tundem temporis atque defcendendo confumpturum *. Deirde

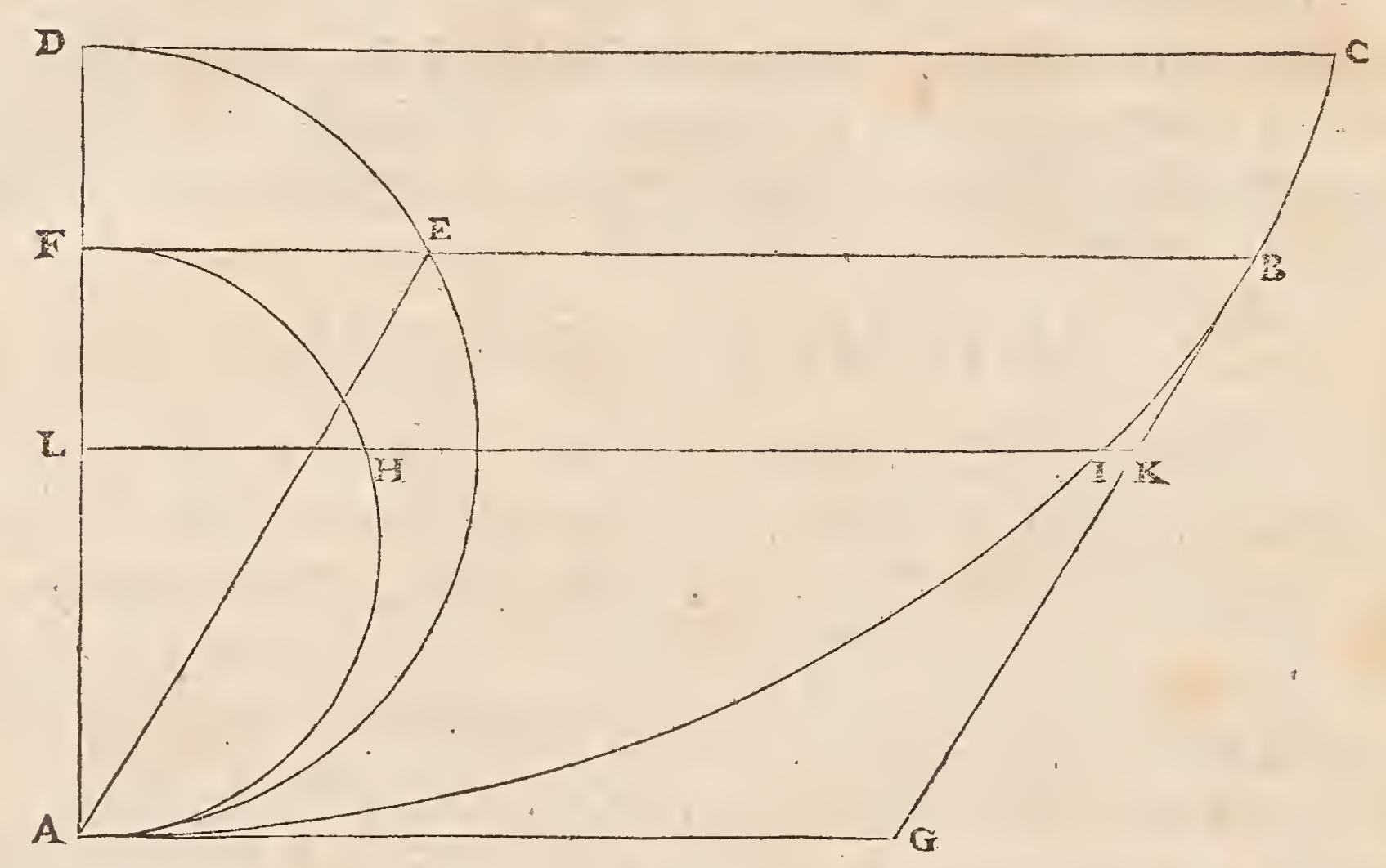

rurfus per A ad B perventurum, ac fingularum ejufmodi reciprocationum, in magnis parvifve cycloidis arcubus peractarum, tempora fore ad tempus cafus perpendicularis per axem $D$. f, ficut circumferentia circuli tota ad diametrum fuam.

\section{PROPOSITIO X X VI.}

\section{I} Ifdem pofitis, fi ducatur infuper recta borit ontalis H I que arcum B A fecet in $\mathrm{I}$, circumferentiam vero $\mathrm{F} \mathrm{H} \mathrm{A}$ in $\mathrm{H}$ : dico tempus per arcum B I, ad tempus per arcum I A poft B I, cam rationem babere quam arcus circumferentic $\mathrm{F} H$ ad $\mathrm{H} A$.

Óccurrat enim recta $\mathrm{H}$ I tangenti $\mathrm{B} \mathrm{G}$ in $\mathrm{K}$, axi $\mathrm{D}$ A in $\mathrm{L}$. Eft itaque tempus per arcum B $A$, ad tempus motus æquabilis per B G cum * Prop. 24 huj. celeritate dimidia ex B G, ficut arcus F H A ad rectam F A $*$. Tempus autem dicti motus æquabilis per B G, eft ad tempus motus æquabilis per в $\mathrm{K}$, cum eadem celeritate dimidia ex B G, ficut B G. ad B $\mathrm{K}$ longitudine, hoc eft, ficur $\mathrm{F}$ ad F L. Et rurfus tempus motus æquabilis, cum dicta celeritate, per $\mathrm{B} \mathrm{K}$, ad tempus per ar*Prop. 24.huj. cum B I, ficut F L ad arcum F H *. Igitur ex æquo erit tempus per $\operatorname{arcum}$ B A ad tempus per B I, ut arcus F H A $\mathrm{Ad}$ H. Et dividendo, \& convertendo, tempus per B I, ad tempus per I A poft $B$, ut arcus $F$ id ad $\mathrm{H}$ A. quod erat demonftrandum. 
59

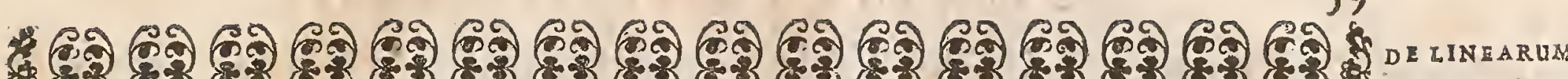

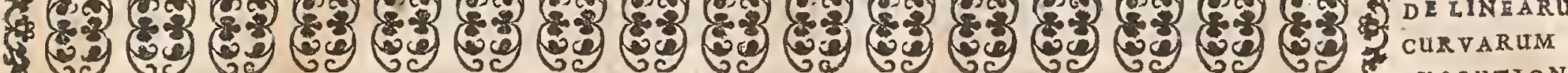

\section{HOROLOGII OSCILLATORII}

$$
P A R S \text { TERTIA. }
$$

De linearum curvarum erolutione $E$ dimenfione.

\section{E F I N I T I O N ES.}

I.

II INE $A$ in unam partem inflexa vocetur quam recte omnes tangentes ab eadem parte contingunt. Si autem portiones qualdam rectas lineas babuerit, ba ip se product pro tangentibus babentur.

\section{I.}

Cum autem dua bujusmodi lines ab eodem puncto egrediuntur, quarum convexitas unius obverfa fit ad cavitatem alterius, quales funt in figura adfcripta curva $\mathrm{A} B \mathrm{~B}, \mathrm{~A} D \mathrm{E}$, amba in eandern partem carva dicantur.

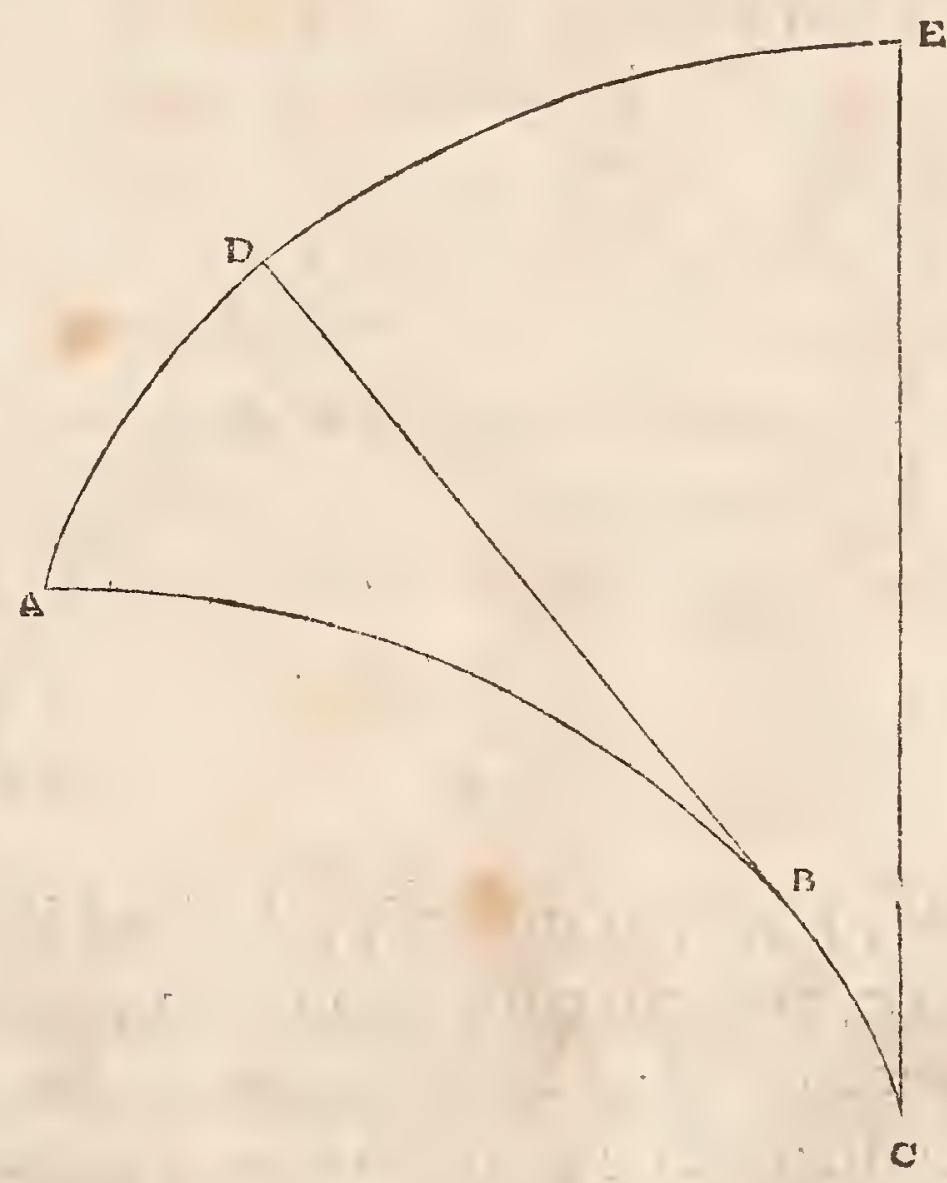

I I I.

Si lines, in unam partem cave, filum feu linea flexilis circumplicata intelligatur, EG manente una fili extremitate illi 
DIINARUM affixa, altera extremitas abducatur, it a ut pars ea que folu-

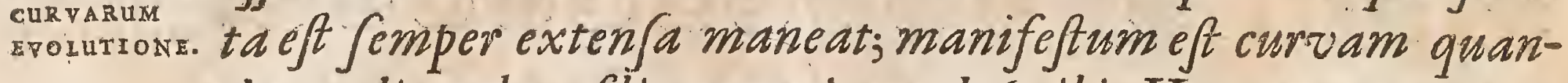
dam aliam hac fili extremitate dejcribi. Vocetur autem ea, Defcripta ex evolutione.

\section{I $V$}

Illa vero cui flum circumplicatum erat, dicatur Evoluta. In figura fuperiori, A B C eft evoluta, A D E de cripta ex evolutione $\mathrm{ABC}$, ut nempe cum extremitas fili ex $\mathrm{A}$ venit in $\mathrm{D}$, pars fli exten $\int a$ it $\mathrm{D}$ B rect a, reliqua parte $\mathrm{B} \mathrm{C}$ adbuc applicata curve A B C. Manifefum eft autem D B tangere evolutam in $\mathrm{B}$.

\section{PROPOSITIO I.}

Dicta omnis, qua evolutam tangit, occurret line ex ervolutione defcripte ad angulos rectos.

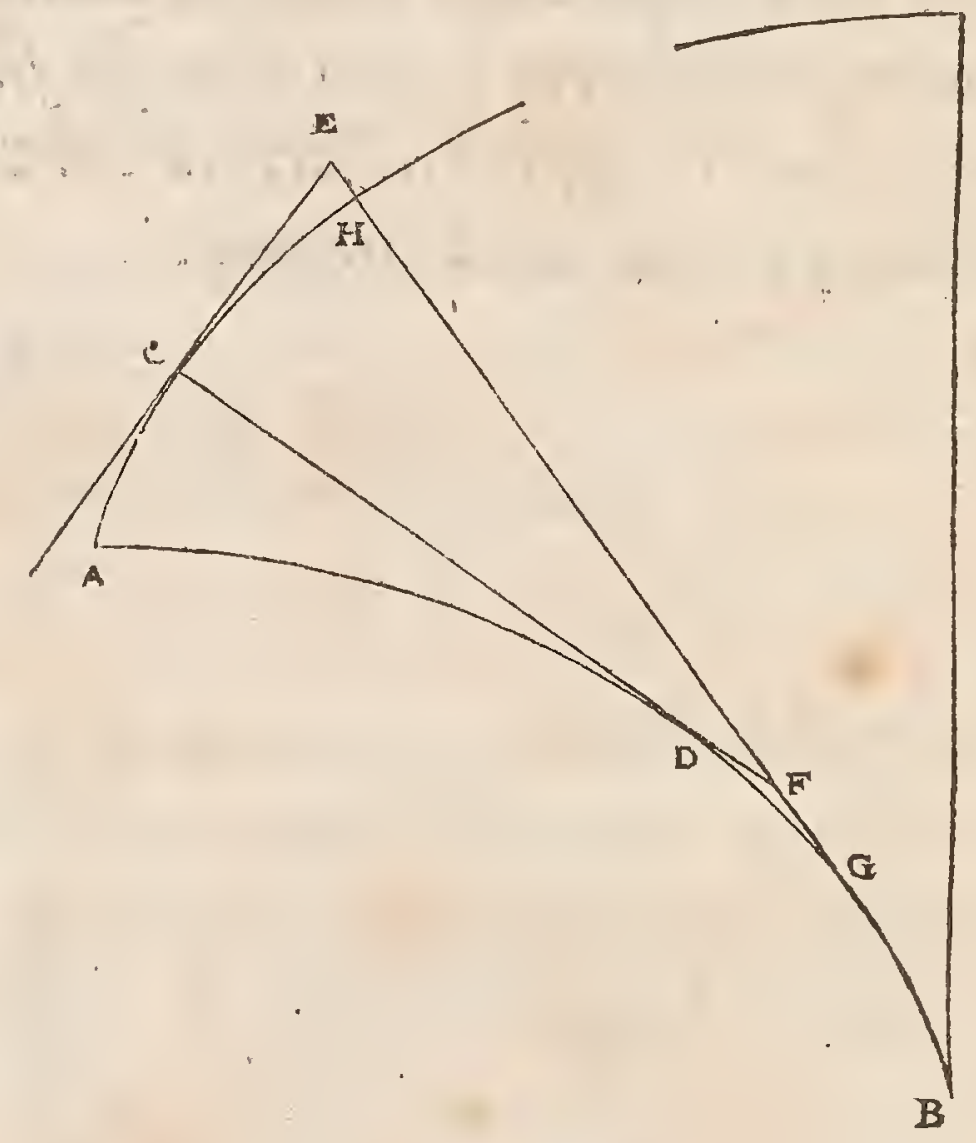

Sit A B evoluta, A H vero qux ex evolutione illius defcripta eft. Recta autem $\mathrm{F} D \mathrm{C}$, tangens curvam $\mathrm{AD}$ in $\mathrm{D}$, occurrat in C curvæ A C H. Dico ei occurrere ad angulos rectos: hoc eft, fi ducatur $C$ E recta perpendicularis $C D$, dico eam in $C$ tangere curvam $A$ C H. Quia enim D C tangit evolutam in D, apparet ipfam referre pofitionem fili tunc cum ejus extremitas pervenit in c. Quod fi igitur oftenderimus filum, in tota reliqua defcriptione curvæ $\mathrm{A} C \mathrm{H}$, nufquam pertingere ad rectam $\mathrm{C}$ E præterquam in c puncto, ma- 
nifeftum erit rectam $C$ E ibidem curvam $A C H$ contingere:

Sumatur punctum aliquod in a $\mathrm{C}$ præter $\mathrm{C}$, quod fit $\mathrm{H}$, fitque curvarum primo remotius à principio evolutionis a quam punctum $\mathrm{C}, \&$ intelligatur pars libera effe $H . G$, cum extremitate fua ad $H$ pervenit. Tangit ergo $\mathrm{H}$ G lineam $A B$ in $G$. Cumque interea dum defcribicur pars curvæ C H, evolutus fit arcus D G, occurret C D à parte $D$ producta ipfi $H G$, ut in F. Ponatur autem G H occurrere rectæ C E in E. Quia igitur duæ fimul D F, F G, majores funt quam $D G$, five curva ea fuerir five recta: fiet addendo utrinque rectam D C, ut rectx C E, F G fimul majores fint recta C D \& ipfa D G. Sed propter evolutionem, apparet utrifque fimul, rectæ C. D, \& linex D G, æquari rectam H G. Ergo duæ fimul C F, F G majores quoque erunt recta $H G$; \& ablata communi F G, erit C F major quam H F. Sed E major eft quam F C, quia angulus C trianguli F C E eft reetus. Ergo F E omnino major quam $\mathrm{F}$ H. Vnde apparet, $\mathrm{ab}$ hac quidem parte puncti $c$, fili extremitatem non pertingere ad rectam $\mathrm{C}$.

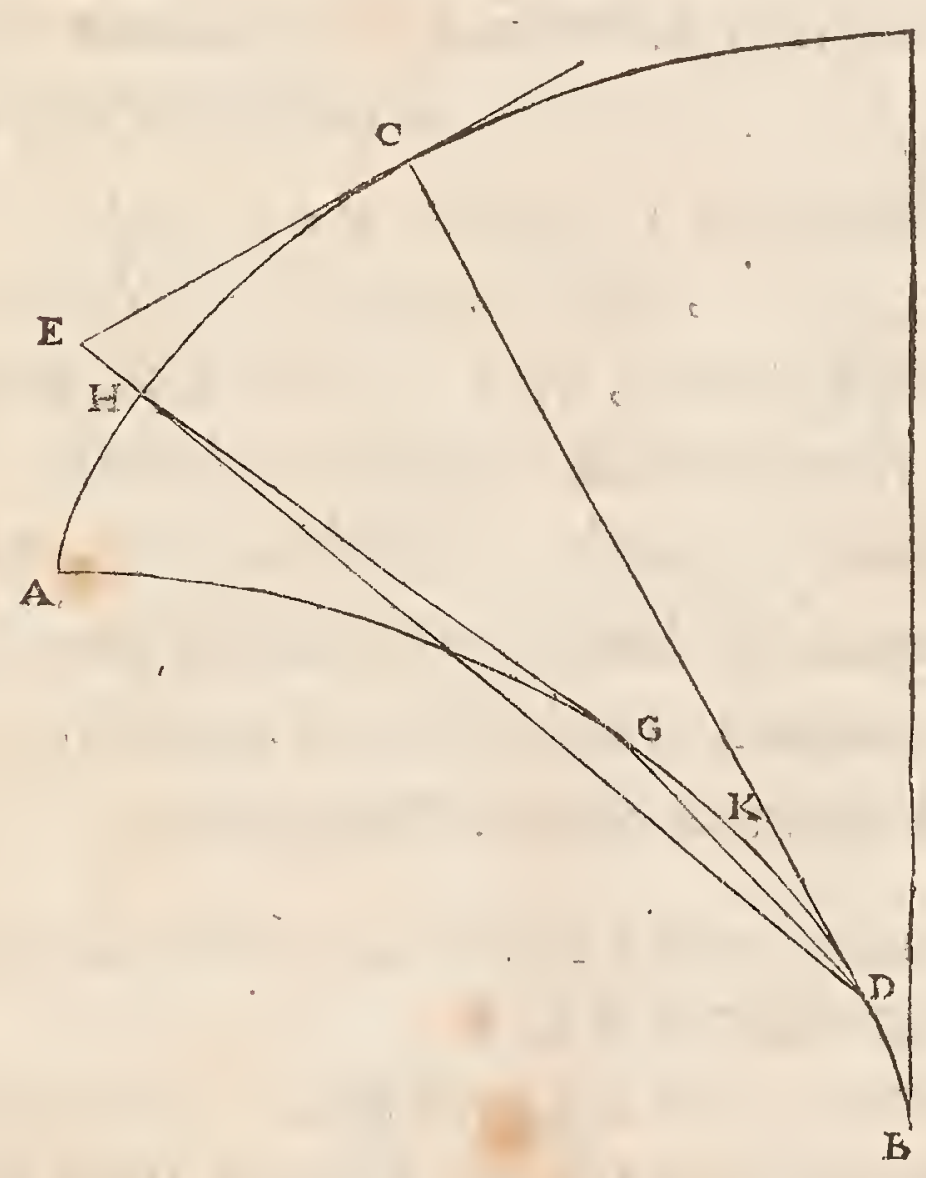

Sit jam punctum $\mathrm{H}$ propinquius principio evolutionis $\mathbb{A}$ quam punctum c. fitque fili pofitio $\mathrm{H}_{\mathrm{G}}$, tunc cum ejus extremitas effet in $\mathrm{H}, \&$ ducantur rectæ $\mathrm{D} G, \mathrm{D} \mathrm{H}$, quarum hæc occurrat rectæ $\mathrm{C} \mathrm{E}$ in $\mathrm{E}$. apparet autem $\mathrm{D} G$ rectam non poffe effe in directum ipfi $H G$, adeoque $H G D$ fore triangulum. Iam quia recta $D$ G vel minor eft quam D K G, vel eadem, fi nempe evolutx pars D G recta fit; addirâ utrique $G H$, erunt rectx $D G, G$ f fimul minores vel 
De LINEARUm $æ$ quales duabus iftis, fcilicet D K G \& G H, five his æquali rectæe. EYOLUTIONE. D C. Duabus autem rectis.D G, G H minor eft recta D H. Ergo hæC minor utique erit rectâ D C. Sed D E major eft quam D C, quia in triangulo D C E angulus C eft rectus. Ergo D H multo minor quam $D$ E. Situm eft ergo punctum $H$, hoc eft extremitas fili $G \mathrm{H}$, intra angulum D C E. Vnde apparet neque inter A \& C ufquam illam pertingere ad rectam $C$ E. Ergo $C$ E tangit curvam A C in $C$; ac proinde D C, cui C E ducta eft perpendicularis, occurrit curvæ ad angulos rectos. quod erat demoniftrandum.

Hinc etiam manifeftum eft curvam $\mathrm{A} H \mathrm{H}$ in partem unam inflexam effe, \& in eandem partem cavam ac ipfa A G B, cujus evolutione defcripta eft. Omnes enim tangentes linex $A \mathrm{H} C$, cadune extra fpatium D.G A H C: omnes vero tangentes lineæ A G D, intra dictum fpatium. unde liquet cavitatem A H C refpicere convexitatem $A G D$.

\section{PROPOSITIO II.}

\section{$\mathrm{O}$}

Mnis curva linea terminata, in unam partem cava, ut $\mathrm{A} B \mathrm{D}$, poteft in tot partes dividi, ut fisingulis partibus jubienfa recte ducantur, velut $\mathrm{A} \mathrm{B}, \mathrm{BC}, \mathrm{CD} ; \mathcal{E}^{2}$ aे fingulis item divifionis punctis, ip $\int a g u e$ curve extremitate recte ducantur curvam tangentes, ut A N, BO, C P, que occurrant iis que in proxime fequentibus divifionis punctis curre ad angulos rectos infiftunt, quales funt linea B N, CO, D P; ut inquam fubten fa quaque babeat ad fibi adjacentem curve perpendicularem, velut $\mathrm{A} B$ ad $\mathrm{B}$ N, $\mathrm{BC}$ ad C O, C D ad D P, rationem majorem quavis ratione propolita.

Sit enim data ratio linex E F ad $\mathrm{F}$ G, qux recto angulo ad $\mathrm{F}$ jungantur, \& ducatur recta G E H.

Intelligatur primo curva $A B D$ in partes tam exiguas fecta punctis $B, C$, ut tangentes quæ ad bina quæque inter fe proxima puncta curvam contingunt, occurrant fibi mutuo fecundum angulos qui finguli majores fint angulo $\mathrm{F} \mathrm{E} \mathrm{H}$; quales funt anguli $\mathrm{A} \mathrm{K} \mathrm{B}$, $B L C, C M D$. quod quidem fieri poffe evidentius eft quam ut demonftratione indigeat. Ductis jam fubtenfiS A B , B C, C D, \& ereCtis curvæ perpendicularibus B N, C.O, D P, quæ occurrant productis $A K, B L, C M$, in $N, O, P$ : dico rationes fingulas rectarum, $A B$ ad $B N, B C$ ad CO, CD ad D $P$, majores effe ratione $E$ E ad $F G$. 
HOROLOG. OSCILLATOR.

Quia enim angulus $\mathrm{A} \mathrm{K}$ B major eft angulo $\mathrm{H}$ E F, eritrefiduus il

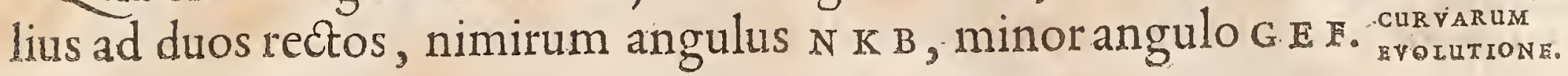

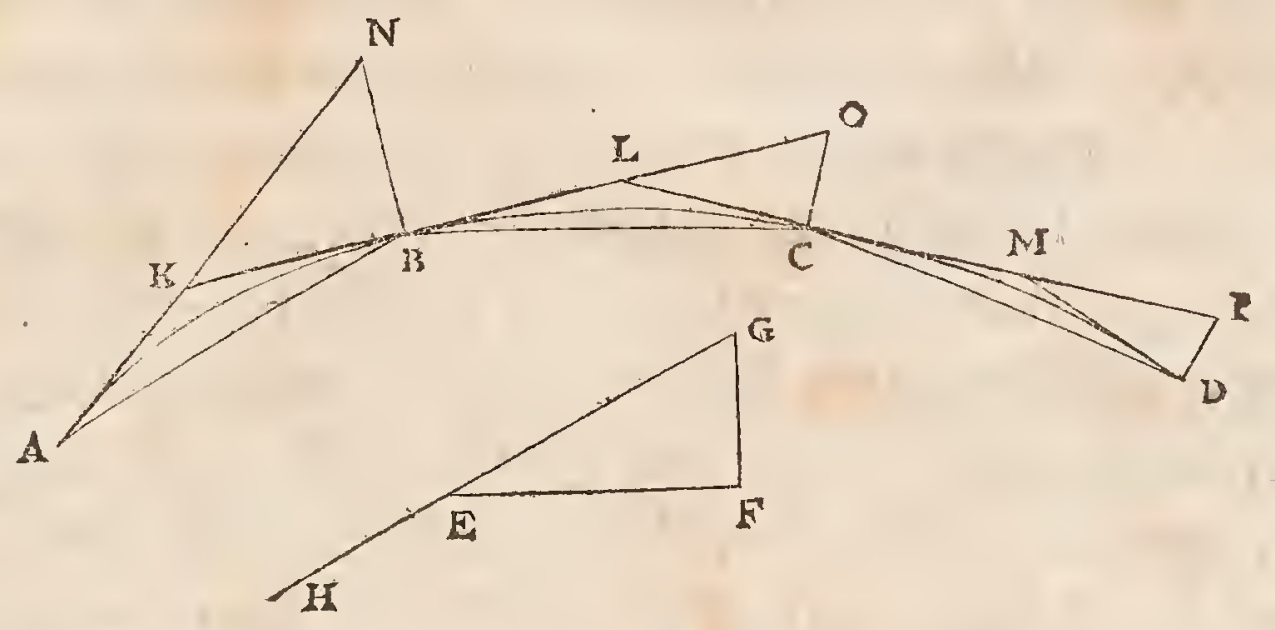

Angulus autem $B$ trianguli $\mathrm{K}$ B $N$ eft rectus, ficut $\&$ angulus $\mathrm{F}$ in triangulo E F G. Ergo major erit ratio $\mathrm{K} B$ ad $\mathrm{B} N$ quam $\mathrm{E} F$ ad $\mathrm{F}$ G: Sed $\mathrm{A} B$ major eft quam $\mathrm{K} B$, quoniam angulus $\mathrm{K}$ in triangulo $\mathrm{A} \mathrm{KB}$ eft obtufus, eft enim major angulo $\mathrm{H}$ E $\mathrm{F}$ qui eft obtufus ex confructione. Ergo ratio A B ad B $N$ major erit ratione $\mathrm{k}$ B ad B N; ac proinde omnino major ratione E F ad F G. Eodem modo \& ratio $B$ C ad C O, \& C D ad D P, major oftendetur ratione $E$ F ad $\mathrm{E}$ G: Itaque conftat propofitum.

\section{P R O P OS I T IO I I I.}

D

$V$ a curva in unam partem inflexa $\sigma^{2}$ in eafdem partes cava ex eodem puncto egredi nequeunt, ita ad fe invicem comparate, ut recta omnis que alteri earum ad angulos rectos occurrit, fimiliter occurrat EF reliqua.

Sint enim, fi fieri poteft, hujufmodilineæ curvæ A C E, A G K, communem terminum habentes $\mathrm{A}$, \& fumpto in exteriore illarum

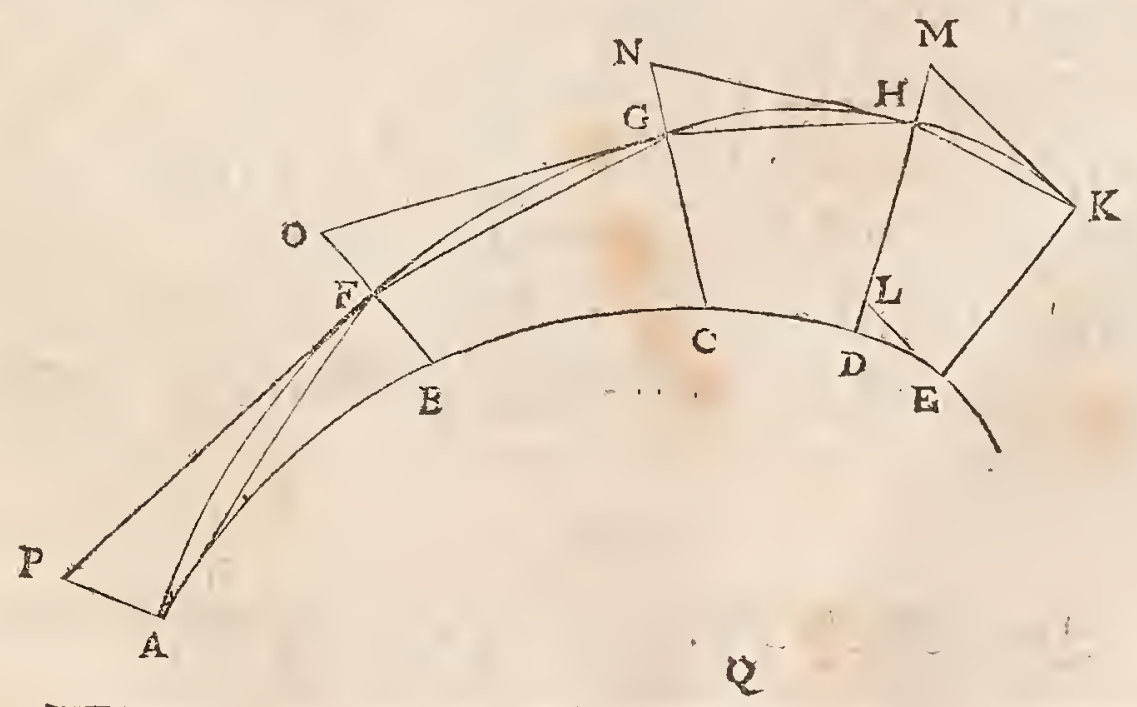

puncto quolibet $\mathrm{K}$, fit inde educta $\mathrm{K}$ в recta, curvæ $\mathrm{A} \mathrm{G}$ K occuxrens ad angulos rectos, ac proinde etiam curvæ $\dot{A} C \cdot E$. 
DanxNaArum Poteft jam recta quædam fumi major curva $\mathrm{K} G \mathrm{~A}$, quæ fit $\mathrm{Q}$. Di-

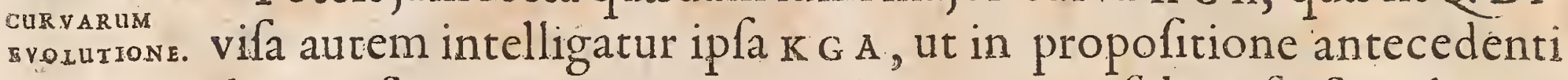
dictum fuit, in tot partes punctis $H \mathrm{G} \mathrm{F}$, ut fubtenfæ fingulæ $\mathrm{K} \mathrm{H}$, H G, G F, F A, ad perpendiculares curvæ fibi contiguas $\mathrm{H} \mathrm{M}, \mathrm{G}$, $\mathrm{E} O, A \mathrm{P}$ majorem rationem habeant quam linea $\mathrm{Q}$ ad rectam $\mathrm{K} \mathrm{E}$. Itaque \& omnes fimul dictæ fubtenfæ ad omnes dictas perpendiculares majorem habebunt rationem quam $\mathrm{Q}$ ad $\mathrm{K}$ E. Producantur autem perpendiculares eædem \& occurrant curvæ $A C E$ in $D$, $C, B$, nimirum ad angulos rectos ex hypothefi. Erit jam $\mathrm{K}$ E minor quam M D. Etenim, ducta E I ipfi $\mathrm{K}$ E perpendiculari, quoniam K E occurrit linex curvæ E C A ad angulos rectos, tanget E L curvam $A C E$, occurretque neceffario rectx $M D$ inter $D \& M$. Vnde cum $\mathrm{K}$ E fit breviffima omnium quæ cadunt inter parallelas $\mathrm{E} \mathrm{L}$, $K M$, crit ea minor quam $M I$, ac proinde minor quoque omnino quam $M$ D. Eodem modo \& $\mathrm{H}$ D minor oftendetur quam $N$ C, \& G C minor quam O B, \& F B minor quam $P$ A. Cum fit ergo $P A$ major quam $F B$, erunt dux fimul $P A$, o $F$ majores quam o B. Item quum o B fit major quam $G \mathrm{C}$, erunt dux fimul o $B, N G$, majores quam N C. Sed duæ P A, O F majores erant quam o B. Itaque tres fimul PA, OF, NG omnino majores erunt quam N C. Rurfus, quia $\mathrm{N}_{\mathrm{C}}$ major quam $\mathrm{H}$ D, erunt duæ fimul $\mathrm{N} C, \mathrm{MH}_{\mathrm{H}}$ majores quam $\mathrm{M} D$. Vnde, fi loco N C fumantur tres hæ ipfa majores P A, O F, N G, erunt omnino hæ quatuor $\mathrm{I} A, \mathrm{O}, \mathrm{F}, \mathrm{N} \mathrm{G}, \mathrm{M}$ H majores quam $\mathrm{M} \mathrm{D}$ : ac proinde exdem quoque omnino majores recta $\mathrm{K} E$, quia ipfa $M D$ major erat quam $\mathrm{K}$ E. Diximus aurem fubrenfas omnes A F, F G, $\mathbb{G} \mathrm{H}, \mathrm{H} \mathrm{K}$ majorem rationem habere ad omnes perpendiculares $\mathrm{P}$, O F, N G, M H, quam linea $\mathrm{Qad} \mathrm{K}$. Ergo cum dictis perpendicularibus minor etiam fit $\mathrm{K} \mathrm{E}$, habebunt dictx fubtenfx ad $\mathrm{K} \mathrm{E}$ omnino majorem rationem quam $\mathrm{Q} a d \mathrm{~K} \mathrm{E}$. Ergo fubtenf $x$ fimul fumptæ majores erunt reota Q. Hæc autem ipsâ curvâA $G \mathrm{~K}$ major fumpta fuit. Ergo fubtenfx A F, F G, G K, H K fimul majores erunt curva A G K cujus partibus fubtenduntur; quod eft abfurdum, cum fingulæ fuis arcubus fint minores. Non igitur poterunt effe duæ curvæ linex quæ quemadmodum dictum fuit fefe habeant. quod erat demonftrandum.

\section{PROPOSITIOIV.}

\section{S I ab eodem puncto duc lines exeant in partem unam in- $\checkmark$ flexa, $\xi^{2}$ in eandem partem cave, ita vero mutuo com-



ì puncto communi coepta, defcribetur.

Sunto lineæ A B C, A D E, in partem unam inflexæ, \& quarum utraque in eafdem partes cava exiftat, habeantque communem terminum a punctum. Omnes autem rectx tangentes lineam $A B C$, velut $B D, C E$, occurrant lineæ $A D E$ ad angulos rectos. Dico evolutione ipfius $\mathrm{A} B \mathrm{C}$, à termino $\mathrm{A}$ inçepta, defcribi $\mathrm{A} D \mathrm{E}$.

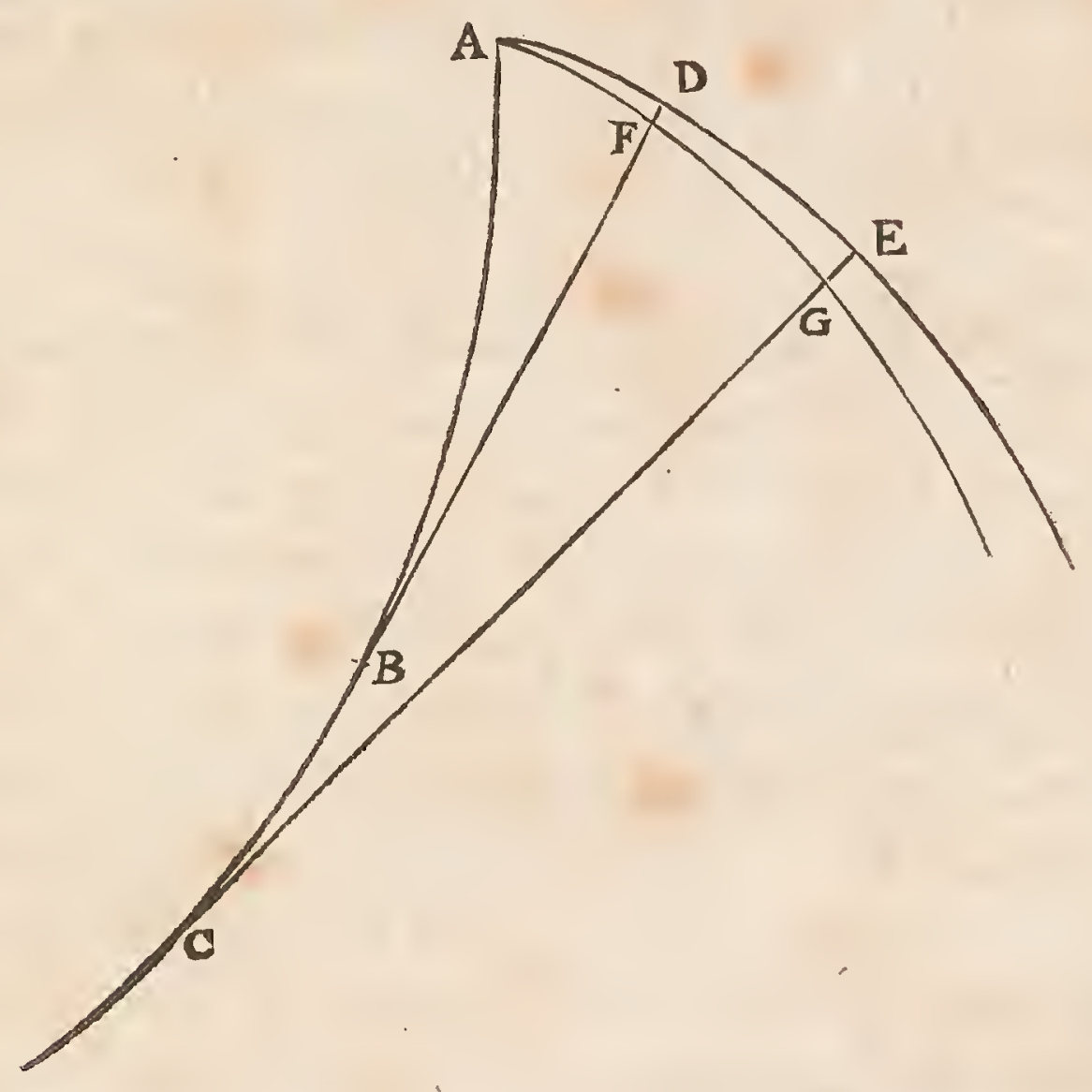

Si enim fieri poteft, defcribatur dicta evolutione alia quxdam curva A F G. Ergo linex rectæ quælibet, evolutam A B C tangences, ut B D, C E, occurrent ipfi A F G ad angulos rectos *, puta in F * Brop. T. haj. \& G. Sed eædem tangentes etiam ad rectos angulos occurrere ponuntur lineæ A D E. Sunt igitur lineæ curvæ A D.F, A F G, eodem puncto $\mathbb{A}$ terminatx, inque partem unam flexx, \& ambæin eandem partem cavx, quippe utraque in eandem atque ipfa $A B C$; nam de linea A D E conftat ex hypothefl, de A F G vero ex propofitione prima hujus; \& omnes quæ uni earum occurrunt ad angulos rectos, etiam alteri fimiliter occurrunt. quod quidem fieri non. poffe antea oftenfum eft*. Quare conftat ipfam A D E defcriptum * Prop. 3, huj. iri evolutione lineæ A B C. quod erat demonftrandum. 
I I Cycloidem recta linea in vertice contingat, fuper qua, $\checkmark$ tanguam bafi, alia cyclois priori fimilis EG aqualis conftituatur, initium fumens à puncto dicti verticis; recta qualibet inferiorem cycloidem tangens, occurret fuperioris portioni, fibi fuperpofite, ad angulos rectos.

Tangat cycloidem $\mathrm{A}$ В $\mathrm{C}$ in vertice $\mathrm{A}$ recta $\mathrm{A} G$, fuper qua, tanquam bafi, fimilis alia cyclois conftituta fit A E F, cujus vertex $F$. Cycloidem autem A B C tangat recta B $\mathrm{K}$ in B. Dico eam productam occurrere cycloidi A E F ad angulos rectos,

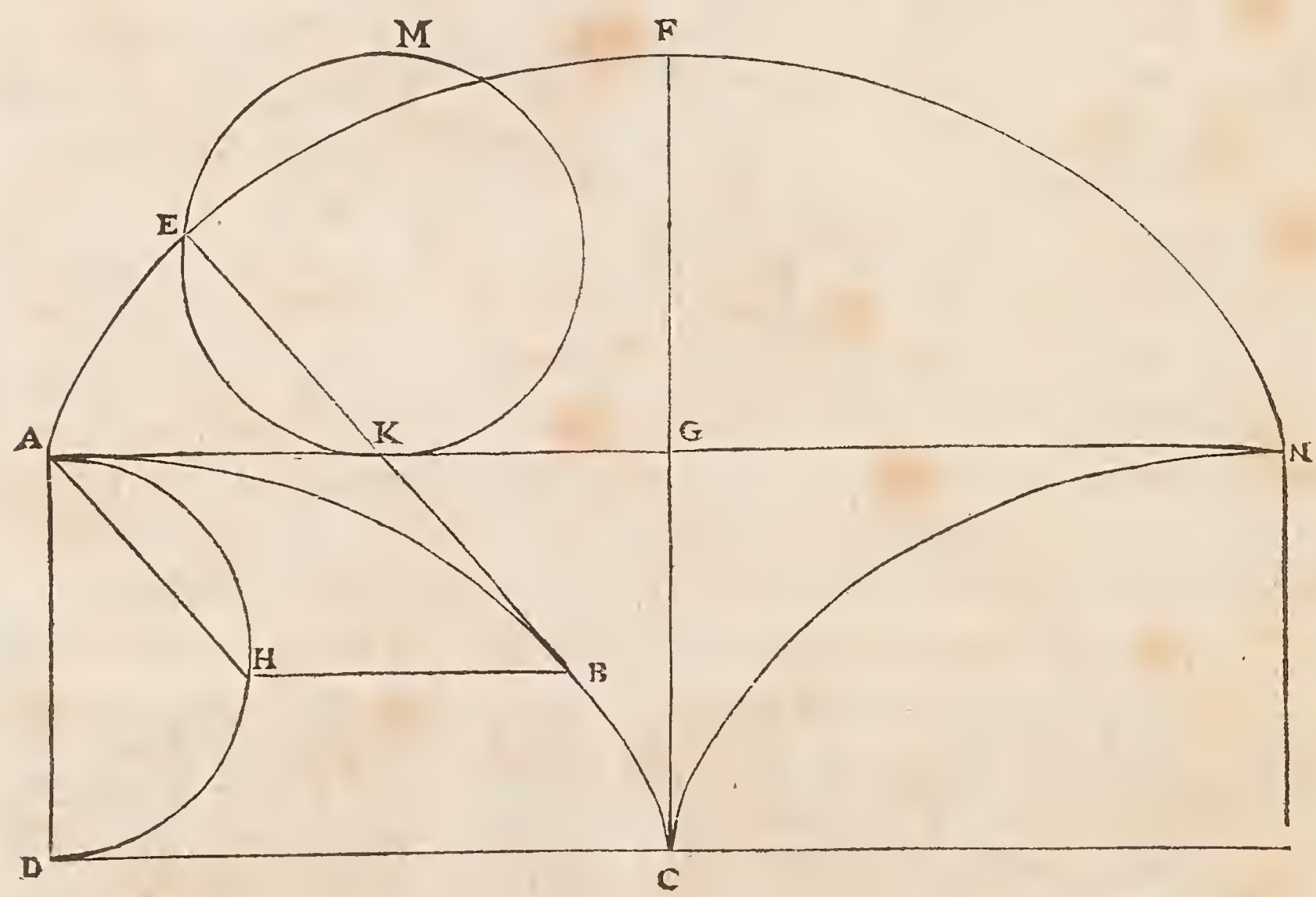

Defcribatur enim circa A D, axem cycloidis A B C, circulus genitor $A \mathrm{H} D$, cui occurrat $\mathrm{B}$ H, bafi parallela, in $\mathrm{H}$, \& jungatur $\mathrm{H} A$. Quia ergo $B$ K tangit cycloidem in $B$, conftat eam parallelam effe * Propof. rs. rectæ $\mathrm{HA}$ *. Itaque $\mathrm{A} \mathrm{H}$ B K parallelogrammum eft, ac proinde $\mathrm{A} \mathrm{K}$ partis 2. * Propof. I æqualis $\mathrm{H}$ в, hoc eft, arcui $\mathrm{A} \mathrm{H}^{*}$. Sit porro jam defcriptus circulus KM , genitori circulo, hoc eft ipfi $\mathrm{A} H \mathrm{D}$, xqualis, qui tangat bafin $A \mathrm{G}$ in $\mathrm{K}$, rectam vero $\mathrm{B} \mathrm{K}$ productam fecet in puncto $\mathrm{E}$. Quia ergo ipfi A $\mathrm{H}$ parallela eft $\mathrm{B} \mathrm{K} \mathrm{E}$, ac proinde angulus $\mathrm{E} \mathrm{K}$ A $æ$ qualis $\mathrm{KA} H$, manifeftum eft $\mathrm{B} \mathrm{K}$ productam abfindere à circulo $\mathrm{K} \mathrm{M}$ arcum xqualem ei quem à circulo $\mathrm{A} H \mathrm{D}$ abfcindit recta $\mathrm{A} \mathrm{H}$. Itaque arcus. $\mathrm{K} \mathrm{E} æ q_{\text {qualis }}$ eft arcui $\mathrm{A} \mathrm{H}$, hoc eft rectx $\mathrm{H} \mathrm{B}$, hoc eft rect $\mathrm{K}$. . Hinc 
vero fequitur, ex cycloidis proprietace, cum circulus genitor $M K_{D E}$ LINEARUM tangebat regulam in $\mathrm{K}$, punctum defcribens fuiffe in $\mathrm{E}$. Itaque curvarum recta $\mathrm{K} \mathrm{E}$ occurric cycloidi in $\mathrm{E}$ ad angulos rectos*. Eft autem $\mathrm{K} \mathrm{E}$ * Propof, is. ipfa в K producta. Ergo patet productam B K occurrere cycloidi ad angulos rectos. quod erat demonftrandum.

\section{PROPOSITIO VI.}

Amicycloidis evolutione, à vertice capta, alia femicy. $\checkmark$ clois defcribitur evolute aqualis $\sigma$ fimilis, cujus bafis eft in ea recta que cycloidem evolutam in vertice contingit.

Sit femicyclois A B C, cui fuperimpofita fit alia fimilis A EF, quemadmodum in propofitione præcedenti. Dico, fi linea flexilis, circa femicycloidem A B C applicata, evolvatur, incipiendo $a b_{A}$, eam defcribere extremitare lua ipfam femicycloidem $A E F$. Quia enim ex puncto A egrediuntur femicycloides A B C, A E F, in unam partem inflexæ, \& ambæ in eandem cavæ, ac præterea ita comparatæ, ut omnes tangentes femicycloidis A B C occurrant femicycloidi $\mathrm{A} \mathrm{E} F$ ad angulos rectos, fequitur hanc evolutione illius, à termino A incepta, defcribi* quod erat demonftrandum. * propor. 4*

Et apparet, fi dimidiam cycloidem, ipfi A B C gemellam, contrario fitu $a b$ altera parte linex $\mathrm{C}$ G difponamus, velut $\mathrm{C} \mathrm{N}$, ejus evolutione, vel etiam dum filum, jam extenfum in C F, circa eam replicatur, alteram femicycloidem $\mathrm{F} N$ fili extremitate defcriptum iri, qux fimul cum priore A E F integram conftituat.

Atque ex his, \& propofitione 25 de defcenfu gravium, manifeftum jam eft quod fupra in Conftructione Horologii de æquabili penduli motu dictum fuit. Patet enim perpendiculum, inter laminas binas, fecundum femicycloidem inflexas, fufpenfum agitarumque, motu fuo cycloidis arcum defcribere, ac proinde xqualibus temporibus quaflibet ejus reciprocationes abfolvi. Non refert enim utrum in fuperficie, fecundum cycloidem curvata, mobile feratur, an filo alligatum lineam ipfam.in aëre percurrat, cum urrobique eandem libertatem, eandemque in om. nibus curva punctis inclinationem ad motum habeat.

\section{PR O POS I T IO VII.}

(1) quad linea fui axis, fove diametri circuli genitoris, 
Repetita enim figura præcedenti: cum poft totam femicycloiBYOLUTIONE. $\operatorname{dem}$ A B C evolutam, filum occupet rectam $C F$, qux dupla eft A D , propterea quod axes cycloidum A B C, A E F lune xquales; apparet lemicycloidem ipfam A B C, filo fibi circum applicito æqualem, duplam effe fui axis A D, ac totam proinde cycloidem. axis fui quadruplam.

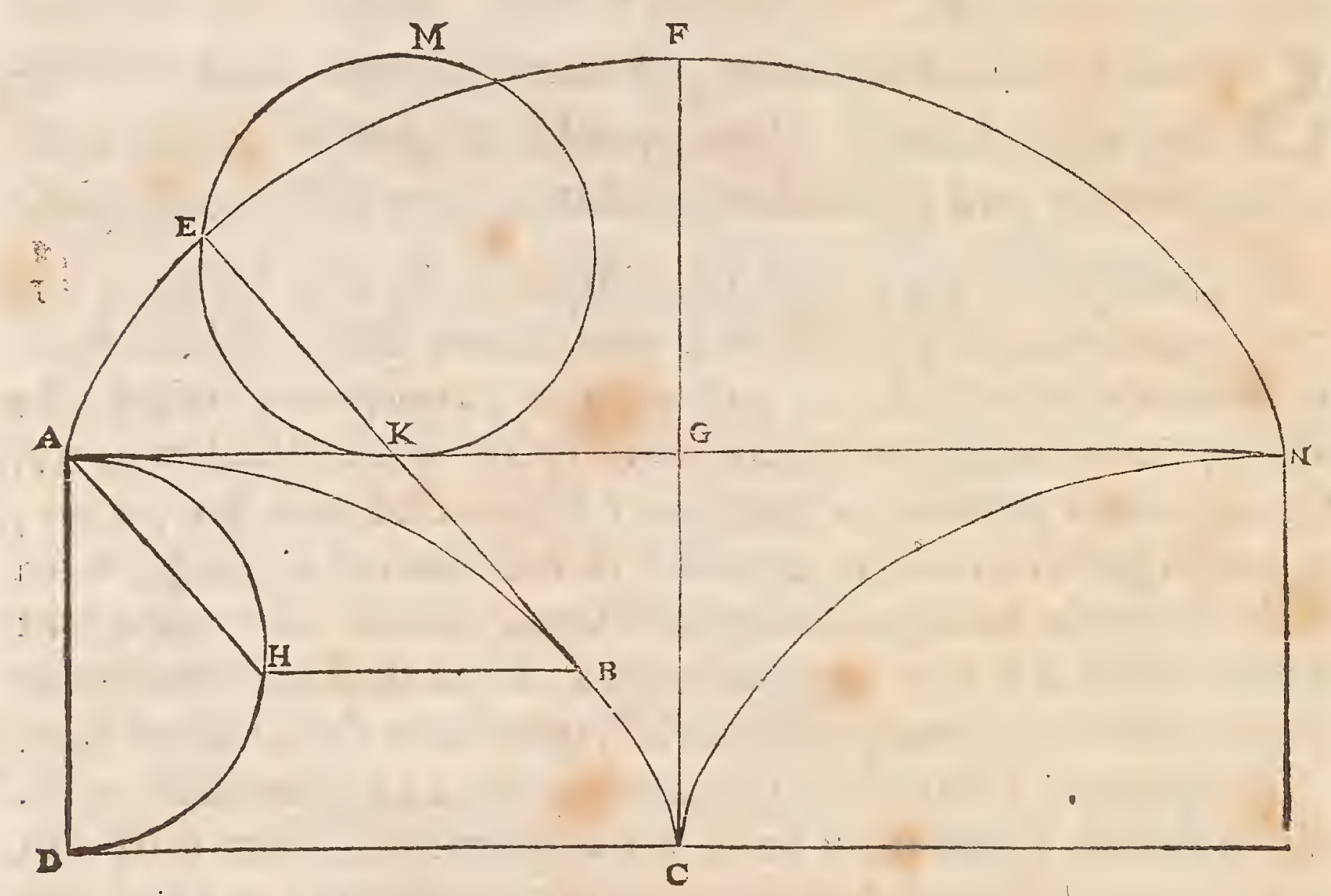

A pparet etiam tangentem в $\mathrm{E}$, quæ refert partem fili extenfam; antea curvæ parti в A applicatam, huic ipfi longitudine æquari. Eft autem B $\mathrm{E}$ dupla ipfius B $\mathrm{K}$, five $\mathrm{A} \mathrm{H}$, quoniam in propofitione quinta oftenfum eft $\mathrm{K}$ E ipfi $\mathrm{A}$ H xqualem effe. Itaque pars $c y-$ cloidis $A$ B rect $A_{A}$, five $B \mathrm{~K}$, dupla erit : exiftente nimirum B $\mathbf{H}$ parallela bafi cycloidis: idque ubicumque in ea punctum $B$ fumptum fuerit.

Hanc cycloidis dimenfionem primus invenit, via tamen longe alia, eximius geometra Chriftophorus Wren Anglus, eamque deinde eleganti demonftratione confirmavit, qua edita eft in libro de cycloide viri clariffimi Ioannis Wallifij. De eadem vero linea, alia quoque multa extant pulcherrima inventa noftri temporis mathematicorum, quibus præcipuè occafionem præbuere problemata quædam à Blafio Pafchalio Gallo propofita, qui in his ftudiis præcellebat. Is cum fua, tum aliorum inventa recenfens, primum omnium Merfennum lineam hanc in rerum natura advertiffe ait. Primum Robervallium tangentes ejus defini- 
viffe, ac plana \& folida dimenfum effe. Item centra gravitatis de LINEARuas tum plani, tum partium ejus inveniffe. Primum Wrennium cur- curvarum $v \mathfrak{x}$ cycloidis æqualem rectam dediffe. Me quoque primum reperiffe dimenfionem abfolutam portionis cycloidis, quæ rectâ, bafi parallelâ, abfcinditur per punctum axis, quod quarta parte ejus à vertice abeft, quæ nimirum portio æquatur dimidio hexagono æquilatero, intra circulurn genitorem defcripto. Seipfum denique folidorum ac femifolidorum, tam circa bafin quàm circa axem, centra gravitatis definiviffe, itemque partium eorum. Lineæ etiam ipfius ( fed hæc poft acceptam à Wrennio dimenfionem) centrum gravitatis inveniffe, \& dimenfionem fuperficierum convexarum, quibus folida ifta corumque partes comprehenduntur; earumque fuperficierum centra gravitatis. Ac denique dimenfionem curvarum cujufvis cycloidis, tam protractx quam contractx: hoc eft earum qux defcribuncur à puncto intra vel extra circumferentiam circuli genitoris fumpto. Et horum quidem demonftrationes à Pafchalio funt editæ. A quibus fuas quoque, de eadem linea, fubtiliffimas meditationes expofuir Cl. Wallifius, atque eadem illa omnia fuo marte fe reperiffe, ac problemata à Pafchalio propofita folviffe contendit. Quod idem. $\&$ doctiflimus Loverafibi vindicat. Quantum vero unicuique debeatur, ex fcriptis eorum eruditi dijudicent. Nos propterea tanrum præcedentia retulimus, quod filentio prætereunda non videbantur egregia adeo inventa, quibus factum eft ut, ex lineis omnibus, nulla nunc melius aut penitiùs quam cyclois cognita fit. Methodum vero noftram, qua in hac metienda ufi fumus, in aliis quoque experiri libuit, de quibus porro nunc agemus.

\section{PROPOSI TIO VIII.}

\section{Vjus lines evolutione parabola defcribatur often - dere.}

Sic paraboloides A B, cujus axis A D; vertex A; proprietas autem ifta, ut ordinatim ad axem applicata $B D$, cubus abfciffe ad verticem $D$ A xquetur folido; bafin habenti quadratum $D$ B, altitudinem vero $x$ qualem line $x$ cuidam dat $M$; qux quidem curva pridem geometris nota fuit; \& pouatur axi $D \mathrm{E}$ juncta in directum $A E$, qux habeat $\frac{8}{27}$ ipfius $M$. Iam fi filum continuum circa E A B applicetur, idque ab E evolvi incipiar, dico defcri- 
70 CHR IS T I A I HV GENII

DEINARAR ptam ex evolutione effe parabolam EF, cujus axis $E A G$, vertex CURVARUM $\mathrm{E}$, latus rectum $x$ quale duplæ $\mathrm{E} \mathrm{A}$.

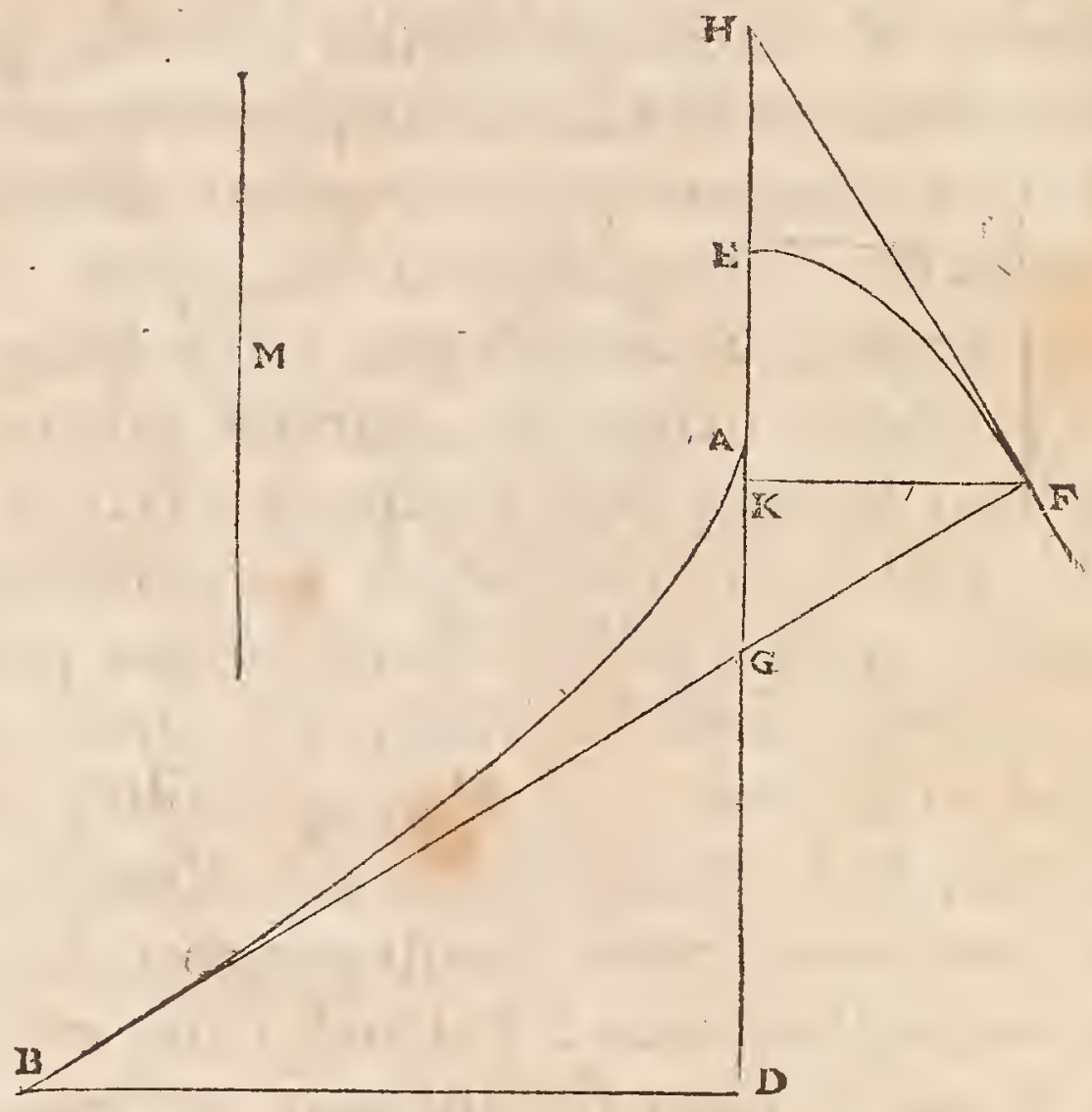

Sumpto enim in curva $A$ B puncto quolibet $B$, ducatur qux in ipfo tangat curvam recta $B$ G, occurrens axi E $A$ in $G$. \& exG ducatur porro G F, quæ ad rectos angulos occurrat parabolæ E $\mathrm{F}$ in F; \& fit ipfi G F perpendicularis $\mathrm{F}$ H, qux parabolam in $\mathrm{F}$ continget; $\&$ denique $\mathrm{F} \mathrm{K}$ ordinatim ad axem $\mathrm{E} \mathrm{G}$ applicetur.

Eft igitur K $\mathrm{G}$ æqualis dimidio lateri recto, hoc eft, ipfi E A; ac proinde, additâ vel ablatâ utrimque $\mathrm{A} \mathrm{K}$, erit $\mathrm{E} \mathrm{K}$ æqualis $\mathrm{A} \mathrm{G}$. Eft autem $A$ G triens ipfius $A D$, quoniam B $G$ tangit paraboloidem in $B$ : illud enim ex natura curvæ hujus facile demonftrari poteft. Ergo $\& \mathrm{E} \mathrm{K} x$ qualis eft trienti $\mathrm{A} D: \& \mathrm{~K} \mathrm{H}$, quæ ex natura parabolæ dupla eft $\mathrm{K} \mathrm{E}, \mathfrak{x q u b i t u r}$ duabus tertiis A $\mathrm{D}$. Itaque cubus ex $\mathrm{K} \mathrm{H}$ xqualis eft $\frac{8}{27}$ cubi ex $A$ D, hoc eft, folido bafin habenti quadratum $\mathrm{D} B$, altitudinem vero $x$ qualem $\frac{3}{{ }_{2}} \mathrm{M}$, hoc eft, ipfi A E. Quamobrem ut quadratum $\mathrm{D} B$ ad quadratum $\mathrm{K} H$, ita erit $\mathrm{K} H$ longitudine ad $\mathrm{A} E$, hoc eft ad $\mathrm{K}$ G. Erat autem $\mathrm{K}$ H æqualis $\frac{2}{3} \mathrm{~A} \mathrm{D}$, hoc eft ipfi $G$ D. Ergo ut quadratum B $D$ ad quadratum $D$ Gita eft $\mathrm{H} \mathrm{K}$ ad $\mathrm{K} \mathrm{G}$. Vt autem $\mathrm{H} \mathrm{K}$ ad $\mathrm{K} \mathrm{G}$, ita eft quadratum $\mathrm{F} \mathrm{K}$ ad quadratum $\mathrm{K}$ G. Ergo ficut quadratum B $\mathrm{D}$ ad quadratum $\mathrm{D} G$, ita quadratum $\mathrm{F} \mathrm{K}$ ad quadratum $\mathrm{K}$ G. Et proinde ficut $\mathrm{B} \mathrm{D}$ ad $\mathrm{D} G$ longitudine, ita $\mathrm{F}$ x ad $\mathrm{K}$ G. Vhide fequitur B G $\mathrm{F}$ effe lineam rectam. Sed G F occurrit parabolæ E F ad angulos rectos. Ergo apparet B G, tangentem paraboloidis, productam occurrere eidem parabolæad 
HOROLO G. OSCILLATOR. angulos rectos. Idque fimiliter de quavis illius tangente demonAtrabitur. Ergo conftat ex evolutione linex E A B, ä termino E in- CURVARUM cepra, defcribi parabolam E F ${ }^{*}$. quod erat demonftrandum, ${ }^{*}$ rop. 4. huj.

\section{P R O P O I T I O I X.}

D Ectam lineam invenire aqualem date portioni curva 1 paraboloidis, ejus nempe in qua quadrata ordinatim applicatarum ad axem, funt inter $\int e$ ficut cubi abfcifjarum ad verticem.

Quomodo hoc fiat ex prop. præcedenti manifeftum eft. Parabola vero $\mathrm{E} F$ ad conftructionem non requiritur, qux fic peragetur. Data quavis parte paraboloidis hujus A B, cui rectam æqualem invenire oporteat, ducatur B G tangens in puncto B, quæ occurrat axi $A$ G in $G$. Tanget autem $f_{1} A$ G fuerit tertia pars $A D$, inter

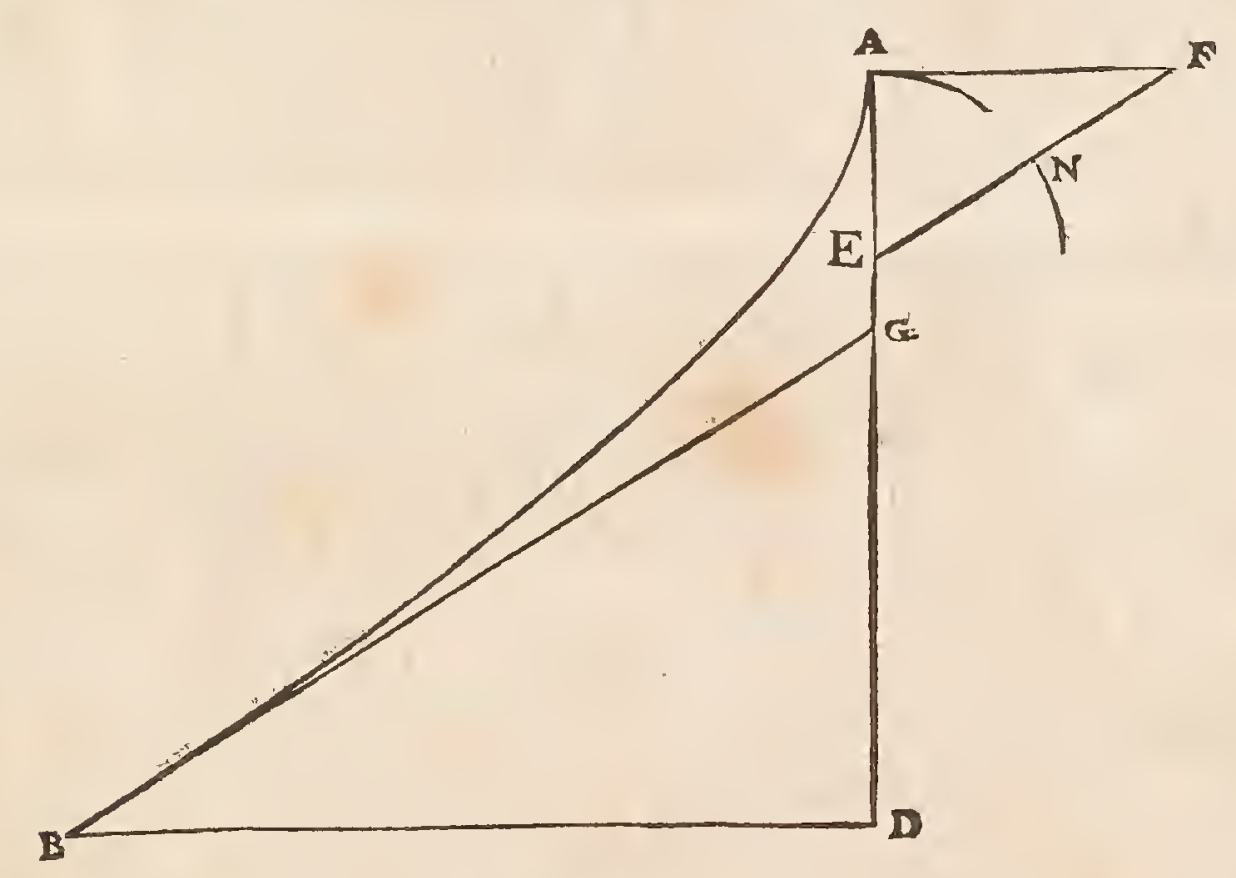

verticem \& ordinatim applicatam B D interceptæ. Porro fumpta A E æquali $\frac{8}{27}$ linex $\mathrm{M}$, quæ latus rectum eft paraboloidis A B, ducatur E $\mathrm{F}$ parallela B G, occurratque linex A F, qux parallela eft $B$, in $F$. Iam fiadrectam $B$ G addatur $N F$, exceffus rect $E$ F fupra $E A$, habebitur recta æqualis curvæ $\mathrm{A}$ B. Cujus demonftratio ex ante dictis facile perfpicitur.

Semper ergo curva $A$ B tantum fuperat tangentem $B$ G, quantum recta $\mathrm{E}$ F rectam $\mathrm{E}$ A.

Rurfus autem hic in lineam incidimus, cujus longitudinem alii jam ante dimenfi funt. Illam nempe quam anno 1659 Ioh. Heuratius Harlemenfis rectæ æqualem oftendit, cujus demonftratio poft commentarios Ioh. Schotenii in Cartefii Geometriam, eodem anno editam, adjecta eft. Et ille quidem omnium primus curvam lineam, ex earum numero quarum puncta quxlibet geo. 
DE INEARUM metricè definiuntur, ad hanc menfuram reduxit, cum fub ident

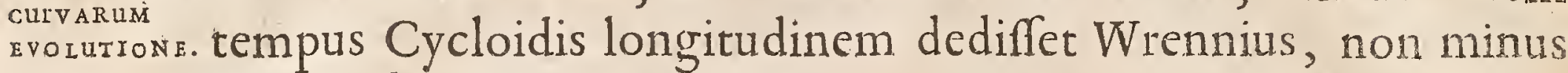
ingeniofo epicheremate.

Scio equidem, ab edito Heuratii invento, Docifimum Wallifium Wilhelmo Nelio, nobili apud fuos juveni, idem attribuere voluiffe, in libro de Ciffoide. Sed mihi, quxillic adfert perpendenti, videtur non multum quidem $a b$ invento illo Nelium $a b$. fuiffe, neque tamen plane id adfecutum effe. Nam neque ex de-monftratione ejus, quam Wallifius affert, apparet illum fatis perfpexiffe quænam foret curva illa, cujus, fi conftrueretur, menfu. ram datam fore videbat. Et credibile eft, fi fciviffet ex earum numero effe qux jampridem Geometris cognitx fuerant, vel ipfum, vel alios ejus nomine, tam nobile inventum Geometris maturius impertituros fuiffe, quod, fi quod aliud, merebatur ut Archimedeum illud eivnn exclamarent. Sane ejufdem inventi, tanquam à fe profecti, etiam Fermatius, Tholofanus fenator ac Geometra peritiflimus, demonftrationes confcripfit, quæ anno 1660 excufx funt; fed illæ fero utique.

Cum vero in his fimus, etiam de nobis dicere licear, quid ad. promovendum tam eximium inventum contulerimus: fiquidem $\&$ Heuratio ut eo perveniret occafionem præbuimus, \& dimenfionem curvæ parabolicx ex hyperbolæ data quadratura, quæ Hcuratiani inventi pars eft, ante ipfum atque omnium primi reperimus. Etenim fub finem anni 1657 in hæc duo fimul incidimus, curvæ parabolicæ quam dixidimenfionem, \& fuperficiei conoidis parabolici in circulum reductionem. Cumque Schotenio, aliifque item amicorum, per literas indicaffemus, duo quædam non vulgaria circa parabolam inventa nobis fefe obtuliffe, corumque alterum effe conoidicæ fuperficiei extenfionem in circulum, ille litteras eas cum Heuratio, quo tum familiariter utebatur, communicavit. Huic vero, acutilfmi ingenii viro, non difficile fuit intelligere, conoidis iftius fuperficiei affinem effe dimenfronem ipfrus curvæ parabolicx. Qua utraque inventa, ulterius inde inveftigans, in alias iftas curvas paraboloides incidit, quibus rectæx æuales abfolute inveniuntur.

Ac de Conoidis quidem fuperficie in planum redacta, ne quis forte teftimonium defideret, pauca hæc adfcribere vifum eft ex literis viri clariffimi, atque inter præcipuos hodie Geometras cenfendi, Franc. Slufii, quibus eo ipfo anno mihi inventum illud, ac prolixius forte quam pro merito, gratulatus eft. In quibus literis 
24. Decemb. anni 1657. datis, ifta habentur. Dwo tantum addo, unum DE LINEARUM

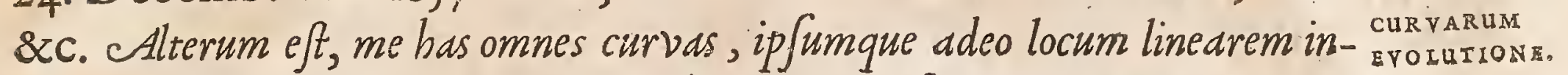
tegrum, nibilipene facere pre invento boc tuo, quo fuperficiei in conoide parabolico rationem ad circulum fue bajeos demonftrafti. Hanc pro circuli quadratura pulcherrimiam aimazaziv prafero libens iis omnibus, quas ex loco lineari nec paucas olim deduxi, ¿テ quas tecum, fi ita jufferis, data occafione communicabo.

Anno autem infequenti etiam fuperficies conoidum hyperbo. licorum \& fphrroidum reperi, quomodo ad circulos reduci poffent, conftructionefque eorum problematum, non addita tamen. demonftratione, Geometris quibufcum tunc litterarum commercium habebam, in Gallia Pafchalio aliifque, in Anglia Wallifio impertii, qui non multo poft fua quoque fuper his, una cum aliis multis fubtilibus inventis in lucem edidit, fecitque ut noftris demonftrationibus perficiendis fuperfederem. Quoniam vero non inelegantes vif $x$ funt conftuctiones noftrx, neque adhuc publice extant, placet hoc loco illas adfcribere.

\section{Conoidis parabolici fuperficiei curve circulum aqualem invenire.}

It datum conoides cujus fectio per axem parabola $\triangle$ в $\mathrm{C}$; axis $\checkmark$ ejus $B$ D, vertex $B$, diameter bafis $A C$, qui fit axi $B$ D ad an-

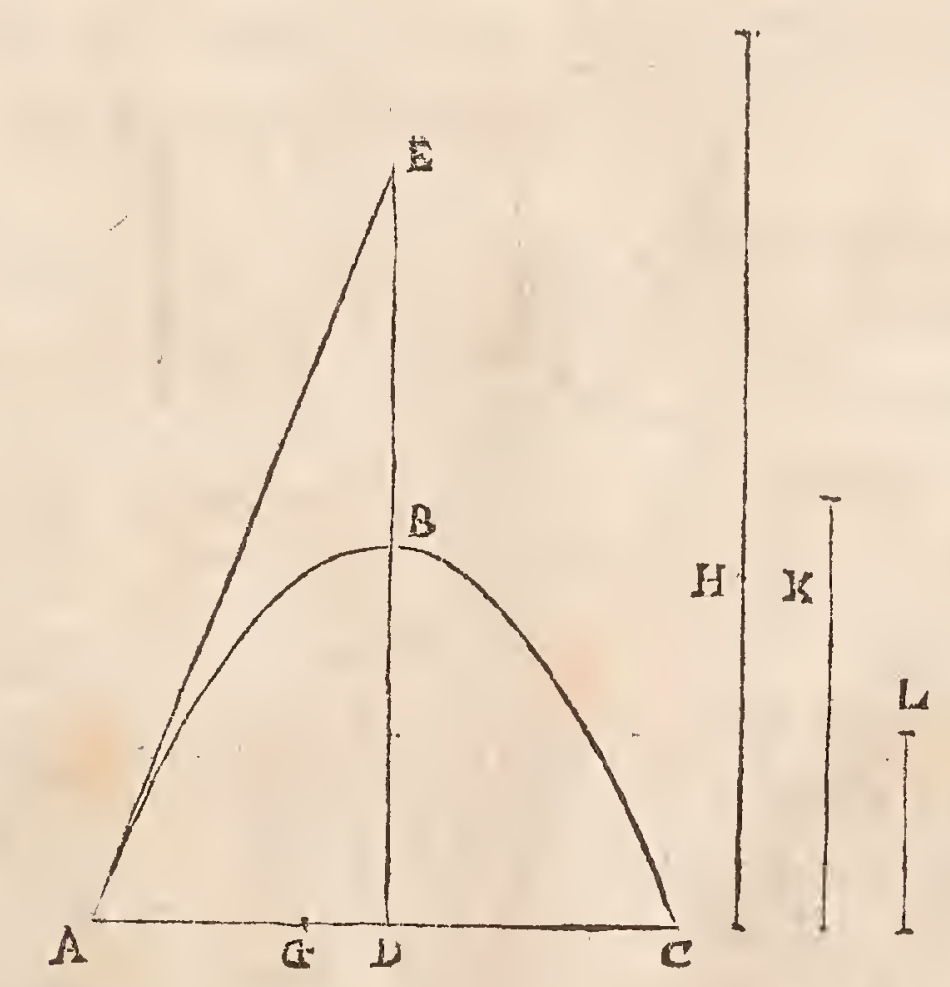

gulos rectos. Et oporteat fuperficiei portionis curvæ invenire circulum æqualem.

$\mathrm{K}$ 


\section{4}

\section{CHR I T I A I HVGEN II}

D IINEARU Producto axe à parte verticis, fumatur B E æqualis B D, \& junCURVARUM YOTUTIONE. gatur $E A$, qux parabolam $A B C$ in $A$ continget. Porro fecetur $A D$ in $G$, ut fit $A G$ ad $G D$ ficut $E A$ ad $A D$. Et utrifque fimul $A E$, D G æqualis ftatuatur recta $\mathrm{H}$. Item trienti bafis A C æqualis fit recta $\mathrm{L}$; \& inter $\mathrm{H} \& \mathrm{I}$ media proportionalis inveniatur $\mathrm{K}$. qua tanquam radio circulus defcribatur. Is æqualis erit fuperficiei curvæ conoidis $A$ B $C$. Hinc fequitur, $f_{1}$ fuerit $A E$ dupla $A D$, fuperficiem conoidis curvam ad circulum bafeos fore ut 14 ad 9. Si A E tripla A D, ut 13 ad 6. fi A E quadrupla A D, ut $1_{4}$ ad s. Atque ita femper fore ut numerus ad numerum, $f_{1}$ A E ad A D ejufmodi rationem habuerit.

\section{Spharoidis oblongi fuperficiei circulum aqualem invenire.}

E

Sto fphæroides oblongum cujus axis A B, centrum C, fectio peraxem ellipfis $A D B E$, cujus minor diameter $D E$.

Ponatur D F æqualis C B, feu ponatur F alter focorum ellipfeos A D B E, rectæque F D parallela ducatur B $G$, occurrens productx

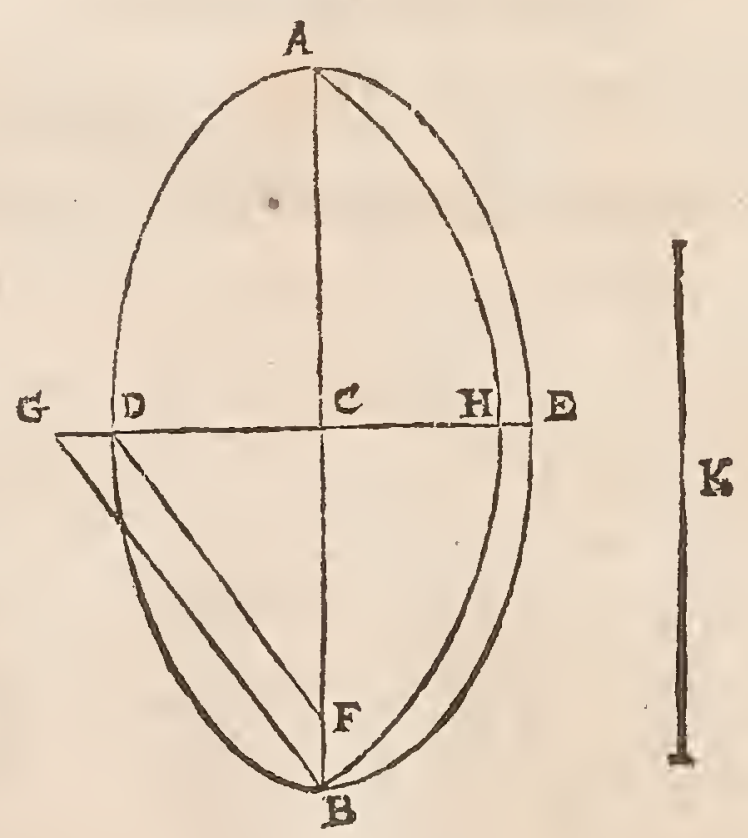

E $D$ in $G$. centroque $G$, radio $G B$, defcribatur fuper axe $A$ B arcus circumferentix $B$ H $A$. Interque femidiamerrum $C$ D \& rectam utrifque æqualem, arcui A H B \& diametro D E, media proportionalis fit recta $\mathrm{K}$. Erit hæc radius circuli qui fuperficiei fphæroidis A D B E æqualis fit. 
It fphroides latum cujus axis A B, centrum C, fectio per axem ellipfis A D B E.

Sit rurfus focorum alteruter $F$, divifâque bifariam $F \mathrm{C}$ in $\mathrm{G}$, inrelligatur parabola $A_{\text {G }}$ B qux bafin habeat axem $A B$, verticem

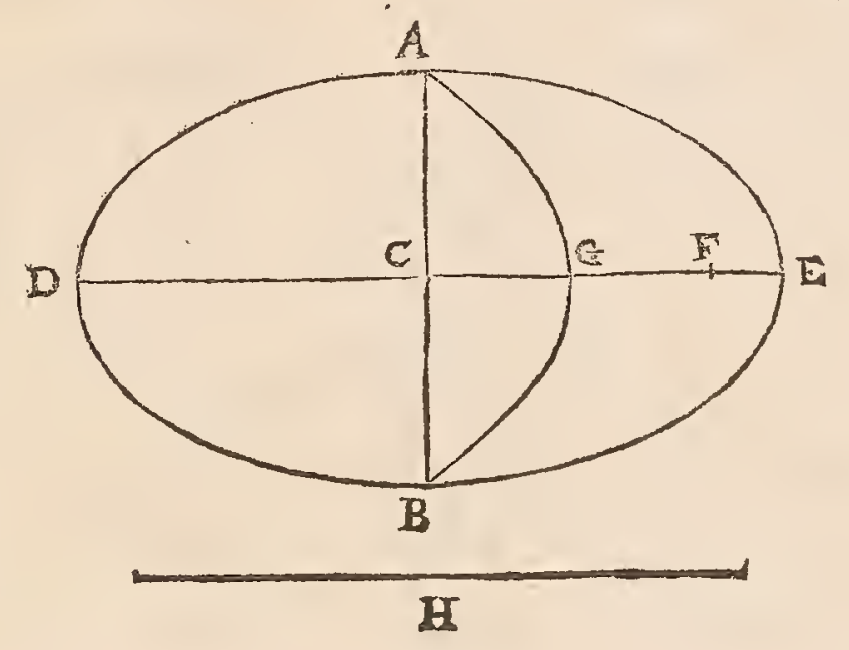

vero punctum G. Sitque inter diametrum D E, \& rectam curvæ parabolicæ A G B æqualem, media proportionalis linea $\mathrm{H}$. Erit hæc radius circuli qui fuperficiei fphæroidis propofiti æqualis fit.

\section{Conoidis byperbolici Juperficiei curva circulum aqualem invenire.}

$\mathrm{E}$ Sto conoides hyperbolicum cujus axis A $B$, fectio per axem hyperbola $C A D$, cujus latus tranfverfum $E A$, centrum $F$, latus rectum $A$ G.

Sumatur in axe recta A $H$, xqualis dimidio lateri recto A G. \& ut $\mathrm{H} F$ ad A $\mathrm{F}$ longitudine ita, fit A F ad $\mathrm{F}$ K potentiâ. Et intelligatur vertice $\mathrm{K}$ alia hyperbola defcripta $\mathrm{K} L \mathrm{M}$, codem axe \& centro $\mathrm{F}$ cum priore, quæque latera rectum \& tranverfum illi reciproce proportionalia habeat. Occurrat autem ipfi producta B $C$ in $M$, fitque A L parallela B C. Erit jam ficut fpatium A L M B, tribus rectis lineis \& curva hyperbolica comprehenfum, ad dimidium quadratum ex B C, ita fuperficies conoidis curva ad circulum bafeos fux, cujus diameter $\mathrm{C} D$. Vnde conftructio reliqua facile abfolverur, pofitâ hyperbolæ quadraturâ,

Quum igitur conoidis parabolici fuperficies ad circulum redigatur, æque ac fuperficies fphæræ, ex notis geometrix regulis; in fuperficie fphrroidis oblongi, ut idem fiat, ponendum eft arcus 
DE LINEARUM circumferentix longitudinem æquari poffe lineæ rectæ. Ad fphæroidis vero lati, itemque ad conoidis hyperbolici fuperficiem eadem ratione complanandam, hyperbolæ quadratura requiritur. Nam parabolicx linex longitudo, quam in fphroide hoc adhibuimus, pendet à quadratura hyperbolæ, ut mox oftendemus.

Verum, quod non indignum animadverfione videtur, invenimus abfque ulla hyperbolica quadraturæ fuppofitione, circulum æqualem conftrui fuperficiei utrique fimul, fphæroidis lati \& conoidis hyperbolici.

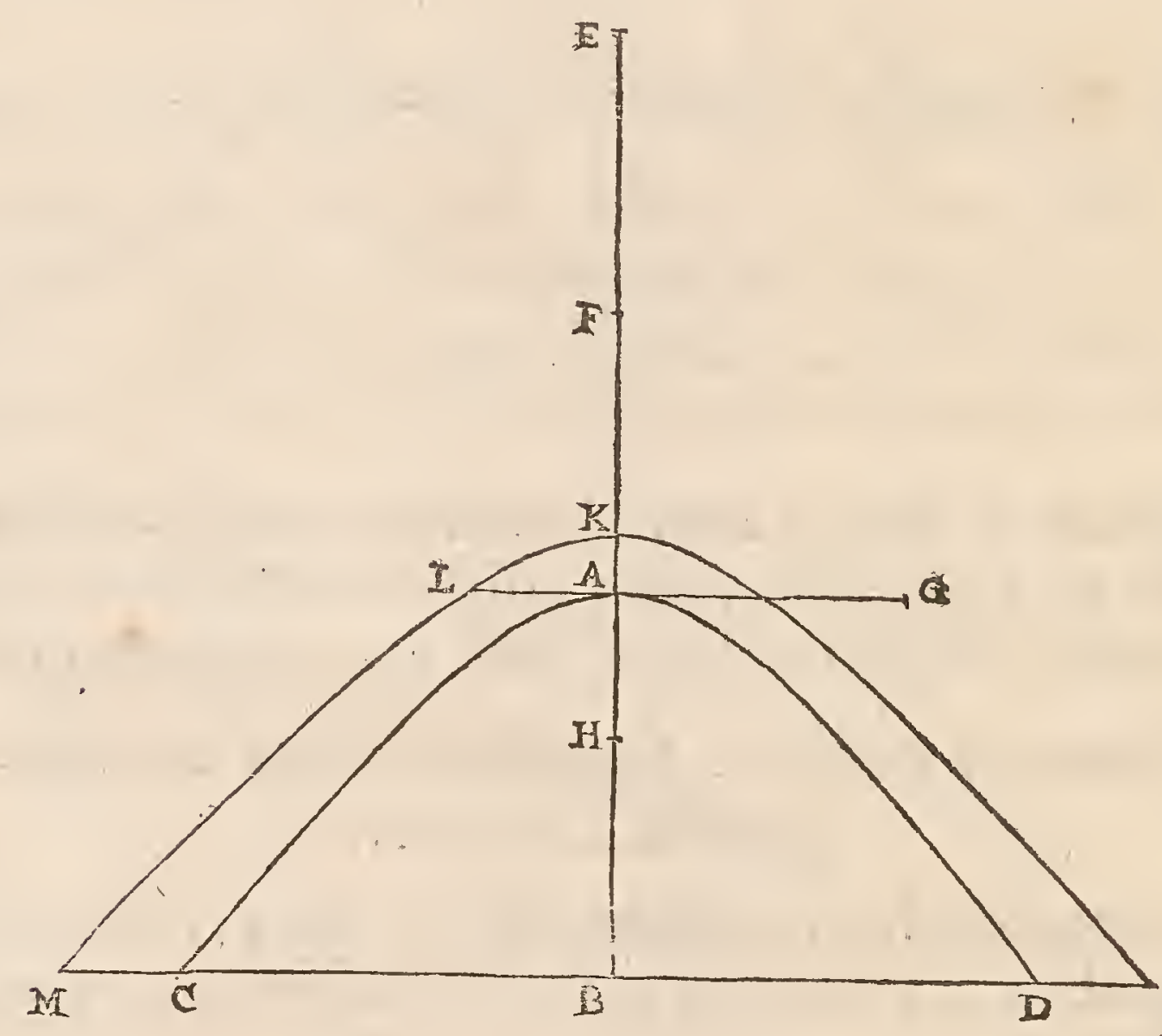

Dato enim fphæroide quovis lato, poffe inveniri conoides hyperbolicum, velcontra, dato conoide hyperbolico, poffe inveniri phæroides latum ejufmodi, ur utriufque fimul fuperficiei exhibeatur circulus æqualis. cujus exemplum in cafu uno cæereris frmpliciore fufficiet attuliffe.

Sit fphæroides latum cujus axis's $\mathrm{I}$, fectio per axem ellipfis $s \mathrm{x}$ I $\mathrm{K}$; cujus ellipfis centrum $\mathrm{O}$, axis major $\mathrm{T} \mathrm{K}$. ponatur autem ellipfis hæc ejufmodi, ut latus tranverfum $\mathrm{T}$ K habeat ad latus rectum eam rationem, quam linea fecundum extremam \& mediam rationem fecta, ad partem fui majorem.

Sumatur B C potentia dupla ad s o, item B A potentia dupla ad o K. \& fint hæ quatuor continue proportionales B C, B A, B F, 
B E, \& ponatur E $\mathrm{P}$ æqualis $\mathrm{E}$ A. Intelligatur jam conoides hy- De tiNeARUM perbolicum $\mathrm{O} F \mathrm{~N}$, cujus axis F. P; axi adjecta, five latus tranfverfum $\mathrm{F} B$; dimidium latus rectum æquale B $\mathrm{C}$.

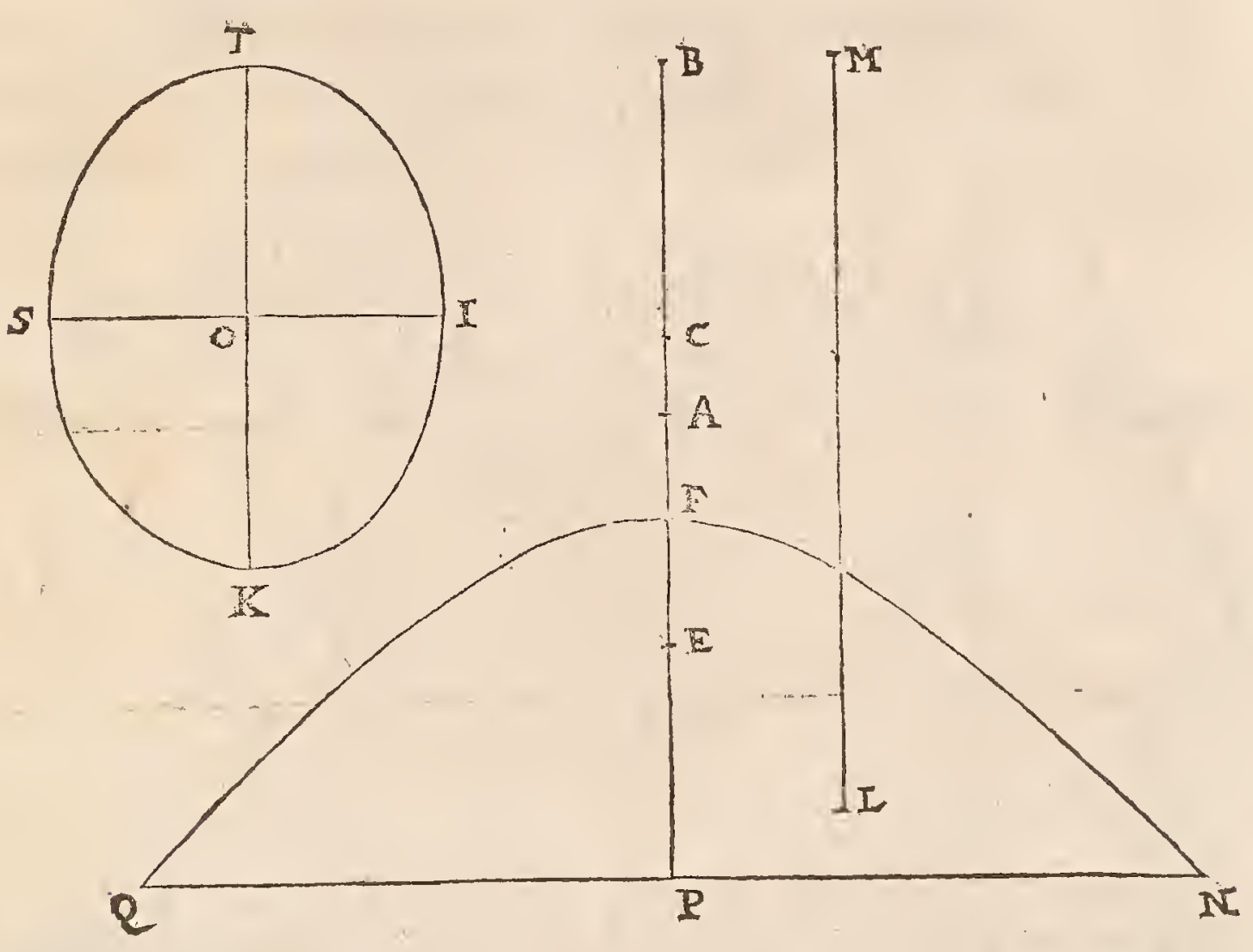

Hujus conoidis fuperficies curva, unà cum fuperficie fphæroi: dis $\mathrm{S} I$, æquabitur circulo cujus datus erit radius $\mathrm{M} L$, qui nempe poffit quadratum $\mathrm{x} \mathrm{K}$ cum duplo quadrato s I.

\section{Curve parabolice aqualem rectam lineam invenire.}

CIt parabolæ portio $A B C$, cujus axis $B$ K, bafis $A$ C axi ad an$\checkmark$ gulos rectos; \& oporteat curvæ A B $C$ rectam æqualem invenire.

Accipiatur bafi dimidix $\mathrm{A} \mathrm{K}$ æqualis recta I E, quæ producatur ad $\mathrm{H}$, ut fit $\mathrm{I} \mathrm{H} x$ qualis $\mathrm{A} G$, qux parabolam in puncto bafis $\mathrm{A}$ contingens, cum axe producto convenit in G. Sit jam portio hyperbolæ $D E F$, vertice E, centro I defcriptæ, cujufque diameter fit $\mathrm{E} H$; bafis vero $\mathrm{D} H \mathrm{~F}$ ordinatim ad diametrum applicata. Latus rectum pro lubitu fumi poreft. Quod fi jam fuper bafi D F intelligatur parallelogrammum conftiturum D P Q F, quod portioni D E $\mathrm{F} x q u a l e$ fit; ejus latus $\mathrm{P} Q$ ita fecabit diametrum hyperbolæ in R, ut R I fit æqualis curvæ parabolicæ A B, cujus dupla eft A B C. A pparet igitur hinc quomodo à quadratura hyperbolæ pendeat curvæ parabolic menfura, \& illa ab hac viciflim. 

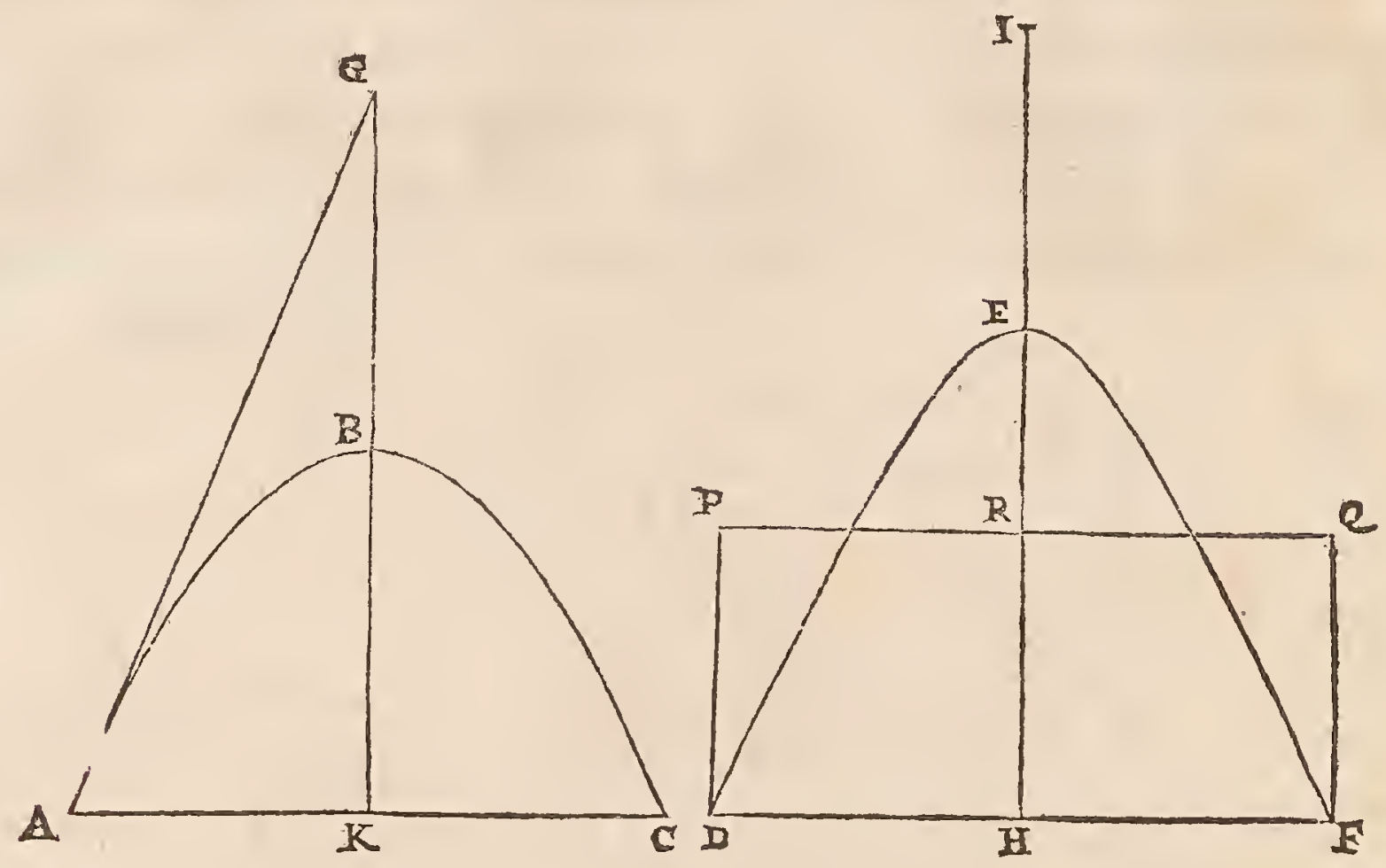

cipiunt, logarithmorum admirabili invento. Cum per hos hyperbolæ quadratura, ut olim invenimus, numeris quam proxime explicetur. Eft autem regula hujufmodi.

Sic D A B portio hyperbolæ, cujus afymproti $c s, c v$, ductis $D E, B V$ parallelis afymptoto $S$ C.

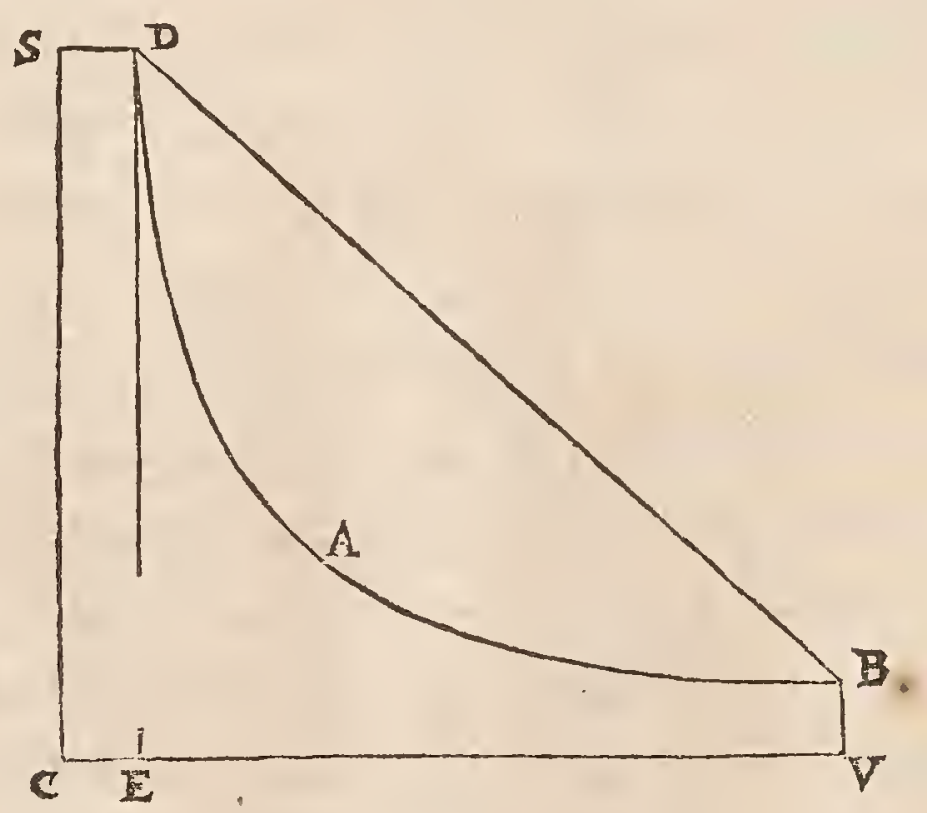

Accipiatur differentia logarithmorum qui conveniunt numeris, eandem inter fe rationem habentibus quam rect $\mathrm{D} E, \mathrm{~B} V$; ejufque differentiæ quæratur logarithmus. Cui addatur logarith- 
mus hic (qui femper eft idem) O, 36221, j6887. Summa erit loga- DE UINEARUX rithmus numeri qui fpatium D E V B A D defignabit, tribus rectis \& curva D.A B comprehenf, in parribus qualium parallelogrammum DCeftro0000, 00000 . Vnde porro facile quoque habebitur area portionis D A B.

Sir ex. gr. proportio D E ad B v ea qux 36 ad 5 .

$\mathrm{Ab} \quad \mathrm{r}, 55630,25008, \log \mathrm{r}^{\circ} .36$. auferatur $0,69897,00043 \cdot \log r^{\text {us }} \cdot 5$.

Erit 0,85733 , 14969. differ. logarorum.

Et $9,93314,92856$. logar ${ }^{\text {us }}$. differentix.

Cui addatur $0,36221,56887$. logar ${ }^{\text {us }}$. femper addendus.

Fit $\quad 10,29536,49743 . \operatorname{logar}{ }^{\text {us }}$. Sparii DEV B A D.

Habebic hujus logarithmi numerus in characteres, quum characteriftica fit io. Quxratur itaque primo numerus proxime minor, conveniens invento logarichmo, qui numerus eft 19740 . Deinde ex differentia logarithmi ejufdem, \& proxime eum in tabula fequentis, reliqui characteres eliciantur 81026, fcribendi polt priores, ut fiat 197408,10260 , addito ad finem zero, ut efficiatur numerus characterum ir. Eft ergo area fpatii D E V B A D proxime partium 197408, 10260, qualium partium parallelogrammum D C eft 100000,00000 .

\section{P R O P OS I T I O X.}

\section{TIneas curvas exbibere quarum evolutione ellipfes $E$ byperbola defcribantur, rectasgue invenire iifdem cur- vis aquales.}

Sit ellipfis vel hyperbole qualibet A B, cujus axis tranfverfus A C; centrum figuræ D; latus rectum duplum ipfius A E. Et fumpto in fectione quovis puncto, ut $\mathrm{B}$, applicetur ordinatim ad axem recta в K, \& ad dictum punctum в tangens ducatur qux conveniat cum axe in F; fitque B G ipfi $\mathrm{F} B$ perpendicularis, axique occurrat in G; \& producatur B G ufque ad $\mathrm{H}$, ut B H ad H G ha. beat rationem eam qux componitur ex rationibus G F ad F K; \& A D ad D E.

Dico curvam E H M, cujus puncta omnia inveniuntur eodem modo quo punctum $\mathrm{H}$, effe eam cujus evolutione, unà cum recta $E A$, defcribetur fectio $A$ B. Ipfam autem $B$ H tangere curvam in 


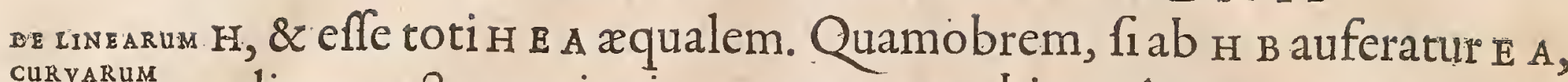

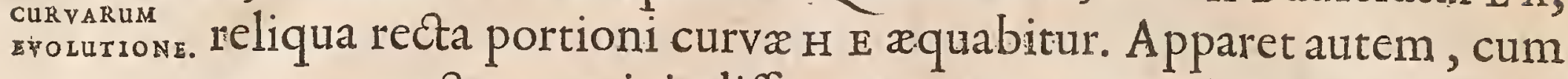
curvæ puncta quævis indifferenter, certaque ratione inveniantur, effe eam utróbique ex earum genere, quæ merè geometricæ cenfentur. Vnde \& relatio horum omnium punctorum ad puncta axis A C, xquatione aliqua exprimi poterit, quam æquationem ad fextam dimenfionem afcendere invenio; minimumque habere ter-
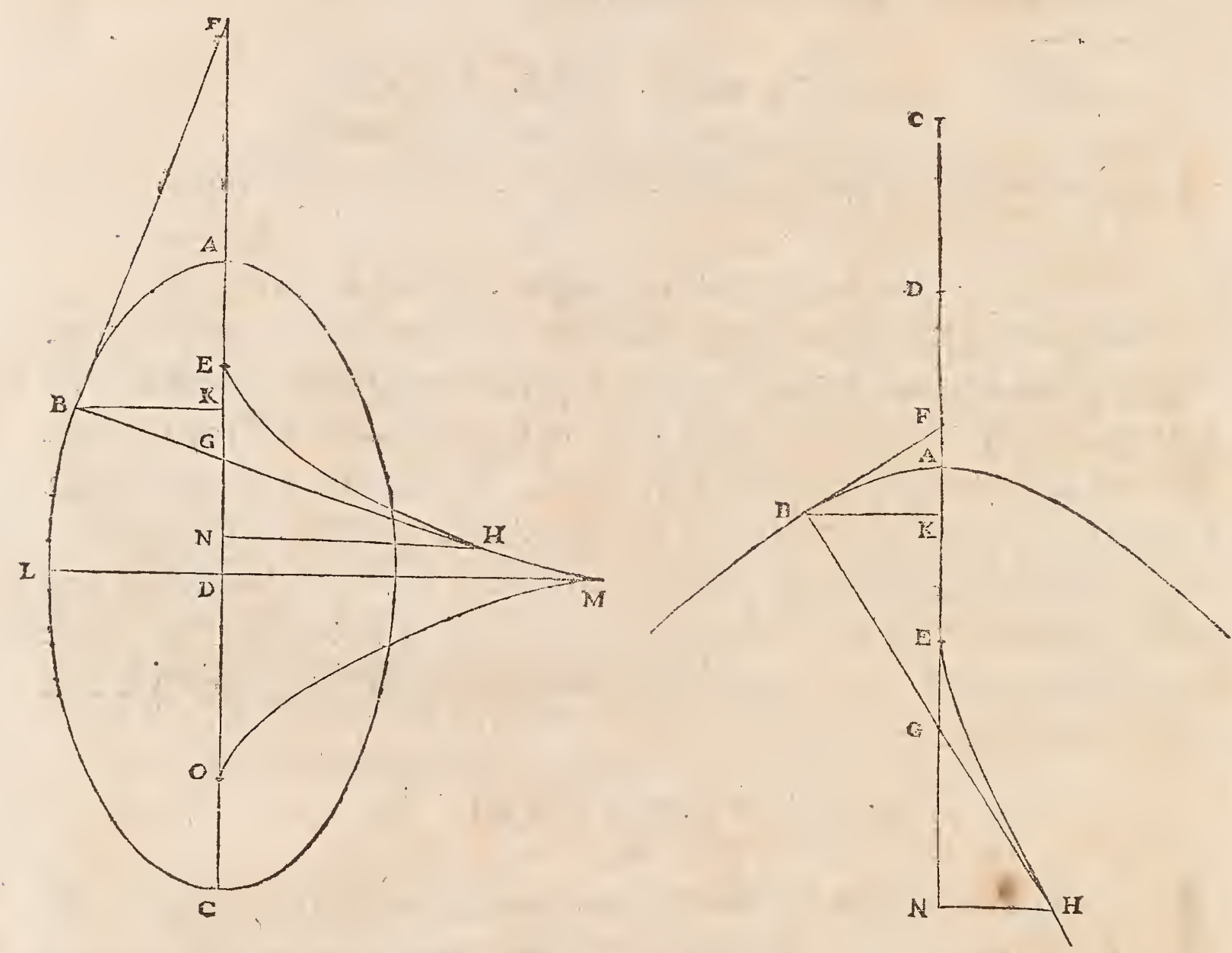

minorum, fi fuerit A B hyperbola cujus latera tranfverfum rectumque æqualia. Tunc enim ducta ex quovis curvæ puncto, ut $\mathrm{H}, \mathrm{ad}$ axem C A N perpendiculari $\mathrm{H}$; vocatâque $\mathrm{A} \mathrm{C}, a ; \mathrm{CN}, x ; \& \mathrm{NH}$, $y$; erit femper cubus ab $x x-y y$-a a xqualis $27 x x y y$ a a. Sed hoc cafu brevius quoque multo, quam prædicta conftructione, curvæ E H M puncta reperiri poffunt, ut in fequentibus oftendetur.

Cærerum notandum eft, in ellipfi fingulos quadrantes fingularum linearum evolutione defcribi; ficur quadrans a B L evolutione line $\mathrm{A} E \mathrm{E} \mathrm{M}$, quadrans C L evolutione fimilis huic oppofitx C O M. Eft enim hrc in fectione utraque diverfitas, quod cum principium quidem curvæ $\mathrm{EH}$ M, tam in ellipfi quam in hyperbola, fit punctum E, fumpta A E æquali $\frac{1}{2}$ lateris recti; in hyperbola in infinitum inde dicta linea extenditur, at in ellipfi finitur 
in puncto axis minoris $\mathrm{M}$, fumpta $\mathrm{L}$ M $æ$ quali $\frac{1}{2}$ lateris recti, fecun- DE LINEARUKA dum quod poffunt ordinatim applicatæad dictum minorem axem. CuRVARUM Namque hos terminos effe hujus curvx, facile apparebit ortum ejus confideranti, quodque in ellipf eft ficut A D ad D E, ita $\Sigma \mathrm{M}$ ad $\mathrm{M}$ D.

Horum autem demonftrationi non immorabimur, fed ad ipfam methodum tradendam pergemus, qua \& hæ curvæ ex fectionibus conicis, \& aliæ innumeræ ex aliis quibufcunque datis inveniuntur.

\section{P R O P O S T IO X I.}

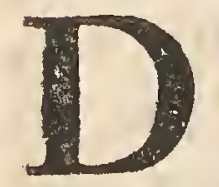

Atâ lineâ curvấ, invenire aliam cujus evolutione illa defcribatur; EG oftendere quod ex unaquaque curva geometrica, alia curva itidem geometrica exiftat, cui rectalinea aqualis dari poffit.

Sit curva quxpiam, vel pars ejus, in partem unam inflexa $A B F_{,}$ \& recta K L, ad quam puncta omnia referantur; \& oporteat invenire curvam aliam, ut DE, cujus evolutione ipfa A B E defcribatur.

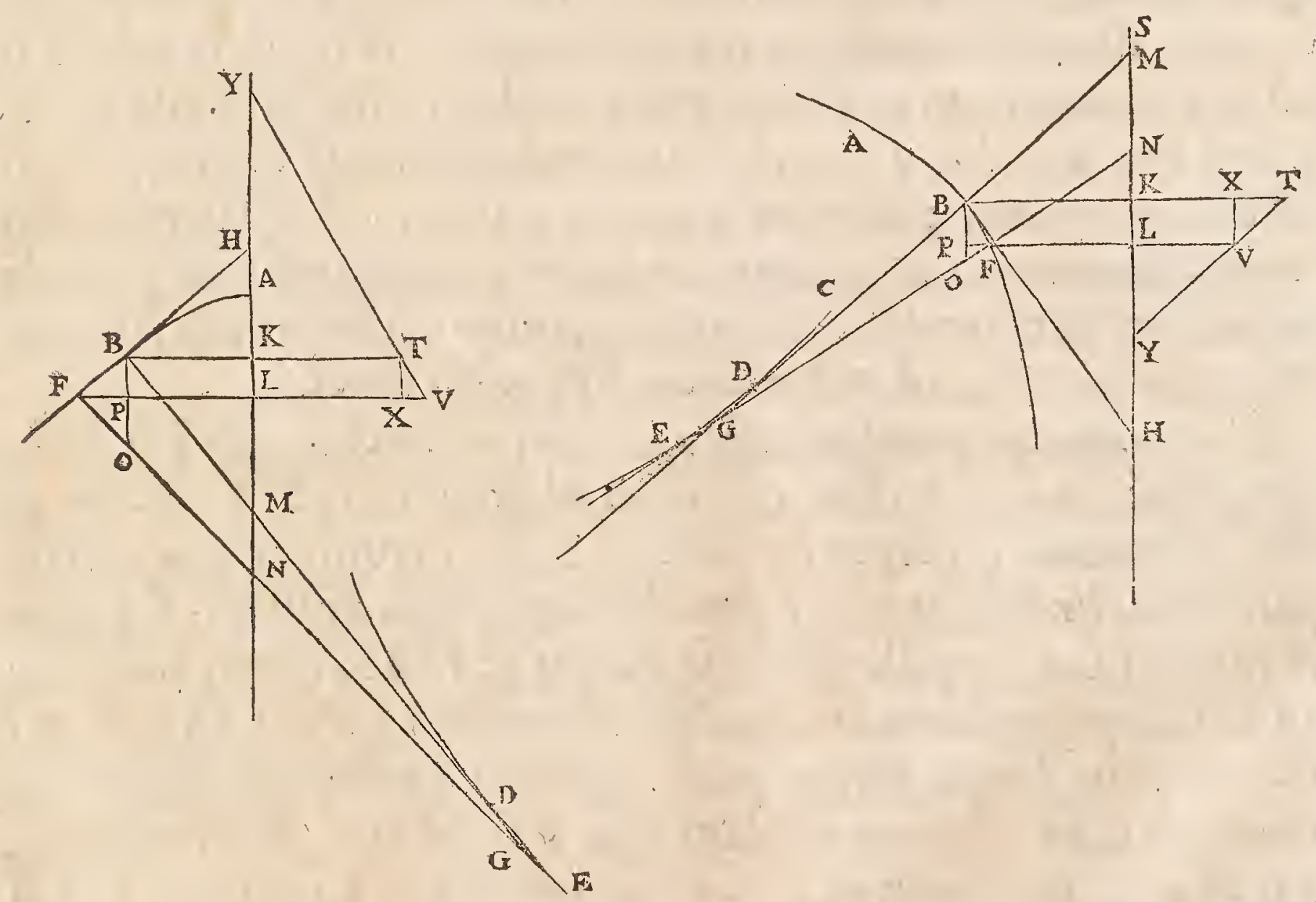

Donatur jam inventa; \& quoniam tangentes omnes curva $D E$; neceffe eft occurrere linex A B , ex evolutione defcriptæ, ad angulos rectos; patet quoque viciflim eas qux ipfi A B $\mathrm{F}$ ad rectos angulos infiftunt, ut $\mathrm{B} \mathrm{D}, \mathrm{FE}$, tacturas evolutam $\mathrm{C} \mathrm{DE}$. 
DE Infarum
GuRVARUM . Intelligantur autem puncta $B, F$, inter fe proxima; \& fi quidem grozuTIOAE. à parte A evolutio incipere ponatur, ulteriufque inde diftet $\mathrm{F}$ quam $B$, etiam contactus $\mathrm{E}$ ulterius quam $\mathrm{D}$ diftabit $\mathrm{ab} \mathrm{A}$; interfectio vero rectarum $B D, F E$, qux eft $G$, cadet ultra punctum $D$ in recta B D. Nam concurrere ipfas B D, F E neceffe eft, cum curvæ B $\mathrm{F}$ ad partem cavam infiftant rectis angulis.

Quanto autem punctum $\mathrm{F}$ ipfi $\mathrm{B}$ propinquius fuerit, tanto propius quoque puncta $\mathrm{D}, \mathrm{G} \& \mathbb{E}$ convenire apparet; ideoque, fi interftitium B $\mathrm{F}$ infinite parvum intelligatur, tria dicta puncta pro uno eodemque erunt habenda; ac præterea, ductâ rectâ B $\mathrm{H}$, quæ curvaln in $B$ tangat, eadem quoque pro tangente in $\mathrm{F}$ cenfebitur. Sit B o parallela $\mathrm{K} \mathrm{L}, \&$ in hanc perpendiculares cadant $\mathrm{B} \mathrm{K}$, $F L$ : Tecetque $F$ rectam $B$ in $P$, \& fint puncta notata $M, N$, in quibus rectæ, B D, FE, occurrant ipfi $\mathrm{K}$ L. Quia igitur ratio B G ad G M eft eadem qux B o ad $\mathrm{M} N$, data hac dabitur \& illa; \& quia recta $\mathrm{B} \mathrm{M}$ datur magnitudine ac pofitione, dabitur \& punctum $\mathrm{G}$ in producta $B$. , five $D$ in curva $C D E$, quia $G \& D$ in unum convenire diximus. Datur autem ratio B o ad $\mathrm{M} N$; fimpliciter quidem in Cycloide, ubi primùm omnium illam inveftigavimus, invenimufque duplam; in aliis vero curvis, quás hactenus examinavimus, per duarum datarum rationum compofitionem. Nam quia ratio $B$ o ad $\mathrm{M} N$ componitur ex rationibus B O ad B P, five $\mathrm{N} \mathrm{H}$ ad $\mathrm{L} \mathrm{H}$, \& ex B $\mathrm{P}$ five $\mathrm{KL}$ ad $\mathrm{MN}$; patet fi rationes hæurreque dentur, etiam ex iis compofitam rationem $\mathrm{B}$ o ad $\mathrm{M} N$ datum iri. Illas vero dari in omnibus curvis geomerricis, in fequentibus parebit; ac proinde iis femper curvas adfignari poffe, quarum evolutione defcribantur, quxque ideo ad rectas lineas fint reducibiles.

Ponatur primò parabola effe $\mathrm{A} B \mathrm{~F}$, cujus vertex $\mathrm{A}$, axis $\mathrm{A} Q$. Cum igitur lineæ $\mathrm{B}$ M, F N, fint parabolæ ad angulos rectos; ductæque fint ad axem A Q perpendiculares B K, F L, erunt, ex proprictate parabolæ, fingulæ $\mathrm{M} \mathrm{K}, \mathrm{NL}$ dimidio lateri recto æquales; \& ablata communi $L \mathrm{M}$, xquales inter fe $\mathrm{KL}, \mathrm{MN}$. Hinc, quum ratio $\mathrm{B} \mathrm{G}$ ad $G M$ componatur ex rationibus $N H$ ad $H L, \& K L$ ad $M N$, uti dictum fuit, firque earum pofterior ratio xqualitatis; liquet rationem B G ad G M fore eandem qux $\mathrm{N} \cdot \mathrm{H}$ ad $\mathrm{H} \mathrm{L}$; \& dividendo, $B$ M ad M G, eandem qux N L ad L $H$, five $M$ Kad KH; nam L H, K H pro eadem habentur, propter propinquitatem punctorum B,F.Data autem eft ratio $\mathrm{M} \mathrm{K}$ ad $\mathrm{K} \mathrm{H}$, dato puncto $\mathrm{B}$; quoniam tam $\mathrm{MK}$, quam $\mathrm{K} \mathrm{H}$ dantur magnitudine; nam $\mathrm{M} \mathrm{K} x$ quatur dimidio lateri recto, $\mathrm{K}$ H vero duplæ $\mathrm{K}$ A. Daraque etiam eft pofitione \& magni- 
rudine recta $B$. Ergo $\&$ M data erit, adeóque \& punctum $G$, DE LINEARum

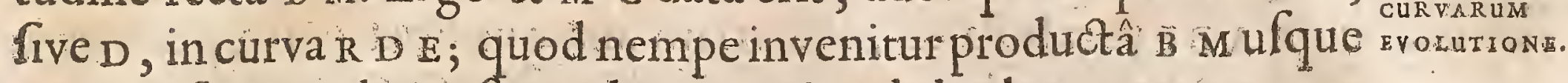
in $G$, ut fit $B$ M ad $M G$ ficut lateris reeti ad duplam $x \mathrm{~A}$.

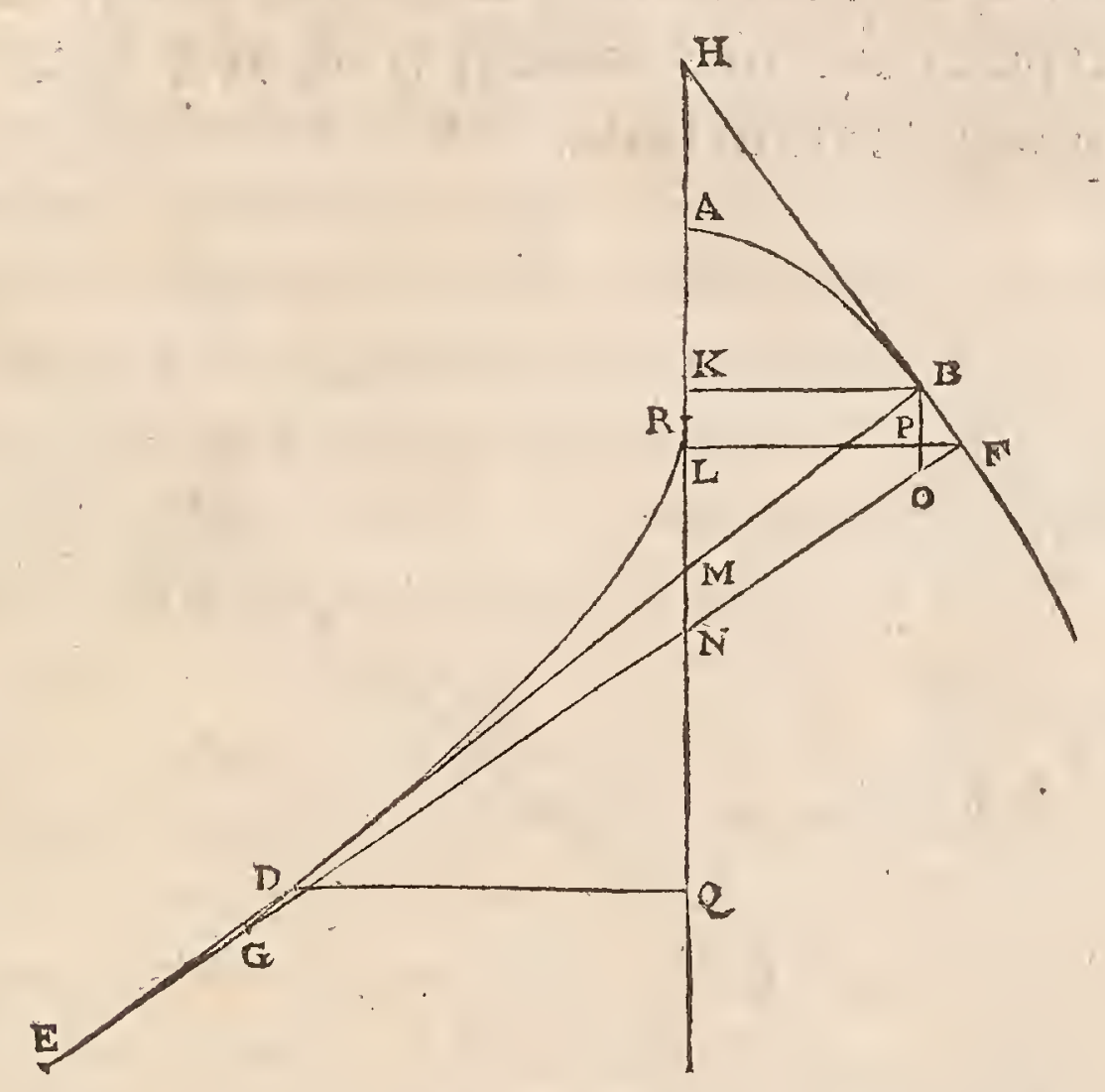

Et fic quidem, adfumptis in parabola A B $\mathrm{F}$ aliis quotlibet punotis preter $\mathrm{B}$, totidem quoque puncta linex $\mathrm{R} \mathrm{D}$ E, fimili ratione, invenientur; arque hoc ipfo lineam $\mathrm{R} D \mathrm{D}$ geometricam effe conftat, unáque proprieras ejus innotefcit, ex qua cæteræ deduci poffunt. $V t$ fi inquirere deinde velimus, quanam æquatione exprima. tur relatio punctorum omnium curvæ C D E ad rectam A Q: ducta in hanc perpendiculari $\mathrm{D}$, , vocatoque latere recto parabolx $A B \mathrm{~F}$; $a ; \mathrm{AK}, b ; \mathrm{A}, x ; \mathrm{QD}, y$. Quoniam ratio $\mathrm{B} \mathrm{M}$ ad $\mathrm{M} \mathrm{D}$, hoc eft, $\mathrm{KM}$ ad $M Q$, eft ea qux $\frac{1}{2} a$ ad $2 b$, eftque ipfa $\mathrm{KM} x \frac{1}{2} a$, erit $\& \mathrm{MQ}$

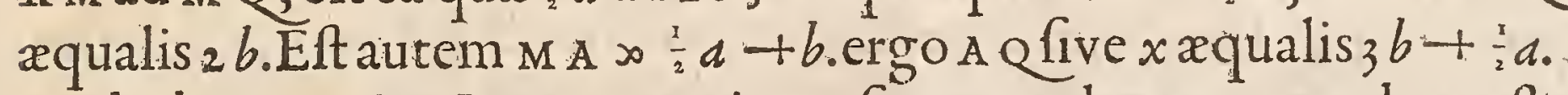
$V$ nde $b \infty \frac{1}{3} x-\frac{1}{6} a_{0}$. Porro quoniam, ficut quadratum $\mathrm{M} \mathrm{K}$, hoc eft, $\frac{z}{4} a$ ad quadratum $\mathrm{x}$ B, hoc eft, $a b$, ita qu. $\mathrm{M}$, hoc eft, $4 b b$ ad qu. QD; erit qu. QD, five $y y_{\infty} \frac{16 b_{3}}{4} \cdot$ Vbi, fi in locum $b$ fubltituatur $\frac{t}{3} x-\frac{1}{6} a$, quod illi xquale inventum eft, fiet $y y$ s. 16 cub. $\frac{1}{3} x-$ $\frac{1}{6}$ divifis per $a$. Ac proinde $\frac{27}{16}$ a y $y$ subo ab $x-\frac{1}{2} a$. Accipiarur $\mathrm{A}$ i in axe parabole $x \frac{1}{2} a$; eritque $\mathrm{R} Q \infty x-\frac{1}{2} a$. Curvam igitur $\mathrm{C} D$ ejus naturæ effe liquer, ut femper cubus lineær $\mathrm{Q} x$ quetur parallelepipedo, cujus bafis qu. QD, altitudo $\frac{27}{16}$ a ; ac proinde ipfam paraboloidem effe, cujus evolutione defcribi parabolam A B fupra oftendimus; cujus nimirum paraboloidis latus rectum æquetur ${ }^{27} \frac{7}{6}$ lateris recti parabolæ A B. tunc enim hujus latus rectum æquale fit $\frac{16}{27}$ lareris recti paraboloidis, quemadmodum ibi fuit definitum. 
Quomodo porro ratio о в ad B $P$, five $\mathrm{N}_{\mathrm{H}}$ ad H L, non tantum

cum A B F parabola eft, fed etiam alia quxlibet curva geometrica, femper inveniri poffit manifeftum eft. Quoniam tantum reeta $\mathrm{F}$ H ducenda eft, qux curvam in adfumpto puncto $\mathrm{F}$ tangat, \& I N ipfi $F$ H perpendicularis: unde $N$ H \& $\mathrm{H} L$ datæ erunt, ac proinde ratio quoque earum data.

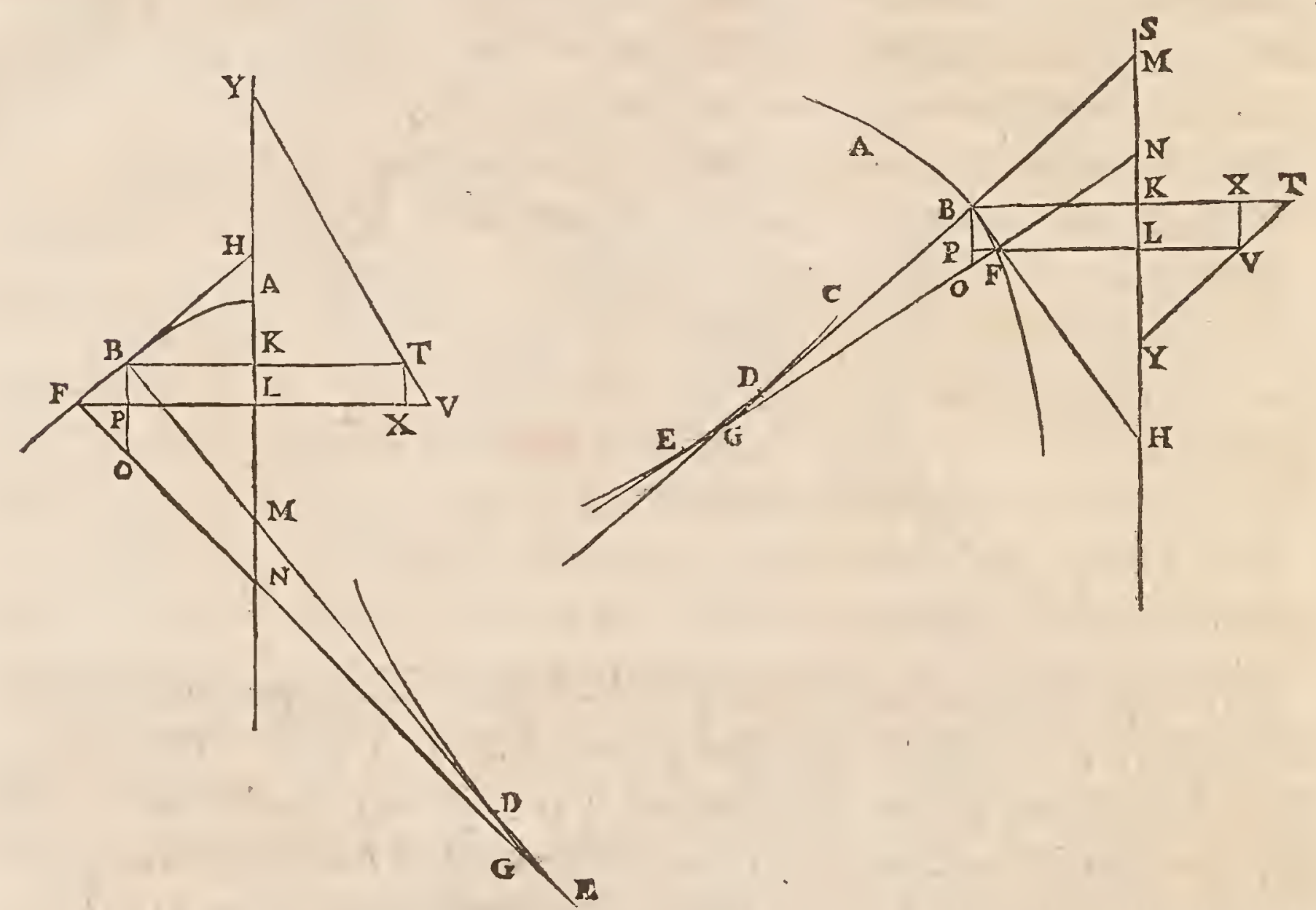

At non xque liquet quo pacto ratio $\mathrm{K} \mathrm{L}$ ad $\mathrm{M} \mathrm{N}$ innotefcat; quam tamen femper quoque reperiri poffe fic oftendemus.

Sint rectæ $K \mathrm{~T}, \mathrm{~L} V$, perpendiculares fuper $\mathrm{K} \mathrm{I}$, fitque $\mathrm{K} \mathrm{T}$ æqualis $\mathrm{K} \mathrm{M}, \& \mathrm{~L}$ v $æ$ qualis $\mathrm{L} N, \&$ ducatur $\mathrm{v}$ x parallela $\mathrm{L} N$, quæ occurrat ipfi $\mathrm{K} \mathrm{T}$ in $\mathrm{X}$. Quoniam ergo femper eadem eft differentia duarum $\mathrm{LK}, \mathrm{N} \mathrm{M}$, quæ duarum $\mathrm{L} N, \mathrm{~K} M$, hoc eft, quæ duarum $\mathrm{L} V, \mathrm{~K} T$; eft autem differentix ipfarum $L \mathrm{~V}, \mathrm{~K} T$ rqualis $\mathrm{X} T, \& \mathrm{x} \mathrm{v}$ ipfi $\mathrm{L} \mathrm{K}$; eric proinde $\mathrm{N} M æ$ qualis duabus fimul $\mathrm{V} X, \mathrm{X} T$, vel ei quo $\mathrm{v} \mathrm{X}$ ipfam $x \mathrm{~T}$ fuperat. Atque adeo, fi data fuerit ratio $v \mathrm{x}$ ad $x \mathrm{~T}$, data quoque erit ratio $v \mathrm{x}$ ad utramque fimul $\mathrm{v} x, \mathrm{x} T$, vel ad exceffum $v \mathrm{X}$ fupra $\mathrm{X} T$, hoc eft, data erit ratio $\mathrm{V} \times$ five $\mathrm{L} \mathrm{K}$ ad $\mathrm{N} M$.

Sciendum eft autem, quoniam $\mathrm{K} T$ ipfi $\mathrm{K} M, \& \mathrm{~L}$ ipfi $\mathrm{L} N$, æquales fumptæ funt, locum punctorum $\mathrm{T}, \mathrm{V}$, fore lineam quandam vel rectam vel curvam datam, ut mox oftendetur. Et fiquidem fit linea recta; ut contingit $\mathrm{f}_{1}$ А B $\mathrm{F}$ coni fectio fuerit, \& $\mathrm{K} \mathrm{L}$. axis ejus; conftat rationem $\mathrm{v} \mathrm{x}$ ad $\mathrm{x} \mathrm{T}$ datam fore, data pofitione ipfus lineæ $v \mathrm{~T}$, quæ. locus eft punctorum $\mathrm{v}, \mathrm{T}$; femperque ean- 
dem tunc haberi dictam rationem, qualecunque fuerit interval- DE IINEARUM $\operatorname{lum} \mathrm{K} \mathrm{L}$.

At fi locus alia linea curva fuerit, diverfa erit ratio $\mathrm{V} \times \mathrm{Xd} \mathrm{X} \mathrm{T}$, IVOLUTIONE. prout majus minufve fuerit intervallum $\mathrm{K} \mathrm{L}$. In quirendum eft autem quænam fitura fir ifta ratio, cum $\mathrm{K} L$ infinite parvum imaginamur, quoniam \& puncta B, F, proxima in vicem pofuimus. Similiter itaque \& puncta $v, T$, lineæ curvæ minimam particulam intercipere intelligendum eft; unde recta $\mathrm{V} T$, cum ea qux in $\mathrm{T}$ curvam contingit, coincidet. Sit ergo tangens illa $\mathrm{T} \mathrm{Y}$; poteft enim duci quoniam curva, ad quam funt puncta $T, V$, geometrica eft. Ratio igitur y K ad $\mathrm{K}$ T data erit, adeoque \& $\mathrm{v}$ x ad X T. ex qua etiam rationem $\mathrm{L} K$ ad $\mathrm{N} M$ dari oftendimus.

Quxnam vero fit linea ad quam funt puncta $\mathrm{T}, \mathrm{v}$, invenitur ponendo certum punctum $\mathrm{s}$ in recta $\mathrm{K} \mathrm{L}$, \& vocando $\mathrm{S}, x ; \mathrm{K} \mathrm{T}$, $\gamma$. Nam quia data elt curva A B F, eique B $M$ ad angulos rectos ducta, invenietur inde quantitas linex $\mathrm{K} \mathrm{M}$, per methodum tangentium à Cartefio tradiram, quæ ipfi $\mathrm{K}$ T, five $y x$ quabitur, \& ex ea $æ q u a t i o n e$, natura curvæ $\mathrm{T}$ v innotefcet, ad quam deinde tangens ducenda eft. Sed clariora omnia fient fequenti exemplo.

Sit A в F paraboloides illa, cui fuperius rectam xqualem invenimus; in qua nempe cubi perpendicularium in rectam $\mathrm{s} \mathrm{K}$, fintinter fe ficur quadrata ex ipfa $s \mathrm{~K}$ abfciffarum. Er oporteat invenire curvam C DE cujus evolutione paraboloides S B F defcribatur.

Hic primum ratio B o ad в $\mathrm{P}$ facile invenitur, quia tangentem paraboloidis in puncto B duci fcimus, fumpta $S \mathrm{H} x q u a l i \frac{1}{2} \mathrm{~S} \mathrm{~K}$. Cui tangenti cum B $\mathrm{M}$ ad angulos rectos infiftat, dantur jam linex $\mathrm{M} \mathrm{H}, \mathrm{H} \mathrm{K}$, ac proinde earum incer fe ratio, quæ eft eadem quæ $\mathrm{O} B$ ad B P.

$V t$ autem ratio $B \mathrm{P}$, five $\mathrm{K} L \mathrm{ad} \mathrm{M} N$ innotefcat, ponantur ad $\mathrm{K} L$ perpendiculares rectæ $\mathrm{K} T, L V$, æquales fingulis $\mathrm{K} M, \mathrm{LN}$, fitque $\mathrm{V}$ x parallela $\mathrm{L}$ K. I am quia ex duabus fimul $\mathrm{K} L, \mathrm{~L} N$, aufereńdo $\mathrm{K} M$, relinquitur $M \mathrm{~N}$; hoc eft, auferendo ex duabus $\mathrm{XV}, \mathrm{V} \mathrm{L}$, five $\mathrm{X} \mathrm{V}, \mathrm{X} \mathrm{K}$, ipfam $\mathrm{K} \mathrm{T}$; hinc autem relinqui apparet $\mathrm{V} \mathbf{X} \& \mathrm{X} \mathrm{T}$ : erunt igitur hæduæ $\mathrm{v} x, \mathrm{X}$ T ipf $\mathrm{M} N$ $æ q u a l e s$, ac proinde ratio $\mathrm{K} L$ ad $\mathrm{M} N$ eadem quæ $\mathrm{V} \mathrm{X}$ ad duas fimul $\mathrm{V} \mathrm{X}, \mathrm{X} \mathrm{T}$. Vt autem hæc ratio innotefcat cum intervallum $\mathrm{K} L$ eft minimum; oportet fecundum prædicta inquirere quis fit locus, five linea ad quam funt puncta $\mathrm{T}, \mathrm{V}$. Quod ut fiat fit latus rectum paraboloidis A B F $x$ a; $\mathrm{s} \mathrm{K} \times x ; \mathrm{K} \mathrm{T} x y$.

Quia igitur proportionales funt $\mathrm{K} \mathrm{H}, \mathrm{KB}, \mathrm{K} \mathrm{M}$, eftque $\mathrm{H} \mathrm{K}>$ L iij 
Da IINBARUa $\frac{3}{2} x: \mathrm{K}$ B ex natura paraboloidis æqualis R. cub.a a $x$ x y:fiet K M, hoc eft $\mathrm{K}$ T $>\frac{2}{3}$ R.cub. a a $x \times y$, ac proinde $\frac{3}{27} a$ a $x \times y^{3}$. Vnde patet locum punctorum $\mathrm{T}, \mathrm{V}$, effe paraboloidem illam, quam cubicam vocant geometræ. Cui proinde ad $\mathrm{T}$ tangens ducetur, fumptâ $S Y$ duplâ ipfius $s \mathrm{~K}$, junctâque $\mathrm{Y} T$. Et jam quidem ratio $\mathrm{v} x$ ad duas fumul v X,X $T$, quam diximus eandem effe ac KL ad $M$, erit ea qux $\mathrm{Y}$ K ad utramque fimul $\mathrm{Y} \mathrm{K}, \mathrm{K} \mathrm{T}$. Hæc autem ratio data eft, ergo $z$ ratio $K \mathrm{~L}_{\text {ad }} \mathrm{M}$ N. Sed \& rationem o в ad P B datam effe oftenfum eft. Ergo, cum ex duabus hifce componatur ratio B D ad D M, ut fupra patuit, dabitur \& hæc; \& dividendo, ratio B M ad M D; adeoque \& punctum $D$ in curva $D E$.

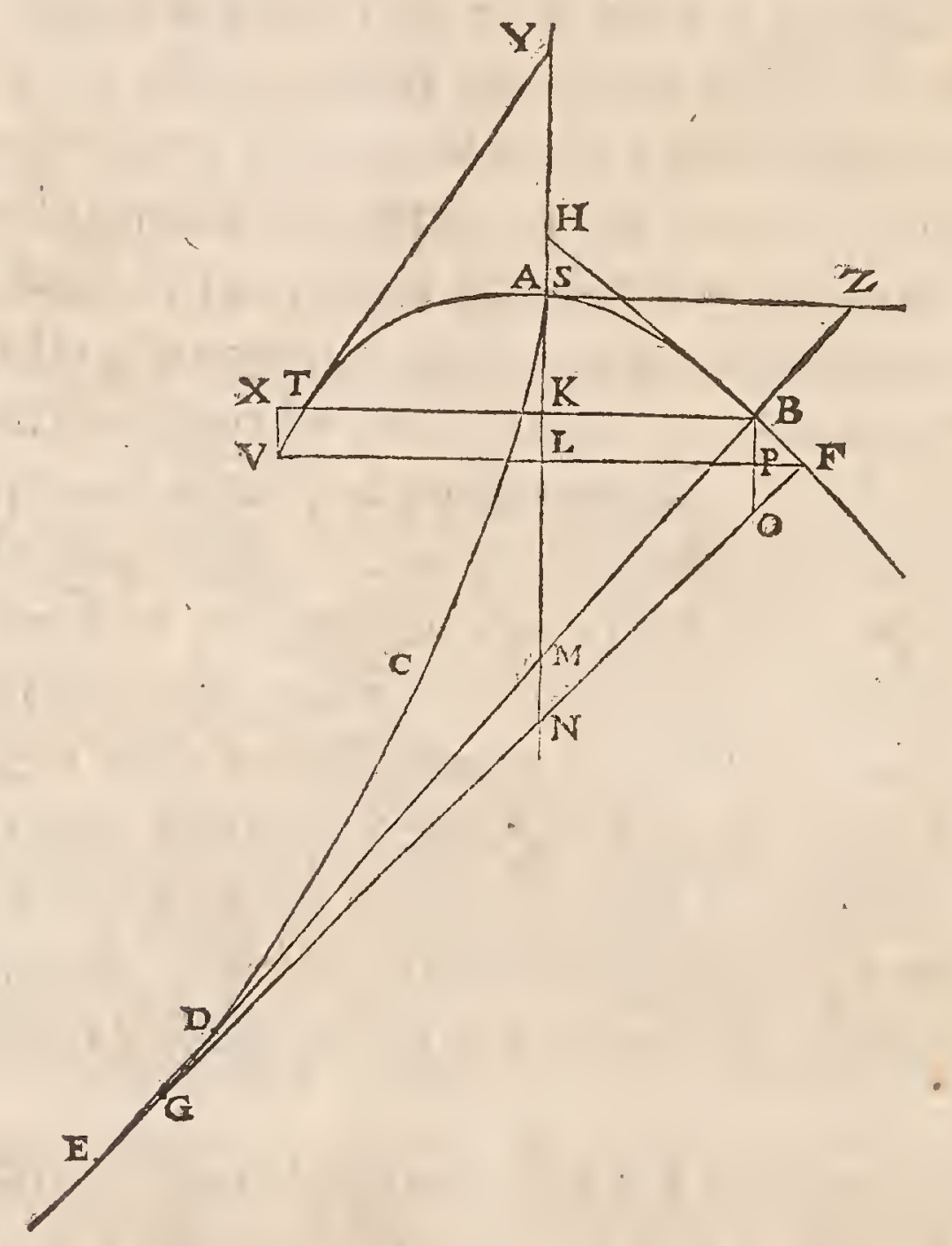

Ad conftuctionem autem breviffimam hoc pacto hic perveniemus. $\mathrm{K} T$ five $\mathrm{K} M$ dicta fuit $y$. Itaque $\mathrm{M} H$ erit $y+\frac{3}{2} x$. Et $\mathrm{M} \mathrm{H}$ ad $\mathrm{H} \mathrm{K}_{\text {, }}$ five о в аd в $\mathrm{P}$, ut $y+\frac{3}{2} x$ ad $\frac{3}{2} x$. five, fumptis omnium duplis, ut $2 y$ $+3 x$ ad $3 x$. Deinde quia $\mathrm{Y} \mathrm{K} x 3 x$, erit $\mathrm{Y} \mathrm{K}$ ad $\mathrm{Y} \mathrm{K}+\mathrm{K} \mathrm{T}$, five per pradicta, $\mathrm{KL}_{\mathrm{Ld}} \mathrm{N}, \mathrm{ut} 3 x$ ad $3 x+y$. Atqui ex rationibus o $\mathrm{B}$ ad B $\mathrm{P}, \& \mathrm{KL} \mathrm{ad} \mathrm{M} \mathrm{N}$, componi diximus rationem B D ad D M. Ergo ratio B D ad D M erit compofita ex rationibus $2 y+3 x \operatorname{ad} 3 x, \& 3 x$ ad $3 x+y$; ideoque erit ea qux $2 y+3 x$ ad $3 x+y$. \& dividendo, ratio B M ad M D, eadem qux $y$ ad $3 x+y$.

Sit $\mathrm{s} z$ perpendicularis ad $\mathrm{s} \mathrm{k}$, eique occurrat $\mathrm{M}$ B producta in $\mathrm{z}$. 

Quia ergo ratio B $M$ ad $M D$ inventa eft ea qux $y$ ad $y+3 x$, hoc eft $D$ E LINAARUMA quie M Kad MK $+3 \mathrm{~K} \mathrm{~s}$. Sicut autem M K ad M K $+3 \mathrm{~K} \mathrm{~s}$, ita M B ad CuR VARUM $\mathrm{MB}+3 \mathrm{BZ}$ : erir proinde $\mathrm{M}$ B ad $\mathrm{M}$ D ut $\mathrm{M}$ B ad $\mathrm{M}$ B +3 B $\mathrm{Z}$. Vnde liquet $\mathrm{M} D$ xqualem fumendam ipfi $\mathrm{M} B+3 \mathrm{~B} \mathrm{z}$. Atque ita quorlibet puncta curvæ C D E invenire licebit. Cujus curvæ portio quælibet ut D s, rectæ D B, quæ paraboloidi S A B ad angulos rectos occurrit, xqualis erit. Conftat autem geometricam effe, \& fivelimus, poffumus æquatione aliqua relationem exprimere punctorum omnium ipfius ad puncta axis $s . K$.

Simili modo autem, fi inquiramus in paraboloide illa five parabola cubica, in qua cubi ordinatim applicatarum ad axem, funt inter fe ficut portiones axis abfciffre, inveniemus curvam cujus evolutione defcribitur, quæque proinde rectæ linex æquari poterit, nihilo difficiliori conftructione per puncta determinari. Nam fi fuerit illa $S$ A B ; axis $S \mathrm{M}$; (dicitur autem improprie axis in hac curva, cum forma ejus fit ejufmodi, ut ductâ s $z$, quæ fecet s m ad angulos rectos, ea portiones fimiles curva habeat ad partes oppo-

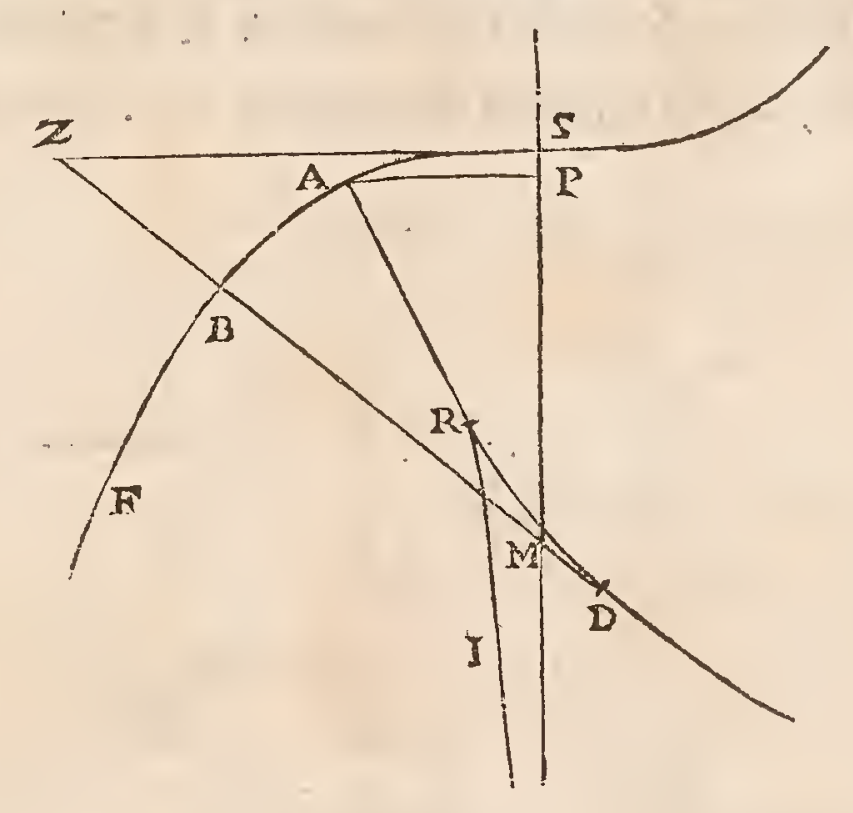

fitas;) agatur per punctum quodlibet $\mathrm{B}$, in paraboloide fumptum, recta $\mathrm{B} \mathrm{D}$, qux curvam ad angulos rectos fecet, axique ejus occurrat in $\mathrm{M}$, rectæ veros $\mathrm{z}$ in $\mathrm{z}$. Deinde fumatur $\mathrm{F}$ $\mathrm{D}$ qualis dimidix $\mathrm{B} \mathrm{M}$, unà cum fefquialtera $\mathrm{B} \mathrm{z}$. Eritque $\mathrm{D}$ unum è punctis curvæ quæfitæ $\mathrm{R} D$ vel $\mathrm{R} I$, cujus evolutione, juncta tamen recta quadam $\mathrm{R} A$, defcribetur paraboloides $\mathrm{A}$ A $\mathrm{B}$. Sunt autem hic, quod notatu dignum eft, quodque in aliis etiam nonnullis harum paraboloidum contingir, duæ evolutiones inpartes contrarias, quarum utraque à puncto certo A initium capit; ita ut evolutione ipfius A R D, in infinitum porro continuata, defcribatur paraboloidis pars infinita A B F; evolutione autem totius $\mathrm{F} \mathrm{H} \mathrm{K}$, fimiliter in infinitum extenfr, tantum particula a s. Punctumautem a definitur, fumptâ s p qux fit ad 


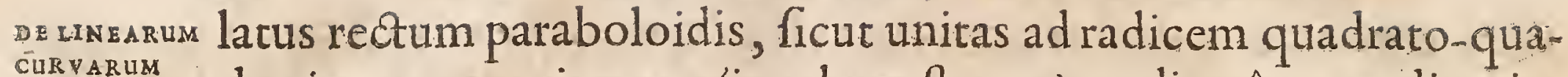
EVOLUIIONE. draticam numeri 9 II25, (is cubus eft ex 4 ) applicatâque ordinacim $P A . V n d e$ porro punctum $R$, confinium duarum curvarum $R D, R I$, invenitur ficut cætera omnia harum curvarum, hoc eft, ficut pun. ctum $\mathrm{D}$ modo inventum fuit.

Denique, quxcunque fuerit ex paraboloidum genere curva s $\mathrm{A}$ B, femper æque facile curvam aliam, cujus evolutione ipfa defcribatur, quæque propterea rectæ adæquari poffit, per puncta inveniri comperimus. Atque adeo conftructionem univerfalem fequenti abella exhibemus, qux quoufque libuerit extendi poterit.

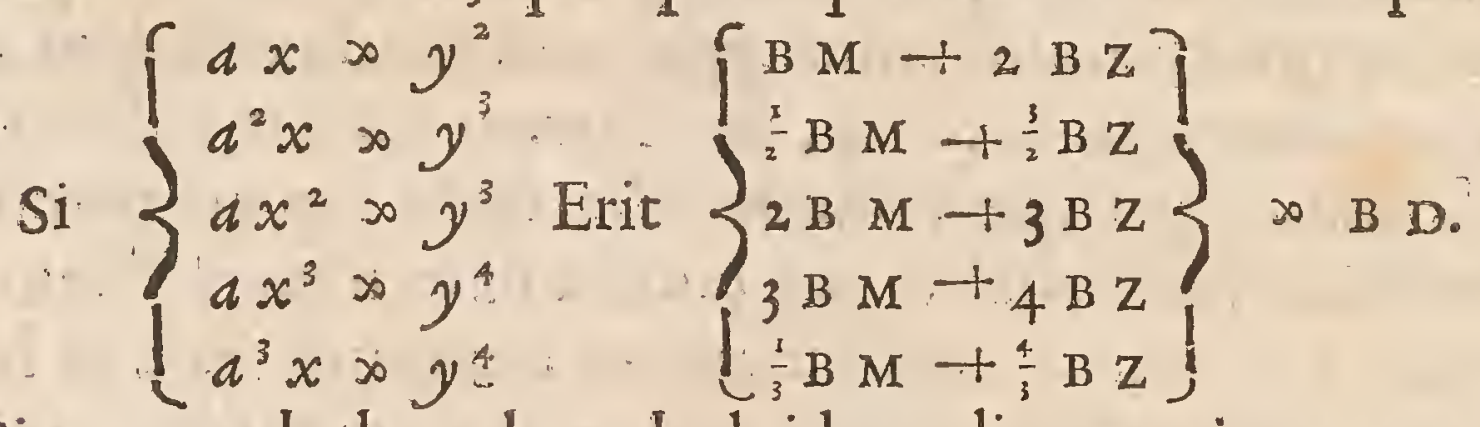

Sit s в parabola, vel paraboloidum aliqua, cujus vertex s; recta $s \cdot k$ vel axis, vel axi perpendicularis, ad quam referuntur æquarione puncta paraboloidis; \& ipfa quidem s K femperad partem cavam ducta intelligitur; cui perpendicularis s z. Ponendo jam $\mathrm{s} \mathrm{K} \times x$;

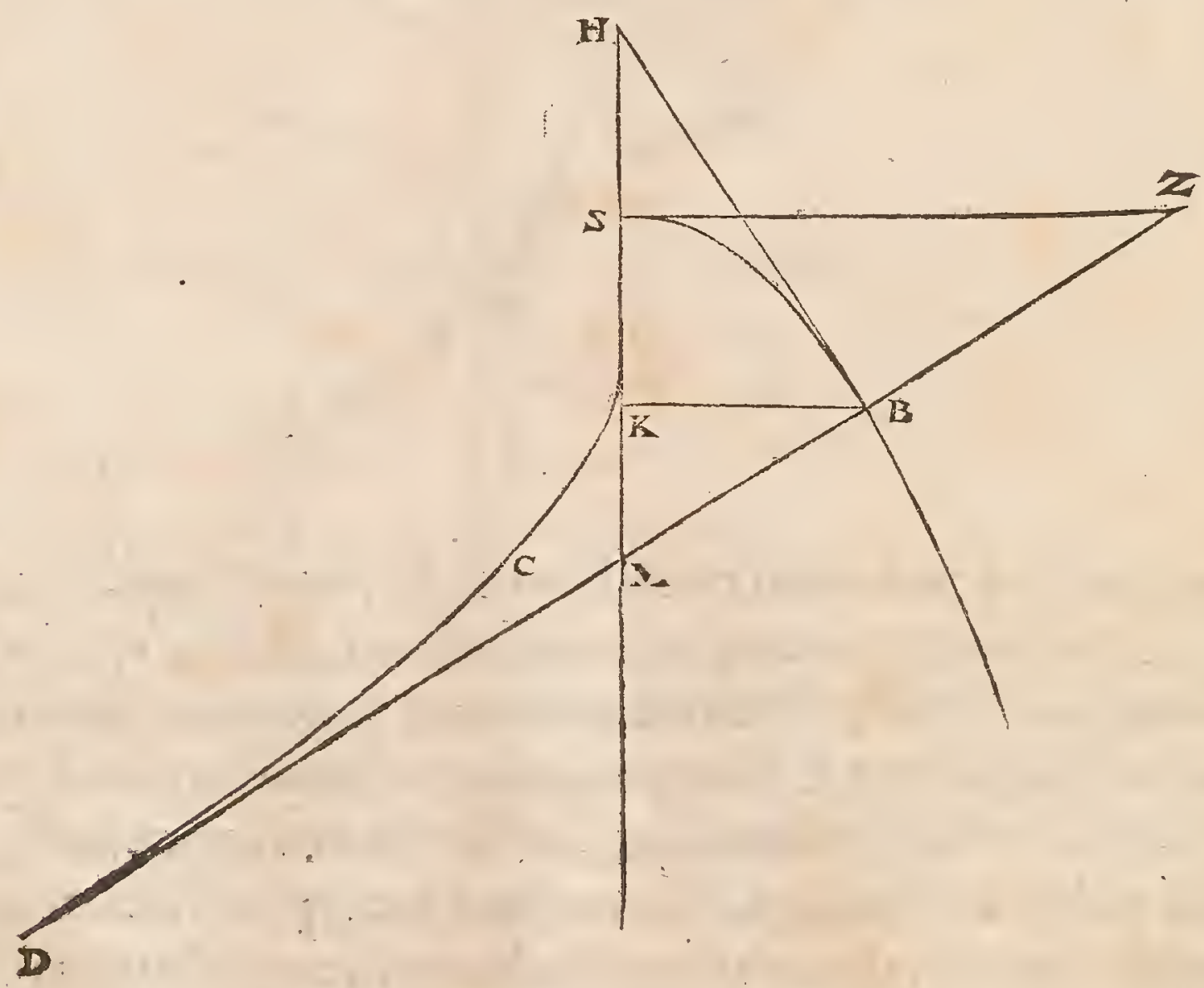

s $\mathrm{K} x y$, quæ à puncto quovis curvæ perpendicularis eft ipfis $\mathrm{K}$; \& latere recto curvæ $x$ a; prior pars tabelli, quæad finiftram eft, naturam fingularum paraboloidum fingulis æquationibus explicat. Quibus refpondent in parte dextra quantitates linex B D, qux fi curve s $A$ infiltat ad angulos rectos, exhibitura fit punctum $D$ 

fectione fit, ei fcimus convenire æquationem tabellæ primam, $a x$ Curotutione. $x y^{2}$; cui refpondet ab altera parte $B M+2 B z$ $x$ B $D$. Vndelongitudo linex B D cognof citur, adeoque inventio quotlibet punEtorum curva C D. Quam quidem, hoc cafu, paraboloidem effe fupra demonftratum fuit, eam nempe, cujus æquatio tertia eft hujus tabellæ.

Conftruitur autem tabella hoc pacto, ut B $\mathrm{M}$ fumatur multiplex fecundum numerum qui eft exponens poreftatis $x$ in æquatione; B $z$ vero, multiplex.fecundum exponentem poteftatis $y$; ex his autem utrifque compofitx accipiatur pars denominata $a b$ exponente potéftatis $a$.

Præter hafce autem paraboloides lineas, alias item invenimus, à quibus, non abfimili conftructione, deducuntur curvæ rectis comparabiles. Affimilantur autem hyperbolis, eo quod afymptotos fuas habent, fed tantum angulum rectum conftituentes. Et harum primam quidem ftatuimus hyperbolam ipfam, qux eft è coni fectione.

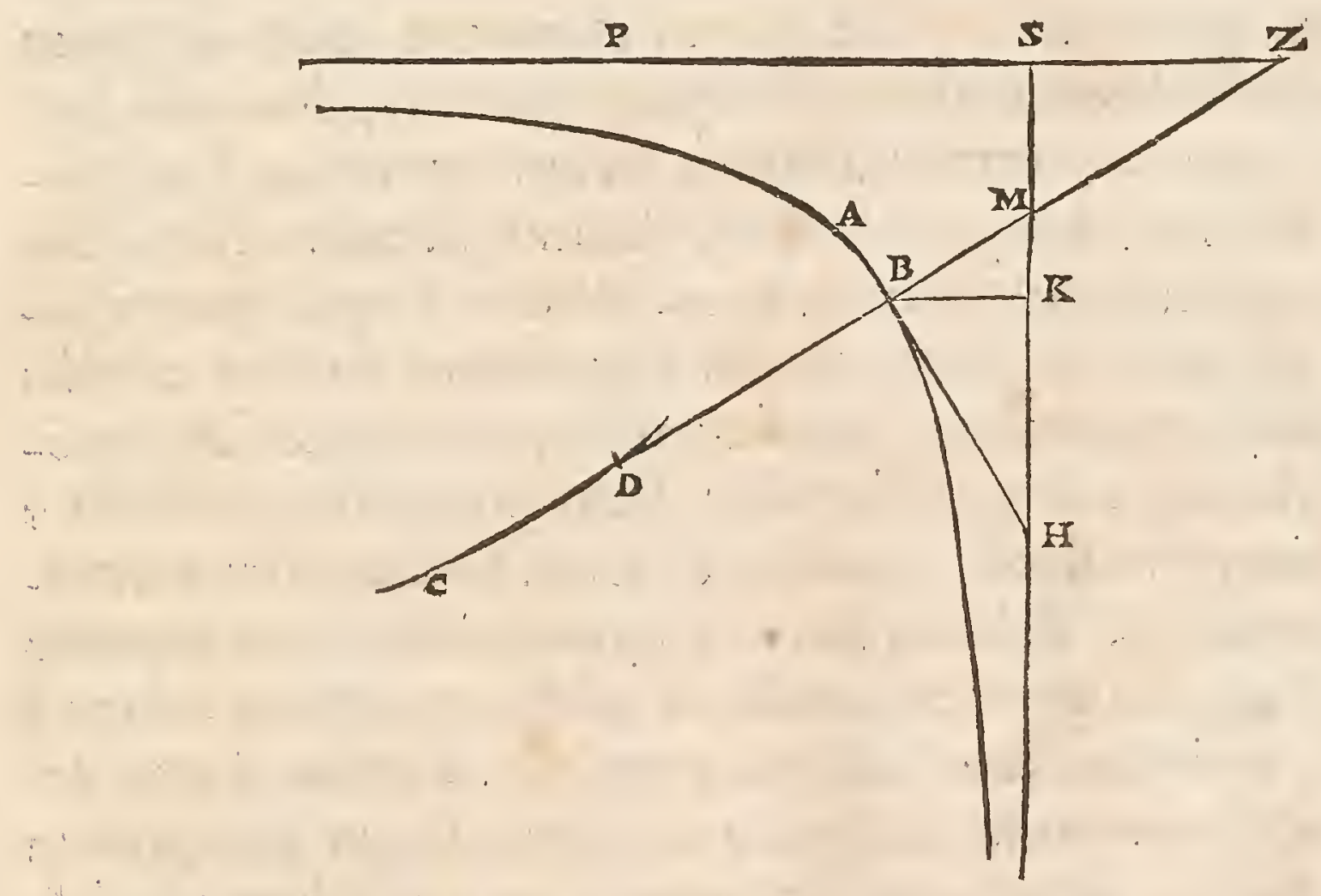

Reliquarum vero naturam ut explicemus; funto p s, $s \mathrm{~K}$, afymptoti curvæ $A B$, rectum angulum comprehendentes, \& à curvæ puncto quolibet B ducatur B K parallela $\mathrm{P} s$, fitque $\mathrm{S}$ K $\infty x$; K B so $y$. Si igitur hyperbola fit A B, fcimus rectangulum linearum $\mathrm{s} \mathrm{K}$, $\mathrm{K} \mathrm{B}$, hoc eft, rectangulum $x y$ femper eidem quadrato $x$ quale effe, quod vocetur $a$ a.

Proxima vero hyperboloidum erie, in qua folidum ex quadrato 

DE LANEARM linea $\mathrm{S} \mathrm{K}$, in altitudinem $\mathrm{K}$ B ductum, hoc eft, folidum $x y$, cubo certo requabitur, qui vocetur $a^{3}$. Atque ita innumeræ aliæ hujus generis hyperboloides exifunt, quarum proprietatem fequens tabella fingulis xquationibus exhiber, fimulque rationem contruendi curvam $\mathrm{D} \mathrm{C}$, cujus evolutione quæque generetur.

$$
\text { Si }\left\{\begin{array}{lll}
x y & x & a^{3} \\
x^{2} y & \infty & a^{3} \\
x y^{2} & \infty & a^{3} \\
x^{3} y & \infty & a^{4} \\
x y^{3} & \infty & a^{4}
\end{array} \text { Erit }\left\{\begin{array}{l}
\frac{1}{2} B M+\frac{1}{2} B z \\
\frac{2}{3} B M+\frac{1}{3} B z \\
\frac{B}{3} B M+\frac{2}{3} B z \\
\frac{3}{4} B M+\frac{1}{4} B z \\
\frac{1}{4} B M+\frac{3}{4} B z
\end{array}\right\} x B D .\right.
$$

Recta $D$ B M $Z$ curvam $A$ B, ut anrea quoque, fecat ad angulos rectos, occurritque afymptotis $\mathrm{S} \mathrm{K}, \mathrm{S}$ P, in $\mathrm{M} \& \mathrm{Z}$. Si igitur exempli gratia hyperbola fuerit A B, cujus xquatio eft $x y^{5} a^{2}$, fumetur $B D x=3 \quad+B$, quemadmodum tabella precipit. Eritque punctum $D$ in curva $D$ c quáfita, cujus alia quotlibet puncta fic inveniri poterunt, \& portio ejus quæliber rectæ lineæ adæquari. Et hrc quidem eadem illa eft curva, cujus relationem ad axem hyperbolæ fuperius æquatione expreffimus. Conftructio autem tabellæ hujus plane eadem eft qux luperioris.

Cæterum, quoniam tum ad harum curvarum, tum ad earum quæ ex paraboloidibus nafcuntur conftructionem, ducendæ funt linex D B Z, qux ad datum punctum в fecent curvas A B, five ipfarum tangentes $\mathrm{B} H$, ad angulos rectos; dicemus in univerfum quomodo hæ tangentes inveniantur. In æquarione itaque, quæ cujufque curvæ naturam explicat, quales æquationes duabus tabellis præcedentibus exponuntur, confiderare oportet quæ fint exponentes poteftatum $x \& y$, \& facere ut, ficut exponens poteftatis $x$ ad exponentem poteltaris $y$, ita fit $\mathrm{S} \mathrm{K}$ ad $\mathrm{K}$ H. Iuncta enim $\mathrm{H} \mathrm{B}$ curvam in B continget. Velut in tertia hyperboloide, cujus æquatio eft $x y^{2}>a^{3}$ : quia exponens poteftatis $x$ efti, poteftatis autem $y$ exponens 2 ; oportet effe ut I ad 2 ita S Kad K H. Horum autem demonftrationem noverune analyticæ artis periti, qui jam pridem omnes has lineas contemplari cœperunt; \& non folum parabo. loidum iftarum, fed \& fpatiorum quorundam infinitorum, inter hyperboloides \& afymptotos interjectorum, plana folidaque dimenfi funt. Quod quidem \& nos, facili atque univerfali methodo, expedire poffemus, ex fola tangentium proprietate fumpta demonftratione. Sed illa non func hujus loci. 


\section{HOROLOGII OSCILLATORII

\author{
$P A R S Q U A R T$.
}

De centro Ofcillationis.

Entrorum Ofcillationis, feu Agitationis, inveltigationem olim mihi, fere adhuc puero, aliifque multis, doctiffimus Merfennus propofuit, celebre admodum inter illius temporisGeometras problema, prout ex litteris ejus ad me datis colligo, nec ron ex Cartefii haud pridem editis, quibus ad Merfennianas fuper his rebus refponfum continetur. Poftulabat autem centra illa ut invenirem in circuli fectoribus, tam ab angulo quam à medio arcu fufpenfis, atque in latus agitatis, item in circuli fegmentis, \& in triangulis, nunc ex vertice, nunc ex media bafi pendentibus. Quod eo redir, ut pendulum fimplex, hoc eft, pondus filo appenfumreperiatur ea longitudine, ut ofcillationes faciat temporum eorundem ac figuræ iftx, uti dictum eft, fufpenfx. Simul vero pretium operæ, fi forte quæficis farisfeciffem, magnum fane $\&$ invidiofum pollicebatur. Sed à nemine id quod defiderabat tunc obtinuit. Nam me quod attinet, cum nihil reperirem quo vel primus aditus ad contemplationem eam patefceret; velut à limine repulfus, longiori inveftigatione tunc quidem abftinui. Quivero rem fefe confeciffe fperabant viri infignes, Cartefus, Honoratus Fabrius, aliique, nequaquam fcopum attigerunt, nifl in paucis quibufdam facilioribus, fed quorum ramin demonftrationem nullam idoneam, ut mihi videtur, attulerunt. Idque comparatione eorum qux hic trademus manifeftum fore fpero, fi quis forte quæ ab illis tradita funt, cum noftris hifce contulerit; quæ quidem \& certioribus principiis demonftrata arbitror, \& expcrimentis prorfus convenientia reperi. Occafio vero ad hæc denuo tenranda, ex pendulorum automati noftri remperandorum ratione oblata eft, dum pondus mobile, præter id quod in imo eft, illis applico, ut in defcriptione horologii fuit explicatum. Hinc melioribus aufpiciis atque à prima origine rem exorfus, tandem difficultates omnes fuperavi, nec tantum problematum Merfennianorum folutionem, fed alia quoque illis dificiliora reperi, \& 
92 CHR I T I A N I HGENII

DE EERTEO

OS CIILAIIONIS.

viam denique, qua in lineis, fuperficiebus, folidifque corporibus certa ratione centrum illud inveftigare liceret. Vnde quidem, præter voluptatem inveniendi quæ multum ab aliis quæfita fuerant, cognofcendique in his rebus naturæ leges decretaque, utilitatem quoque eam cepi, cujus gratia primo animum ad hæc applicueram, reperta illa horologii temperandi ratione facili \& expedita. Acceffit autem hoc quoque, quod pluris faciendum arbirror, ut certæ, fæculifque omnibus duraturæ, menfuræ definitionem abfolutiffimam per hæc tradere poffem; qualis eft ea qua ad finem horum adjecta reperietur.

\section{DEFINITIONES.}

I.

D Endulum dicatur figura qualibet gravitate pradita, 1 five linea fuerit, five fuperficies, five folidum, ita fufpenfa utcirca punctum aliquod, vel axem potins, qui plano borizontis parallelus intelligitur, motum reciprocum vi gravitatis fus continuare poffit.

I I.

Axis ille borizontis plano parallelus, circa quem penduli motus feri intelligitur, dicatur axis Ofcillationis.

I I I.

Pendulum fimplex dicatur quod flo vel linea inflexili,gravitatis experte, confare intelligitur, ima fui parte pondus affixum gerente; cujus ponderis gravitas, velut in unum punetum collecta, cen fenda ett.

\section{V.}

Pendulum verò compofitum, quod pluribus ponderibus conftat, immutabiles diftantias fervantibus, tum inter $\int e$, tum ab axe Ofcillationis. Hinc foura qualibet fuppenfa, ac gravitate predita, pendulum compofitum dicipoteft, quatenus cogitatu in partes quotlibet eft divifibilis.

V.

Pendula ifochrona vocentur, quorum Ofcillationes, per ara cus fimules, aqualibus temporibus peraguntur. 


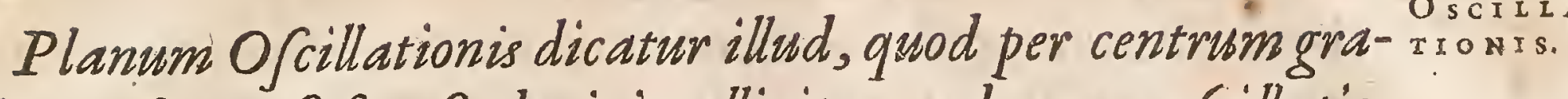
vitatis fgure fupenfe duci intelligitur, ad axem of cillationis rectum.

\section{I I.}

Linea centri, recta que peri centrum gravitatis figure ducitur, ad axem of cillationis perpendicularis.

\section{I I I.}

Linea perpendiculi, recta in plano of cillationis, ducta ab axe of cillationis, ad horizontis planum perpendicularis.

I X.

Centrum of cillationis rel agitationis frgur cujulibet, dicatur punitum in linea centri, tantum ab axe of cillationis difans, quanta eft longitudo pendulifimplicis quod figurs ifochronum fit.

\section{$\mathrm{X}$.}

eAxis gravitatis, linea quevis recta, percentrum gravitatis figure tranfiens.

X I.

Figura plana, vel.linea in plano fita, in planum agitari dicatur, cum axis of cillationis in eodem cum figura lineave eft plano.

\section{I I.}

Edem vero in latus agitari dicantur, cum axis of cilla. tionis ad figure lineave planum rectus eft.

\section{I I I.}

Quando pondera in rectias lineas duci dicentur, id ita eft intelligendum, ac fo numeri lineave, quantitates ponderumerationemque inter fe mutuam exprimentes, ita ducantur.

\section{H Y P O T H ES ES.}

I.

I I ondera quotlibet, vi gravitatis Ju, moveri incipiant; $\checkmark$ non poffe centrum gravitatis ex ipfis compofite altius, quam ubi incipiente motu reperiebatur, afcendere.

$M$ iij 


\section{4}

CHRISTIANI HVGENII

DE CENTRO

OSCILLA-

T $70 \mathrm{~N}$ IS.

Altitudo autem in his fecundum diftantiam à plano horizontali confideratur, graviaque ponuntur ad hoc planum, fecundum rectas ipfi perpendiculares, defcendere conari. Quodidem ab omnibus, qui de centro gravitatis egerunt, vel ponitur expreffe, vel à legentibus fupplendum eft, cum abfque eo centri gravitatis confideratio locum non habeat.

Ipfa vero hypothefis noftra quominus fcrupulum moveat, nihil aliud fibivelle eam oftendemus, quam quod nemo unquam negavit, gravia nempe furfum non ferri. Nam primo, fi unum quodpiam corpus grave proponamus, illud vi gravitatis fux altius afcendere non poffe extra dubium eft. afcendere autem tunc intelligitur fcilicet, cum ejus centrum gravitatis afcendit. Sed \& idem de quotliber ponderibus, incerfe per lineas inflexiles conjunctis, concedi neceffe eft, quoniam nihil vetat ipfa tanquam unum aliquod confiderari. Itaque neque horum commune gravitatis centrum ultro afcendere poterit.

Quod fi jam pondera quotlibet non inter fe connexa ponantur; illorum quoque aliquod commune centrum gravitatis effe $1 \mathrm{ci}^{\circ}$ mus. Cujus quidem eentri quanta erit alticudo, tantam ajo \& gravitaris ex omnibus compofitæ alticudinem cenferi debere; fiquidem omnia ad eandem illam centri gravitatis altitudinem deducï poffunt, nullâ aliâ accerfitâ potentiâ quam quæipfis ponderibus ineft, fed tantum lineis inflexilibus ea prolubitu conjungendo, ac circa gravitatis centrum movendo; ad quod nulla vi neque potentia determinata opus eft. Quare, ficut fieri non poteft ut pondera quædam, in plano eodem horizontali pofita, fupra illud planum, vi gravitatis fux,omnia æqualiter attollantur; ita nec quorumlibet ponderum, quomodocunque difpofitorum, centrum gravitatis ad majorem quam habet altitudinem pervenire poterit. Quod autem diximus pondera qualiber, nulla adhibita vi, ad planum horizontale, per centrum commune gravitaris eorum tranfiens, perduci poffe, fic oftendetur.

Sint pondera A, B, C, pofitione data, quorum commune gravia tatis centrum fit $D$. per quod planum horizontale ductum pona. tur, cujus fectio recta $\mathrm{E} F$. Sint jam lineæ inflexiles D A, D B, D C, quæe pondera fibi invariabiliter connectant; quæ porro moveantur, donec A fit in plano $\mathrm{E}$ ad $\mathrm{E}$. Virgis vero omnibus per æquales angulos delatis, erunt jam $B$ in $G, \& \subset$ in $H$.

Rurfus jam в \& c connecti intelliganturvirgâ \& G, qux fecet pla num $\mathrm{E}$ in $\mathrm{F}$; ubinecelfario quoque erit centrum gravitatis bino- 
HOROLOG. OS CILLATOR. rum iftorum ponderum connexorum, cum trium, in $E, B, H$, PO- DE CENTRO

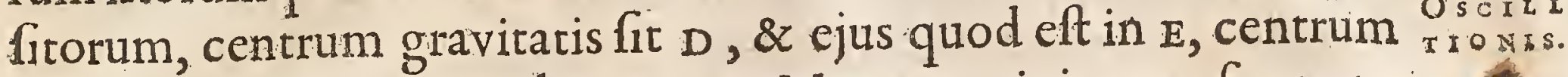
gravitatis fit quoque in plano E D F. Moventur igitur rurfus pondera $H, G$, fuper puncto $F$, velut axe, abfquevi ulla, ac fimul utraque ad planum $\mathrm{E} F$ adducuntur, adeo ut jam tria, qux prius erant in $A, B, C$, ad ipfam fuicentri gravitatis $D$ altitudinem, fuo ipforum æquilibrio, tranflata appareat. quod erat oftendendum. Eadem: que de quotcúque aliis elt demonítratio.

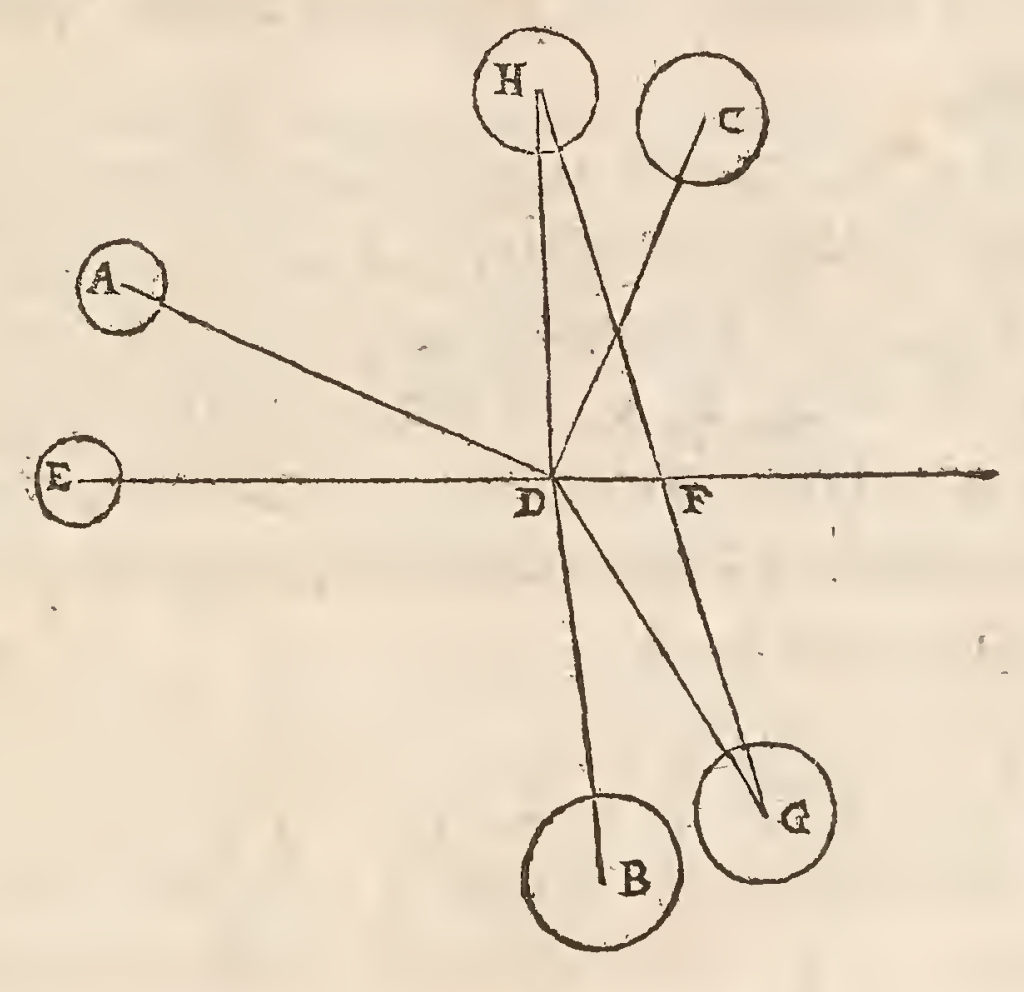

Hre autem hypothefis noftra ad liquida etiam cokpora valer, ac per eam non folum omnia illa, qua de innatantibus habet Archimedes, demonftrari poffunt, fed \& alia pleraque Mechanic theoremata. Et fanè, fi hac eadem uti fcirent novorum operum machinatores, qui motum perpetuum irrito conatu moliuntur, facile fuos ipfl errores deprehenderent, intelligerentque rem eammechanica ratione haud quaquam poffibilem effe.

\section{I.}

Remoto aëris, alioque omni impedimento manifefto, quem admodum in Sequentibus demonstrationibus id intelligi vo* luimus, centrum gravitatis penduli agitati, equales arcus defcendendo ac af cendendo percurreve.

De pendulo fimplici hoc demonftratum eft propofitione 9 de Defcenfu gravium. Idem vero $\&$ de compofito tenendum effe declarat experientia; fi quidem, quæcunque fuerit penduli figura, 
DE CENPRO æque apta continuando motui reperitur, nifi in quantum plus Oscris a- minufve aëris objectu impeditur.

\section{PROPOSITIO I.}

3 Onderibus quotlibet ad eandem partem plani exiftenti1 bus $f_{l}$ à jongulorum centris gravitatis agantur in planum illud perpendiculares; he fingula in fua pondera discte. tantundem fimul efficient, ac perpendicularis, à centro gravitatis ponderum omnium in planum idem cadens, ducta in pondera omnia.

Sint pondera A, B, C, fita ad eandem partem plani, cujus fectio recta $D F$, inque ipfum à fingulis ponderibus ducantur perpendiculares $A D, B$ E, C F. Sit autem $\mathrm{G}$ punctum centrum gravitatis ponderum omnium $A, B, C$, à quo ducatur perpendicularis in idem planum G F. Dico fummam productorum, quæ fiunt à fingulis ponderibus in fuas perpendiculares, xquari producto ab recta $G H$ in omnia pondera $A, B, C$.

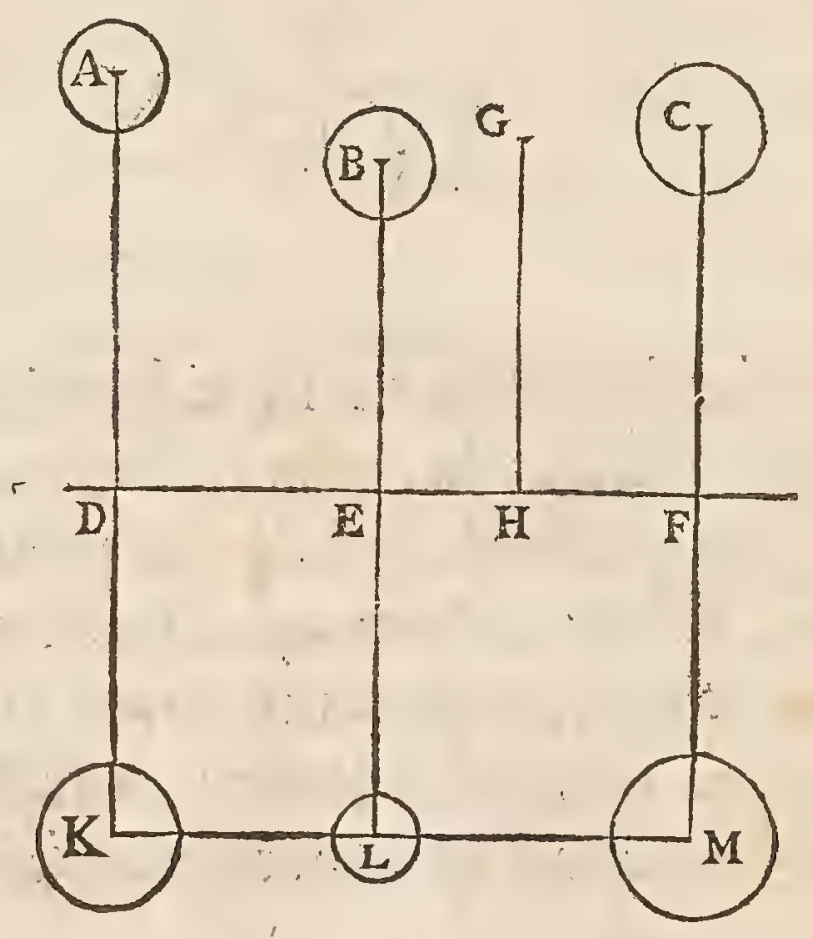

Intelligantur enim perpendiculares, à fingulis ponderibus eduet $x$, continuari in lareram partem plani $\mathrm{F}$, fintque fingul $\mathrm{DK}$, E L, F M, ipf H G xquales; omnefque linex, inflexiles virgas referant, ad horizontem parallelas; \& ponantur in $\mathrm{K}, \mathrm{L}, \mathrm{M}$, gravitates ejufmodi, quæ fingulæ cum fibi oppofitis A, B, C, æquilibrium faciant ad interfectionem plani D E F. Omnes igitur $\mathrm{K}, \mathrm{L}$, $M$, rquiponderabunt omnibus A, B, C. Erit autem, ficut longitudo A D ad D K, ita pondus $K$ ad pondus $A$, ac proinde $D$ A du in magnitudinem $A$, æquabitur $D K$, five $G H$, ductæ in $K$. Simili- 
HOROLOG OSCILLATOR.

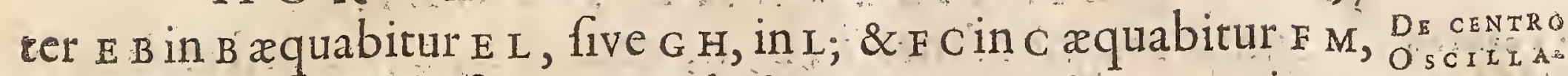

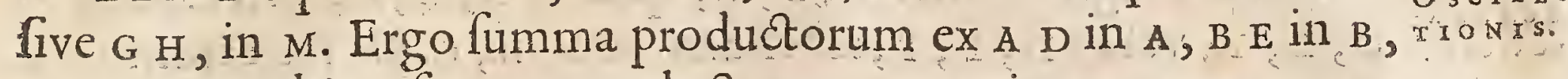
$C \mathrm{~F}$ in $\mathrm{F}, \gtrless$ quabitur fumm productorum $\mathrm{ex} \mathrm{G} H$ in omnes $\mathrm{K}, \mathrm{L}, \mathrm{M}$. Quum autem $\mathrm{K}, \mathrm{L}, \mathrm{M}$, æquiponderentipfis A, B, C, etiam iifdem $A, B, C$, ex centro ipforum gravitatis G fufpenfis, xquiponderabunt. Vnde, cum diftantia $G \mathrm{H}$ æqualis fit fingulis $D \mathrm{~K}, \mathrm{EL}, \mathrm{F}$ M, neceffe eft magnitudines $\mathrm{A}, \mathrm{B}, \mathrm{C}$, fimul fumptas, æquari ipfis $\mathrm{K}, \mathrm{L}$, M. Itaque \& fumma productorum ex $G \mathrm{H}$ in omnes $\mathrm{A}, \mathrm{B}, \mathrm{C}$, xquabitur productis ex $D A$ in $A, E B$ in $B, \& F C$ in $C$. quod erat demonftrandum.

Etfi vero in demonftratione pofitx fuerint $\operatorname{rectx} \mathrm{A} D, G \mathrm{H}$, CF, horizonti parallelæ, \& planum ad horizontem erectum; patet, fi omnia fimul in alium quemlibet fitum tranfponantur, eandem manere productorum æqualitatem, cum rectæ omnes fint exdem qux prius. Quare conftat propofitum.

\section{PR O P O S I I O I I.}

1 Ofitis qua prius, fe pondera omnia A, B, C, ent aqualia; 1 dico fummam omnium perpendicularium A D, B E, C F, equari perpendiculari, à centrogravitatis ducta, $\mathrm{GH}$, multiplici fecundum ponderum numerum.

Quum enim fumma productorum, à ponderibus fingulis in fuas perpendiculares, xquetur producto ex G H in pondera omnia; fitque hic, propter ponderum æqualitatem, fumma illa productorum xqualis producto ex uno pondere in fummam omnium perpendicularium; iremque productum ex $\mathrm{G} \mathrm{H}$ in pondera omnia, idem quod productum ex pondere uno in $\mathrm{G} \mathrm{H}$, multiplicem fecundum ponderum numerum : patet fummam perpendicularium neceffario jam æquari ipfi $\mathrm{G} \mathrm{H}$, multiplici fecundum ponderum numerum. quod erat demonftrandum.

\section{P R O P OS I T IO. I I I.}

I magnitudines quadam defcendant omnes, vel afcen-
dant, licet inaqualibus intervallis; altitudines de cen. fus vel a cenfus cujufque, in ipfam magnitudinem ducte, efficient fummam productorum equalem ei, que fit ex altitudine defcenfus vel afcenfus centri gravitatis omnium magnisudinum, ducta in omnesmagnitudines. 
DSENtro Sunto magnitudines $A, B, C$, qux ex A, B, C, defeendant in Tons. D, E, F; Vel exD, E, afeendant in $A, B, C$. Sitque earun centrum gravitatis omnium, $\operatorname{dum}$ funt in $A, B, C$, eadem al titudine cum puncto $G$; cum vero funt in $D, E, F$, eadem altitudine cum puncto $\mathrm{H}$. Dico fumnam productorum ex altitudine $\mathrm{A} D$ in $A, B$ in $B, C F$ in $C$, æquari producto ex $G$ in omnes $A, \dot{B}, C$.

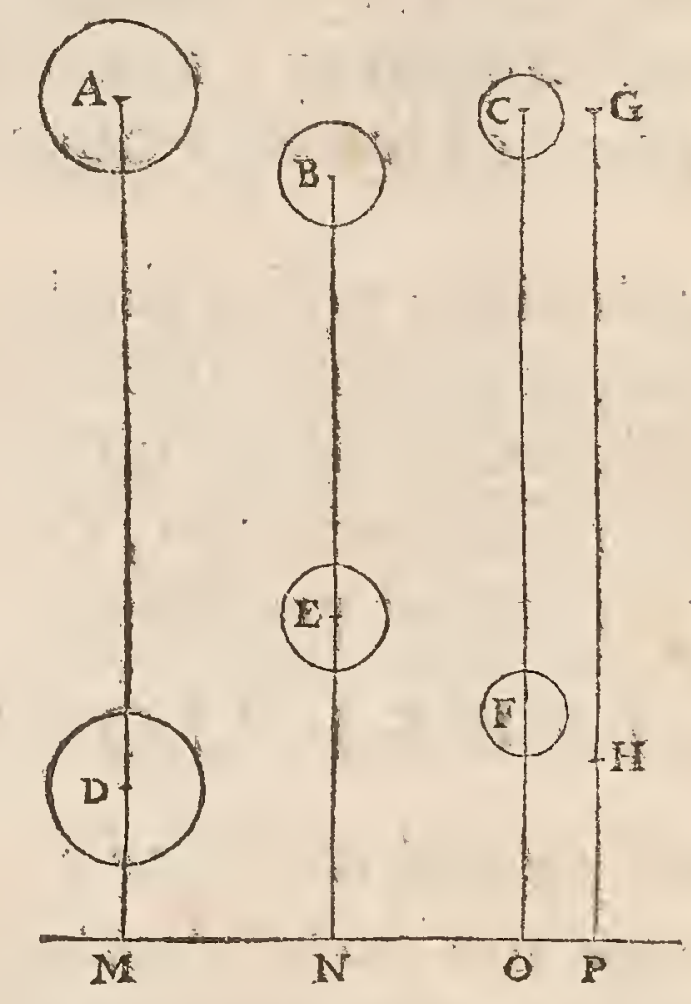

Intelligatur enim p̈lanum horizontale cujus fectio redta $\mathrm{M}$, at que in ipfum incidant productx $A D, B$ B , C F \& G H, in $\mathrm{M}, \mathbb{N}, \mathrm{O}, \mathrm{P}_{\text {. }}$

Qula igitur fumma productorum ex $A M$ in $A, B N$ in $B, C$ in * Prop.x. huj. C, xqualis eft facto ex $G$ P in omnes $A, B, C *$. Similiterque fumma productorum ex $D M$ in $A, E N$ in $B$, $F O$ in $C$, xqualis facto ex $H P$ in omnes $A, B, C$;fequitur \& exceffum priorum productorum fupra poAteriora, æquari facto ex $\mathrm{GH}$ in omnes magnitudines $A, B, C$. Dictum vero exceffum xquari manifeftum eft productis ex $A D$ in $A$, $B$ E in B , C F in C. Ergo hæc fimul etiam xqualia erunt producto ex $G \mathbf{H}$ in omnes A, B, C. quod erat demonftrandum.

\section{PROPOSITIO IV.}

(1 pendulum è pluribus ponderibus compofitum; atque è 1 quiete dimifum, partem quamcunque of cillationis integre confecerit, at que inde porro intelligantur pondera ejus fingula, relicto communi vinculo, celeritates acquifitas furfum convertere, ac quou gque po/funt afcendere; boc facto, centrim gravitatis ex omnibus compofite, ad eandem altitudinem rea verfum erit, quam ante inceptain of cillationem obtinebat. 
Sit pendulum compofitum ex ponderibus quotlibet $A, B, C$, DE CENTRO virgx, vel fuperficiei pondere carenti, inhærentibus. Sitque fuf- í siss. penfum ab axe per $\mathrm{D}$ punctum ducto, qui ad planum, quod hic confpicitur, perpendicularis intelligatur. In quo eodem plano etiam centrum gravitatis $\mathrm{E}$, ponderum $A, B, C$, pofitum fit; lineaque centri $\mathrm{D} E$, inclinetur ad lineam perpendiculi $\mathrm{D} F$, angulo E D F : attracto, nimirum, eo ufque pendulo. Hinc vero dimitti jam ponatur, ac partem quamlibet of cillationis conficere, ita ut pondera $A, B, C$, perveniant in $G, H, K$. Vnde, relicto deinceps communi vinculo, fingula intelligantur acquifitas celeritates furfum convertere, (quod impingendo in plana quædam inclinata, velut $Q Q$, fieri poterit, ) \& quoufque poffunt afcendere, nempe in $\mathrm{L}, \mathrm{M}, \mathrm{N}$. Quo ubi pervenerint, fit centrum gravitatis omnium punctum $\mathrm{P}$. Dico hoc pari altitudine effe cum puncto $\mathrm{E}$.

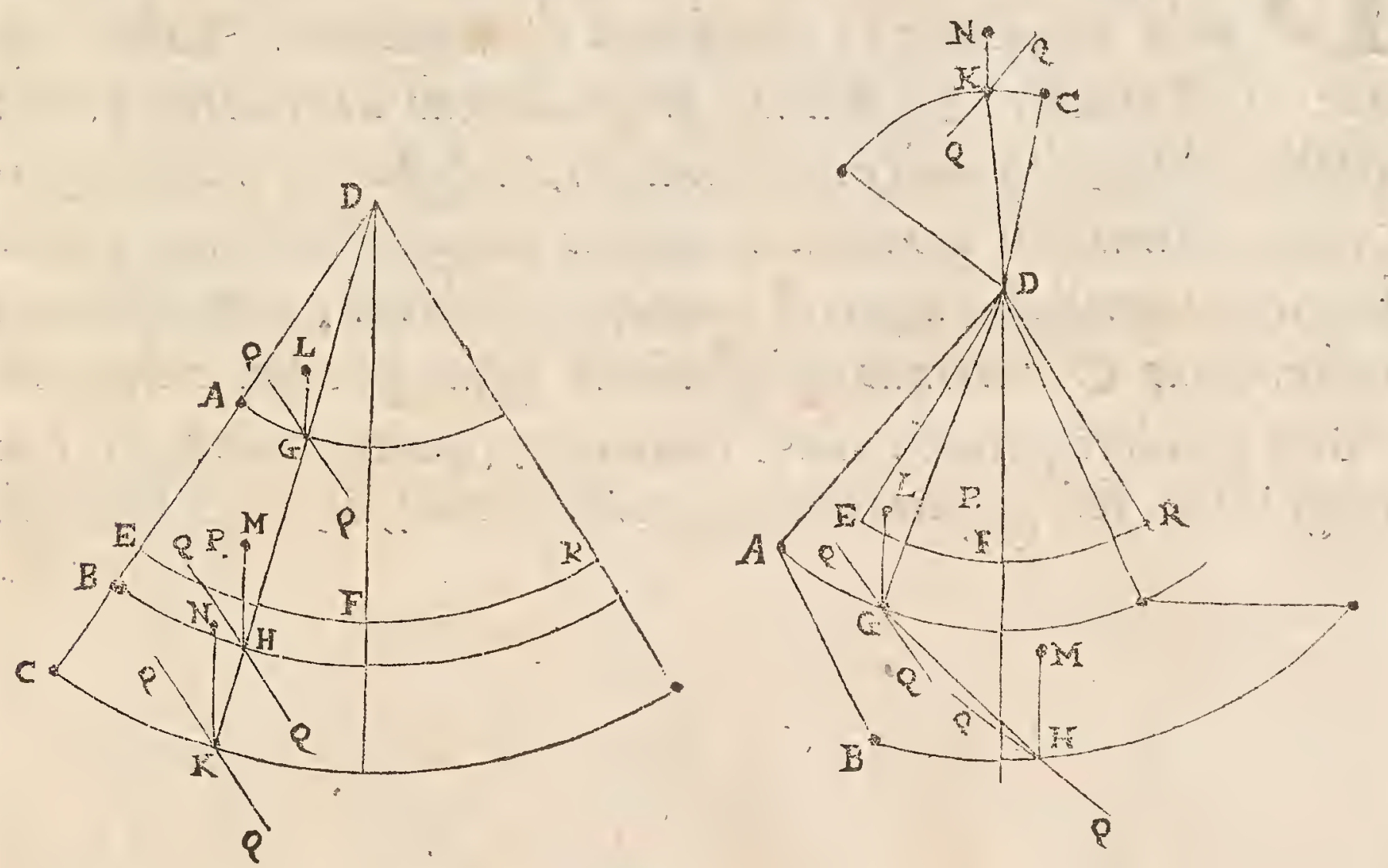

Nam primum quidem, conftat $\mathrm{P}$ non altius effe quam $\mathrm{E}$, ex prima fumptarum hypothefium. Sed nec humilius fore fic oftendemus. Sit enim, fi poteft, $\mathrm{P}$ humilius quam $\mathrm{E}$, \& intelligantur pondera ex iifdem, ad quas afcenderunt, altitudinibus recidere, qux funt $L G, M H, N K$. Vnde quidem eafdem celeritates ipfis acquiri conftat, quas habebant ad afcendendum ad iftas altitudines*, hoc eft, eas ipfas quas acquifierant motu penduli ex C B A D in * Propor, 4 . K H G.D.Quare, fi cum dictis celeritatibus ad virgam fuperficiemve, cui innexa fuere, nunc referantur, eique fimuladhærefcant, motumque fecunduminceptos arcus continuent; quod fiet, $f_{1}$ priufquam virgam attingant, à planis inclinatis Q Q repercuffa intelli- 
100

CHRISTIANI HVGENII

DE GENTRO OSCILIATIONIS.

gantur; abfolvet, hoc modo reftitutum pendulum, of cillationis partem reliquam, æquè á fi abfque ulla interruptione motum continuaffet. Ita ut centrum gravitatis penduli, E, arcus æquales $\mathrm{E} \overline{\mathrm{P}}$, $F R$, defcendendo ac afcendendo percurrat, ac proinde in $\mathrm{R}$ eadem ac in $\mathrm{E}$ altitudine reperiatur. Ponebatir autem $\mathrm{E}$ effe altius quam $p$ centrum gravitatis ponderum in $\bar{L}, \mathrm{M}, \mathrm{N}$, pofitorum. Ergo \& $\overline{\mathrm{R}}$ altius erit quam $\mathrm{P}$ : adeoque ponderum ex $\bar{L}, \mathrm{M}, \mathrm{N}$, delapforum centruin gravitatis, altius, quam unde defcenderat, afcendiffet. * Hypoth. s. quod eft abfurdum*. Non igitur centrum gravitatis $\mathrm{p}$ humilius eft his. quam $\mathrm{E}$. Sed nec altius erar. Ergo xque altum fit neceffe eft. quod erat demonftrandum.

\section{P R O P O S I T I O V.}

A Ato pendulo ex ponderibus quotlibet compofito, fi fingula ducantur in quadrata diftantiarum fuarum ab axe of cillationis, Ef fumma productorum dividatur per id quod fit ducendo ponderum fummam, in diftantiam centrigravitatis communis omnium ab eodem axe ofcillationis; orietur longitudo penduli fimplicis compofito ifochroni, frve diftantia inter axem $\sigma^{2}$ centrum of cillationis ipfus penduli compofiti.

Sint pondera pendulum componentia, (quorum nec figura nec magnitudo, fed gravicas tantum confideretur), A, B , c, fufpenfa
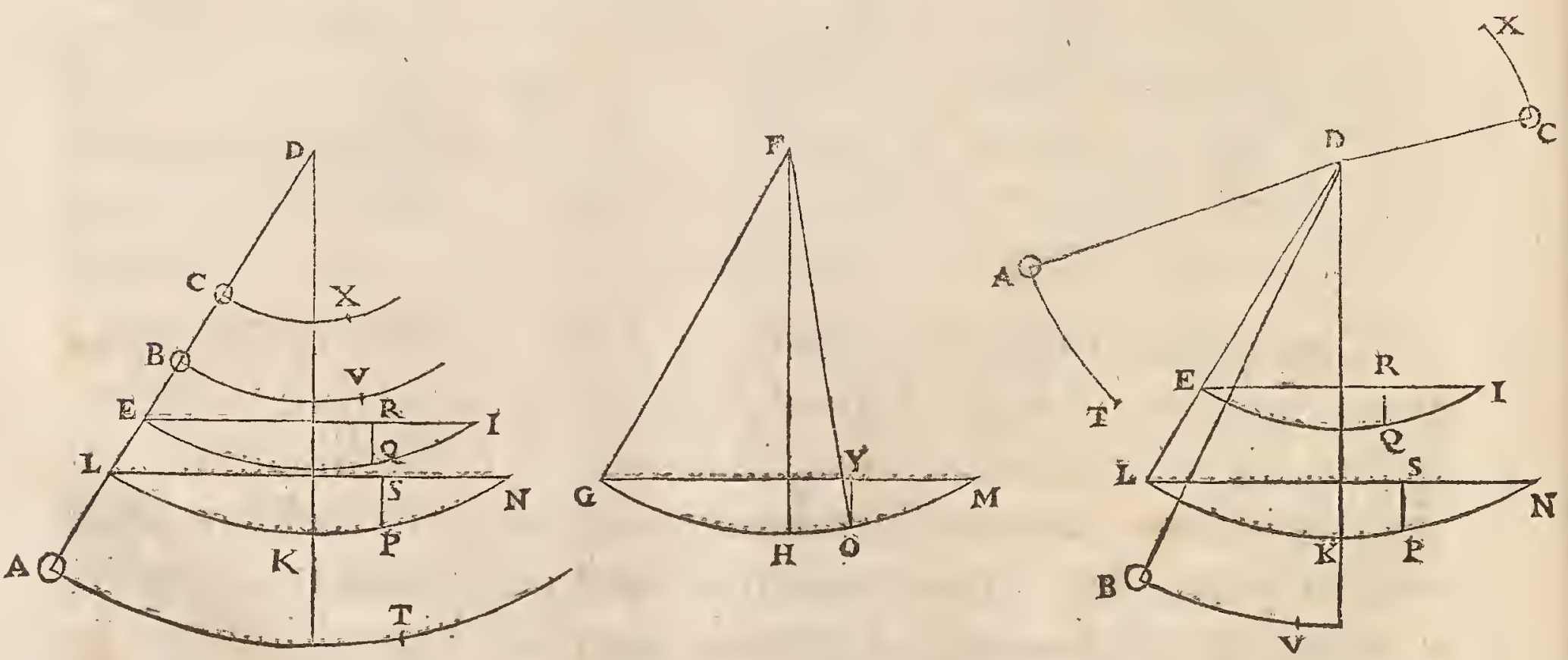

ab axe, qui per punctum $D$, ad planum quod confpicitur, rectus in. telligitur. In quo plano fit quoque eorum centrum commune gravitaris $\mathrm{E}$; nam pondera in diverfis effe nihil refert. Diftantia puncti $\mathrm{ab}$ axe, nempe recta $\mathrm{E}$, vocetur $d$. Item ponderis $A$ diftantia $A D$, fit $e ; B D, f ; C D, g$. Ducendo itaque fingula pondera in qua- 
HOROLOG. OSCILLATOR.

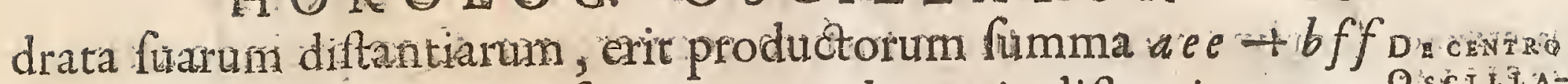
$+c g g$. Et rurfus, ducendo fummam ponderum in diftantiam cen o'seis is. tri gravitatis omnium, productum $x$ quale erit ad $+b d+c d * V n$ - * Prop.r. huj

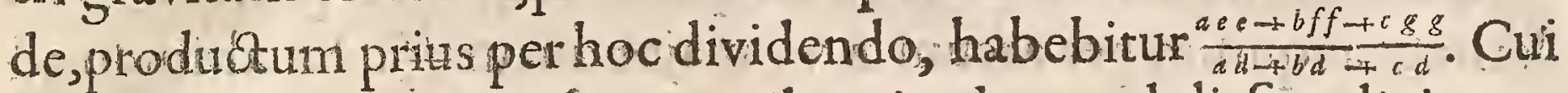
longirudini fi xqualis ftatuatur longirudo penduli fimplicis $\mathrm{F}$, qua erian $x$ vocabirur; dico hoc illi compofito ifochronum effe.

Ponantur enim tum pendulum F G, tum linea centri D E, æquaLibus angulis à linea perpendiculi remora, illud $\mathrm{ab} \mathrm{FH}, \mathrm{hæc}$ ab D K, arque inde dimiffa librari, \& in recta $\mathrm{D}$ E fumatur $\mathrm{D}$ a qualis $\mathrm{F}$ G. I taque pondus $\mathrm{G}$ penduli $\mathrm{F}$, incégra ofcillatione arcum $\mathrm{G} \mathrm{M}$ percurrer, quem linea perpendiculi f in medium fecabit. punctum. vero $\mathrm{L}$ afcumilli fímilem \& $\&$ qualem $\mathrm{z}$, quem medium dividet D. I terique centrun gravitaris $\mathrm{E}$, percuret fimilem arcum EI. Qúod fin arcubus $\mathrm{G} M, \overline{\mathrm{L}}$, fumptis punctis quibullibet, fimiliter iplos dividentibus, ut o \&z $\mathrm{s}$, eàdem celeritas effe oftendatur ponderis $\mathrm{G}$ in $\mathrm{O}, \&$ puneti in $\mathrm{P}$; conftabit inde æqualibus temporibus utrofque arcus percurri, ac proinde pendulum $\mathrm{F} G$, pendulo com pofito ex A, B, C, ifochronum effe. Oftendetur autem hoc modo.

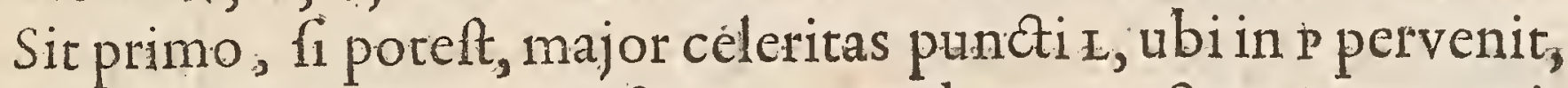
quam ponderis gin 0 . Conftat autem, dum punctum i percurrit arcum L $P$, fimul centrum graviitàtis $\mathrm{E}$ percurrere arcum fimilem $\mathrm{E}$ Q. Ducantur à punctis $\mathrm{Q}, \mathrm{P}, \mathrm{O}$, perpêndiculares furfum, quæ occurrant fubtenfis arcum $\mathrm{E}, \mathrm{I}, \mathrm{N}, \mathrm{GM}$, in $\mathrm{R}, \mathrm{s}, \mathrm{Y}$. \& $\mathrm{S}$ P vocetur $y$ : Vnde, cum fit ut $\mathrm{I} D, x$, ad $\mathrm{E} D$, $d$, ita $\mathrm{S}, y$, ad $\mathrm{R} \mathrm{Q}$; eric $\mathrm{R}$ Q $q u a-$ lis $\frac{d y}{x}$. Iam quia pondus $\mathrm{G}$ eam celeritatem habet in $O$; qua valet ad eandem unde defcendit altitudinem afcendere, nempe per arcum o M, vel perpendicularem o $\mathrm{Y}$ ipfi $\mathrm{P}$ s æqualem; punctum igitur $L$, ubi in P pervenerit, majorem ibi celeritatem habebic, quam qua afcenditur ad altitudinem $P$ s. Dum vero $L$ tranfic in $P$, fimul pondera $A, B, C$, fimiles arcus percurrunt ipf $\mathrm{E} P$, nimirum $A T$, $\mathrm{B} \mathrm{V}, \mathrm{CX}$. Eltque puncti $\mathrm{L}$ celeritas in $\mathrm{P}$, ad celeritatem ponderis $A$ in $T$, quum vinculo codem contineantur, ficut diftantia $D \mathrm{~L}$ ad D A. Sed ut quadratum celeritatis puncti $L$, quam habet in $\mathbf{P}$, ad quadratum celeritatis puncti $\mathrm{A}$ in $\mathrm{T}$, ita eft altitudo ad quam illa celeritate afcendi poteft, ad altitudinem quò hac celeritate afcendi poteft*. Ergo etiam, ut quadratum diftantix D $\mathrm{L}$, quod eft $x$, ad * Prop. 3. \& 4 . quadratum diftantix $\mathrm{DA}$, quod eft $e e$, ita eft alritudo quo afcen- part. 2. ditur celeritate puncti $\mathrm{L}$, quum eft in $\mathrm{P}$, (quæ altitudo major dicta eft quam p s five $y$, ad alritudinem quo afcenditur celeritate ponderis $\mathrm{A}$ in $\mathrm{T}$; fi nempe poltquam in $\mathrm{T}$ pervenit, relicto pendulo, 
DE CENTRo feorfim motum fuum furfum converteret. Qúx proinde altitudo Tx A A s. major erit quam $\frac{e e y}{x x}$.

Eadem ratione, erit altitudo ad quam afcenderet pondus $\mathrm{B}, \mathrm{ce}$ leritate acquifita per arcum B $\mathrm{v}$, major quam $\frac{f f y}{x x}$. Et altitudo ad quam afcenderet pondus $\mathrm{c}$, celeritare acquifita per arcum $\mathrm{c} \mathbf{x}$, major quam $\frac{s g y}{x x}$. Vnde, ductis fingulis altitudinibus iftis in fua pondera, erit fumma productorum major quam $\frac{a e \hat{e} y+b f f y+c g g y}{x x}$. qux proinde major quoque probatur quam $\frac{a d y+b d y+c d y}{x}$. Nam quia pofita eft longitudo $x$ xqualis $\frac{a e c+b f f+c g g}{a d+b d+c d^{\prime}}$; erit $a d x+b d x+c d x$ xquale a ee $+b f f+c g g$. Et ductis omnibus in $y, \&$ dividendo per $x x$, erit $\stackrel{a d y+b d y+c d y}{x} x$ quale $\frac{a e e y+b f f y+c g g y}{x x}$. Vnde quod dictum eft confequitur. Eft autem fumma ifta productorum æqualis $e$, quod fit ducendo altitudinem, ad quam afcendit centrum gravitaris commune ponderum $A, B, C$, in fummam ipforum ponderum, $a+b+c$; fi nempe fingula, uti dictum, feorfim quoufque poffunt moveantur. Quantitas vero $\frac{a d y+b d y+c d y}{x}$ producitur ex defcenfu centri gravitaris eorundem ponderum, (qui defcenfus eft $\mathrm{R} Q$, five $\frac{d y}{x}$, ut fupra inventum fuit, ) in eandem quoque ponderum fummam $a+b+c$. Ergo quum prius productum altero hoc majus oftenfum fuerit, fequitur afcenfum centri gravitatis ponderum $A, B, C, f$, relicto pendulo ubi pervenere in $T, v, x$, fingula celeritates acquifitas furfum convertant, majorem fore ejufdem centri gravitatis defcenfu, dum ex A, B , C, moventur in $T, v, x$. quod eft abfurdum, cum dictus afcenfus defcenfui æqualis effe debeat, per antecedentem.

Eodem modo, fi dicatur celeritatem puncti i , ubi pervenerit in $\mathrm{P}$, minorem effe celeritate ponderis $\mathrm{G}$ quum in o pervenerit; oftendemus afcenfum poffibilem centri gravitatis ponderum $A, B$, $C$, minorem effe quam defcenfum, quod eidem propofitioni antecedenti repugnat. Quare relinquitur ut eadem fit celeritas punCti $\mathrm{L}$, ad $\mathrm{P}$ tranflati, qux ponderis $\mathrm{G}$ in $\mathrm{O}$. Vnde, ut fuperius dictum, fequitur pendulum fimplex $\mathrm{F}$ G compofito ex A, B, C, ifochronum effe.

\section{PROPOSITIO VI.}

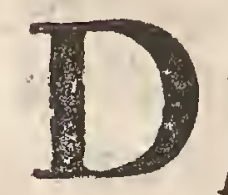

Ato pendulo ex quotcunque ponderibus aqualibus compofito; la fumma quadratorum factorum à diftantiis, quibus unumquodque pondus abeft ab axe of cillationis, ap- 
pliceturad difantian centri gravitatis communis ab eodem $D_{E} C E N T R$ ofcillationis axe, multiplicem fecundum ip forum ponderum x numerum, orietur longitudo penduli fimplicis compofro ifochroni.

Sint porita eadem qux prius, fed pondera omnia inter fe rqua. lia intelligantur, \& fingula dicantur a. Rurfus vero nulla eorum. magnitudo confideretur, fed pro minimis habeantur, quantum ad extenfionem.

Itaque penduli fimplicis ifochroni longitudo, per propofitio nem antecedentem, erit $\frac{a e e+a f f+a g z}{a d+a d+a b}$. Vel, quia quantitas divifa ac dividens utraque per a dividitur, fiet nunc eadem longitudo, $\frac{e t+f f \rightarrow s g}{j d}$. Quo fignificatur fumma quadratorum à diftantiis ponderum ab axe of cillationis, applicata ad diftantiam centri gravitatis omnium at codem of cillationis axe, multiplicem fecundum numerum ipforum ponderum, qui hic eft 3 . facile enim perfpicitur numerum hunc, in quem ducitur diftantia $d$, refpondere neceffario ipfi ponderum numero. Quare conftat propofitum.

Quod fi pondera xqualia in unam lineam rectam conjuncta fint, atque ex termino ejus fuperiore fufpenfa ; conftat diftantiam. centri gravitatis, ex omnibus compofite, ab axe of cillationis, multiplicem fecundum ponderum numerum, æquari fummæ diftantiarum omnium ponderum ab eodem of cillationis axe*; ac proinde, * Prop. a huj. hoc cafu, habebitur quoque longitudo penduli fimplicis, compofito ifochroni, fi fumma quadratorum à diftantiis ponderum fingulorum $\mathrm{ab}$ axe ofcillarionis, dividatur per fummam earundem omnium diftantiarum.

\section{DEFINITIO XIV.}

SI fuevint in eodem plano, foura quadam, bt) linea recta 1 que ipfam extrinfecus tangat; $E$ per ambitum figure alia recta, plano ejus perpendicularis, circumferatur, Juperficiemque quandam defcribat, que deinde fecetur plano per dictam tangentem ducto ES ad dicte figure planum inclinato; folidum comprebenfin à duobus planis iftis, E parte foperfic ciei defcripts, inter utrumque planum intercepta, vocetur Cunevs fuper figura illa, tanquam baj $\hat{L}$, abfijfus.

In fchemate adjecto, eft A B E C figura data; recta eam tangens 
D: CENTRO M D; quix vero per ambitum ejus circumfertur, E F; cuneus au(1) SCILIA-

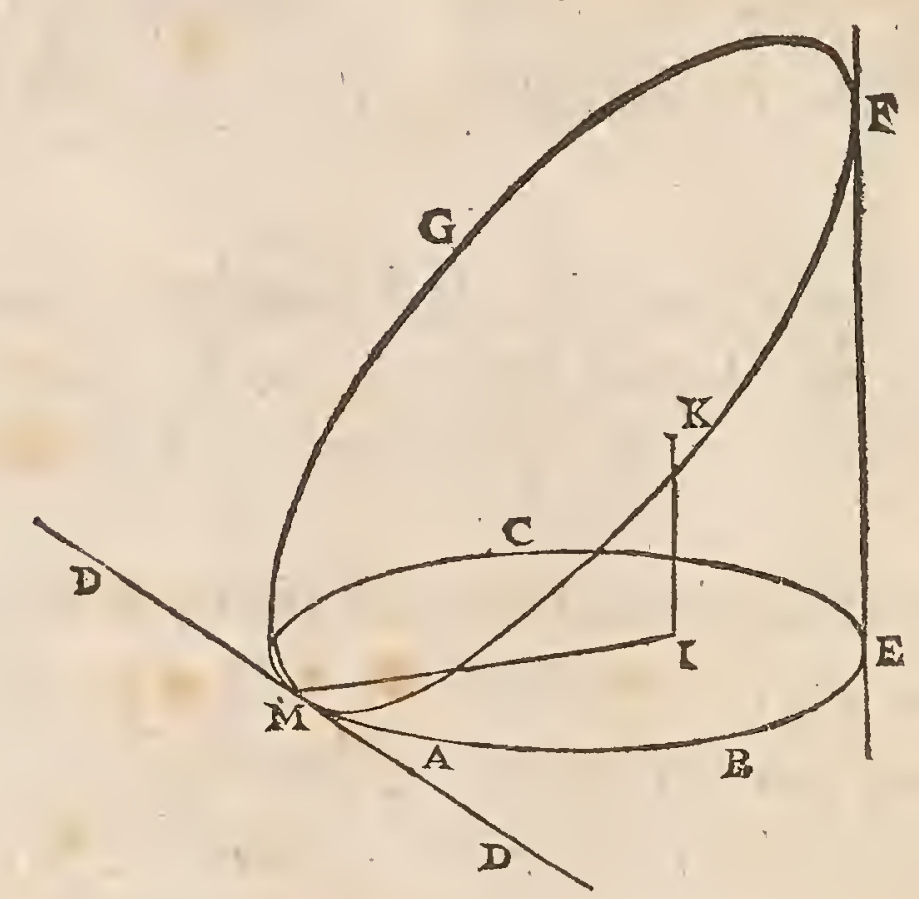

tem figura folida planis A B E C, M $\mathrm{G}, \&$ parte fuperficiei, recta $\mathrm{E}$ F defcriptæ, comprehenfa.

\section{DEFI N I I I O X V.}

D Iftantia interrectam, per quam cuneus ab foifJus eft, $G^{3}$ punitum bafeos, in quod perpendicularis cadit à cune $\dot{\imath}$ centro gravitatis, dicatur cunei Subcentrica. Nempe in figura eadem, $\int \mathrm{L} \mathrm{K} / \mathrm{lt}$ centrum gravitatis cunei, recta vero $\mathrm{K} \mathrm{I}$ ad bafin ejus A B E C perpendicularis ducta fit, Ev rur us I M perpendicularis ad A D; erit I M, quam Jubcentricam dicimus.

\section{PROPOSITIO VII.}

Vneus fuper plana fgura qualibet ab ciffus, plano inclinato ad angulum femirectum, a qualis eft folido, quod fit ducendo figuram eandem, in altitudinem aqualem difianti.e centri gravitatis figure, ab recta per quam abfiffus eft cuneus.

Sit, fuper figura plana A C B, cuneus A B D ablcilfus plano ad angulum femirectum inclinato, ac tranfeunte per $\mathrm{E} E$, rectam tangentem figuram $A C B$, inque ejus plano fitam. Centrum vero gravitatis figuræ fit $\mathrm{F}$, unde in rectam $\mathrm{E} \mathrm{E}$ ducta fit perpendicularis F A. Dico cuncum A C B æqualem effe folido, quod fit ducendo figuram $\mathrm{A} C \mathrm{C}$ in altitudinem ipfi $\mathrm{F}$ A xqualem.

Intelligatur enim figura $\mathrm{A} C \mathrm{~B}$ divifa in particulas minimas æqua- 
HOROLOG. OSCILLATOR.

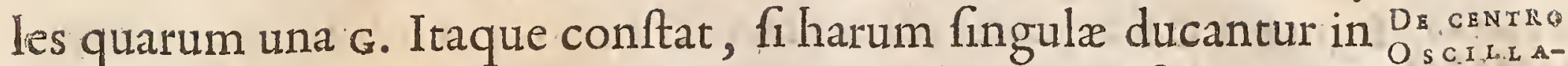
diftantiam fuam ab recta $\mathrm{E} E$, fummam productorum fore $æ q u a-$ т I $\mathrm{N}$ Is. lem ei quod fit ducendo rectam A $\mathrm{F}$ in particulas omnes*, hoc eft, * Prop. x. huj. ei quod fit ducendo figuram ipfam $A C B$, in altitudinem xqualem. A F. Atqui particulæ fingulæ ut $G$, in diftantias fuas $G$. H ductæ, æquales funt parallelepipedis, vel prifmatibus minimis, fuper ipfas erectis, atque ad fuperficiem obliquam A $D$ terminatis, quale eft $\mathrm{GK}$; quia horum alcitudines.ipfis diftantiis $\mathrm{G} H æ q$ quantur, propter angulum femirectum inclinationis planorum $A D$ D $\&$ A $B$. Patetque ex his parallelepipedis totum cuneum A B D componi. Ergo \& cuneus ipfe æquabitur folido fuper bafi. A C B, altitudinem haben. ti rectæ F A æqualem. quod erat demonftrandum.

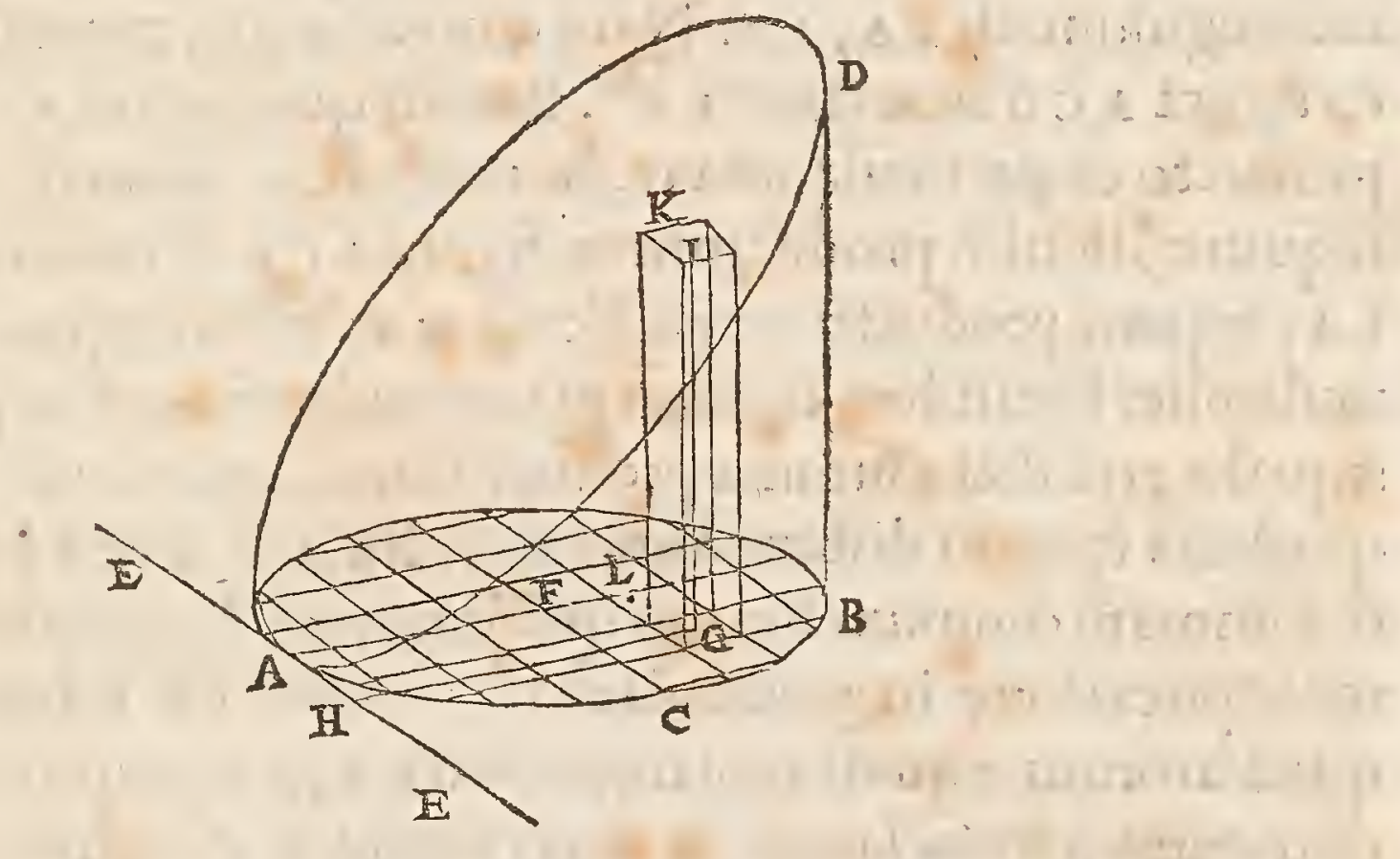

\section{PROPOSITIO VIII.}

I Ifguram planam linea recta tangat, divifaque intelli- gatur figura in particulas minimas aquales, atque it fongulis ad rectam illam perpendiculares ducte: erunt omnium barum quadrata, fimul fumpta, equalia rectangulo cuidam, multiplici fecundum ip farum particularum numerum; quod nempe rectangulum fit aे diftantia centri gravitatis figure ab cadem recta, $\sigma^{\circ}$ à fubcentrica cunei, qui perillam fuper figura abfinditur.

Pofitis enim cæteris omnibus qux in conftuctione præcedenti, fit I A cunei A B D fubcentrica inrectam E E. Oportet igitur oftendere, fummam quadratorum omnium à diftantiis particularum 
106

DE CENTro figuræ A C B æquari rectangulo ab F A, L A, multiplici fecundum OSCTISA- particularum numerum.

Et conftat quidem ex demonftratione præcedenti, altitudines parallelepipedorum fingulorum, ut $\mathrm{G} \mathrm{K}$, æquales effe diftantiis parcicularum, qux ipforum bafes funt, ut $\mathrm{G}, \mathrm{ab}$ recta $\mathrm{A} \mathrm{E}$. Quare, fi jam parallelepipedum $\mathrm{G} . \mathrm{K}$ ducamus in diftantiam $\mathrm{G} \mathrm{H}$, perinde eft ac $\mathrm{fl}_{\mathrm{I}}$ particula G ducatur in quadratum diftantix G H. Eodemque modo fe res haber in reliquis omnibus. Atqui producta omnia parallelepipedorum in diftantias fuas ab recta $\mathrm{A} E$, æquantur fimul produ* Prop. r. haj. Cto ex cuneo A B D in diftantiam $L_{A} *$, quia cuneus gravitat fuper puncto L. Ergo eriam fumma produetorum à particulis fingulis G, in quadrata fuarum diftantiarum $a b$ recta $A \mathrm{E}, x$ quabitur producto ex cuneo $A B D$ in rectam $L A$, hoc eft, producto ex figura $A$ C $B$ in rectangulum $a b$ F $A, I A$. Nam cuneus $A B D$, æqualis eft producto ex figura $A$ C $B$ in rectam $F A$. Rurfus quia figura $A$ C $B$ æ . qualis eft producto ex particula una $G$, in numerum ipfarum particularum; fequitur, dictum productum ex figura $\mathrm{A}$ С $\mathrm{B}$ in rectangulum $\mathrm{ab} \mathrm{FA}$, I A, xquari producto ex particula $\mathrm{G}$ in rectangulum $\mathrm{ab} \mathrm{F} A, \mathrm{I}_{\mathrm{A}}$, multiplici fecundum numerum particularum G. Cui proinde etiam $æ q u a l i s$ erit dicta fumma productorum, à particulis fingulis $\mathrm{G}$ in quadrata fuarum diftantiarum ab recta $\mathrm{A} E$, five à particula una $\mathrm{G}$ in fummam omnium horum quadratorum. Quare, omiffa utrinque multiplicatione in particulam $\mathrm{G}$, neceffe eft fummam eandem quadratorum æquari rectangulo ab F A, I A, multiplici fecundum numerum particularum in quas figura $\mathrm{A} C \mathrm{~B}$ divifa intelligitur. quod erat demonftrandum.

\section{PR O P O S I T I O I X.}

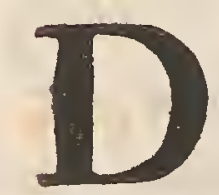
Atâ frgurâ planâ E़ in codem plano lineâ rectâ, que vel fecet figuram vel non, ad quam perpendiculares cadant à particulis singulis minimis $\mathcal{E}^{\circ}$ aqualibus, in quas figura divifa intelligitur; invenire fummam quadratorum ab omnibus iftis perpendicularibus; frve planum, cujus multiplex, fecundum particularum numerum, dicta quadratorsm fum. me aquale fit.

Sic data figura plana A в C, \& in eodem plano recta $\mathrm{E} D$; divisâque figurâ cogitatu in particulas minimas æquales, intelligantur $a b$ unaquaque earum perpendiculares ductx in rectam E D , ficut à particula $\mathrm{F}$ ducta eft $\mathrm{F} K$. Oporteatque invenire 


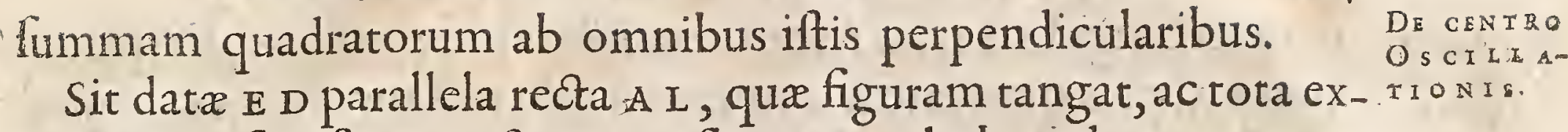
tra eam pofita fit. Potelt autem figuram vel ab eadem parte ex qua eft $\mathrm{E} D$, vel à parte oppofita contingere. Diftantia vero centri gravitatis figuræa $a$ recta $A$ I fic recta $G A$, fecans $E D$ in $E ; \&$ fubcentrica cunei, fuper figura abfcifli plano per rectam A L, fit $\mathrm{H}$ A. Dico fummam quadratorum quæfitam æquari rectangulo $\mathrm{A} G \mathrm{H}$ una cum quadrato $\mathrm{E} G$, multiplicibus fecundum particularum numerum, in quas figura divifa intelligitur.
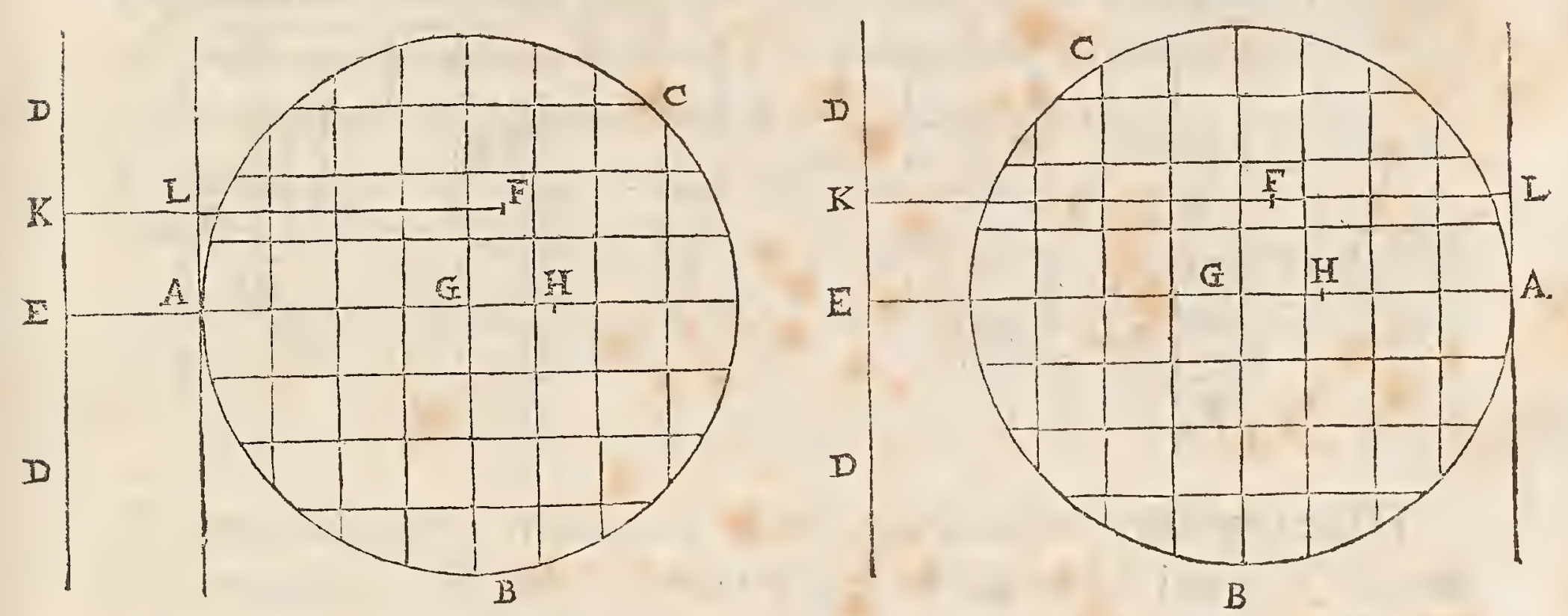

Occurrat enim $\mathrm{F}$, fi opus eft producta, tangenti $\mathrm{x}$ in $\mathrm{L}$ puncto. Itaque primum, eo cafu quo recta e D à figura diftat, \& tangens $\mathrm{A}$ I ad eandem figuræ partem ducta eft, fic propofitum often. detur. Summa omnium quadratorum $\mathrm{F}$ K $x$ quatur totidem quadratis $\mathrm{KL}$, una cum bis totidem rectangulis $\mathrm{K} \mathrm{LF}, \&$ totidem infuper quadratis L F. Sed quadrata $\mathrm{K}$ L æquantur toridem quadratis E A. Et rectangula K L F æqualia effe conftat totidem rectangulis E A G, quia omnes F $\mathrm{L} x$ quales totidem $G A^{*}$. Er denique quadrata * Prop. 2. huj. I $\mathrm{F} æ$ quantur totidem rectangulis $\mathrm{HA} \mathrm{G} *$, hoc eft, totidem qua- ced. dratis A $\mathrm{G}$ cum totidem rectangulis A $\mathrm{G}$ H. Ergo quadrata omnia.F $\mathrm{K}$ æqualia erunt toridem quadratis $\mathrm{EA}$, cum totidem duplis rectangulis E A G, atque infuper totidem quadratis A G cum totidem rectangulis A G H. Atqui tria ifta; nempe quadratum E A cum duplo rectangulo E A G \& quadrato A G; faciunt quadratum E G. Ergo apparet quadrata omnia $\mathrm{F}$ Kæquari totidem quadratis $\mathrm{E} G$, una cum totidem rectangulis $\AA \mathrm{G} \mathrm{H}$. Quod erat oftendendum.

Porro in reliquis omnibus cafibus, quadrata omnia $\mathrm{F} x \mathfrak{x}$ quantur totidem quadratis $\mathrm{K} L$, minus bis totidem rectangulis $\mathrm{K} L \mathrm{~F}$, plus totidem quadratis $L F$; hoc eft, totidem quadratis $\mathrm{E} A$, minus totidem duplis rectangulis $\mathrm{EA} G$, plus toridem quadratis $\mathrm{A} G$, cum to-

$$
\mathrm{O} \text { ij }
$$


Da centro dem rectangulis a G H. Atqui, omnibus hifcecafibus, fit quadraOscrisa- cumEA, plus quadrato A G, minus duplo refangulo E A G, æquale quadrato E G. Ergo rurfus quadrata omnia F. K æqualia erunt totidem quadratis E $\mathrm{G}$, una cum totidem rectangulis A $\mathrm{G}$ H. Quare conftat propofitum.
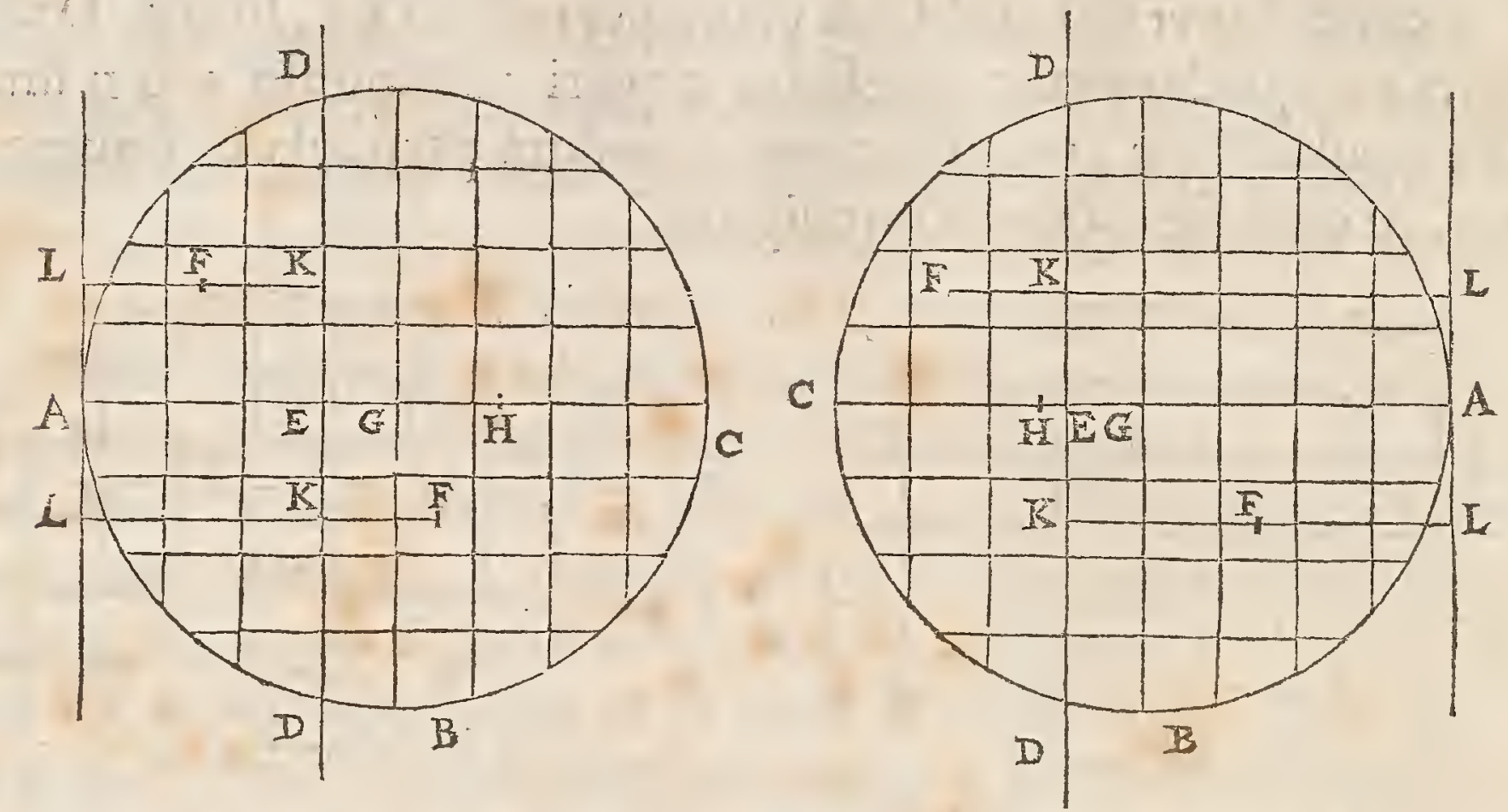

Hinc fequitur, rectangulum $\mathbb{A} G \mathrm{H}$ eadem magnitudine effe, utriufvis cunei fubcentrica fuerit $A H$; hoc eft, five per hanc, frve per illam tangentium parallelarum A $L$ abfciffi. Itaque $\mathrm{A} G$ unius cafus ad A $\mathrm{G}$ alterius, ut $\mathrm{H}$ G hujus ad $\mathrm{H}$ G illius. Sicut autem rectæ A G.inter fe, ita in utroque cafu cunei per A L abfciff, ut colligitur ex prop. 7. huj. Ergo ita quoque reciproce G. H ad G H.

A pparet eriam, dato figuræ planæ centro gravitatis $G, \&$ fubcentrica cunei, per alterutram tangentium parallelarum $\mathrm{A}$ L abfciffi, dari quoque cunei, per tangentem alteram $\mathrm{A} L \mathrm{abf}$ cifli, fubcentricam.

\section{P R O P O S I T I O X.}

Dofitis que in propofitione pracedenti; $f$ data recta $\mathrm{E} D$ 1. tranfeat per $G$, centrum gravitatis figura $A B C$; erit fum-

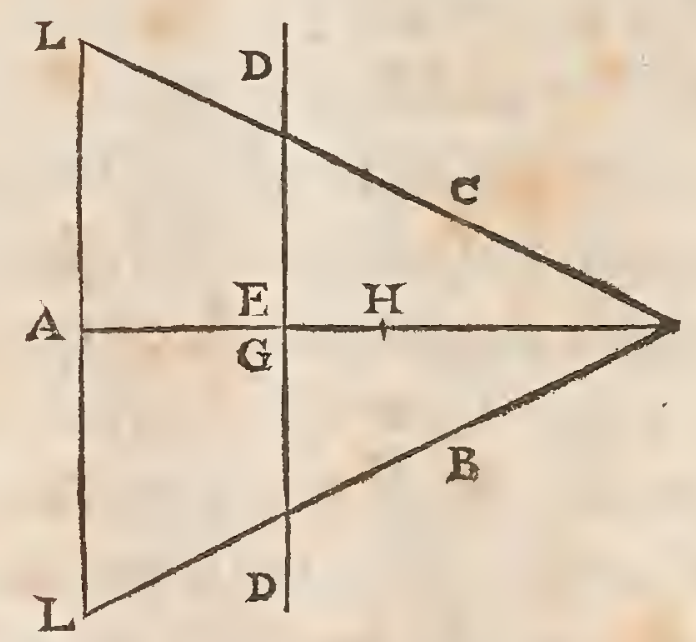

ma quadratorum à distantiis particularum, in quas figura 
divifa intelligitur, ab recta $\mathrm{E} D$, aqualis rectangulo foli $\mathrm{A} G \mathrm{H}, \mathrm{DE}$ OENTRO multiplici fecundum ip arum particuliurum numerum.

Hoc enim manifeftum eft, quum nullum tunc fit quadratum E G.

\section{PROPOSITIO XI.}

D Oftis rurges cateris ut in precedentium penotuma $\int_{l}$

$\mathrm{DE}$ fit axisfigura plana A B C, in duas aquales fimilefque portiones cam dividens, fitque infuper $\mathrm{V} G$ diftantia centri gravitatis dimidia figure $\mathrm{D}$ A D ab rect a E D, cunei vero, fuper ipfam abfciffi per ipfam $\mathrm{E} D$, fubcentrica $\mathrm{CX}$; erit re-

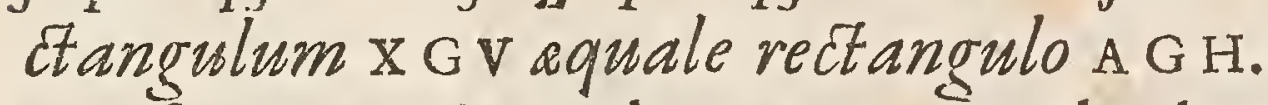

Eft enim rectangulum $x \in \mathrm{V}$, multiplex fecundum numerum particularum figuræ D A D, xquale quadratis omnibus perpendicularium à particulis ejufdem figuræ dimidix in rectam E D ca. dentium*. Ac proinde idem rectangulum X G V , multiplex fecun- * Prop. 8. huj.

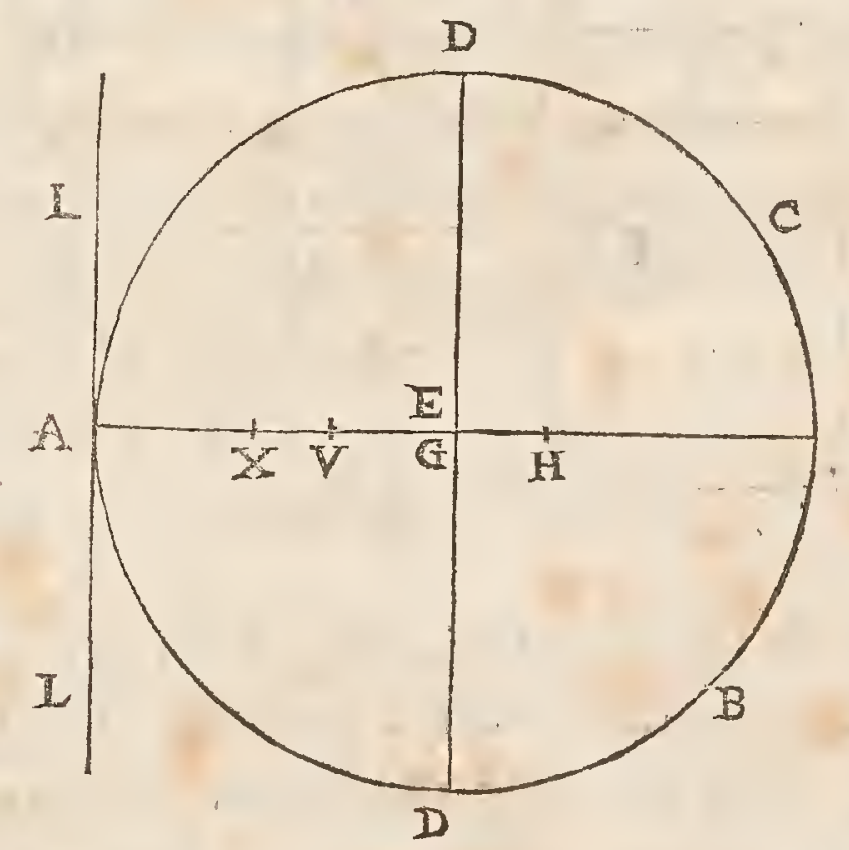

dum numerum particularum totius figuræ A B C, æquale erit quadratis perpendicularium, $\mathrm{ab}$ omnibus particulis figuræ hujus in re. ctam E D demiffarum; hoc eft, rectangulo $\AA$ G H multiplici fecundum eundem particularum numerum, ut conftat ex propof. prxcedenti. Vnde fequitur rectangula x G V, A G H inter fe æqualia effe. quod erat demonftrandum.

\section{P R O P O S I T I O X I I.}

1 Atis in plano punctis quotlibet; fiex centro gravitatis. ab omnibus datis punctis, ad puncturn aliquod in circuli illins

$\mathrm{O}$ iij 
Sint data puncta A B C D : centrumque gravitatis eorum, five magnitudinum $x$ qualium ab ipfis fufpenfarum, fit $\mathrm{E}$; \& centro $\mathrm{E}$ defcribatur circulus quilibet $f$, in cujus circumferentia fumpto puncto aliquo, ut $F$, ducantur ad id, à datis punctis, rectæ A F, B F, C F, D F. Dico earum omnium quadrata, fimul fumpta, xqualia effe plano cuidam dato, femperque eidem, ubicunque in circumferentia punctum $\mathrm{F}$ fumprum fuerit.

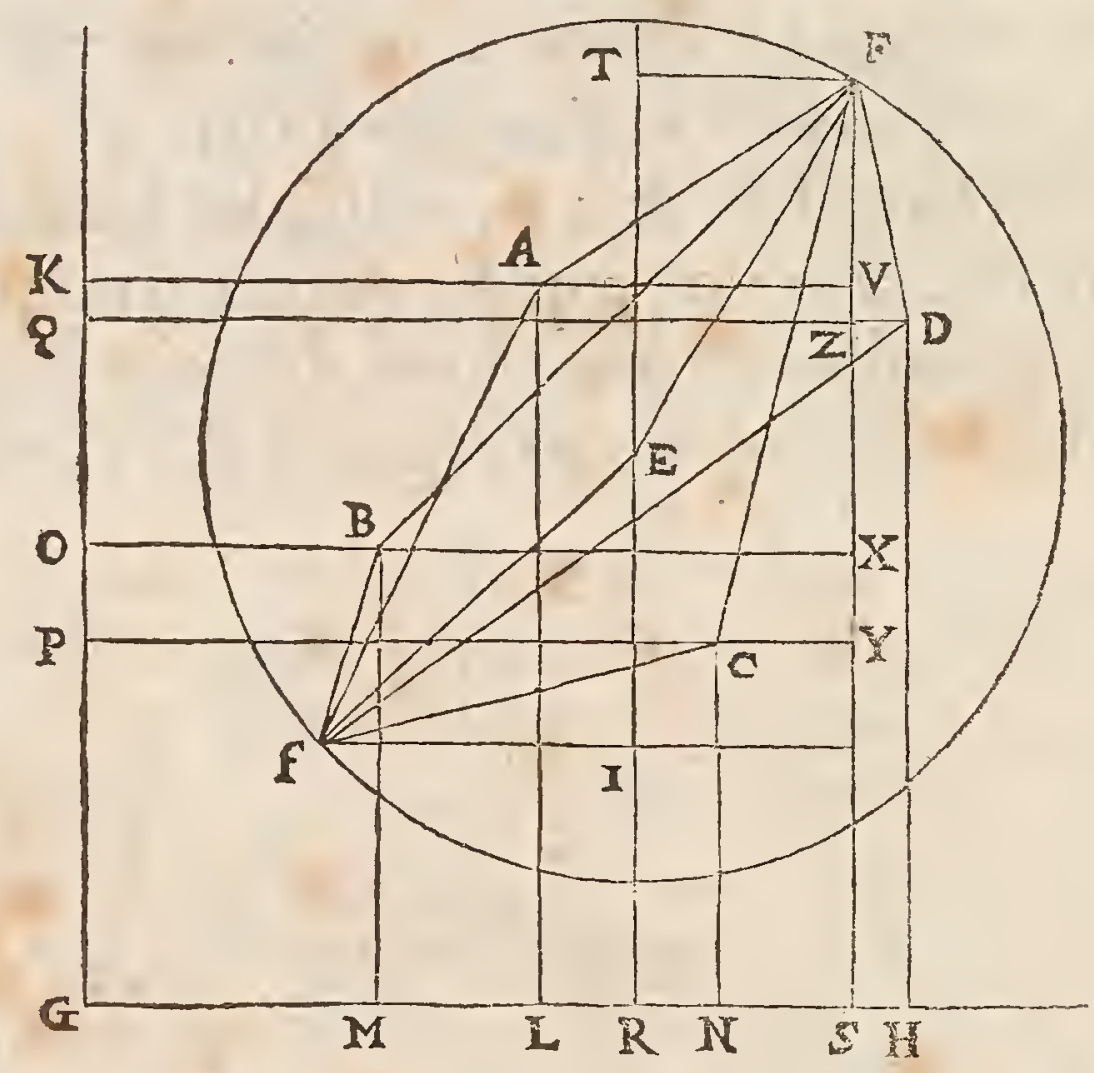

Ducantur enim rectx $\mathrm{GH}, \mathrm{GK}$, angulum rectum confticuentes, \& quarum unicuique omnia data puncta fint pofita ad eandem partem. Et à fingulis in utramque harum perpendiculares agantur $\mathrm{A} L, A \mathrm{~K} ; \mathrm{B} \mathrm{M}, \mathrm{BO}$; C N, C P; D H, D Q. A centro autem gravitatis $\mathrm{E}$, \& à puncto $\mathrm{F}$, in alterutram duarum, $\mathrm{G}$ H vel $\mathrm{GK}$, perpendiculares E R, F S. Et item, à datis punctis, in ipfam $\mathrm{F}$ s perpendiculares $\mathrm{AV}$, $B X, C Y, D$ z. Et F T perpendicularis in ipfam E R. Porro fit jam
A $L>a$
A K $\infty$
radius $\mathrm{E} F>z$
$\mathrm{B} \mathrm{A}>b$
B $\bigcirc \propto f$
G S $>x$
$\mathrm{C} N \infty{ }^{\mathrm{N}} \infty$
$D H>d$
C $\mathrm{P} \times g$
$D Q \infty b$

Quia autem $\mathrm{E}$ eft centrum gravitatis punctorum $\mathrm{A}, \mathrm{B}, \mathrm{C}, \mathrm{D}$; f addantur in unum perpendiculares $\AA \mathrm{L}, \mathrm{B} \mathrm{M}, \mathrm{CN}, \mathrm{D} \mathrm{H}$, compofitaque ex omnibus dividatur in tot partes, quot funt data puncta; * Prop. 2 . huj. carum partium uni æqualis erit $\mathrm{E} R *$. Similiterque, divisâ in toti- 
dem partes fummâ perpendicularium $A \mathrm{~K}, \mathrm{~B} O, \mathrm{C} P, \mathrm{D} Q$, earum uni æqualis erit perpendicularis, ducta ex $\mathrm{E}$ in rectam $\mathrm{GK}$, five ipfa DE CENTRE OSCIILA$\mathbb{R}_{\mathrm{G}} *$. Itaque, fi fumma omnium $\mathrm{AI}, \mathrm{B} \mathrm{M}, \mathrm{CN}, \mathrm{DH}$, five $a+b$ TIONIS. $+c+d$ vocetur $l$ : fumma vero omnium, $\mathrm{A} K, \mathrm{~B} \mathrm{O}, \mathrm{CP}, \mathrm{D}$, five * Prop. 2, huj. $e+f+g+h$, vocetur $m$ : \& numerus, datorum punctorum multitudinem exprimens, dicatur $\theta$; erit E R $\infty \frac{l}{\theta} ; \& \mathrm{R} \mathrm{G} \infty \frac{\pi}{\theta}^{m}$. Cumque

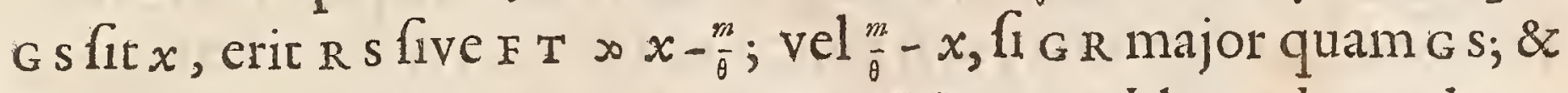
femper quadratum $\mathrm{F}$ T $x$ x $x x-2 \frac{x m}{\theta}+\frac{m m}{\theta \theta}$. quo ablato ab quadrato

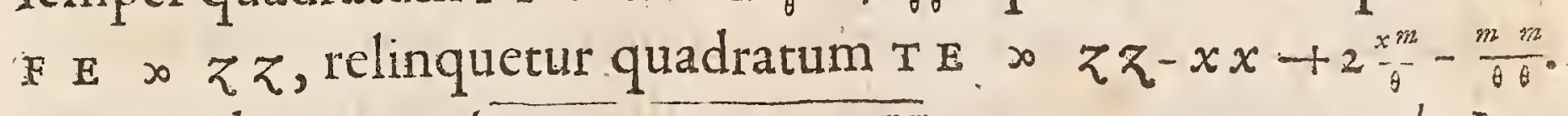

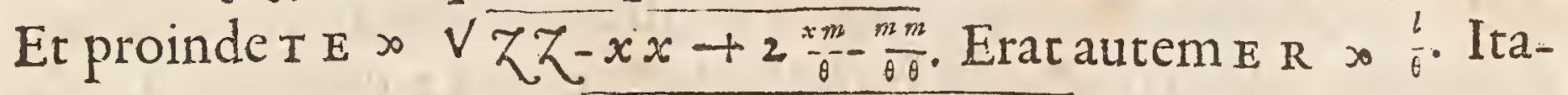

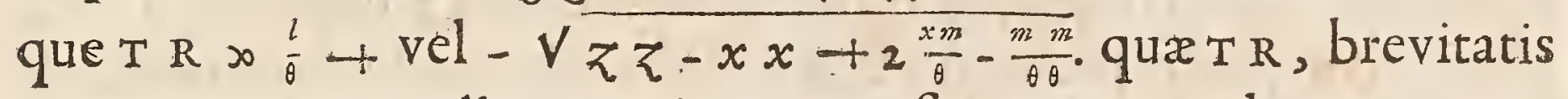
gratia, dicatur $y$. Colligamus jam porro fummam quadratorum om nium $F A, F B, F C, F D$. Quadratum A $F$ equatur quadratis A $V, V F$. Eft autem $A$ v $æ$ qualis differentiæ duarum $\mathrm{V} K, A K$, five duarum $S \mathrm{G}, \mathrm{AK}$; acproinde $\mathrm{A} \mathrm{V} \infty x-e \operatorname{vel} e-x ; \&$ qu. A $\mathrm{y} \infty x x-2 e x+$ $e$ e. $\mathrm{V} F$ vero $æ$ qualis eft differentiæ duarum $\mathrm{F} S, \mathrm{v} s$ five duarum $\mathrm{F} s$, A L ; ac proinde V F $>y$-a vel $a-y$; \& qu. V F $\infty y y-2 a y+a a$.

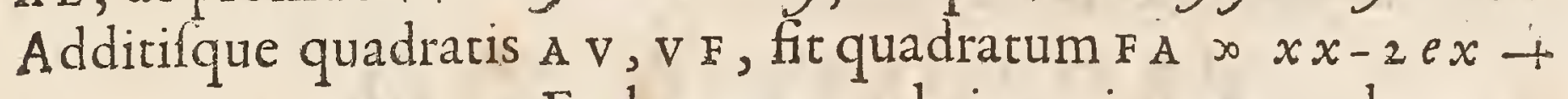
$e e+y y-2 a y+a a$. Eodemque modo invenientur quadrata reliquarum F B , FC, FD; atque omnia ordine difpofita erunt hæc;

$$
\begin{aligned}
& \text { qu. FA }>x x-2 e x+e+y y-2 a y+a a_{0} \\
& \text { qu. F B } x x-2 f x+f f+y y-2 b y+b b . \\
& \text { qu. F } \infty x x-2 g x+g g+y y-2 y+c c . \\
& \text { qu. FD } \infty x x-2 b x+b b+y y-2 d y+d d .
\end{aligned}
$$

Horum vero fumma; $\mathrm{fl}$ ponamus quadrata $e e+f f+g g+b b x_{\infty}$ $n n$; \& quadrata $a a+b b,+c c+d d x k k$; erit ifta, $\theta x x-2$ $m x+n n+\theta y y-2 l y+k k$. Siquidem $\theta$ erat numerus datorum punctorum ideoque \& quadratorum, pofitumque fúerat $e+f+$ $g+b>m, \& a+b+c+d \times l$.

In ifta vero fumma, fi in terminis $\theta$ y $y \& z l y$, pro $y$, ponatur id cujus loco pofitum erat, nempe $\frac{l}{\theta}+\mathrm{vel}-\sqrt{z z-x x}+2 \frac{\bar{z} m}{\theta}-\frac{m}{\theta \theta}$, fiet $+\theta y y{ }^{\prime \prime} \frac{l l}{\theta}+2 l \vee z z-x x+2 \frac{x m}{\theta}-\frac{m m}{\theta \theta}+\theta z z \theta x x+2 z m-\frac{m m}{\theta}$.

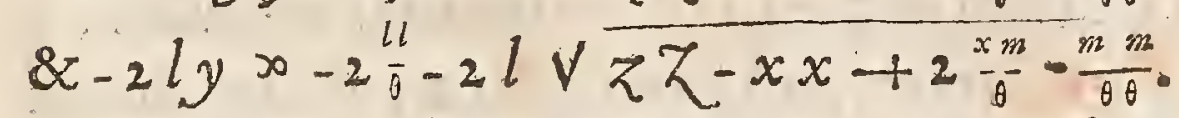

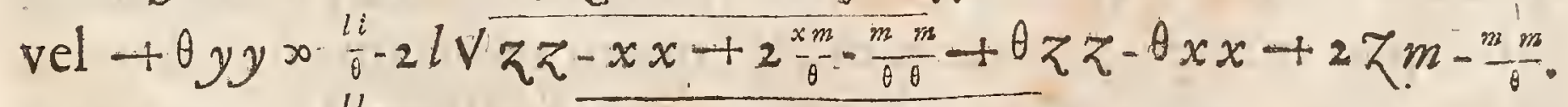
$\&-2 l y x^{\infty}-2 \frac{l l}{\theta}+2 l \vee \overline{z z-x x+2 \frac{x+m}{\theta}-\frac{m m}{\theta \theta}}$.

Ac proinde, utroque cafu, pro $\theta y y-2$ ly habebitur $+\theta z z-\theta x x$ $+2 x m-\frac{m m}{0}$. Quò appofitis reliquis quantitatibus, fumma prædi- 
Ata contentis, $\theta x x-2 x m+n n+k k$, fiet tota fumma, nempe quadratorum FA, FB , EC, FD, $\infty \theta z z+n n+k k-\frac{m m l l}{\theta}$. Quodapparet effe planum datum, cum hæ quantitates omnes datæ fint; femperque idem reperiri, ubicunque in circunferentia fumptum. fuerit punctum $F$. quod erat demonftrandum.

Quod fi puncta data diverfas gravitates habere ponantur, invicem commenfurabiles, ut fi punctum A ponderet ut 2 , B ut 3 , cut 4, D ut 7 , eorumque reperto gravitatis centro, circulus rurfus defribatur, ad cujus circumferentix punctum, à datis punctis rectæ ducantur, ac fingularum quadrata multiplicia fumanturfecundum numerum ponderis puncti fui; ut quadratum A F duplum, B F triplum, C F quadruplum, D F feptuplum; dico rurfus fummam omnium æqualem fore fpatio dato, femperque eidem, ubicunque in circumferentia punctum fumptum fuerit. Patet enim hoc ex præcedenti demonftratione, fi imaginemur puncta ipfa multiplicia fecundum numeros attriburx cuique gravitatis; quafi nempe in A duo puncta conjuncta fint, in B tria, in C quatuor, in D feptem, atque illa omnia æqualiter gravia:

\section{PROPOSITIO XIII.}

\section{I figura plana, vel linea in plano exiftens, aliter atque $\checkmark$ aliter fupendatur à punctis, que, in eodem plano accepta,} aqualiter à centro gravitatis fue diftent; agitata motu in latus, fibi ipfs ifochrona eft.

Sit figura plana, vel linea in plano exiftens A B C, cujus centrum gravitatis $\mathrm{D}$. quo codem centro, circumferentia circuli in eodem plano defcribatur, E C F. Dico, fi à quovis in illa puncto, ut E, C, vel $G$, fufpenfa figura agitetur in latus; fibi ipfr, five eidem pendulo fimplici, ifochronam effe.

Sit prima fufpenfio ex $\mathrm{E}$ puncto, quando autem eft extra figuram, ut hic, putandum eft lineam $\mathrm{E} H$, ex qua figura pendet, rigidam elfe, atque immobiliter ipfl affixam.

Intelligatur figura A B C divifa in particulas minimas æquales, à quarum omnium centris gravitatis, ad punctum $\mathrm{E}$, rectr duct $x$ fint; quas quidem manifeftum eft; quum moveatur figura motu in latus, effe ad axem agitationis perpendiculares. Harum igitur omnium perpendicularium quadrata, divifa fer rectam E D, multiplicem fecuncum numerum particularum in quas figura divifa * Prop. 6. huj. eft, efficiunt longitudinem penduli fimplicis, figuræ ifochroni*, 
quæ fí $\mathrm{K}$ L. Sufpensâ autem figurâ ex puncto $G$, rurfus longitudo $D_{\text {в }}$ CвN r penduli fimplicis ifochroni invenitur, dividendo quadrara om OsCXiLAnia linearum, qua à particulis figura ducuntur ad punctum $G$, per rectam $\mathrm{G} D$, multiplicem fecundum earundem particularum numerum*. Quum igitur puncta G \& E fint in circunferentia defcripta * Prop. 6. huj: centro $D$, quod eft centrum gravitatis figuræ A B C, five centrum

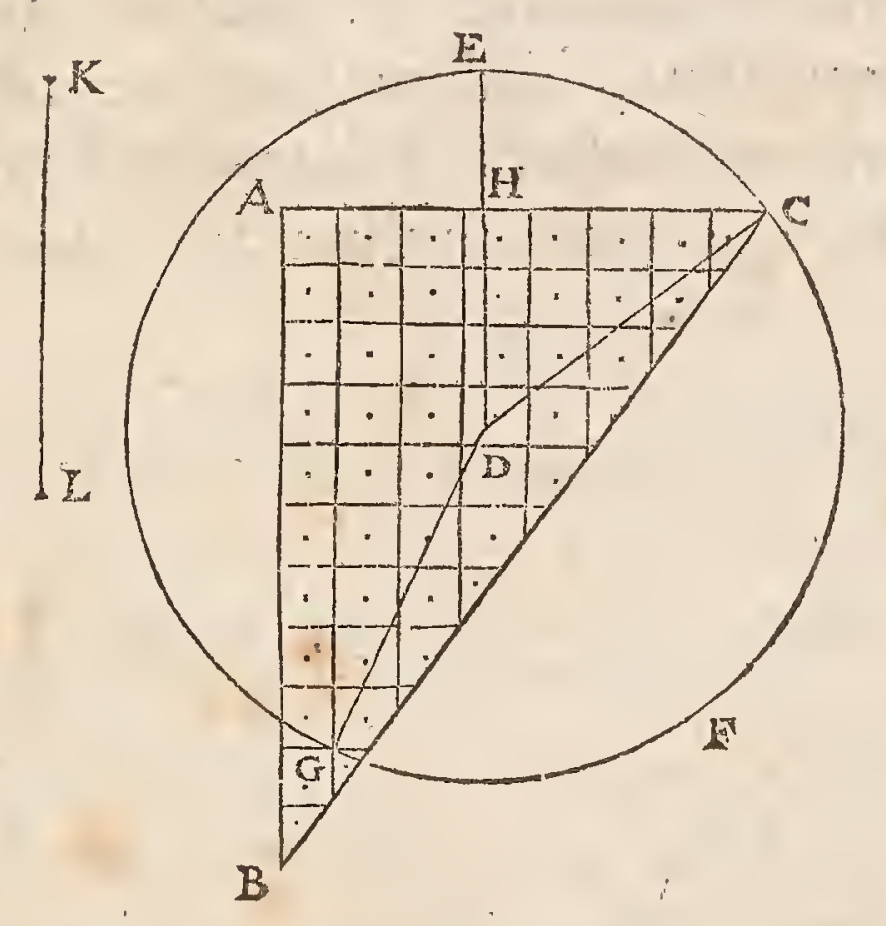

gravitatis punctorum omnium, qua centra funt particularum figuræ æqualium; erit proinde fumma quadratorum à lineis, quæ à dictis particulis ad punctum $\mathrm{G}$ ducuntur, æqualis fummæ quadratorum à lineis quæ ab iifdem particulis ducuntur ad punctum

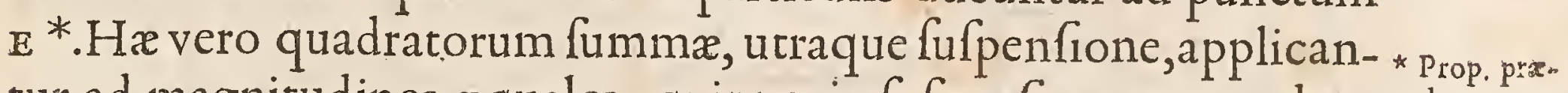
tur ad magnitudines æquales: quippe, in fufpenfione ex $\mathrm{E}$, ad re- ced. ctam E D, multiplicem fecundum numerum omnium particularum; in fufpenfione autem ex $G$, ad rectam D G, multiplicem fecundum earundem particularum numerum. Ergo patet, ex applicatione hac pofteriori, quum nempe fufpenfio eft ex $\mathrm{G}$, fieri longitudinem penduli ifochroni eandem atque ex applicatione priori, hoc eft, eandem ipfi $\mathrm{KL}$.

Eodem modo, fi ex C, vel alio quovis puncto circunferentiæ E C F, figura fufpendatur, eidem pendulo.k $\mathrm{L}$ ifochrona effe probabitur. Itaque conftat propofirum.

$$
\text { PROPOSITIO XIV. }
$$

D Atâ flgurâ folidâ, $\sigma^{2}$ lineâ rectâ interminatâ, quevel extra figuram cadat, velpeream tranféat; divisâque 
Dr ceNrRo figurá cogitatu in particulas minimas equales, à quibus om-

I10N1s. nibus ad datam rectam perpendiculares ducte intelligantur's invenire fummam omnium qua ab ip is funt quadratorum, froe plaxum, cujus multiplex fecundum particularum numerum, dicte quadratorum fummse aquale fit.

Sit data figura folida A B C D, \& linea recta qux, per punctum $\mathrm{E}$ tranfiens, ad planum hujus paginæ erecta intelligatur: quxque veI fecet figuram, vel tota extra cadat. Intellectoque, à fingulis particulis minimis æqualibus, folidum A в C D conftituentibus., velut $F$, rectas duci perpendiculares in datam rectam per $E$, quemadmodum hic $\mathrm{F}$ E, oporteat omnium quadratorum $\mathrm{E}$ E fummam invenire.

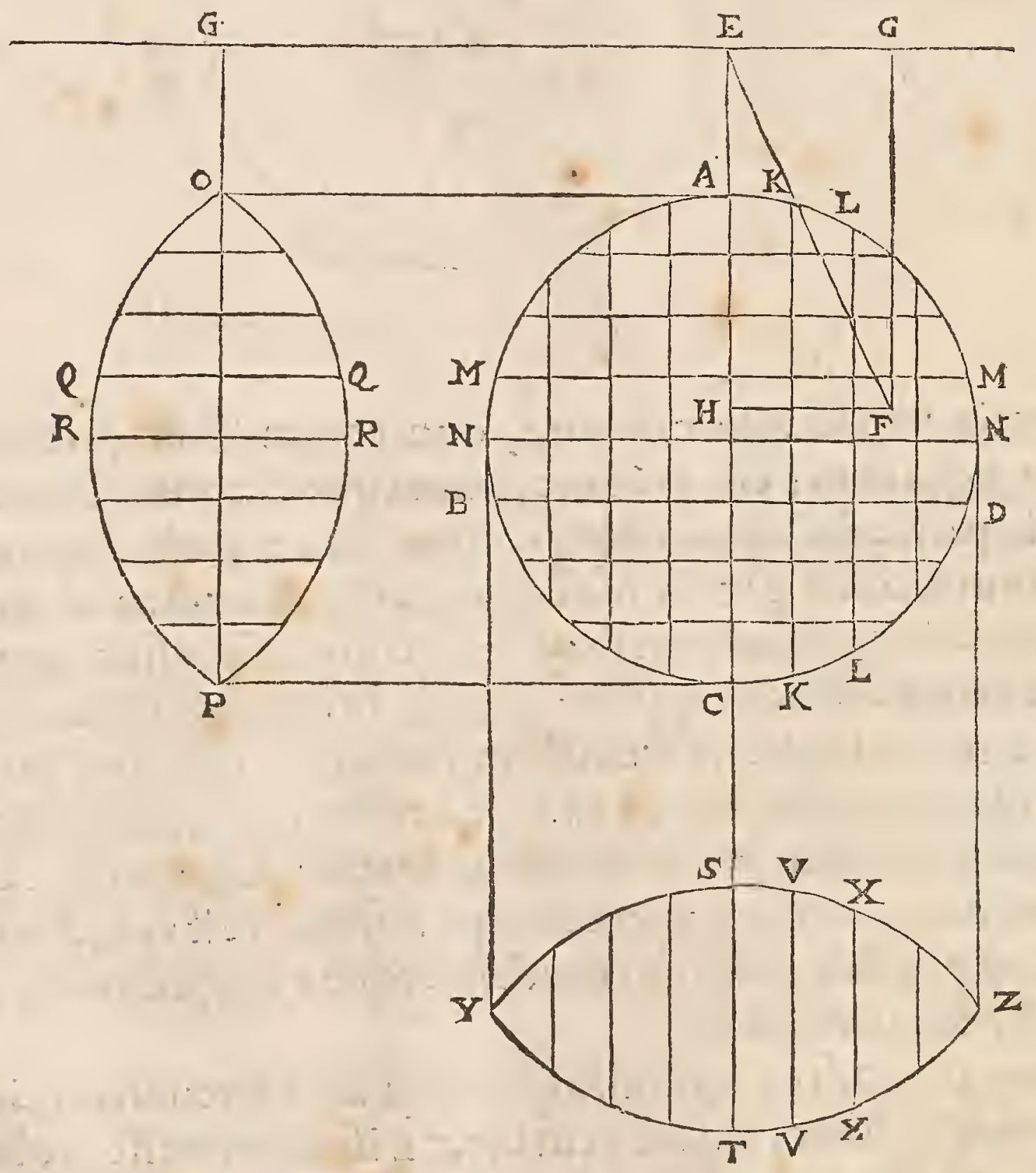

Secetur figura plano E A C, per dictam datam lineam \& per centrum gravitatis figuræ ducto. Item aliud planum intelligarur per eandem lineam datam, perque $\mathrm{E}$; q qux ipfi eft ad angulos rectos. Conftat jam, quadratum rectx cujufque, qux à particula di- 
atarum aliqua, ad lineam dacam per e perpendicularis ducitur, DE CENTRO ficut $F E$, xquari quadratis duarum F G, F H, qux, ab eadem par- тा N Is. ticula, in plana per E G \& E C ante dicta, perpendiculares aguntur *. ${ }_{\text {Eucl. }}^{*}$. lib. . . Quare, fi cognofcere poffimus fummam quadratorum, quæ fiunt ab omnibus perpendicularibus, quæ à particulis univerfis cadunt in plana dicta per E G \& per E C; habebimus etiam huic æqualem fummam quadracorum à perpendicularibus, quæ ab univerfis iifdem particulis cadunt in rectam datam per $\mathbf{E}$ punctum.

Illa vero prior quadratorum fumma colligetur hoc modo. Ponatur primó figuram planam dari $O Q P$, ad latus figuræ folid $\mathrm{A} B$ $C D$, ejufdem cum ipla altitudinis, quæque fit ejufmodi, ut fecta lineis rectis $Q Q, R R$, quæ refpondeant planis figuram folidam A B C D fecantibus $M M, N N$, \& his parallelis; eadem fit dictarum linearum inter $\mathrm{fe}$, qua \& planorum horum ratio, fi nempe fumantur utrinque qux in ordine fibi refpondent. Vtfilinea $\mathrm{R} R$ fit ad $Q \mathrm{Q}$ quemadmodum planum $\mathrm{N}$ ad $\mathrm{M}$. M. Quod fi igitur figura plana $O Q P$, in totidem particulas minimas æquales divifa intelligatur, quot intelliguntur in folido $\mathrm{ABC} D$, erunt etiam in unoquoque fegmento figurx planx, velut $Q Q R R$, tot numero particulæ, quot funt in figurx folidx fegmento $\mathrm{M} \mathrm{M} \mathrm{N} \mathrm{N}$, iftifegmento refpondente; ac proinde \& fumma quadratorum, à perpendicularibus omnium particularum figuræ $\mathrm{O} Q \mathrm{P}$ in planum $\mathrm{E} \mathrm{G}$, æquabitur fummæ quadratorum, à perpendicularibus omnium particularum figuræ folidæ, in idem planum $\mathrm{E} G$ productis. Illa autem quadratorum fumma data erit, fi dentur in figura $O Q P$, cuncoque illius, qux propof. 9. huj. requiri diximus. Ergo his datis, dabitur quoque fumma quadratorum, à perpendicularibus qux, à particulis omnibus folidi A B C D, ducuntur in planum $E$ G.

Ponatur nunc alia item figura plana s $~ \mathrm{~T} z$, ejufdem cum folido A B C D latitudinis, hoc eft, quam includant plana B $Y, D \mathrm{z}$ folidum contingentia, ac parallela plano $\mathrm{E}$ A $\mathrm{C}$, quæque fit ejufmodi, ut, $\mathrm{fe}$ ota lineis rectis $\mathrm{v} v, \mathrm{x} \times \mathrm{x} \& \mathrm{c}$.qux refpondeant planis figuram $\mathrm{A} \mathrm{B} \mathrm{C} \mathrm{D}$ fecantibus, $\mathrm{K} K, \mathrm{~L} L, \&$ his parallelis, faciat eandem inter fe rationem linearum harum atque illorum planorum, fi fumantur qux fibi mutuo refpondent. Iraque rurfus quadrata fimul omnia perpendicularium, à particulis figuræ $S$ y $\mathrm{T} \mathrm{z}$ in rectam $\mathrm{s} \mathrm{T}$ cadentium, æqualia erunt quadratis omnibus perpendicularium quæ, à particulis folidi A B C D, ducuntur in planum A C. lllorum autem fumma quadratorum data erit, fi detur diftantia centri gravitatis figura S Y $T$ Z ab recta B $X$ vel $D \mathrm{Z}$; nec non diftantia indidem centri gra. 
D c centro vitatis cunei fui abfciffi plano per eandem rectam*. Vel, figuras $\$$

OScILA- $T z$ ordinata exiftente, ut-S $T$ fit axis ejus, eadem quadratorum

* Prop. 9 . huj. fumma dabitur, fi detur diftantia centri gravitatis figuræ dimidiæ $s z$ Tabaxe $s$, item centri gravitatis cunei, fuper eadem dimidia * Prop. xr.huj. figura, abfciffi plano per axem ducto *. Ergo, his datis, dabitur quoque fumma quadratorum à perpendicularibus qux, à particulis omnibus folidi A B C D, ductæintelliguntur in planum E A C. Invenimus autem \& fummam quadratorum, à perpendicularibus omnibus in planum per $\mathrm{E}$ G ductis. Ergo \& aggregatum utriufque fummæ habebitur, hoc eft, per fuperius oftenfa, fumma quadrarorum perpendicularium qux, à particulis omnibus folidi A B C D, cadunt in rectam datam per $\mathrm{E}$ tranfeuntem, \& ad paginæ hujus planum erectam. quod erat faciendum.

\section{PROPOSITIO X V.}

I Ifdem pogitis, fi folidum $\mathrm{A} \mathrm{BCD}$ fit ejufmodi, ut figura plaw naS Y T Z, ip/c proportionalis, non habeat notam difiantiam centri gravitatis à tangentibus $\mathrm{B} Y$ vel $\mathrm{DZ}$, vel, wt fubcentrica cunei fuperip a ab ciffl, plano pereasdem B Y vel D Z, ignoretur; in figura tamen proportionali, qua à latere ef, $\mathrm{O} Q \mathrm{P}$. detur diftantia $\Phi \mathrm{P}$, qua centrum gravitatis figure dimidia O P V abeft ab axe O P; licebit binc invenire fummam quadratorum à diftantiis particularum folidi A B C D à plano E C. Oportet autem ut fectiones omnes, N N, M M, fint plana fimilia; utque per omnium centra gravitatis tranfeat planum E c; quemadmodum in prifmate, pyramide, cono, conoidibus, multifque aliis fguris contingit. Atque eorum planorum difantias centri gravitatis, Juper tangentibus axi ofcilla. tionis parallelis, datas effe neceffe eft; uti G fubcentricas cuneorum, qui fuper ipjis abjcinduntur, dustis planis per eafdem tangentes.

Veluti, fr maxima dictarum fectionum fit B D, \& in B intelligatur recta parallela axi $\mathrm{E}$, hoc eft, erecta ad planum quod hic confpicitur, oportet datam effe diftantiam centri gr. fectionis B $D$ à dicta linea in B, qux fit B C; itemque fubcentricam cunei, fuper fectione $\mathrm{B} \mathrm{D}$ abfcifli, plano ducto per eandem lineam in $\mathrm{B}$, qua fubcentrica fit $\mathrm{B} \mathrm{K}$.

Etenim his datis, divisâque $\mathrm{P} v$ bifariam in $\Delta$, fi fiat ficut $\Delta \mathrm{P}$ ad 
HOROLOG. OSCILLATOR.

117

$P \Phi$, ita rectangulum $B C K$ ad fpatium quoddam $z$; dico hocipfum, DE CENTR multiplex per numerum particularum folidi A B C D, æquari fum- is o N s. mæ quæfitæ quadratorum, à diftantiis earundem particularum à plano E $C$.

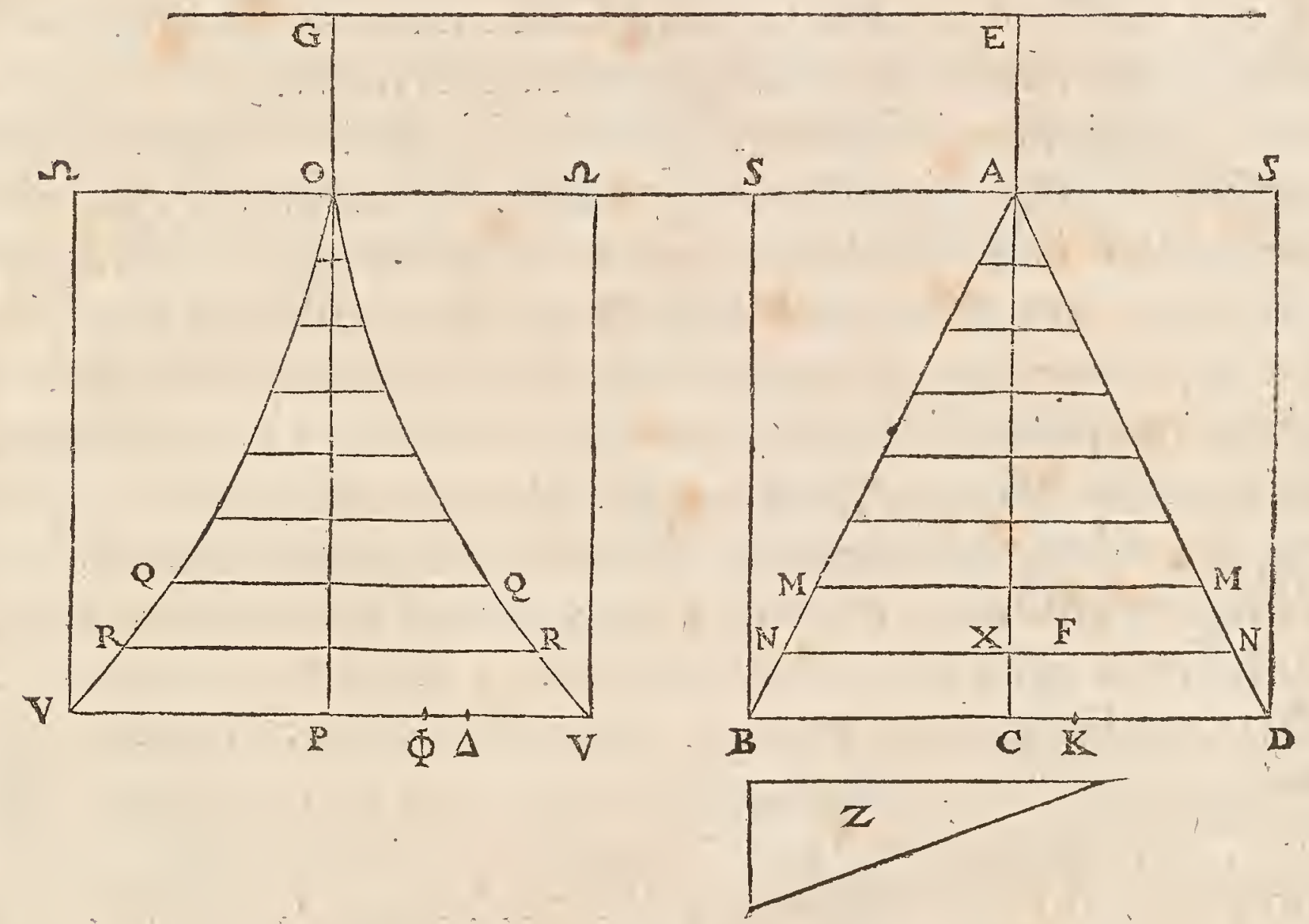

Quadrata enim à diftantiis particularum planx fectionis B $\mathrm{D}$, à plano E C, quod per centrum gravitatis fuæ tranfit; five quadrata à diftantiis particularum folidarum fegmenti B N N D à plano eodem, xquari conftat rectangulo в C K, multiplici per numerum dictarum particularum *. Similiter, fi planæ fectionis $\mathbf{N}$ diftantia * Trop. s. huj. centrigravitatis, ab recta qux in $N$ intelligitur axi $\mathrm{E}$ parallela, fic $\mathbb{N X}$; fubcentrica vero cunei fuper ipfa abfciffi, plano per eandem rectam, fit $\mathrm{N} F$; erunt quadraca à diftantiis particularum planarum fectionis $\mathrm{N} N$ à plano $\mathrm{E} C$, five quadrata à diftantiis particularum folidarum fegmenti N M M N à plano eodem, xqualia rectangulo $\mathbb{N}$ X F,multiplici per numerum particularum ipfarum fectionis $\mathrm{N}$, vel fegmenti N M M N. Eftautem B D divifa fimiliter in $\mathrm{C} \& \mathrm{~K}$, atque $N \mathrm{~N}$ in $\mathrm{X} \& \mathrm{~F}$. Ergo rectangulum B C K ad rectangulum $\mathrm{N} X \mathrm{~F}$, ficut quadratum B D ad quadratum $N$.

Eft autem \& numerus particularum fectionis B $D$, ad numerum particularum fectionis N N, ficut fectiones ipfre; hoc eft, ficut quadratum B D ad quadratum $N$ N. Itaque rectangulum B C K, multiplex per numerum particularum fectionis $\mathrm{B} D$, ad rectangulum $N \times$, multiplex per numerum particularum fectionis $N N^{\prime}$, dupli- 
DE CENTKO OSCIILAS TIONIS. catam habebit rationem quadrati B $\mathrm{D}$ ad quadratum $\mathrm{N} \mathrm{N}$; hoc eff, eam quam quadratum $v$ v ad quadratum $R \mathrm{R}$, in figura proportio. nali. Erit igitur \& dicta prior fumma quadratorum, à diftantiis par. ticularum fegmenti B N N D à plano E C, ad fummam alteram quadratorum, à diftantiis particularum fegmenti $N M M N$, ut qu. $v$ v ad qu. R R. Eademque ratione oftendetur, fummas quadratorum à diftantiis particularum in reliquis fegmentis folidi A B C D, effe inter $f e$ in ratione quadratorum qux fiunt à rectis in figura $\mathrm{o} \mathrm{v} \mathrm{v}$, qua bafi cujufque fegmenti refpondent. Quare fumma quadratorum, à diftantiis particularum omnium fegmentorum folidi $\mathrm{A} B \mathrm{~B} C \mathrm{D}$ à plano $\mathrm{E} C$, erit ad fummam quadratorum, à diftantiis particularum fegmentorum toridem, maximo fegmento æqualium, hoc eft, cylindri vel prifmatis в D S s, eandem cum folido $\mathrm{A}$ В C $\mathrm{D}$ bafin altitudinemque habentis, ficut quadrata omnia rectarum $v \mathrm{v}, \mathrm{R} R$, $\mathrm{QQ}$, \&c. ad quadrata totidem maximo $\mathrm{v} v$ $æ q u a l i a$, hoc eft, ficut folidum rotundum o $\mathrm{V} v$ circa axem $\mathrm{o} P$; ad cylindrum $\mathrm{V} v \Omega \Omega$, qui bafin \& altitudinem habeat eandem. Hanc vero rationem folidi o $\mathrm{v} v$ ad cylindrum $\mathrm{v} \vee \Omega \Omega$, componi conftat ex ratione planorum quorum converfione generantur, hoc eft, ex ratione plani O P. v, ad rectangulum P $\Omega$, \& ex ratione diftantiarum quibus ho rum planorum centra gravitatis abfunt ab axe o p; hoc eft, \& ex ratione $\mathrm{P} \Phi$ ad $\mathrm{P} \Delta$. Et prior quidem harum rationum, nempe plani O P V ad rectangulum $\mathrm{P} \Omega$, eadem eft qux folidi A B C D ad cylindrum vel prifma B $\mathrm{D} s \mathrm{~s}$, hoc eft, eadem quæ numeri particularum folidi A B C D, ad numerum particularum cylindri vel prifmatis B $D$ $\mathrm{s}$ s. Altera vero ratio, nempe $\mathrm{P} \Phi$ ad $\mathrm{P} \Delta$, eft eadem, ex conftructione, qux f patii $z$ ad rectangulum $\mathrm{B}$ C K. Habebit itaque dicta fumma quadratorum, à diftantiis omnium particularum folidi A B C D à plano $\mathrm{E}$ C, ad fummam quadratorum, à diftantiis omnium particularum cylindri vel prifmatis B D s ab eodem plano, rationem eam qux componitur ex ratione numeri particularum folidi A B C D, ad numerum particularum cylindrivel prifmatis B D S $s$, \& ex ratione fpatii z ad rectangulum B C K : hoc eft, rationem quam habet rectangulum $z$, multiplex per numerum particularum folidi A B C D, ad rectangulum $B C K$, mulriplex per numerum particularum cylindrivel prifmatis B D S S. Arqui quarta harum magnitudinum æqua lis eft fecund $x$; nempe rectangulum B C K, multiplex per numerum particularum cylindri vel prifmatis B D $S$, æquale fummæ quadratorum, à diftantiis particularum ejufdem prifmatis vel cylindri B D S s à plano E C. ; fiquidem rectangulum idem B C.K, mulciplex 

diftantiarum particularum ejufdem fegmenti à plano $\mathrm{C}^{*}$. Ergo \& tertia primæ æquabitur; nempe planum $z$, multiplex per numerum particularum folidi A B C D, fummæ quadratorum, à diftantiis particularum folidi ejufdem A B C D à plano E C*. quod erat demonftrandum:

Norandum vero, quando folidum $\mathrm{A}$ B D rotundum eft circa axem A C , fieri femper rectangulum B C K æquale quartæ parti quadrati B C; quoniam fubcentrica cunei, abfcifli fuper circulo $B$ D, plano per tangentem in B, nempe recta B $\mathrm{K}$, xquarur ${ }_{4}^{5}$ radii B C. Vnde, fi $\mathrm{p}$ v æqualis pofita fit в C, fequitur, faciendo ut $\mathrm{I} \Delta$ ad $\mathrm{P} \Phi$ ita rectangulum $\mathrm{B}$ C K, hoc eft, $\frac{1}{4}$ quadrati $\mathrm{B}$ C, hoc eft, qu. $\mathrm{P} \Delta \mathrm{ad}$ planum aliud $\mathrm{z}$, fore hoc rectangulo $\Delta \mathrm{P} \Phi$ $x$ quale. Ac proinde tunc ipfum rectangulum $\Delta P \Phi$, multiplex fecundum numerum particularum folidi A B D, æquari fummæ quæfitæ quadratorum à perpendicularibus omnibus, quæà particulis iifdem cadunt in planum E C.

\section{PROPOS I T I O X V I.}

Th Igura quavis, five linea fuerit, froe fuperficies; fuve 1-1 Folidum; $j$ aliter atque aliter fuppendaiur, agiteturgue fuper axibus inter fe parallelis, quique à centro gravitatis figurse aqualiter diftent, fibi ipfi ifochrona eft.

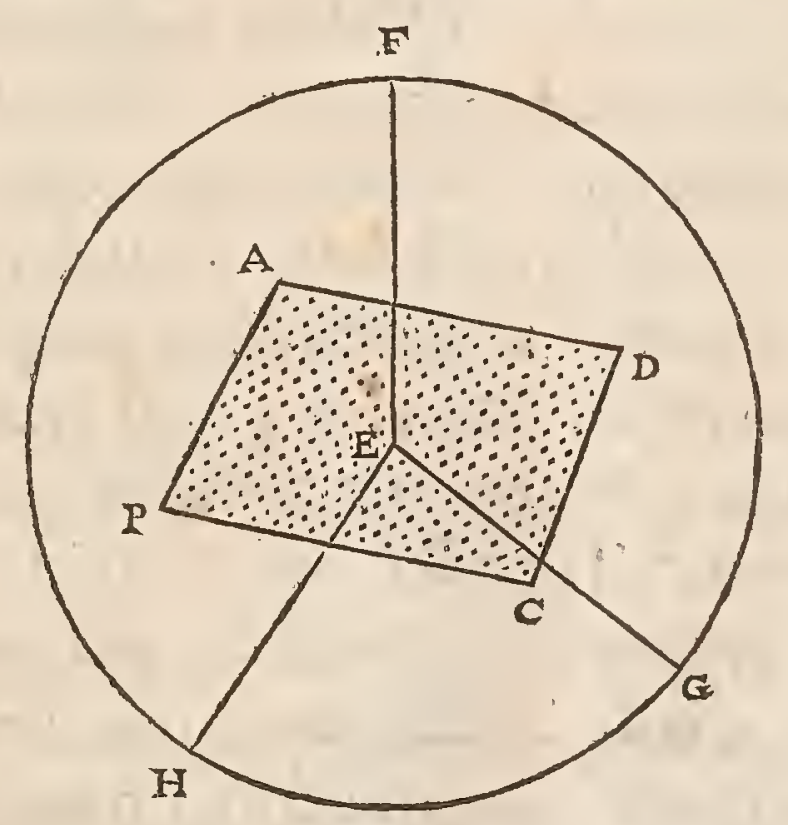

Proponatur magnitudo quævis, cujus centrum gravitaris E puncum, fitque primo fufpenfa ab axe, qui per $\mathrm{F}$ intelligitur hujus paginæ plano ad angulos rectos. Itaque idem planum erit \& planum ofcillationis. In quo fi centro $\mathrm{E}$, radio $\mathrm{E} F$, defcribatur circumferentia F H G, fumptoque in illa puncto quovis, $u t H$, magnitudo fecundò fúfpendi intelligatur ab axe in hoc puncto infixo, atque agitari, manente eodem of cillationis plano. Dico ifochronam fore ribi ipfi agitatx circa axem in $F$. 
DE CENTRO OSCILLATIO IS.

Intelligatur enim dividi magnitudo propofita in particulas minimas æquales.Itaque, quia in utraque illa fufpenfione idem manet of cillationis planum, refpectu partium magnitudinis; manifeftum eft, fi ab omnibus particulis, in quas divifa eft magnitudo, perpendiculares cadere concipiantur in dictum of cillationis planum, illas utraque fufpenfione occurrere ipfi in punctis iifdem. Sint autem hæc puncta ea quæ apparent in fpatio A B C D.

Quum igitur $E$ fit centrum gravitatis magnitudinis propofitæ, ipfaque proinde circa axem, qui per $\mathrm{E}$ punctum erectus eft ad planum A B C D, quovis fitu æquilibrium fervet; facile perfpicitur, quod fi punct is omnibus ante dictis, qux in fpatio A B C D fignantur, xqualis gravitas tribuatur, eorum quoque omnium centrum gravitatis futurum eft punctum $\mathrm{E}$. Quod fivero, ut fieri poteft, in puncta aliqua plures perpendiculares coincidant, illa puncta quafi toties geminata intelligenda funt, gravitatefque toties multiplices accipiendx. Atque ita confideratorum, patet rurfus centrum gravitatis effe $\mathrm{E}$ punctum.

Porro fummam quadratorum ab rectis, quæ ducuntur à dictis punctis omnibus ad punctum $F$, eandem effe patet cum fumma quadratorum ab iis rectis, qux à fingulis particulis magnitudinis propofitæ ducuntur perpendiculares in axem ofcillationis per $\mathrm{F}$ tranfeuntem; quippe cum linex ipf $x$, quarum quadrata intelliguntur, utrobique eandem habeant longitudinem. Similiter etiam, cum fufpenfro eft ex axe per $\mathrm{H}$, patet fummam quadratorum $\mathrm{ab}$ rectis, quæ $\mathrm{ab}$ omnibus punctis, in fpatio A B C D fignatis, ducuntur ad punctum $\mathrm{H}$, eandem effe cum fumma quadratorum, $a b$ iis quæ, à particulis omnibus magnitudinis propofitæ, ducuntur perpendiculares in axem ofcillationis per $\mathrm{H}$ tranfeuntem. Ergo utroque cafu, fi fumma quadratorum ab rectis qux, à punctis omnibus prædictis, ducunturad puncta $\mathrm{F}$ vel $\mathrm{H}$, dividatur per rectas $\mathrm{E} \mathrm{F}$ vel $\mathrm{E} H$, multiplices fecundum numerum particularum in quas magnitudo propofita divifa intelligitur, orictur ex applicatione hac longitudo penduli fimplicis, quod magnitudini fufpenfæ ex $F$ vel th ifochronum fit. Eft autem fumma quadratorum utroque

* Prop rz.huj. cafu æqualis*; \& rectæ quoque E F, E H, interfeæquales; \& particularum idem numerus. Ergo, quum \& applicatæ quantitates, \& quibus illæa applicantur, utrobique æquales fint, etiam longitu. dines ex applicatione ortæ æquales erunt, hoc elt, longitudines pendulorum ifochronorum magnitudini propofitæ fufpenfæ ex F vel ex H. Quare conftat propofitum. 


\section{PROPOSITIO X VII.}

17 Ato plano, cujus multiplex per numerum particula. rum, in quas fuspen a figura divifa intelligitur, aquetur quadratis omnium diftanticum ab axe ofcillationis ; $f i$ illud applicetur ad rectam, equalem distantie inter axem ofillationis E centrum gravitatis Jupenfa magnitudinis, orietur longitudo penduli Implicis ip $\hat{i}$ ifochroni.

Sit figura $A B C$, cujus centrum gravitatis $\mathrm{E}$, fufpenfa $a b$ axe qui, per $\mathrm{f}$ punctum ad planum quod confpicitur, erectus fit. Ponendoque divifam figuram in particulas minimas æquales, à quibus omnibus, in dictum axem, perpendiculares cadere intelligantur : efto, per fuperius oftenfa, inventum planum $H$, cujus multiplex per nu-

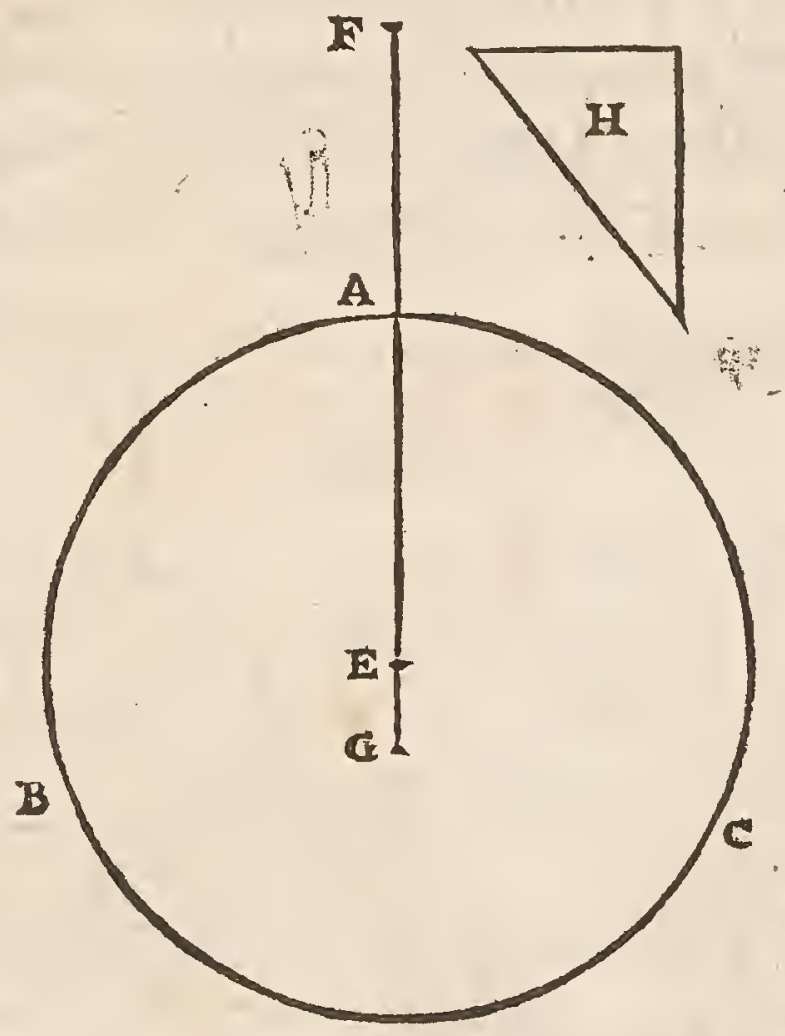

merum dictarum particularum, xquetur quadratis omnibus di.ctarum perpendicularium. Applicatoque plano $\mathrm{H}$ ad rectam F E, fiar longitudo F G. Dico hanc effe longitudinem penduli frmplicis, ifochronas of cillariones habentis magnirudini A B C, agitatæ circa axem per $F$.

Quia enim fumma quadratorum, à diftantiis $a b$ axe $F$, applicata ad diftantiam F E, multiplicem fecundum partium numerum, facit

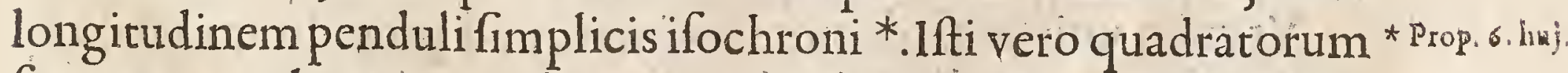
fummæ æquale ponitur planum $\mathrm{H}$, multiplex per eundem particularum numerum. Ergo \& planum $H$, multiplex per eundem particularum numerum, fi applicetur ad diftantiam F E, multiplicem 
DE свтRо fecundum particularum numerum; five, omiffa communi multiIIONIS. plicitate, fi planum $\mathrm{H}$ applicerurad diftantiam $\mathrm{E}$ E; orierur quoque longitudo penduli fimplicis ifochroni. Quam proinde iplam longitudinem F G effe conftat. quod erat demonftrandum.

\section{PROPOSITIO XVIII.}

O I patium planum, cujus multiplex fecundum numerum $\checkmark$ particularum fupense magnitudinis, equetur quadratis difeantiarum ab axe gravitatis, axi of cillationis parallelo; $i d$, inquam, patium $\int i$ applicetur ad rectam, aqualem diftantia inter utrum que dictorum axium, orietur recta aqua lis intervallo, quo centrum of cillationis inferius eft centro gra: vitatis ejufdem magnitudinis.

Efto magnitudo $A B C D$, cujus centrum gravitatis $E$; quæque fufpenfa $a b$ axe, qui per punctum $\mathrm{F}$ ad planum hujus paginx ere ctus intelligitur, habeat centrum ofcillationis G. Porro axi per $\mathrm{F}$ intelligatur axis alius, percentrum gravitatis etranfiens, paralle-

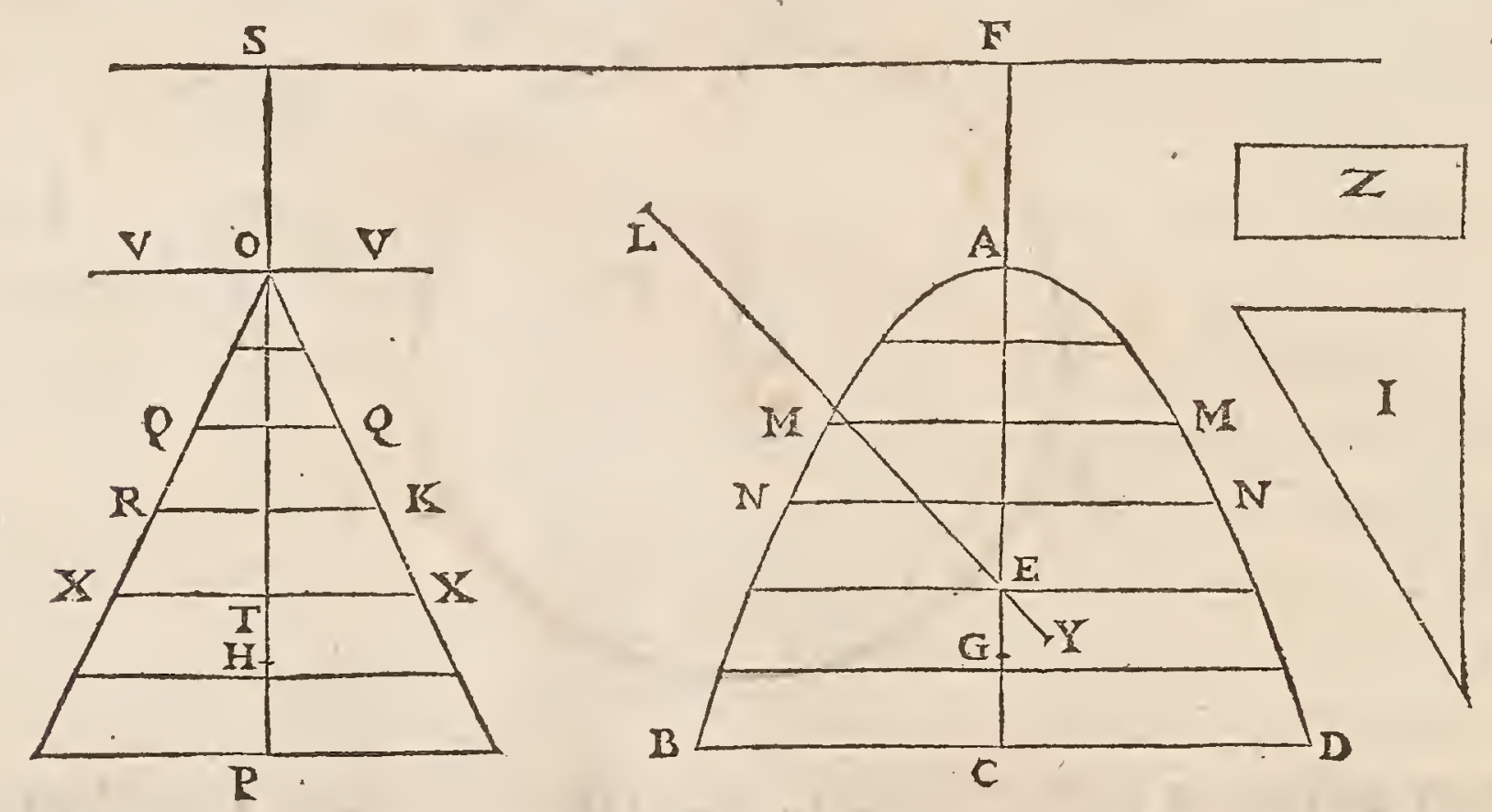

lus. Divifaque magnitudine cogitacu in particulas minimas æqua. les, fit quadratis diftantiarum, ab axe dicto per $\mathrm{E}$, æquale planum 1 , multiplex nempe fecundum numerum dictarum particularum; applicatoque plano I ad diftantiam $\mathrm{F}$, fiar recta quædam. Dico eam $x$ qualem effe intervallo $\mathrm{E} G$; quo centrum of cillationis inferius eft centro gravitatis magnitudinis $A B C D$.

Vt enim univerfali demonftratione quod propofitum eft comprehendamus: intelligatur plana figura, magnitudini $A$ B C $D$ analoga, ad latus adpofita, O Q P; qux nempe, fecta planis horizonta. libus iifdem cum magnitidine A B C D, habeat fegmenta inter- 
HOROLOG. OS CILLATOR. 123 cepta inter bina quæque plana, in eadem inter fe ratione cum feg- DE CENTRO

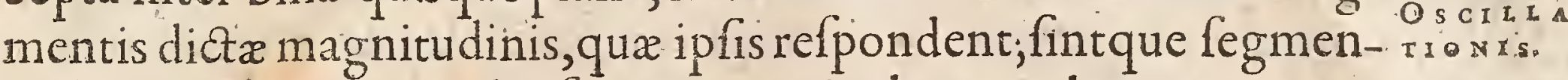
ta fingula figuræ $O Q P$, divifa in tot particulas æquales, quot continentur fegmentis ipfis refpondentibus in figura A B C D. Hæc autem intelligi poffunt fieri, qualifcunque fuerit magnitudo $A B C D$, five linea, five fuperficies, five folidum. Semper vero centrum gravitatis figuræ $O Q P$, quod fit $T$, eadem altitudine effe manifeftum eft cum centro gravitatis magnitudinis A B C D; ideoque, fi planum. horizontale, per $\mathrm{F}$ ductum, fecet lineam centri figurx $\mathrm{O} Q \mathrm{P}$, velut hic in $s$, xquales effe diftantias $s \mathrm{~T}, \mathrm{~F} \mathrm{E}$.

Porro autem conftat quadrata diftantiarum, ab axe of cillationis F, applicata ad diftantiam $\mathrm{E}$ E, multiplicem fecundum numerum particularum, efficere longitudinempenduli ifochroni ${ }^{*}$; quæ lon- * Prop. 6. huj. gitudo pofita fuit F $\mathrm{G}$. Illorum vero quadratorum fummam, æqualem effe perfpicuum eft, quadratis diftantiarum à plano horizontali per $\mathrm{F}$, unà cum quadratis diftantiarum à plano verticali $\mathrm{F} \mathbf{E}$, per axem $\mathrm{F} \&$ centrum gravitaris E ducto*. Atqui quadrata diftan- $*$ Prop. 47. lit. tiarum magnitudinis A B C D à plano horizontali per $F$, xquantur quadratis diftantiarum figurx o $Q P$ ab recta s F. Qux quadrata ( $f_{1} O$ fit punctum fupremum figuræ $O Q P$, \& $\mathrm{H}$ centrum gravitatis cunei fuper ipfa abfciíf, plano per rectam o $\mathrm{v}$, parallelam $\mathrm{s}$ ) ) qualia funt rectangulo o T H \& quadrato $\mathrm{T}$, multiplicibus fecundum numerum particularum dictæ figuræ*, five magnitudinis A B C D. * Prop. 9. huj. Quadrata vero diftantiarum magnitudinis A B C D à plano F E, quantumcumque axis of cillationis $\mathrm{F}$ diftet à centro gravitatis $\mathrm{E}$, femper eadem funt: quæ proinde putemus xquarifpatio $\mathrm{z}$, multiplicifecundum numerum particularum magnitudinis A B C D.

I taque quoniam quadrata diftantiarum magnitudinis $\mathrm{A} B \mathrm{C} D$, $a b$ axe of cillationis $\mathrm{F}, æ q u a n t u r$ iftis, quadrato nimirum $\mathrm{s}$, rectangulo o T H, \& plano z, multiplicibus per numerum particularum ejufdem magnitudinis; fi applicentur hæc omnia ad diftantiam F E five $S T$, orietur longitudo $F$ G penduli ifochroni magnitudini A B C D*. Sed ex applicatione quadrati $\mathrm{T}$ T ad latus fuum S T , orie- ${ }^{*}$ Prop. 6 , huj. tur ipfa $s \mathrm{~T}$, five $\mathrm{F}$ E. Ergo reliqua $\mathrm{E} \mathrm{G}$ eft ea quæ oritur ex applicatione rectanguli o $\mathrm{T} \mathrm{H}, \&$ plani $\mathrm{z}$, ad eandem $\mathrm{S}$ T vel $\mathrm{F}$.

Quare fupereft ut demonftremus rectangulum o $\mathrm{T} \mathrm{H}$, cum plano ż, xquari plano I. Tunc enim conftabit, etiam planum I, applicatum ad diftantiam $\mathrm{F}$ E, efficere longitudinem ip $f_{\mathrm{E}} \mathrm{G}$ xqualem. Illud autem fic oftendetur. Rectangulum o $\mathrm{T}$ H, multiplex fecundum numerum particularum figuræ $O Q P$, five magnitudinis $A$ 
$D_{\text {A CENRo }} \mathrm{C}$, $x$ quatur quadratis diftantiarum figuræab recta $\mathrm{X}^{*} \mathrm{~T}^{*}$, quæ per Oscris- centrum gravitacis $T$ ducitur ipfi $\mathrm{S}$ parallela; ac proinde etiam * Prop.so.huj. quadratis diftantiarum magnitudinis A B C D, à plano horizontali $\mathbb{K} \mathrm{K}$, ducto per centrum gravitatis $\mathrm{E}$; cum diftantiæ utrobique fint exdem. At vero planum $z$, fimiliter multiplex, æquale pofitum fuic quadratis diftantiarum magnitudinis A B C D à plano verticali F E. Ác patet quidem quadrata hæc diftantiarum à plano $\mathrm{F}$ E, una cum dictis quadratis diftantiarum à plano horizontali per $\mathrm{E}$, æqualia effe quadratis diftantiarum ab axe gravitatis per $\mathrm{E}$, qui fit axi $\mathrm{F}$ * Prop. 47.lib. parallelus*. Itaque rectangulum o $т$ н una cum plano $\mathrm{z}$, multiplicia fecundum numerum particularum magnitudinis A B C D, æqualia erunt quadratis diftantiarum ejufdem magnitudinis à dicto axe per E. Sed \& planum I, multiplex fecundum eundem particularum numerum, xquale pofitum fuit iifdem diftantiarum quadratis. Ergo planum $\mathrm{I}$ xquale eft rectangulo o i H \& plano z fimul fumptis. quod oftendendum fupererat.

Hinc rurfus manifeftum fit, quod propofitione 16 demonftratum fuit; nempe magnitudinem quamliber, fi aliter atque aliter fufpendatur arque agitetur, ab axibus parallelis, qui à centro gravitatis fux xqualiter diftent, fibi ipfi ifochronam effe.

Sive enim magnitudo A B C D fufpendatur ab axe F, five ab axe I illi parallelo; patet eadem utrobique effe quadrata diftantiarum abaxe per $\mathrm{E}$, quifit axibus $\mathrm{F}$ vel $\mathrm{L}$ parallelus. Vnde \& planum I, cujus multiplex, fecundum numerum particularum, æquarur quadratorum fummx, utroque cafu idem erit. Hoc vero planum, applicatumad diftantiam centrigravitatis ab axe ofcillationis, qux utroque cafu eadem ponitur, efficit diftantiam qua centrum of cillationis inferius eft centro gravitatis; Ergo etiam hæc diftantia utroque cafu eadem erit. Velut $f_{1}$, facta fufpenfione ex $I$, fuerit dicta diftantia E Y, erit ipfa æqualis E G; \& tota Y L æqualis G F; adeoque, in fufpenfione utraque, idem pendulum fimplexifochronum fit magnitudini $A$ B $C$.

\section{P R O P O S I T I O X I X.}

II magnitudo eadem, nunc brevius nunc longius fupen$\checkmark$ fa, agitetur; erunt, ficut diftantis axium of cillationis à centra gravitatis inter $\int e$, ita contraria ratione diftantia centrorum of cillationis ab eodem gravitatis centro.

Sit magnitudo, cujus centrum gravitatis $A$, fufpenfa primum atque agitata $a b$ axe in $B$, deinde vero $a b$ axe in $c$; fitque in prima. 
fufpenfione centrum of cillationis $D$, in pofteriori vero centrum Dr cENTR a ofcillationis E. Dico effe ut B Aad GA ita E A ad D A.

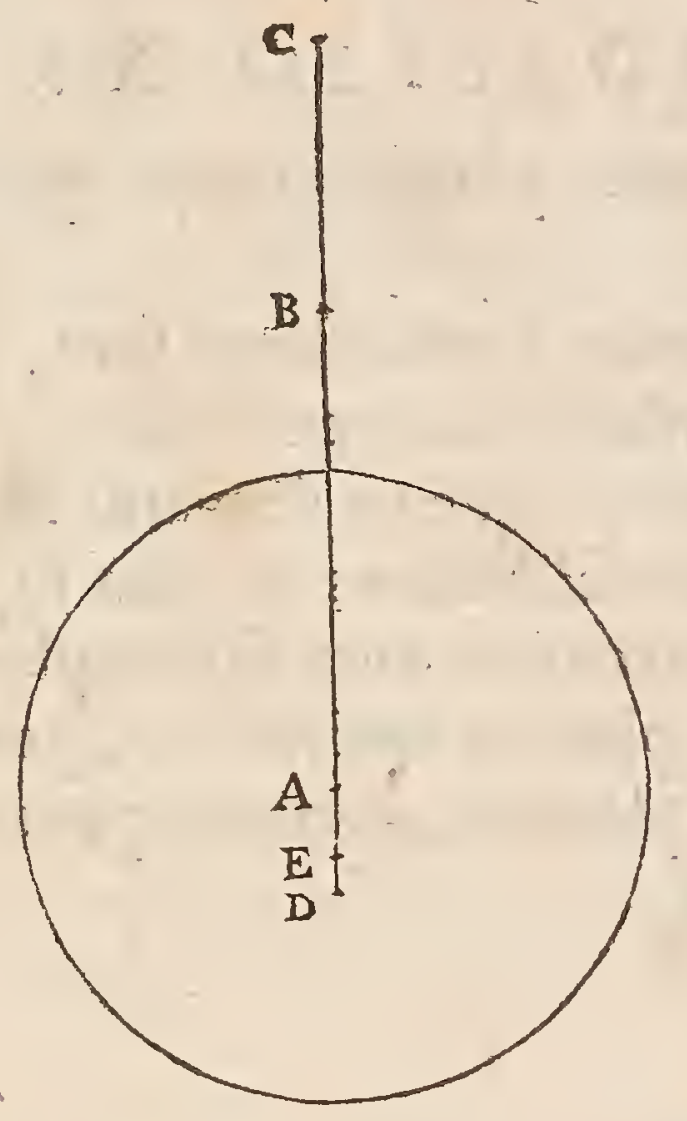

Quum enim, in fufpenfione ex $B$, efficiatur diftantia $A D$, qua nempe centrum of cillationis inferius eft centro gravitatis, applicando ad diftantiam B A fpatium quoddam, cujus multiplex fecundum numerum parricularum minimarum æqualium, in quas magnitudo divifa intelligitur, xquatur quadratis diftantiarum ab axe per A, parallelo axi in B $*$; erit proinde rectangulum B A D dicto fpa- * prop. p:*tio æquale. Item, in fufpenfione ex $\mathrm{C}$, quum fiat diftantia A $\mathrm{E}$, ap- ced. plicando idem dictum patium ad diftantiam $\mathrm{C} A$; erit \& rectangu_ lum $C$ A E eidem fpatio æquale. Itaque æqualia inter fe rectangula $B A D, C A E ;$ ac proinde ratio $B A$ ad C A eadem quæ $A E$ ad $A$ D. quod erat demonftrandum.

Hinc paret, dato pendulo fimplici, quod magnitudini fufpenf $x$ ifochronum fit in una fufpenfione, datoque ejus centro gravitatis; etiam in alia omni fufpenfione, longiori vel breviori, dưmmodo idem maneat planum of cillarionis, longitudinem penduli ifochroni datam effe.

P R O POS IT IO XX.

\section{Entrum Ocillationis $E^{\circ}$ punctum fupenfionis inter fo convertuntur.}

In figura fuperiori, quia, pofita fufpenfione ex B, centrum of cillationis eft $\mathrm{D}$; etiam invertendo omnia, ponendoque fufpen- 
DE CENTRO fronem eXD, erit tunc centrum of cillationis B. Hoc enim exipfa OSCIISA- propofitione præcedenti manifeftum eft.

\section{PROPOSITIO XXI.}

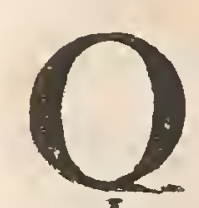

Vomodo in figuris planis centra of cillationis inveniantur.

Intellectis qux hactenus demonftrata funt, facile jam erit in plerifque figuris, quæ in Geometria confiderari confueverunt, definire ofcillationis centra. Atque ut de planis figuris primum dicamus; duplicem in is of cillationis motum fupra definivimus; nempe, vel circa axem in eodem cum figura plano jacentem, vel circa eum qui ad figuræ planum erectus fit. Quorum priorem vocavimus agitationem in planum, alterum agitationem in latus.

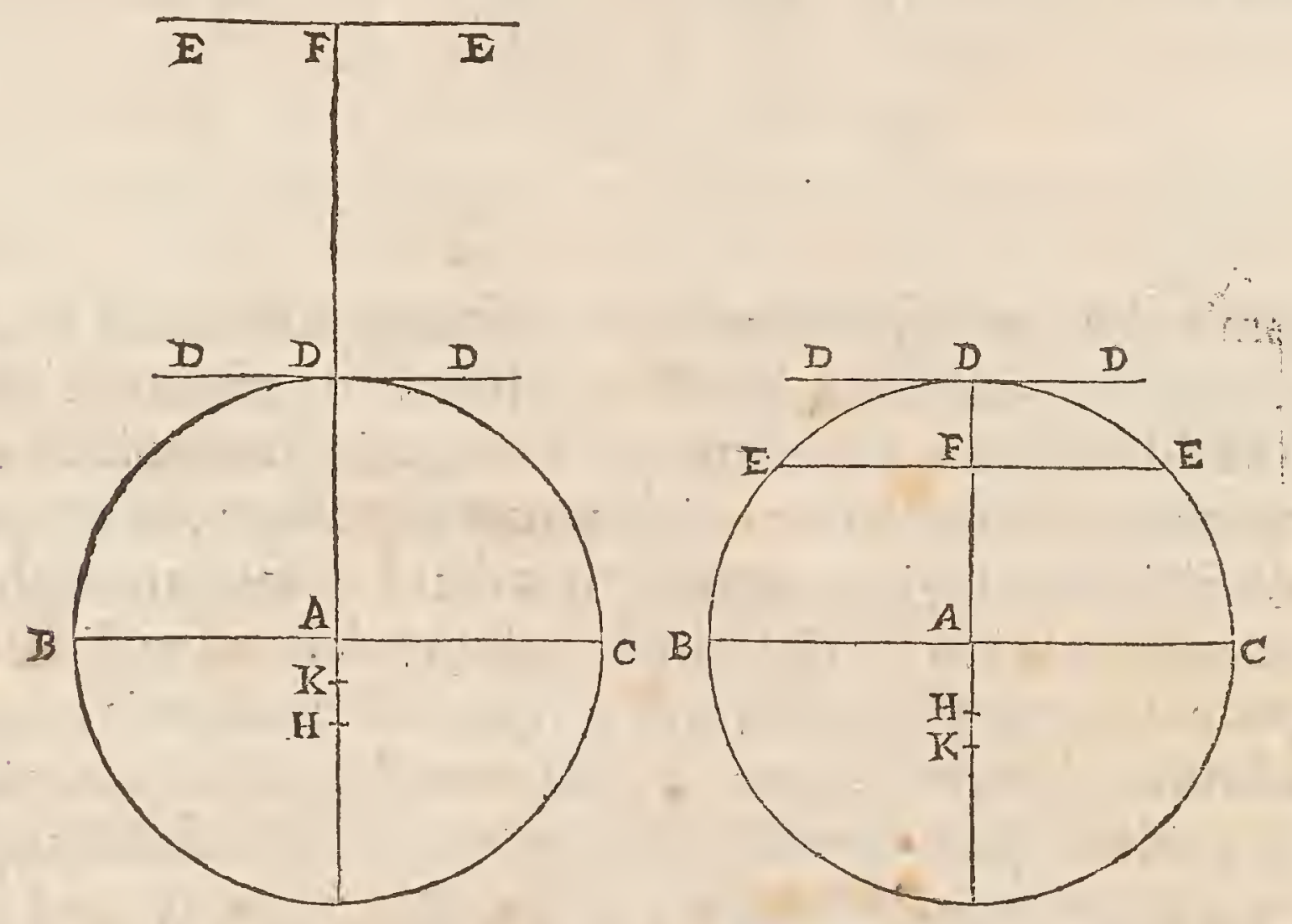

Quod fi priore modo agitetur, nempe circa axem in eodem plano jacentem, ficut figura B C D circa axem E F; hic, fi cuneus fuper figura intelligatur abfciffus, plano quod ita fecet planum figurx, ut interfectio, qux hic eft $\mathrm{D} \mathrm{D}$, fit parallela of cillationis axi ; deturque diftantia centri gravitatis figuræ ab hac interfectione, ut hic $A D$; itemque fubcentrica cunei dicti fuper eadem interfectione, qux hic fit $\mathrm{D} H$. Habebitur centrum of cillationis $\mathrm{K}$, figuræ B D C, applicando rectangulum D A H ad diftantiam F A quoniam ex applicatione hac orietur diftantia $\mathrm{A} \mathrm{K}$, qua centrum of cillationis inferius eft centro gravitatis. Eft enim rectangulum $\mathrm{D}$ A H, multiplex fecundum numerum particularum figuræ B C D, æquale quadratis diftantiarum ab recta $\mathrm{B} \mathrm{A}$, qux per centrum gravi- 
tatis A parallela ducituraxi of cillationis E $\mathrm{E}^{*}$. Quare, applicando idem rectangulum ad diftantiam $F A$, orietur diftantia $A K$, qua centrum of cillationis inferius eft centra gravitatis $A$ *.

Hinc manifeftum eft, fi axis of cillationis fit $\mathrm{D} D$, fieri centrum ofcillationis $\mathrm{H}$ punctum; adeoque longitudinem $\mathrm{DH}$, penduli fimplicis ifochroni figuræ $\mathrm{B} \mathrm{CD}$, effe tunc ipfam fubcentricam cunei, abfcifli plano per D D, fuper ipfam D D. Quod unum ab aliis ante animadverfum fuit, non tamen demonftratum.

Quomodo autem centra gravitatis cuneorum fuper figuris planis inveniantur, perfequi non eft inftituti noftri, \& jam in multis nota funt. Velut, quod fi figura B C D fit circulus, erit D H æqualis $\frac{5}{8}$ diametri. Si rectangulum, erit $\mathrm{DH} \infty \frac{2}{3}$ diametri. Vnde \& racio apparet cur virga, feu linea gravitate prædita, altero capite fufpenfa, ifochrona fit pendulo longitudinis fubfefquialteræ. Confiderando nempe lineam ejufmodi, ac fi effet rectangulum minim latitudinis.

Quod fi figura triangulum fuerit, vertice furfum converfo, fit $D \mathrm{H} \frac{3}{4}$ diametri. Si deorfum, $\frac{1}{2}$ diametri.

Quod autem propofitione 16 demonftratum fuit, id ad hujufmodi figuræ planæ motum ita pertinere fciendum. Nempe, fi aliam atque aliam pofitionem demus figuræ $B C D$, invertendo eam circa axem B A C, ut vel horizonti parallela jaceat, vel oblique inclinetur, manente eodem agitationis axe F E, etiam longitudo penduli ifochroni $\mathrm{f}$ K eadem manebit. Hoc enim ex propofitione illa manifeftum eft.

porro quando figura plana, circa axem ad planum figurxe erectum, agitatur; quam vocavimus agitationem in latus; velut fi figura B C D moveatur circa axem, qui per punctum $\mathrm{F}$ intelligitur ad planum D B C erectus; hic jam præter cuneum fuper figura, qui abfcindirur plano ducto per $D D$, tangentem figuram in puncto fummo, alter quoque confiderandus cuneus, quiabfcinditur plano per $B$ D, tangentem figuram in latere, quaque rangenti $D$ D fic ad rectos angulos. Oportetque dari, preter figura centrum gravitatis A, fubcentricamque H D cunci prioris, etiam fubcentricam $\mathrm{L}$ B cunei pofterioris. Ita enim nota erunt rectangula $D$ A $\mathrm{H}, \mathrm{B}$ A I, quæ fimul fumpta faciunt hic fpatium applicandum, quod deinceps etiam Rectangulum ofcillationis vocabitur. Quod nempe, applicatum ad diftantiam $\mathrm{F}$, dabit diftantiam $\mathrm{A} \mathrm{K}$, qua centrum of cillationis $\mathrm{K}$ inferius eft centro gravitatis $\mathrm{A}$.

Si vero $\mathrm{F}$ A fit axis figurx $\mathrm{B} C \mathrm{D}$, poteft, pro cuneo abfciffo per 
128

B.D fuper figura tota, adhiberi cuneus fuper figura dimidia $D$ B M D som r. abfififlus plano per D M. Nam, fi cunei hujus fubcentrica fuper: $D M$ fit $O A$, diftantia vero centri gr. figuræ planæ $D B M$ ab eadem $D M$ fit $N A$, rquale effe conftat rectangulum $O A N$ rectangulo

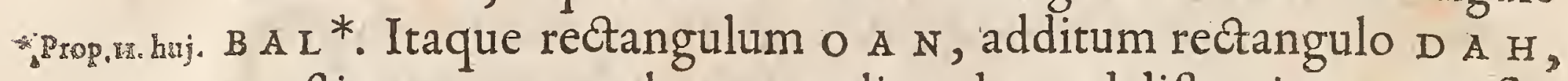
conftituet quoque planum applicandum ad diftantiam $F, A_{2}$ ut fiat diltantia A $\mathrm{K}$.
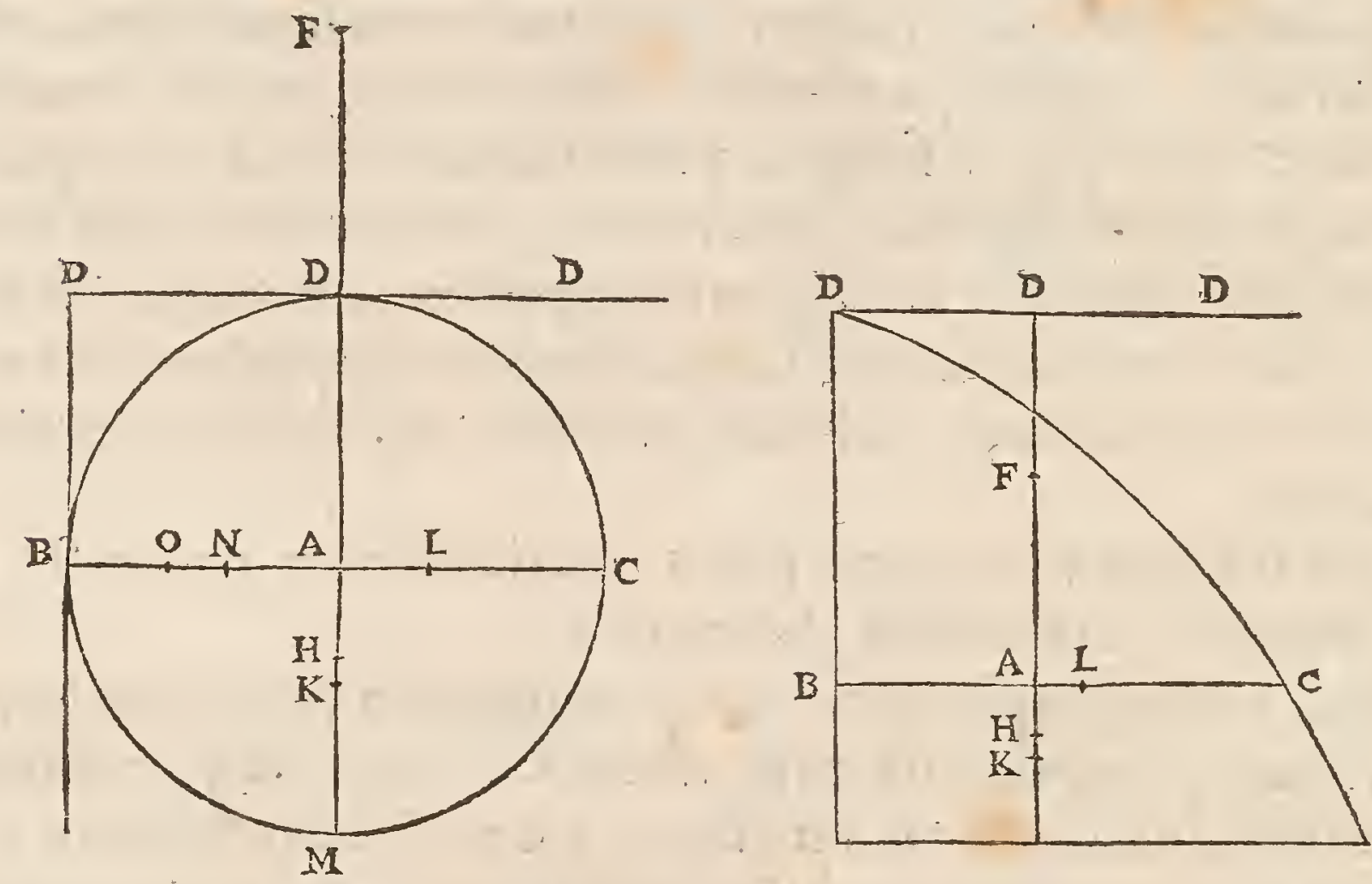

Et horum quidem manifefta eft demonftratio ex præcedentibus, quippe cum rectangula $\mathrm{DAH}, \mathrm{BA}$, vel $\mathrm{DAH}, \mathrm{OAN}$, mulriplicia fecundum numerum particularum figuræ, æqualia fint quadratis diftantiarum à centro gravitatis $\mathrm{A}$; five, quod idem hic eft, $a b$ axe gravitatis axi of cillationis parallelo; ac proinde rectangula dicta, ad diftantiam I A applicata, efficiant longitudinem * Propr.18, huj. intervalli $\mathrm{A} \mathrm{K} *$.

\section{Centrum Ofcillationis Circuli.}

Et in circulo quidem rectangula $D A H, B A L$, inter fe æqualia effe liquet, fimulque efficere femiffem quadrati à femidiametro. Vnde, fi fiat ut F A ad femidiametrum A B, ita hæc ad aliam, ejus dimidium erit diftantia $A K$, à centro gravitatis ad centrum of cillationis. Si igitur circulus ab axe $\mathrm{D}$, in circumferentia fumpto, agitetur, erit $\mathrm{DK}$ Kqualis tribus quartis diametri $\mathrm{D} M$.

Ad hunc modum \& in fequentibus figuris planis centra of cillationis quæfivimus, quæ fimpliciter adfripfiffe fufficiet. Nempe, 


\section{Centrum of cillationis Rectainguli.}

DE CENTRO

OSCIIIATION $1 S$.

In rectangulo omini, ut $\mathrm{C}$ B, fpatium applicandum, five reetangulum of cillationis, invenitur æquale rertiæ parti quadrati à femidiagonio A C. Vnde fequitur, fi rectangulum ab aliquo angulorum fufpendatur, motuque hoc laterali açitetur, pendulum illi ifochronum effe $\frac{2}{3}$ diagonii totius.

\section{Centrum of cillationis Trianguli ifofcelis.}

In triangulo ifofcele, cujufmodi C B D, fpatium applicandum æquatur parti decimæ octavæ quadratià diametro B E, \& vigefimæ quartæ quadrati bafeos C D. Vnde, fi ab angulo bafeos ducatur D G, perpendicularis fuper latus D B, qux occurrat productæ diametro $B$ E in $\mathrm{G}$; fitque $\mathrm{A}$ centrum gravitatis trianguli; divifoque intervallo $G \mathrm{~A}$ in quatuor partes $æ$ quales, una earum $\mathrm{A} \mathrm{K}$ apponarur ipfi. В A ; erit в K longitudo penduli ifochroni, fi triangulum fufpendatur ex vertice $B$. Cum autem ex puncto medix bafis $\mathrm{E}$ fufpenditur, longitudo penduli ifochroni E K æquabitur dimidiæ B G.

A tque hinc liquet, triangulum ifofceles rectangulum, fi ex puncto medix bafis fufpendatur, ifochronum effe pendulo longitudinem diametro fux æqualem habenti. Similiterque, fi fufpendatur ab angulo fuo recto, eidem pendulo ifochronum effe.
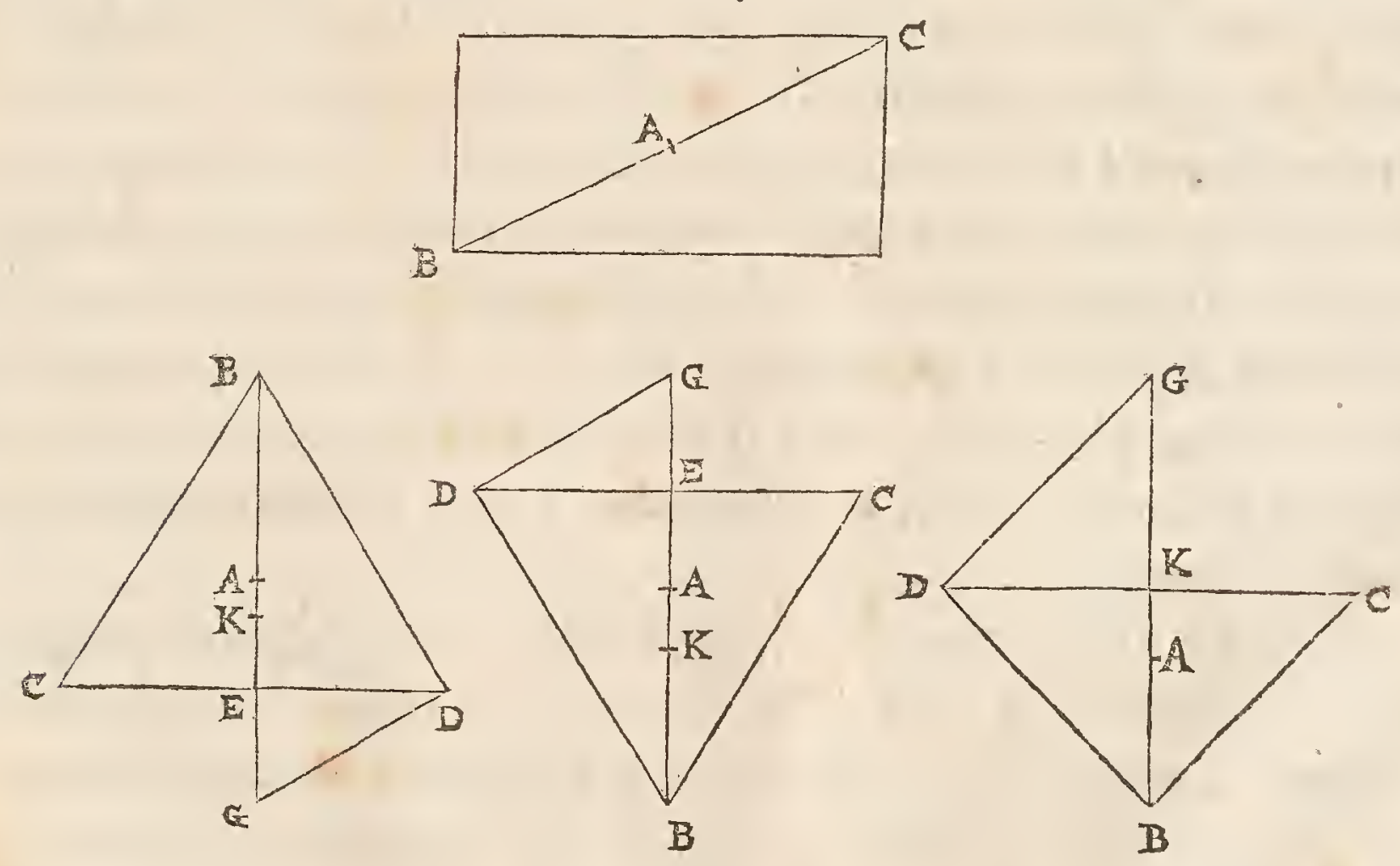

Centrum of cillationis Parabola.

In parabolæ portione recta, fpatium applicandum æquatur $\frac{12}{175}$ quadratiaxis, una cum quinta parte quadrati dimidix bafis. Cum. 
530 CHRISTIA N H HGENII

DE CENTRO que parabola ex verticis punto fufpenfa eft, invenitur penduli TxO.NIs. ifochroni longirudo $\frac{5}{7}$ axis, atque infuper $\frac{1}{3}$ lateris recti. Cum vero ex puncto 'medix bafis fufpenditur; erit ea longitudo $\frac{4}{7}$ axis, \& infu. per $\frac{1}{2}$ lateris recti.

\section{Centrism of cillationis Sectoris circuli.}

In circuli fectore $B C D$, fi radius $B$ C vocetur $r$ : femi arcus $C$, $p$ : femifubtenfa $C E, b$ : fit fpatium applicandum xquale $\frac{1}{2} r r$ $\frac{4 b b r r}{g p p}$, hoc eft, dimidio quadrati B $\mathrm{C}$, minus quadrato B $A ;$ ponendo

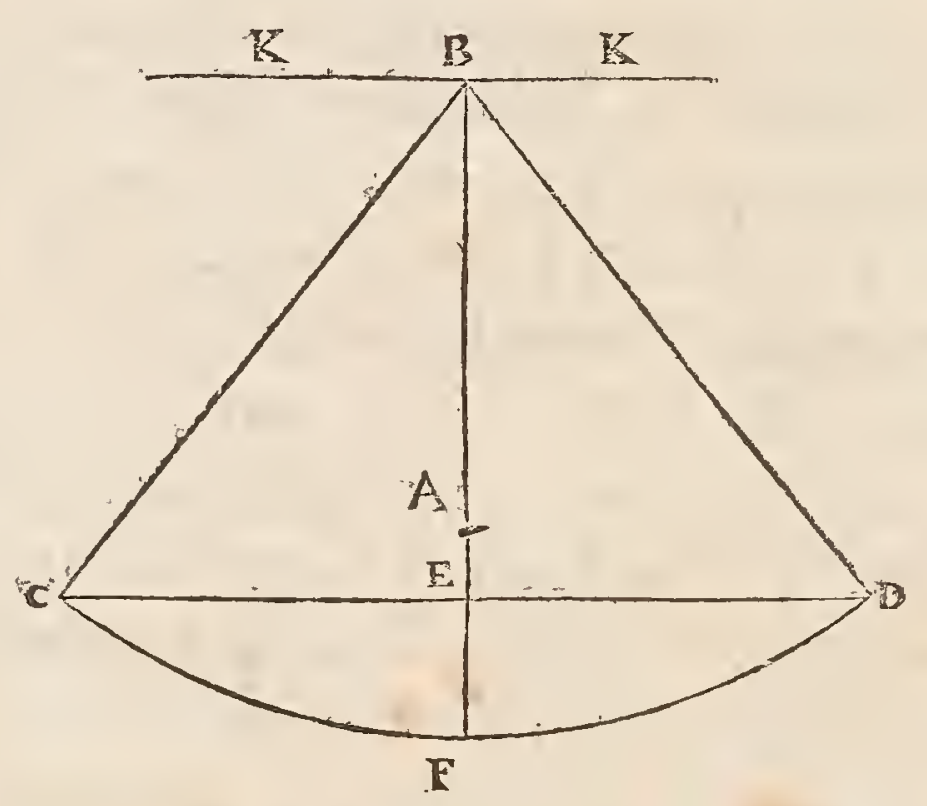

A effe centrum gravitatis fectoris. Tunc enim $B A \infty \frac{2 b r}{30}$. Si autem fufpendatur fector ex B, centro circuli fui, fit pendulum ipfi ifochronum $\frac{3 p r}{4 b}$, hoc eft, trium quartarum rectx, qux fit ad radium в F ut arcus $C F D$ ad fubrenfam $C D$. Hæc autem inveniuntur cognitis fubcentricis cuneorum; tum illius qui fuper fectore toto abfcinditur, plano ducto per в $\mathrm{x}$ parallelam fubtenf $\mathrm{C} D$, cujus cunei fubcentricam fuper $\mathrm{B} K$ invenimus effe $\frac{3}{8} r-\frac{3}{8} a+\frac{3 p r}{8 b}$, vocando $a$ finum verfum E F; tum illius qui fuper dimidio fectore в в C ab_ fcinditur plano per B F, cujus nempe cunei fubcentricam fuper B F invenimus $\frac{3}{8} b-\frac{3 b r}{8 a}+\frac{3 p r}{8 a}$.

Sed \& alia via, fectoris centrum of cillationis, facilius invenitur, qux eft hujufmodi. Intelligarur fectoris в C D pars minima fector B C P, qui trianguli loco haberi poteft. Quadrata autem, à diftantiis particularum ejus à puncto $\mathrm{B}, x$ qualia funt quadratis diftantiarum $\mathrm{ab}$ recta $\mathrm{B} R$, bifariam fectorem dividente, una cum quadratis diftantiarumab recta B $Q$, qux ipfi B $R$ eft ad angulos rectos. Sed, horum quadratorum ad illa, ratio quavis data eft major, quoniam angulus $C$ B 1 minimus; ideoque illa pro nullis habenda funt. 
HOROLOG. OS CILLATOR.

Pofitâ vero $B$ o duarum tertiarum $B R$, hoc eft, pofito o centro $D_{E}$ CENTRO

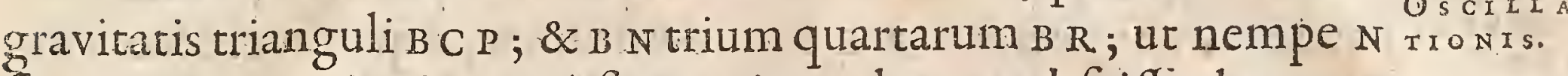
fit centrum gravitatis cunei, fuper triangulo B C Pabfcifli plano per $B$ Q. His pofitis, conftat quadrata, à diftantiis particularum trianguli в C P ab recta B Q, æquari rectangulo N B o multiplici fecundum particularum ejufdem trianguli numerum. Itaque rectangulum N B O, ita multiplex, xquale cenfendum quadratis diftantiarum à puncto в particularum trianguli в C P. Sunt autem quadrata

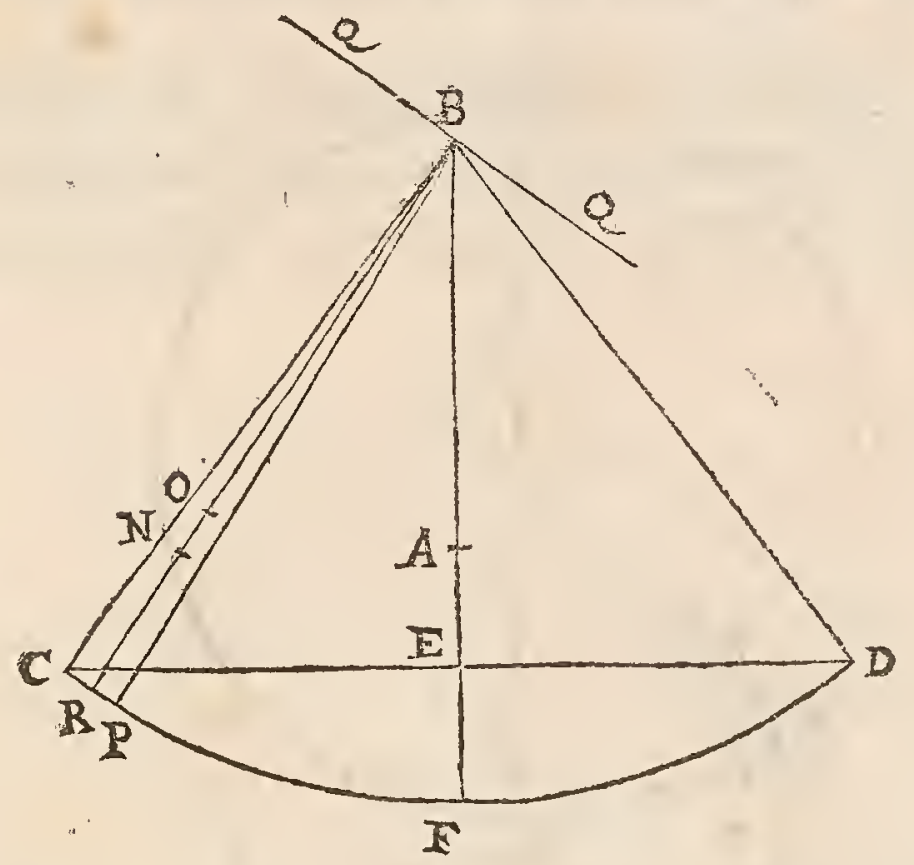

diftantiarum harum, ad quadrata diftantiarum totius fectoris B C D, ficut fector B C P ad fectorem B C D, hoc eft, ficut numerus particularum fectoris B C $\mathrm{P}$, ad numerum particularum fectoris B CD; hoc enim facile intelligitur, co quod fector $B$ C D dividatur in fectores qualis B C P. Ergo rectangulum N B O, multiplex fecundum numerum particularum fectóris B C D, æquale erit quadratis diftantiarum particularum ejus à puncto $\mathrm{B}$. Ideoque rectangulum $\mathrm{NBO}$, applicatum ad B $A$, diftantiam inter fufpenfionem \& centrum gravitatis fectoris, dabit longitudinem penduli ifochroni, cum fector ex в fufpenditur *. Eft autem rectangulum N B O $\infty \frac{\pi}{2}$ * Prop.r7.huj. $r r$ : diftantia autem в $A$, ut jam ante diximus, $\infty \frac{2 b r}{3 p}$. Vnde, facta applicatione, oritur $\frac{i p r}{4 b}$, longitudo penduli ifochroni, ut ante quoque "inventa fuit.

\section{Centrum of cillationis Circuli, aliter quam fupra:}

Eodem modo etiam fimpliciffime, in circulo, centrum of cillationis invenire licet. Sit enim circulus G C F, cujus centrum B; fectorque in eo minimus intelligatur $\mathrm{B} C \mathrm{P}$, ficut ante in fectore B. C D. 


\section{2}

D. CENTRO

OSCILIA-

TIONIS.

Cum igitur, fecundum modo expofita, quadrata, à diftantiís particularum fectoris B C $\mathrm{P}$ ad centrum B, xquentur rectangulo N B O, hoc eft, dimidio quadrato radii, multiplici fecundum fectoris ipfius particularum numerum; circulus autem ex ejufmodi fectoribus componatur ; erunt proinde quadrata, à diftantiis particularum circuli totius ad centrum B, xqualia dimidio quadrato radii, multiplici fecundum numerum earundem circuli particularum.

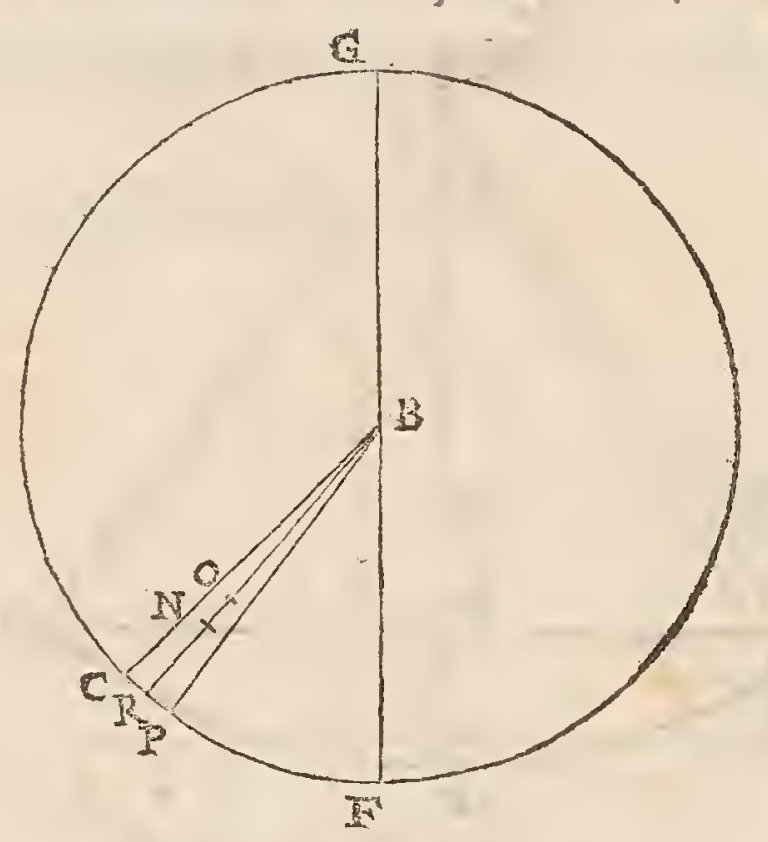

Eft autem B centrum gravitatis circuli. Ergo dictum dimidium quadratum radii, hic erit fpatium applicandum diftantiæ inter fufpenfionem \& centrum $\mathrm{B}$, ut habeatur intervallum, quo centrum * Prop.r8. huj. of cillationis inferius eft ipfo centro ${ }^{*}$. quod \& fupra ita fe habere oftendimus.

\section{Centrum of cillationis Peripheris circuli.}

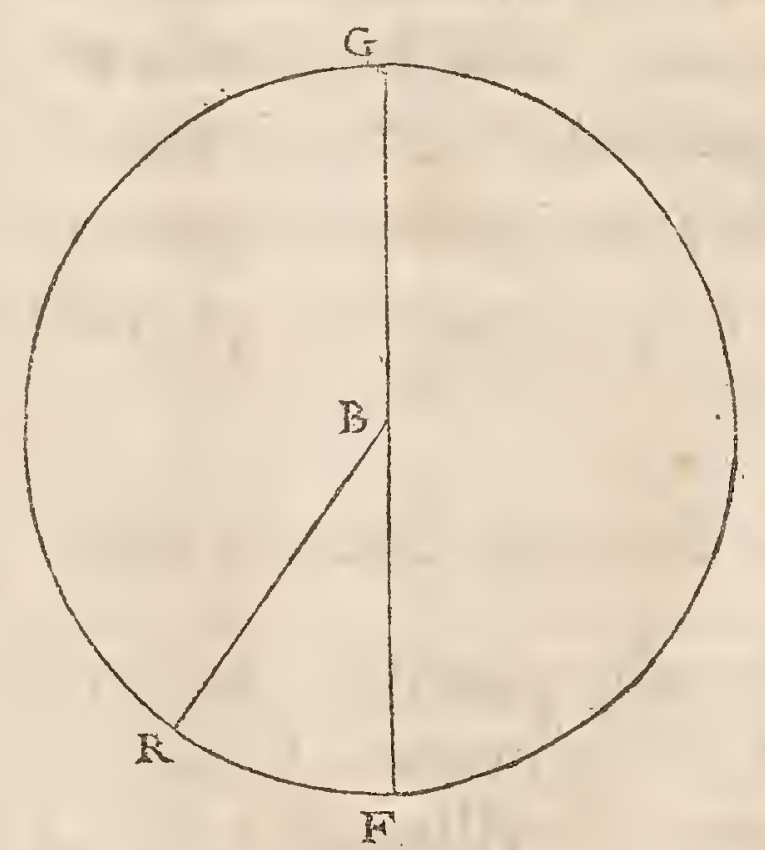

Facilius etiam, centrum of cillationis circumferentix circuli, hoc 

pacto repericur. Efto enim circumferentia defcripta centro $B$, ra- DE CENTRO dio B R. Quadratum igitur B $R$, multiplex fecundum numerum т ON particularum in quas circumferentia divifa intelligitur, æquatur quadratis à diftantiis omnium earum particularum ad centrum $B$; Quare quadratum B R erit hic f patium applicandum *. Patetque * Prop. 18.huj. hinc, fi fufpenfio fit ex $G$, puncto circumferentix, penduli ifochroni longitudinem æquari diametro G F.

\section{Centrum of cillationis Polygonorum ordinatorum.}

Haud abfimiliter \& polygono cuivis ordinato, ur A B C, pendulum ifochronum invenitur. Fit enim, fpatium applicandum, æquale femiffi quadrati perpendicularis ex centro in latus polygoni, una

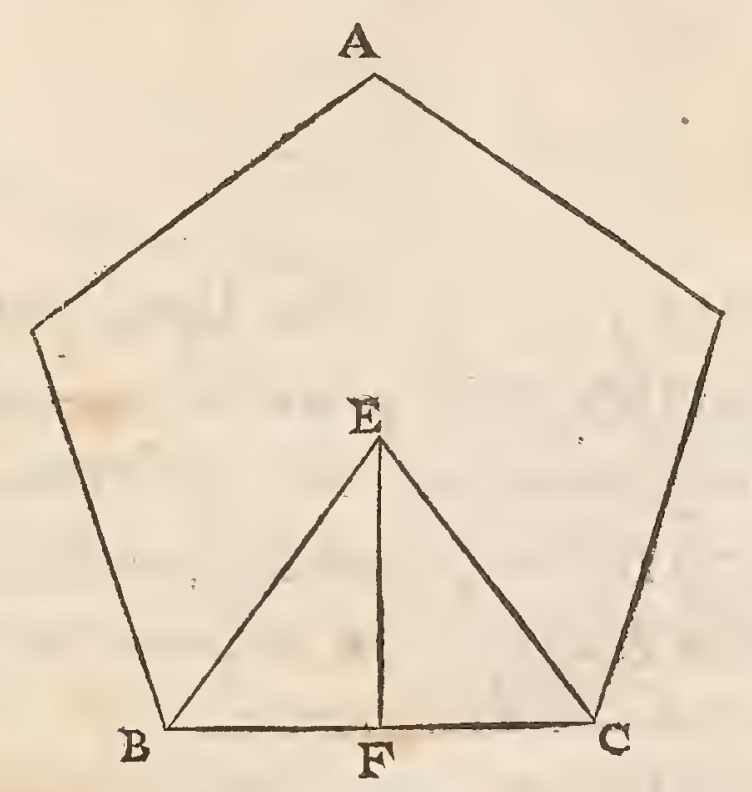

cum vigefima quarta parte quadrati lateris. At, fi perimetro poligoni pendulum ifochronum quæratur, fit fpatium applicandum æquale quadrato perpendicularis à centro in latus, , cum duodecima parte quadrati lateris.

\section{Loci plani E folidiufus in bac Theoria.}

Eft præterea \& Locorum contemplatio in his non injucunda. $\mathrm{Vt}$ fi propofitum fit, dato puncto fufpenfionis $\mathbb{A}$, \& longitudine $A B$, invenire locum duorum ponderum æqualium $C, D$, xqualiter $a b$ A \& à perpendiculari $A B$ diftantium, quæagitata circa axem in $A$, perpendicularem plano per $A C D$, ifochrona fint pendulo fimplici longitudinis $\mathbb{A} \mathrm{B}$.

Ponatur $\mathrm{AB}$ so $a$, ductâque $\mathrm{C} D$, quæ fecet $\mathrm{A} B$ ad angulos rectos in $\mathrm{E}$, fit $\mathrm{A} \mathrm{E}$ indeterminata $\infty x: \mathrm{EC}$ vel E $\mathrm{D} \infty y$. Ergo quadratum A C so $x x+y y$. Hoc vero multiplex fecundum numerum particularum ponderum $\mathrm{C}, \mathrm{D}$, quæ hic minima intelliguntur, æquatur quadratis diftantiarum earundem particularum ab axe 
De centro fufpenfionis A. Ergo quadratum A C five $x x+y y$, applicatum TON IS. ad diftantiam A E, quænempe eft inter axem fufpenfionis \& centrum gravitatis ponderum $\mathrm{C}, \mathrm{D}$, efficier $\frac{x x+y y}{x}$, longitudinem pen* Prop. 77 . huj duli ifochroni*; quam propterea oportet aqualem effe a в five $a$.

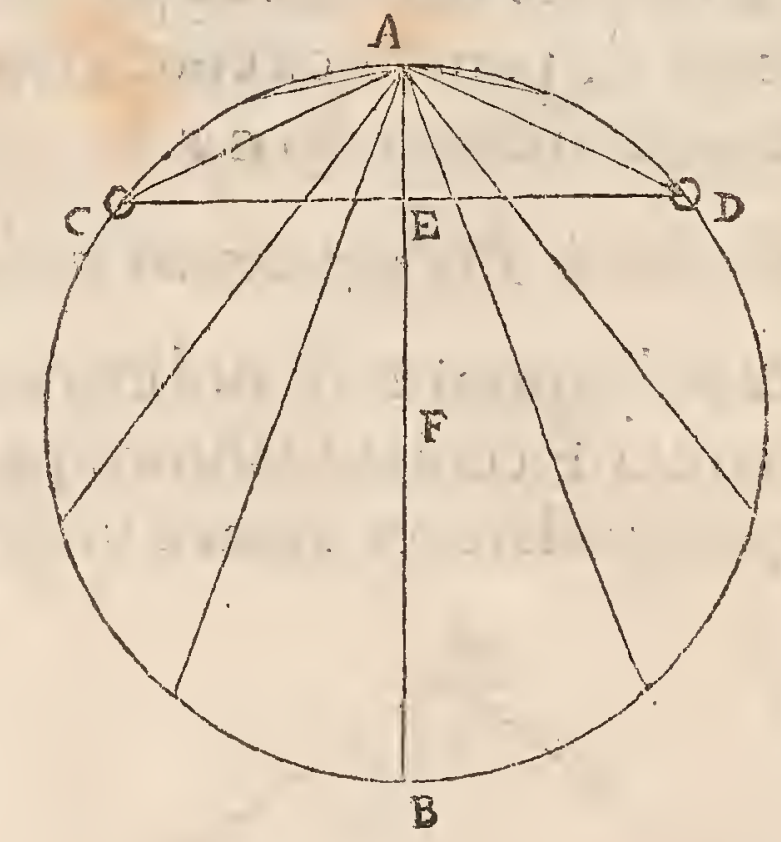

Itaque $\frac{x x+y y}{x}$ s a. Ety $y$ so $a x-x x$. Vnde patet, locum punctorum C \& D, effe circumferentiam circuli, cujus centrum $\mathrm{F}, \mathrm{ubi}$ A B bifariam dividicur, radius autem $\infty \frac{x}{2} a$, five F A. Ergo, ubicunque in circumferentia A C B D duo pondera æqualia, æqualicer $a b$ A diftantia, ponentur,ea, ex A agitata, ifochrona erunt pendulo longitudinem habenti æqualem diametro $\mathrm{A} B$.

A tque hinc manifeftum quoque, \& circumferentiam A C B D, fi gravitas ei tribuatur, \& quamlibet ejus portionem, æqualiter in A vel B divifam, \& ab axe per $A$ fufpenfam, eidem pendulo $A B$ ifochronam effe.

Loci vero folidi exemplum efto hujufmodi. Sit A $\mathrm{N}$ linea inflexilis fine pondere.Propofitum que fit, ad punotum in ea acceptum, ut $\mathrm{M}_{\text {, }}$ affigere ipfi ad angulos rectos lineam, feu virgam, pondere prædiram o M L, ad M bifariam divifam, cujus in latus agitatæ ofcillationes, ex fufpenfione $A$, ifochronæ fint peridulo fimplici longitudinis A $N$.

Ducatur o f parallela $\mathrm{A} N$, \& A H parallela o M, \& fit o R æqualis ${ }_{3}^{2}$ o L. Iraque cunei fuper recta o L, abfciffi plano per o H ducto, fubcentrica erit o R. Sed cunei alterius fuper eadem o $\mathrm{L}$, abfciffi plano per rectam A H, (eft autem cuneus hic nihil aliud quam rectangulum) fubcentrica erit ipfa A M. Quare rectangulum illud, quod fupra Ofcillationis vocavimus, erit folum rectangulum o $\mathrm{M}$. quod nempe, applicatum ad longitudinem $\mathrm{A}$ M, dabir diftanciam centri of cillationis linex o $L$, ex A fufpenf $x$, infra punctum $M$. 
HOROLOG. OSCILLATOR.

Sir jam A N $x$ a: A M $x \quad x$ : M O vel M L $x y$. Eft ergo rectan- Dв сеNTRo

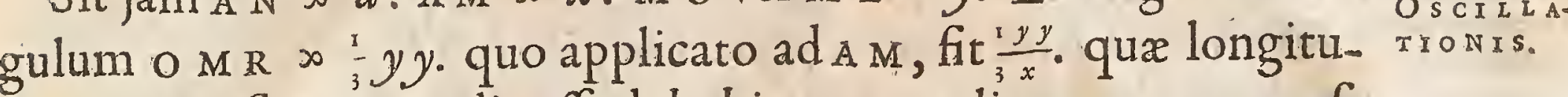
doitaque ipfi $\mathrm{M} x \mathfrak{N}$ qualis effe debebit, cum velimus centrum of cillationis virgx o L effe in $N$. Fit ergo æquatio $\frac{1 y y}{3 x}+x$ so a. Vnde y $x \sqrt{3 a x-3 x x}$. Quod fignificat puncta o \& $\mathrm{L}$ effe ad Ellipfin, cujus axis.minor A $\mathrm{N}$; latus rectum vero, fecundum quod poffune ordinatimad axem hunc applicatx, ipfius $A N$ triplum.

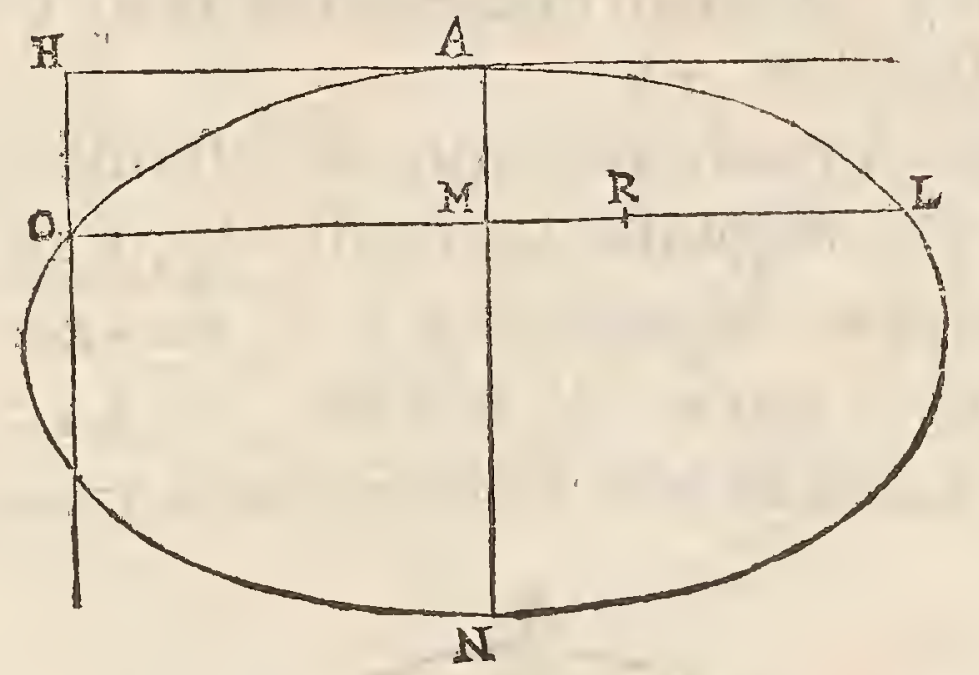

Hinc vero manifeftum fit, cum omnis virga ipfi o c parallela, \& ad Ellipfin hanc'terminata, of cillationes ifochronas habeat pendulo fimplici A $N$, etiam totum Ellipfeos planum, ex A fufpenfum \& in latus agitatum, ipfí A $\mathrm{N}$ pendulo ifochronum fore. Sed \& partem Ellipfeos quamlibet, qua lineis una vel duabus, ad A $N$ perpendicularibus, abfcindecur.

Cæterum adfcribemus \& aliud loci plani exemplum, in quo nonnulla notatu digna occurrunt.

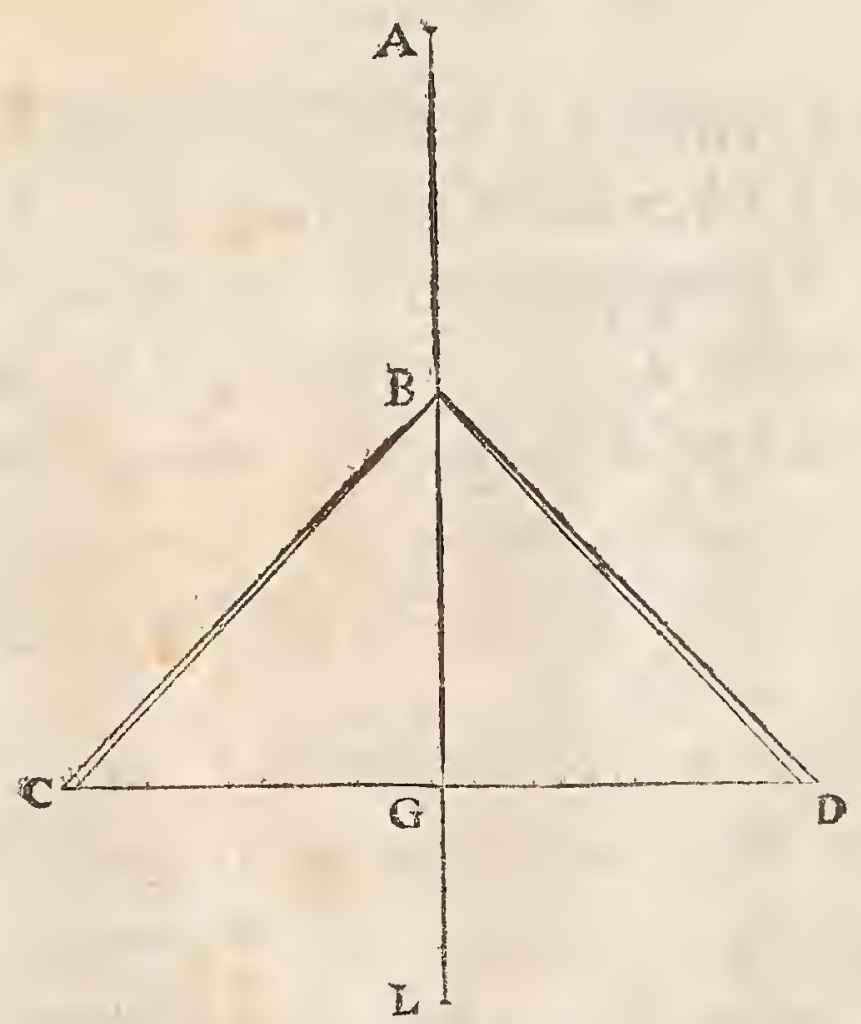

Sit virga A B ponderis expers, fufpenfa ex $A$; oporteatque, ad da- 
tum in ea punctum $B$, affigere triangula duo paria, \& paribus angulis ab axe A Brecedentia, quorum anguli ad B minimi, five infinite parvi exiftimandi, quaque, ira fufpenfa $\mathrm{ab} \mathrm{A}$, ofcillatiónes ifochronasfaciant pendulo fimplici datæ longitudinis $\mathrm{A} L$.

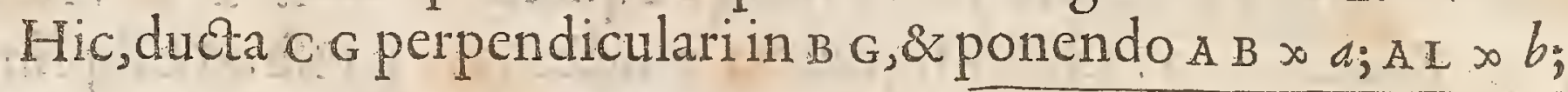
B G $x ; C$ \& $x y$ : invenitur $x$ quatio $y$ so $\sqrt{2 a b-2 a a-\frac{8}{3} a x+\frac{4}{3} b x-x x}$. ex qua pater, bafes triangulorum $c, \& \mathrm{D}$, qux bafes hic ut puncta confiderantur, effe ad circuli circumferentiam; quia nempe habetur terminus fimplex $-x x$.

Licet autem hic animadvertere, quod fi a fit nibilo $x$ qualis, hoc eft, fi punctum, ubi affiguntur trianguli B C , B D, fit idem cum puncto $A$; tum futura fit $x$ quatio $y>\sqrt{\frac{4 b x-x x}{3}}$. Ac proinde, hoc cafu, fi fumatur A $\mathrm{O} x \frac{2}{3} b$, hoc eft, $\infty \frac{2}{3} \mathrm{~A} L$, centroque $\mathrm{O}$ per a circulus defcribatur A D N ; erunt bafes triangulorum A C,

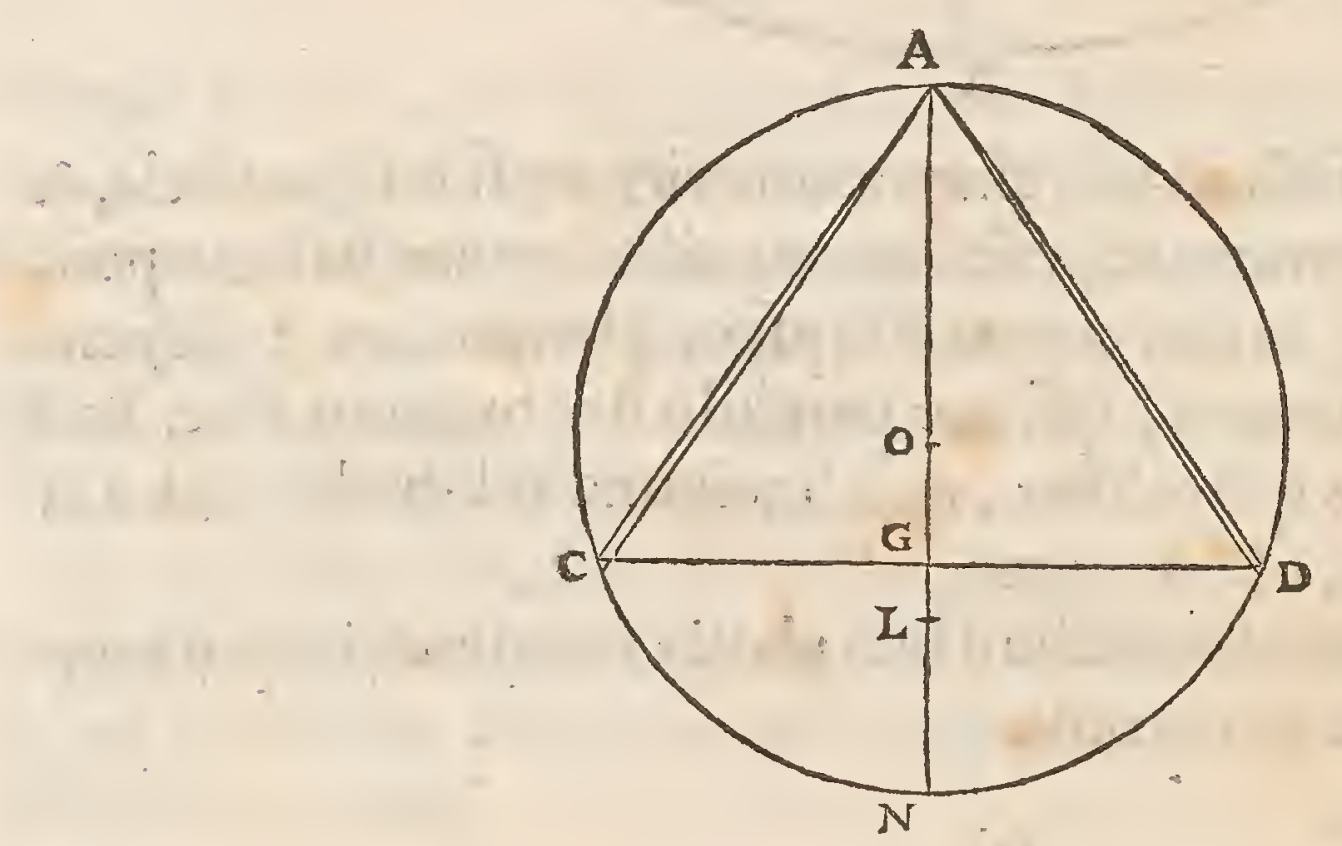

A $D$, ad illius circumferentiam. Cum igitur quælibet duo triangula acuriflima, quæ ex A ad circumferentiam A C N D conftituuntur, magnitudine \& fitu fibi refpondentia, centrum ofcillationis habeant punctum $L$, pofitâ $\mathrm{A} L \infty \frac{3}{4}$ diametri A $\mathrm{N}$; cumque circulus totus ex ejufmodi triangulorum paribus componatur; uti \& portio ejus quælibet, ut A C N D, latera A C, A D æqualia habens; manifeftum eft, tum circuli totius, tum portionis qualem diximus, centrum of cillationis effe in $\mathrm{L}$.

Rurfus, fi in $x$ quatione inventa ponatur $\frac{8}{3} a>0 \frac{4}{3} b$, feu $2 a . x b$; hoc eft, fi triangula affigi intelligantur in $\mathrm{B}$, quod longitudinem A I fecet bifariam, erit $y>\sqrt{2 a a-x x}$. qux $x$ quatio docer, quod fi centro $B$, radio qui poffit duplum $B A$, circumferentia defcribatur, ea erit locus bafum triangulorum acutiffimorum B C, B D, 
HOROLOG. OS CILLATOR.

137

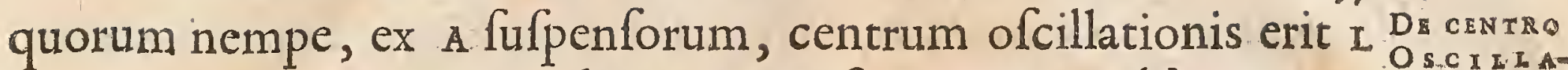
punctum. Cumque \& circulus totus, \& fector ejus quilibet, axem x 9 × $\triangle$ \&. habens in recta $\mathrm{A} I$, ex hujufmodi triangulorum paribus componatur, manifeftum eft \& horum, ex A fufpenforum, centrum ofcillationis effe punctum $\mathrm{L}$.

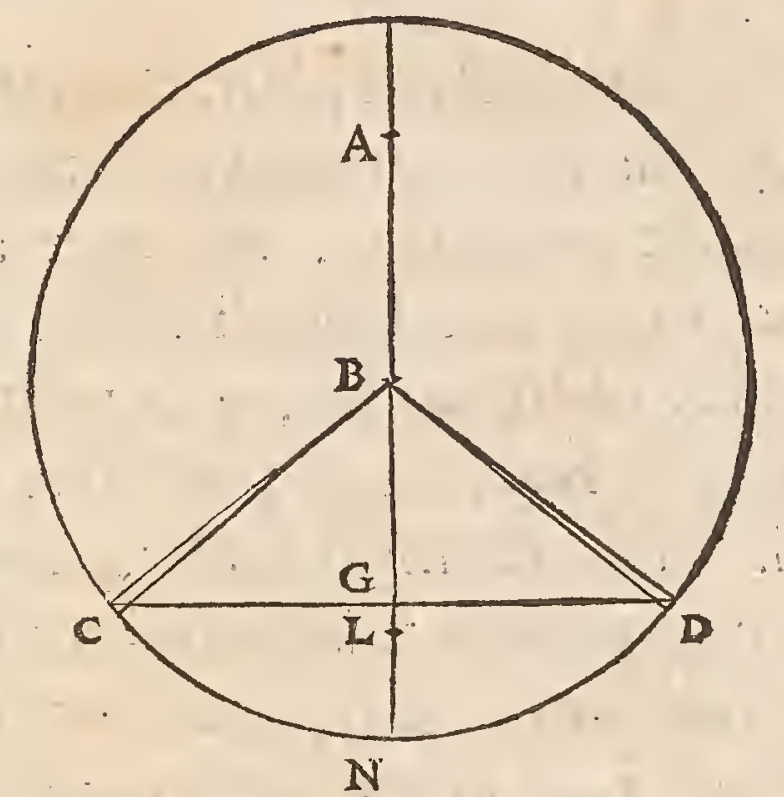

Adeoque quilibet circuli fector, fufpenfus à puncto quod diAtet, à.centro circuli fui, femiffe lateris quadrati circulo infcripti, pendulum ifochronum habebit toti eidem lateri æquale. Atque ita, hoc uno cafu, abfque pofita dimenfione arcus, pendulum fectori ifochronum invenitur.

Porro, ad univerfalem conftructionem $x$ quationis prim $x, y$ $\sqrt{2 a b-2 a a-\frac{8}{3} a x+\frac{4}{3} b x-x x}$, dividatur $\mathrm{A} L$ bifariam in $\mathrm{E}, \&$ adponatur ad $\mathrm{B}$ E pars fui tertia $\mathrm{E} F$; eritque $\mathrm{F}$ centrum defcribendicirculi; radius autem $\mathrm{F}$ o æqualis fumendus ei, quæ potelt duplum differentiæ quadratorum A E, E F.
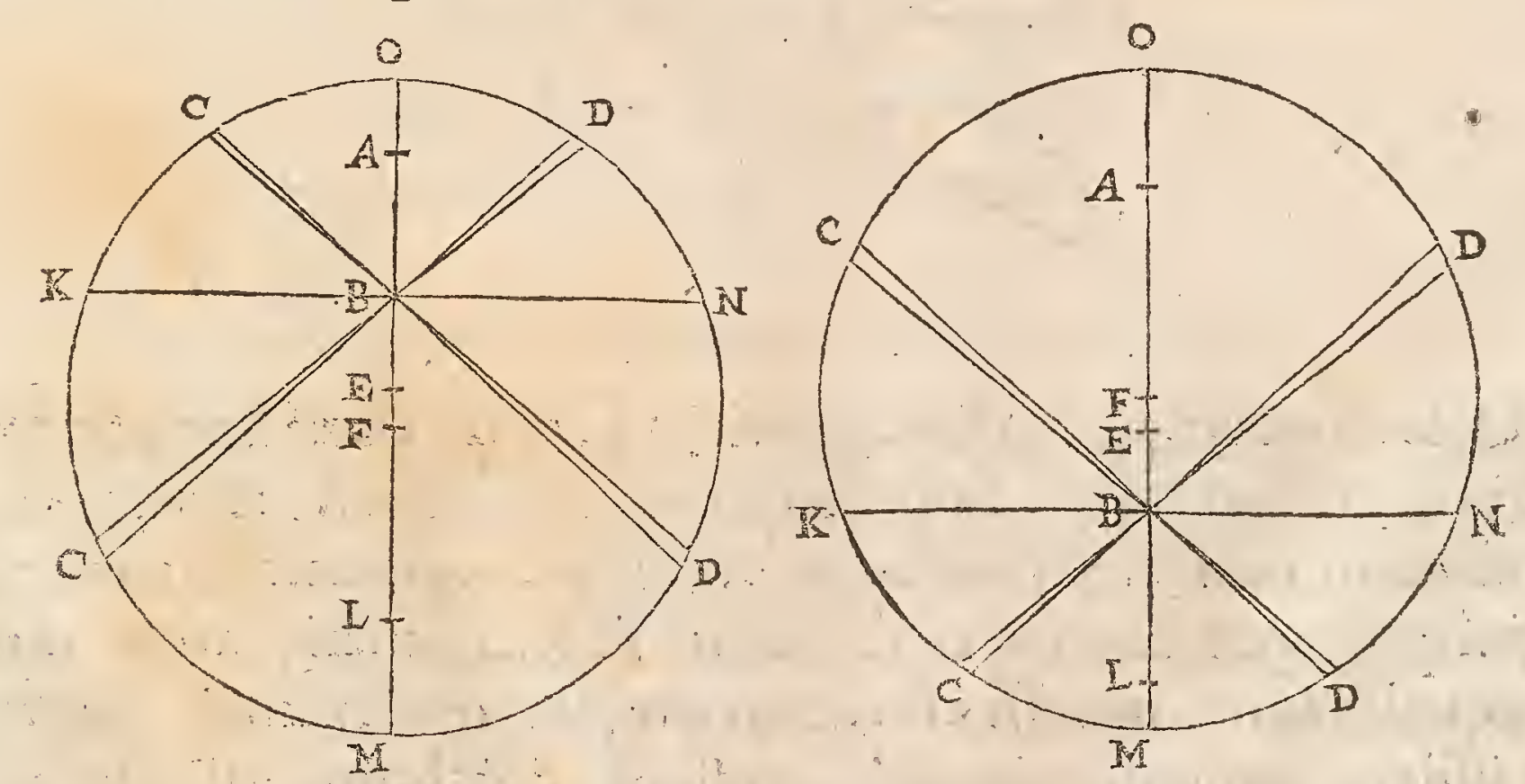

Si itaque, ex puncto $B$, ad defcriptam circumferentiam triangula duo paria acutiflima conftituantur, ut B C, B D; illorum, ex A 

juflibet defcripti circuli, cujus portionis vertex fit in $B$, axis vero in recta $A L$, quales funt utraque $C B D$; pofita fufpenfione ex $A$; centrum of cillationis idem punctum $L$ effe conftat. Atque adeo etiam circuli fegmentorum $\mathrm{KO} N, \mathrm{~K} \mathrm{MN}$, quæ facit reč̃a $\mathrm{K} \mathrm{B} \cdot \mathrm{N}$ perpendicularis ad $\mathrm{A} B$.

Et hæc quidem de moru laterali planorum, ac linearum, animadvertiffe fufficiat. Quibus hoc tantum addimus; inventis centris ofcillationis figurarum rectarum, feu quæ æqualiter ad axem utrinque conftitutæ funt; ut trianguli ifofcelis, vel parabolicæ fectionis rectx; etiam obliquarum, quæ velut luxatione illarum efficiuntur, ut trianguli fcaleni, \& parabolæ non rectæ, centra of cillationis haberi. Vtfi, exempli gratia, triangulum B A C ifofceles, cujus axis $\mathrm{A} D$; à puncto $\mathrm{E}$ fufpenfum intelligarur; fit vero $\&$ aliud triangulum fcalenum $F$ A $G$, axem eundem habens $A D, \&$ bafin $\mathrm{F} \mathrm{G}$ qualem bafi в C; etiam hoc triangulum, ex E fufpen. fum, priori B A cifochronum effe dico.

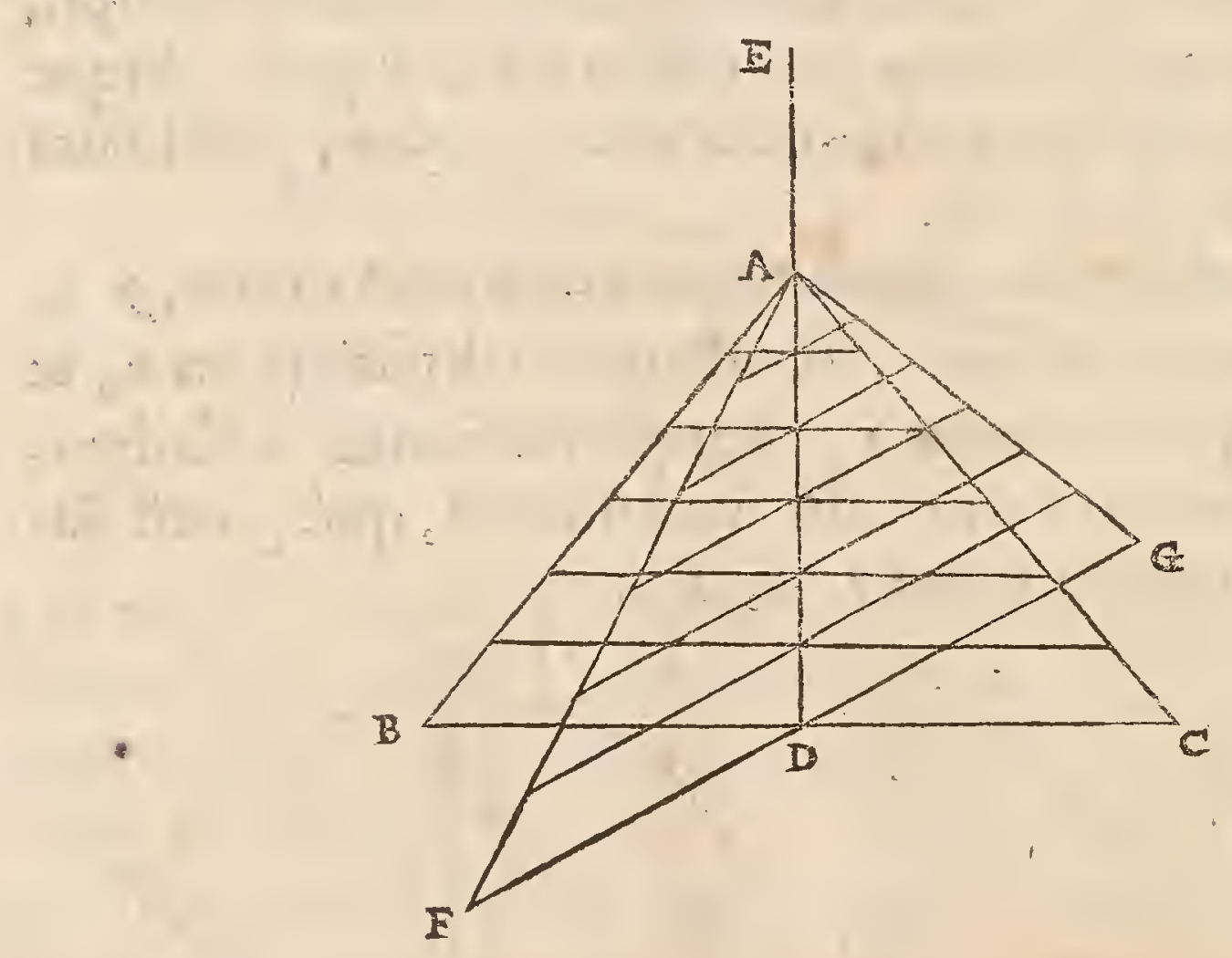

Quia enim virga, feu linea gravis, F G, affixa virgæ fine pondere $E D$ in $D$, fitu obliquo, fufpenfaque ex $E$, ifochrona eft virg $B C$, $*$ Prop. 6. huj. fimiliter in $\mathrm{D}$ affixæ*; idemque evenit in virgis cæreris trianguli utriufque, qux axem $A D$ fecant in iifdem punctis, atque inter fe æquales funt: neceffe eft tota triangula, quæ ex lineis, feu virgis iifdem compofita intelligi poffunt, ifochrona effe. In aliis figuris fimilis eft demonftratio. 


\section{PROPOSITIO XXII.}

Vomodo, in folidis figuris, of cillationis centra inveniantur.

In folidis porro figuris facile quoque, per ante demonftrata, centrum of cillationis invenire licebit. Si enim fit folidum A B C, fufpenfum $\mathrm{ab}$ axe, qui, per punctum $\mathrm{E}$, incelligitur hujus paginæ plano ad rectos angulos; centrum autem gravitatis fit $\mathrm{F}:$ ductis jam per $\mathrm{F}$ planis E F D, G F H, quorum pofterius fit horizonti parallelum, alterum vero per axem $\mathrm{E}$ tranfeat; inventifque, per propofitionem 14, fummis quadratorum à diftantiis particularum folidi A B C à plano G F H, itemque à plano E F D ; hoc eft, inventis rectangulis utrifque, qux, multiplicia fecundum numerum dictarum particularum, æqualia fint dictis quadratorum fummis; rectangula hæc applicata ad diftantiam E E, qua nempe axis fufpenfionis diftat à centro gravitatis, dabunt intervallum $\mathrm{F}$ K, quo centrum agitationis $\mathrm{K}$ inferius eft centro gravitatis $\mathrm{F}$. Hoc enim paret ex propofitione 18. Dabimus autem \& horum exempla aliquot.

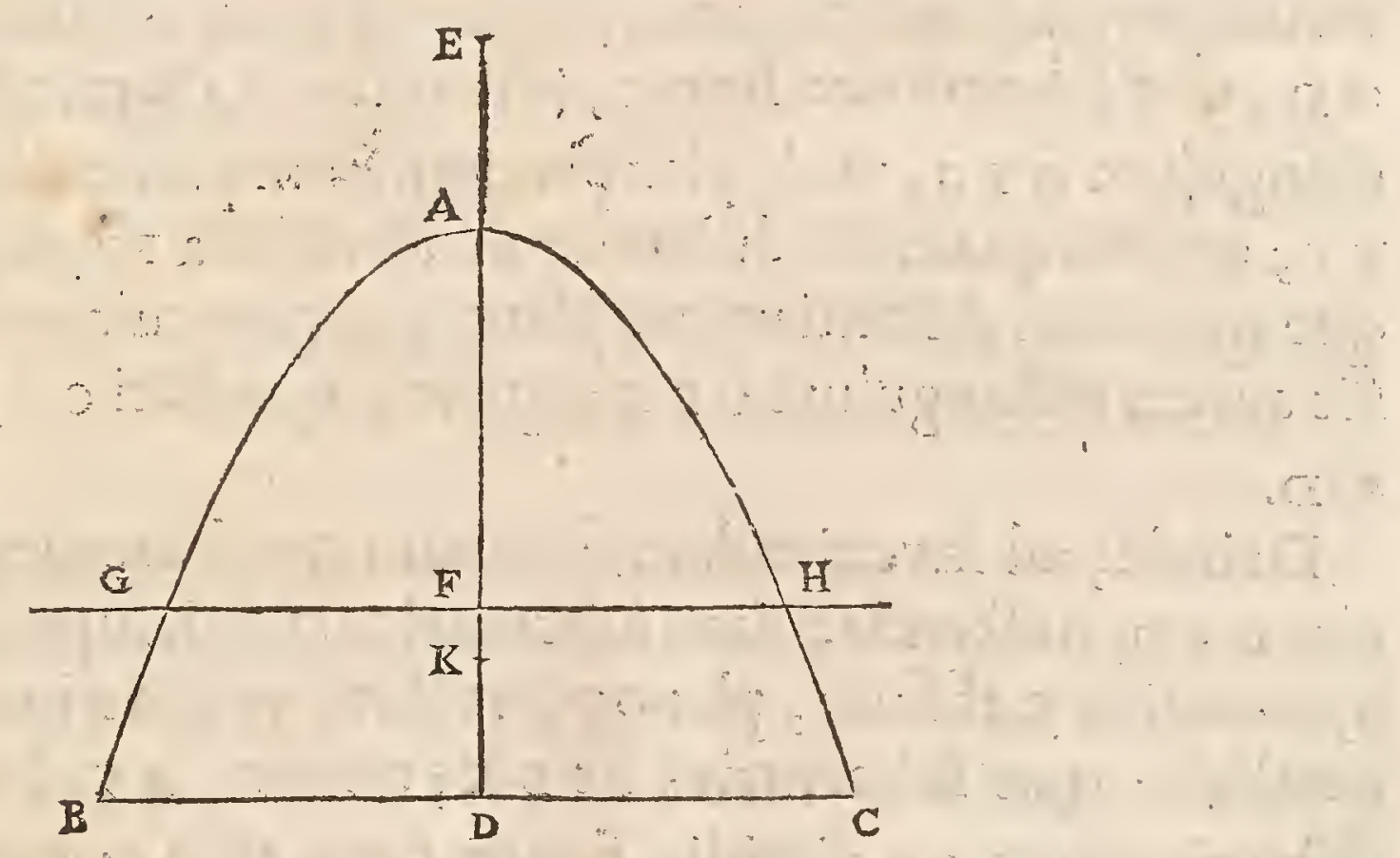

\section{Centrum of cillationis in Pyramide.}

Sic primum $A$ B C pyramis, verticem habens $A$; axem $A D$, bafin vero quadratum, cujus latus B C. ponaturque agitari circa axem qui, per verticem A, fit hujus paginx plano ad angulos rectos.

Hic figura plana proportionalis ov $\mathrm{v}$, à latere adponenda, $\mathrm{fe}$ cundum propofitionem 14 , conftabit ex refiduis parabolicis o P V, quix nempe fuperfunt, cum, à rectangulis $\Omega . P$, auferuntur femiparabolx ov $\Omega$, verticem habenres 0 : 
DI CENTRO OSCILIATIONIS.

140

Sicut enim inter fe fectiones pyramidis $B C, N N$, ita quoque reetæ $V V, R R$, ipfis in figura plana refpondentes. \& ficut centrum gravitatis $\mathrm{E}$ diftat, à vertice pyramidis, tribus quartis axis $\mathrm{A} D$, ita quoque centrum gravitatis $F$, figuræ $O \mathrm{~V} V$, diftabit tribus quartis diametri o p à vertice 0 .

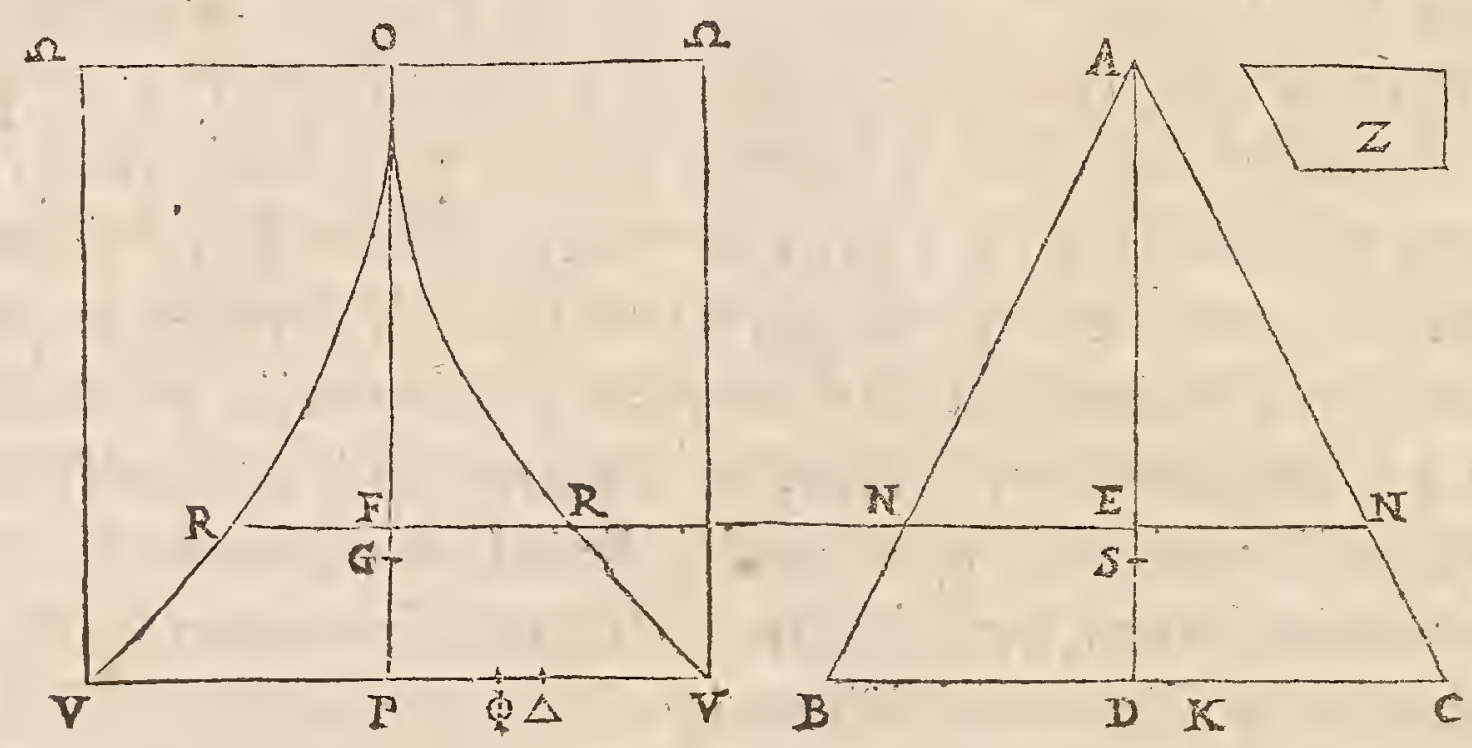

Intellecto porro horizontali plano $\mathrm{N}$, per centrum gravitatis pyramidis $A B C$, quod idem figuram o $v \vee$ fecet fecindum $R F$; invẹtâque fubcentricâ cunei, fuper figura o v v abfciffi plano per $O \Omega$, quæfubcentrica fit $O G$, (eft autem $\frac{4}{5}$ diametri $O P$ ) erit rectangulum o F G, multiplex per numerum particularum figuræ $\mathrm{O}$ * Prop.ro.huj. V V, xquale quadratis diftantiarum ab recta $\mathrm{R} \mathrm{F} *$, ac proinde quoque quadratis diftantiarum à plano $\mathrm{N}$ E, particularum folidi A B C. Fit autem rectangulum o F G $æ$ quale $\frac{3}{80}$ quadrati o $\mathrm{P}$, vel quadrati

\section{A. D.}

Deinde, ad inveniendam fummam quadratorum à diftantiis à plano $A D$, nofcenda primo fubcentrica cunei, fuper quadrata bafi pyramidis B C abfciffi, plano per rectam quæ in B intelligitur axi $\mathrm{A}$ parallela; quæ fubcentrica fit B $\mathrm{K}$; eftque $\frac{2}{3}$ B C. Nofcenda item diftantia centr. gr. dimidix figuræ o P V ab O P; quæ fit $\Phi$ P; eftque ${ }_{\frac{3}{10}}^{3} \mathrm{P} V$. Inde, divisâ bifariam $\mathrm{PV}$ in $\Delta, \mathrm{f}_{\mathrm{f}}$ fiat ut $\Delta \mathrm{P}$ ad $\mathrm{P} \Phi$, hoc eft, ut $\mathrm{Sad}_{3}$, ita rectangulum B.D K, quod eft $\frac{1}{\mathrm{r}_{2}}$ quadrati B C, ad aliud fpatium $\mathrm{z}$; erit hoc, multiplex fecundum numerum parti* Prop.rs huj cularum folidi a B C, xquale quadratis diftantiarum à plano $\mathrm{A} D *$. Apparet autem, fieri fpatium $\mathrm{z}$ æquale $-\frac{\mathrm{x}}{20}$ quadrati B C.

Iraque, totum fpatium applicandum, xquatur hic $\frac{3}{80}$ quadrati $A D$, cum $\frac{t}{20}$ quadrati B $\mathrm{C}$. Vnde, fi fufpenfio, ut hic, pofita fuerit in $A$, vertice pyramidis, ideoque diftantia, ad quam applicatio facienda, 
HOROLOG. OSCILLATOR. I4 A Exqualis $\frac{3}{4}$ A $D$; fiet hinc $E S$, intervallum quo centrum agita- $D_{E} \in \mathbb{E N T R Q}$ tionis inferius eft centro gravitatis, xquale $\frac{1}{20} \mathrm{AD}$, atque infu- I I o N xs.: per $x$ tertix proportionalis duabus A D, B C. five tota A $S$ xqualis $\frac{4}{5} \mathrm{AD}$, prater dictam $\frac{1}{15}$ tertix proportionalis.

\section{Centrum of cillationis Coni.}

Quod fi A в C conusfuerit, omnia eodem modo fe habebunt, nifi quod fpatium $\mathrm{z}$ hic fit æquale rectangulo $\Delta \mathbf{P} \Phi^{*}$, hoc eft $\frac{3}{20} *$ Prop.rs.huj. quadrati P V vel B D, five $\frac{3}{80}$ quadrati B C. Quare, totum fpatium appplicandum, in cono erit $\frac{3}{80}$ quadrati $A D$, una cum $\frac{3}{80}$ quadrati B C. Ac proinde, pofita fufpenfione ex vertice $A$, fiet $E S$, qua centrum agitationis inferius eft centro gravitatis, xqualis $-\frac{1}{20} \mathrm{~A} D$, $\& \frac{1}{20}$ tertiæ proportionalis duabus A D, B C. five tota A $S æ q u a l i s \frac{4}{5}$ $A \mathrm{D}$, una cum - tertix proportionalis duabus $\mathrm{A} D, D$ B. Atque hinc manifeftum eft, $f_{1}$ A $D, D$ B æquales fint, hoc eft, fi conus A B $C$ fir rectangulus, fieri $\mathrm{A}$ s $æ$ qualem axi $\mathrm{A} D$.

Sequitur quoque porro, ex propofitione 20 , conum hunc rectangulum, fi ex $\mathrm{D}$ centro bafeos lufpendatur, ifochronum fore fibi ipfr exvertice a fufpenfo, quemadmodum \& de triangulo rectangulo fupra oftenfum fuit.

\section{Centrum of cillationis Sphare.}

Si A B C fit fphæra, erit figura plana proportionalis, à latere ad. ponenda, $\mathrm{OV} \mathrm{H}$, ex parabolis compofita, quarum bafis communis $\mathrm{OH}, x q u a l i s$ fphræx diametro A D. Sectâ vero fpherâ planis per centrum E, quorum B C fit horizonti parallelum, A D vero verticale: ut inveniatur fumma quadratorum à diftantiis à plano $\mathrm{A} D$, nofcenda eft diftantia centri gr. parabolæ $\mathrm{O} v \mathrm{H}$ ab o H, quæ fit $\Phi P$, eftque $\frac{2}{5} \vee \mathrm{P}$. Deinde, divisâ $\mathrm{PV}$ bifariam in $\Delta$, conftat rectangulum $\Delta \mathrm{p} \Phi$, multiplex per numerum particularum fpheræ $\mathrm{ABC}$, zquari quadratis diftantiarum à plano $\mathrm{A} \mathrm{D}^{*}$. Eft autem rectangu- * Prop. is, in lum $\Delta \mathrm{P}_{\Phi}$ æquale quadrati $\mathrm{P} \mathrm{V}$, vel quadrati $\mathrm{B} \mathrm{E}$ :

Atqui, quadrata diftantiarum à plano $\mathrm{B} C$, xqualia effe liquet quadratis diftantiarum à plano $\mathrm{AD}$, ac proinde eidem rectangulo. $\Delta \mathrm{P} \Phi$, multiplici per dictum particularum numerum. Ergo fpatium applicandum, in fphera $\triangle \mathrm{B} C$, crit duplum rectanguli $\triangle \mathrm{P} \Phi$; ideoque $æ q u a l e \frac{2}{5}$ quadrati à radio $\mathrm{E} B$.

Itaque, fi fphera fu fpenfa fit ex puncto in fuperficie fua $A$, erir 


\section{CHRISTIANI HVGENII}

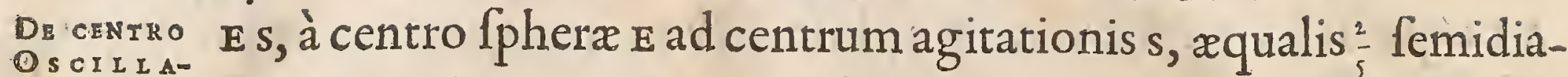
metri A E. Totaque A $S$ xqualis $\frac{7}{10}$ diametri A $D$. Si vero ex puncto alio, ut $\mathrm{L}$, fphera fufpenfa fit ; erit E $S æ q u a l i s \frac{2}{5}$ tertiæ proportionalis duabus $L E, E B$.

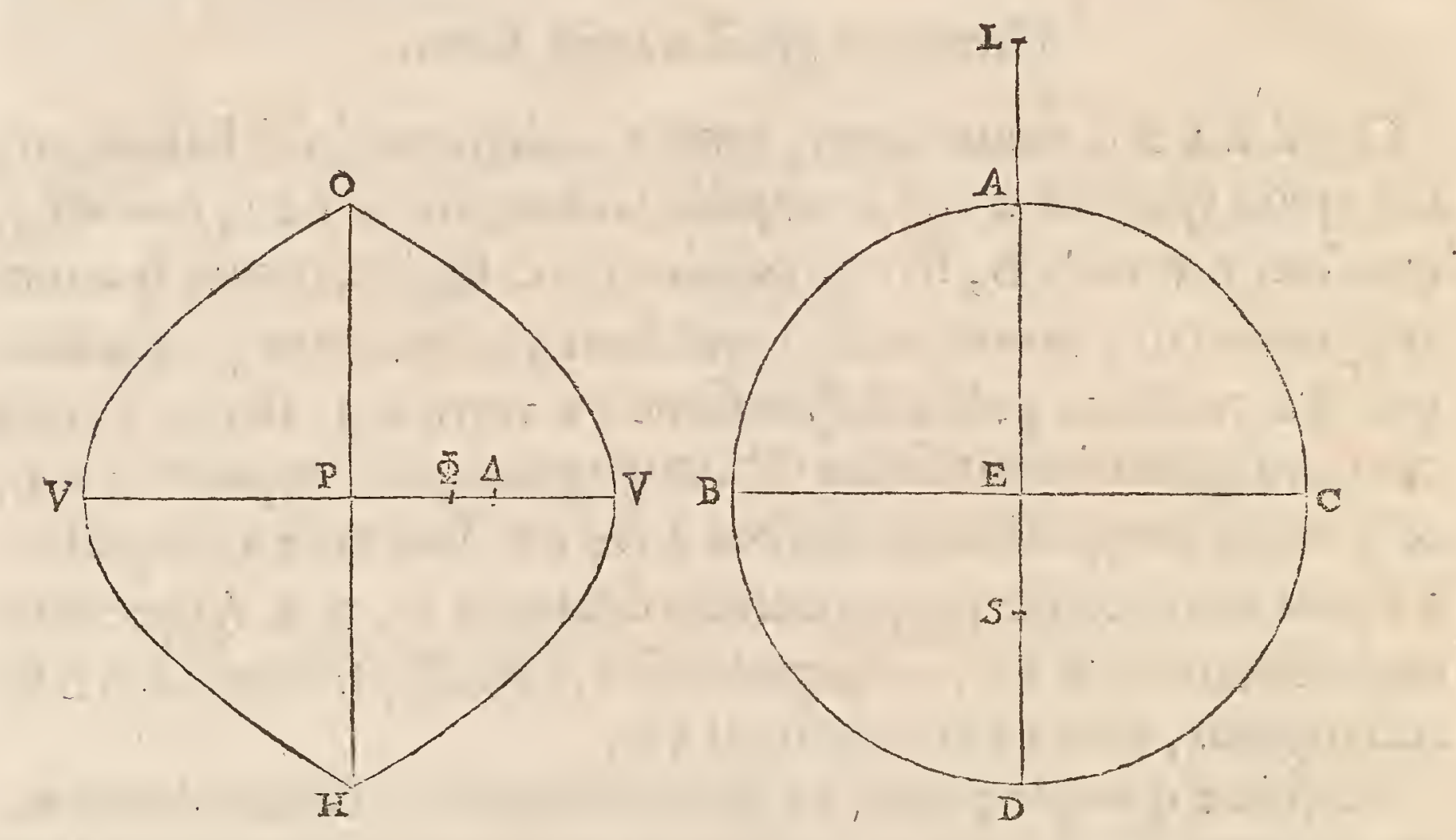

\section{Centrum of cillationis Cylindri.}

In cylindro, invenimus fpatium applicandum $æ$ quari $\frac{x}{i 2}$ quadrati altitudinis, una $\operatorname{cum}^{-}$, quadrati à femidiametro bafis. Vnde fi cylindrus à centro bafis fuperioris fufpendatur, fit longitudo penduli ifochroni xqualis ${ }_{3}^{2}$ altitudinis, una cum femiffe ejus, quæ fit ad femidiametrum bafis ut hæc ad altitudinem.

\section{Centrum of cillationis Conoidis Parabolici.}

In conoide parabolico, rectangulum of cillationis eft $\frac{1}{18}$ quadrati altitudinis, cum $\frac{1}{6}$ quadrati à femidiametro bafis. Vnde, fi à puncto verticis fuerit fufpenfum, fit longitudo penduli ifochroni $\frac{3}{4}$ axis, cum $\frac{1}{4}$ ejus qux fit ad femidiametrum bafis, ficut hæc ad axem, id eft, una cum $\frac{x}{4}$ lateris recti parabolx genitricis.

\section{Centrum of cillationis Conoidis Hyperbolici.}

In conoide quoque hyperbolico centrum of cillationis inveniri poteft. Si enim, exempli gratia, fit conoides cujus fectio per axem, hyperbola $B$ A B; axem habens $A D$, latus tranfverfum $A F$ : eritfigura plana ipfi proportionalis B $\mathrm{KA} \mathrm{K} \mathrm{B}$, contenta baf $\mathrm{B} \mathrm{B}$, 
\& parabolicx linex portionibus fimilibus $A K B$, quæ parabolæ per $D_{E}$ CENTRO

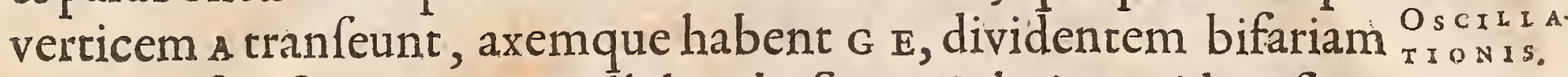
latus tranfverfum $A \mathrm{~F}$, ac parallelum bafi $\mathrm{B} B$. Et hujus quidem figu$r \mathfrak{B} K \mathrm{AK} \mathrm{B}$, centrum gravitatis $\mathrm{L}$, rantum diftat à vertice $\mathrm{A}$; quantum centrum gravitatis conoidis $A B B$; eftque axis $A D$ ad A L, ficur tripla F A cum dupla A D, ad duplam F a cum fefquialtera A D. Deinde \& diftantia centri gr. figuræ dimidix A D B K, ab $A D$, inveniri poteft, atque etiam fubcentrica cunei fuper figura B K A K B, abfciffi plano per A P, parallelam B B; hujus inquam cunei fubcentrica, fuper ipfa $\mathrm{A}$, inveniri quoque poteft; atque ex his confequenter centrum agitationis conoidis, in quavis fufpenfione; dummodo axis, circa quem movetur, fit bafi conoidis parallelus. Atque invenio quidem, $f_{1}$ axis $A$ D lateri tranfverfo $A F$ æqualis ponatur, fpatium applicandum æquari $\frac{1}{20}$ quadrati $\AA \mathrm{D}$, cum $\frac{31}{200}$ quadrati D B. Tunc autem A L eft $\frac{7}{10}$ A D.

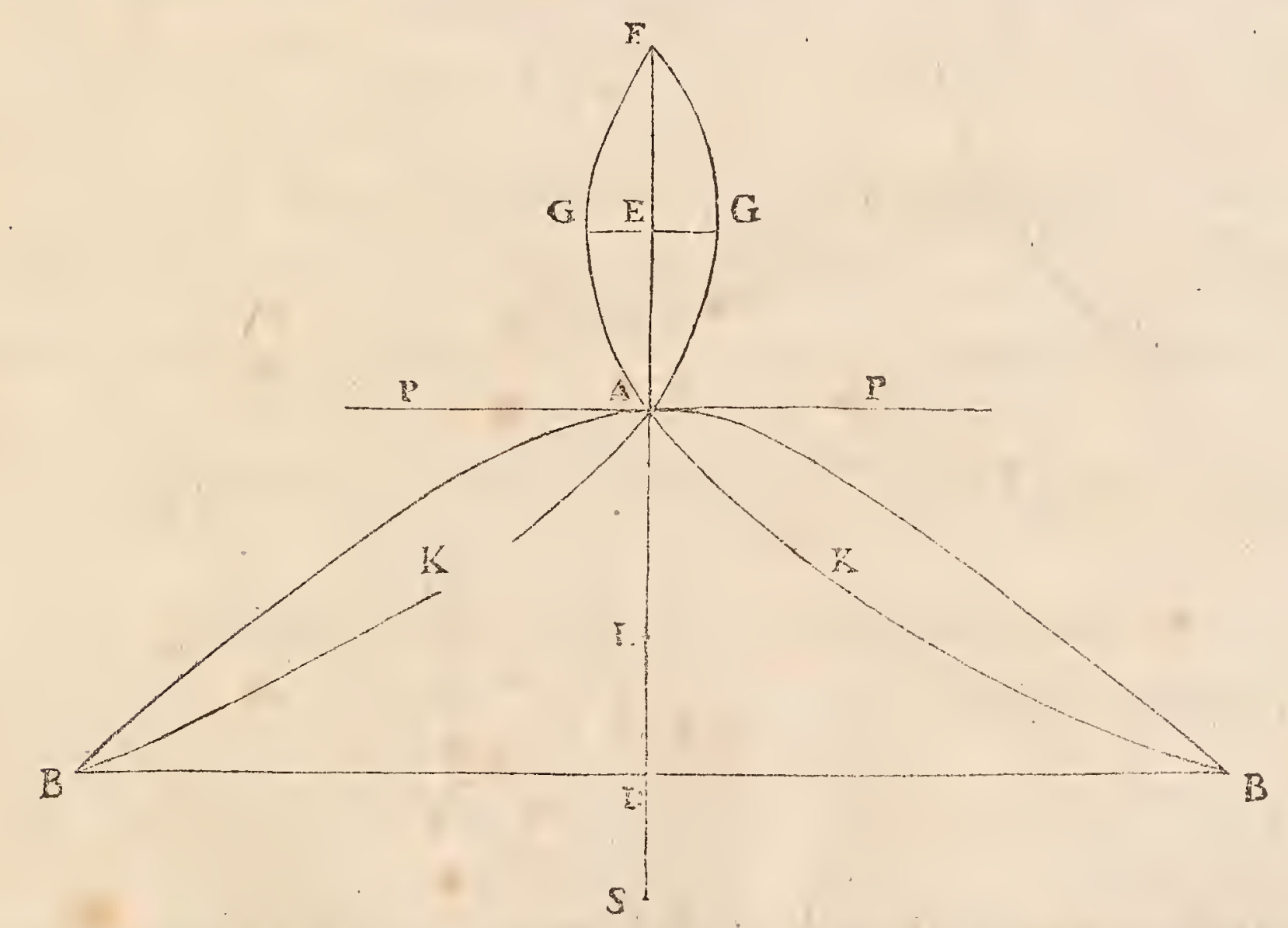

Vnde, fi conoides hujufmodi exvertice a fufpendatur, invenitur longitudo penduli ifochroni, $A S$, æqualis $\frac{27}{35} A D$, cum $\frac{31}{140}$ tertiæ proportionalis duabus A D, D B.

\section{Centrum of cillationis dimidii Coni.}

Denique \& in folidis dimidiatis quibufdam, quæ funt fectione per axem, centrum agitationis invenire licebit. Vt fi fit conus dimidiatus $A B C$, verticem habens $A$, diametrum femicirculi ba- 
feos B C : ejus quidem centrum gravitatis $D$ notum eft, quioniam $A D$ funt $\frac{3}{4}$ rectæ $A \mathrm{E}$, ita dividentis $\mathrm{B} C$ in $\mathrm{E}$, ut, ficut quadrans circumferentix circuli ad radium, ita fint $\frac{2}{3}$ C B ad B E. Tunc enim E eft centrum gravitatis femicirculi bafeos, ideoque in A $\mathrm{E}$ centra gravitatis omnium fegmentorum femiconi $\mathrm{A}$ B $\mathrm{D}$, bafi parallelorum.

Et figura quidem porro proportionalis à latere ponenda, o $v \dot{v}$, eadem eft quæ in cono toto fupra defcripta fuit : per quam nempe invenietur fumma quadratorum, à diftantiis particularum femiconi à plano horizontali $\mathrm{N}$, per centrum gravitatis ducto. Verum quadrata diftantiarum, à plano verticali $\mathrm{M} D \mathrm{O}$, ut colligantur, altera quoque figura proportionalis $\mathrm{s} \mathrm{y} \mathrm{z}$, ficur fupra prop. I 4 . adhibenda eft, cujus nempe fectiones verticales, exhibeant lineas proportionales fectionibus fibi refpondentibus in femicono $\mathrm{ABC}$.
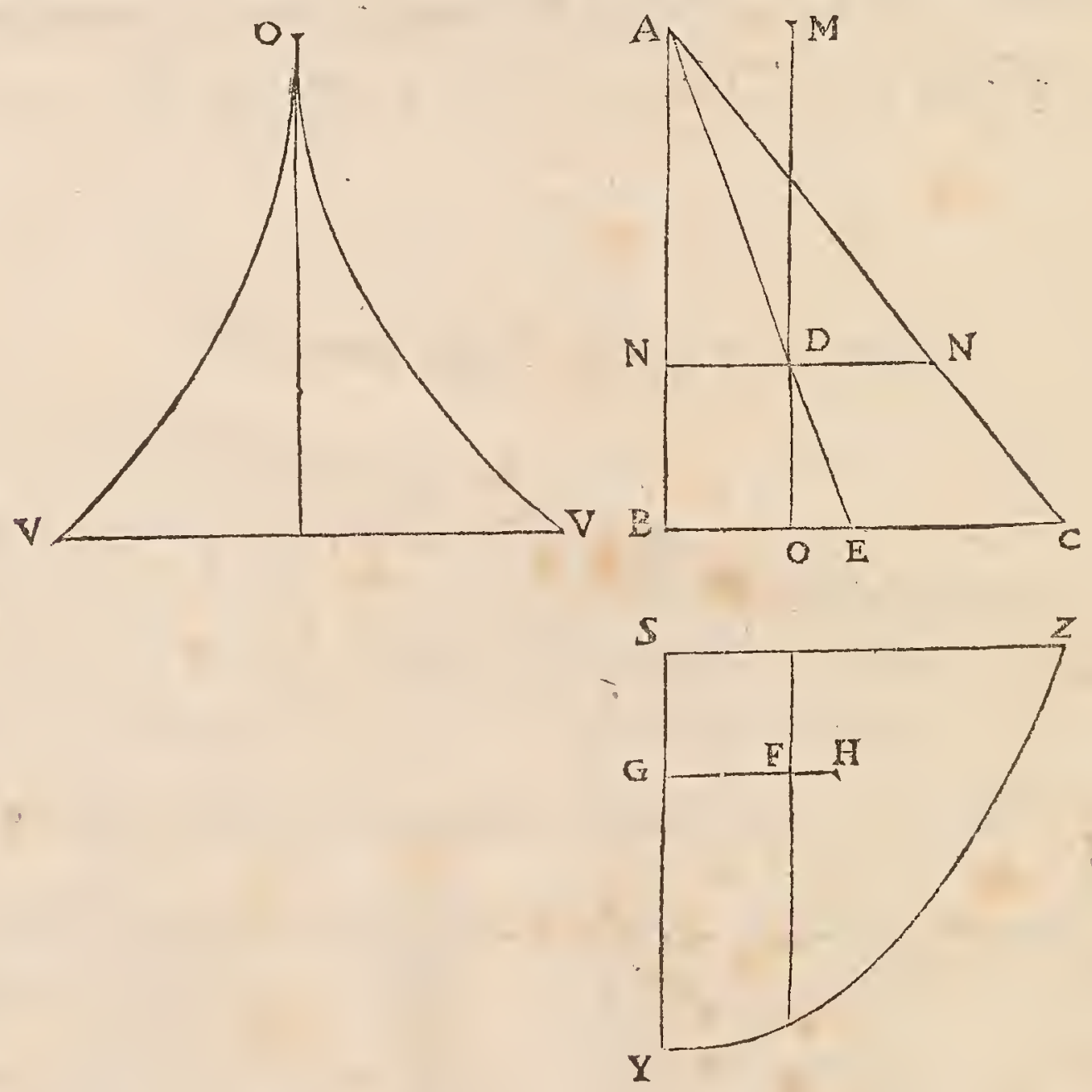

\& hujus figuræ cognofcenda eft diftantia centri gr. F ab sy, quam æqualem effe conftat diftantiæ D N, centri gr. femiconi à plano trianguli A B. pofirâque $\mathrm{H}$ G fubcentricâ cunei abfciffi fuper figura $s \mathrm{Z} Y$, ducto plano per $\mathrm{Y} Y$, nofcendum eft rectangulum $\mathrm{G} F \mathrm{~F}$, cujus nempe multiplex, fecundum numerum particularum femiconi A B C, xquabitur quadratis diftantiarum femiconi in planum M D O. Licebir vero cognofcere rectangulum illud G F $H$, etiamfi fubcentricæ $\mathrm{H}$ G longitudo ignoretur, hoc modo.

Diximus fupra, cum de cono ageremus, quadrata diftantiarum 
à plano per axem ejus, xquari $\frac{3}{80}$ quadrati à diametro bafis, five 3.- quadrati à femidiametro, multiplicis per numerum particularum coni totius. Vnde \& hic, in femicono A B C, quadrata diftantiarum à plano A B $x$ qualia erunt $\frac{3}{20}$ quadrati B $\mathrm{C}$, multiplicis per numerum particularum ipfius femiconi. Sed \& rectangulum $\mathrm{H}$ G F, mul tiplex per numerum particularum femiconi A B C, æquatur quadratis diftantiarum à plano $A B$, ut patet ex propofitione 9. Ergo rectangulum $\mathrm{H}$ G F æquale $\frac{3}{20}$-quadrati в $\mathrm{C}$. Ponendo autem A в $>$ $a$; В С $\rtimes b$; \& quadrantem circumferentix, radio в C defcriptæ, $\infty q$; fit E B $>\frac{2 b b}{3 q .}$. Cujus cum N D tribus quartis $x$ querur, fier proinde $\mathrm{ND}$, five G F $x^{\frac{1}{2} b} \frac{b}{2}$. Cujus quadratum auferendo à rectangulo H G E, quod erat $\frac{3}{20}$ quadrati B C, fiet rectangulum G F H $>0 \frac{3}{20} b 6$ $\frac{264}{499^{\circ}}$. Hoc autem rectangulum, multiplex per numerum particula. rum femiconi A B C, xquatur quadratis diftantiarum à plano $M D O$. At quadratis diftantiarum a plano $M$ X $x$ quantur, ut in cono, $\frac{3}{80}$ quadrati $\mathrm{AB}, \mathrm{five}_{\frac{3}{80}} a a$, multiplices per numerum particularum femiconi а в C. Itaque, totum fpatium applicandum, xquabitur hic $\frac{3}{80} a a+\frac{3}{20} b b-\frac{.64}{49 q^{\circ}}$.

Vnde quidem centrum agitationis invenitur in omni fufpenfrone femiconi, dummodo ab axe qui fit parallelus bafi trianguli à fectione a B. Notandum vero, cum figura s Z Y fit ignotx prorfus naturx, fubcentricam tamen $\mathrm{G} H$, cunei fuper ipfa abfcifil plano per $\mathrm{s} \mathrm{Y}$, hinc inveniri. Nam, quia rectangulum H G F æquale erat $\frac{3}{20} b b$, five quadrati B C, \& G F æqualis $\frac{1 b b}{2}$, fit inde G H xqualis $\frac{3}{10} 9$.

Porro, etiam femicylindri, \& femiconoidis parabolici, centra agitationis inveniri poffunt, arque aliorum infuper femifolidorum; qux aliis inveftiganda relinquimus.

Quemadmodum autem in figuris planis, ita \& hic in folidis figuris locum habet, quod de obliquarum centris agitationis illic diximus, qux veluti luxatione rectarum conftituuntur, quarum centra of cillationis non differunt à centris of cillationis rectarum. Sic, fi coni duofuerint A B C, A F G, alter rectus, alter fcalenus; quorum \& diametri \& bafes æquales; hi ex vertice fufpenfi, vel à quibufcunque axibus, xqualiter à centris corum gravitatis diftantibus, ifochroni erunt; dummodo axis, unde conus fealenus fufpenfus eft, rectus fit ad planum trianguli per diametrum, quod planum bafi eft ad angulos rectos. 


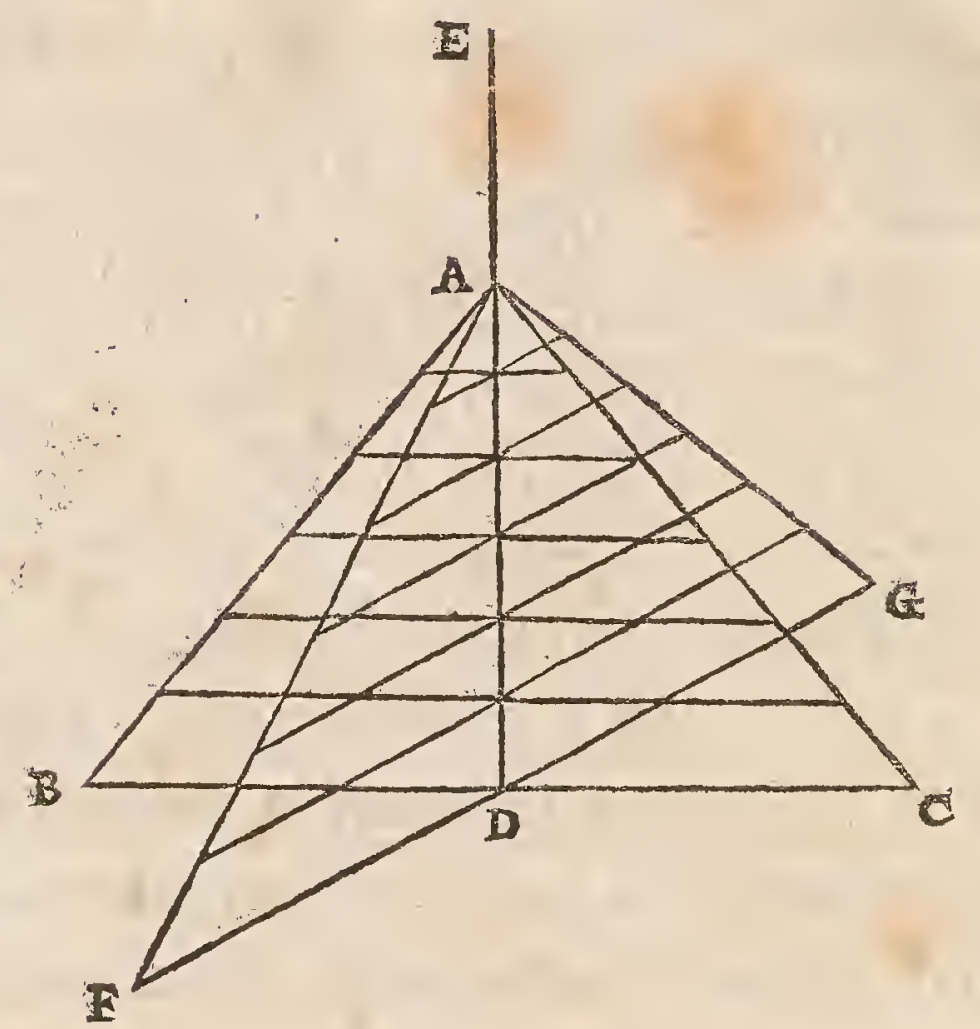

\section{PROPOSITIO XXIII.}

$\mathrm{H}$

Orologiorum motum temperare, addito pondere exiguo Secundario, quod Juper virga penduli, certa ratione divifa. furfum deorfumque moveri poffit.

$V t$ hoc expediamus, primo penduli ipfius, ex virga gravitate prædita, \& appenfo parte ima pondere, compofiti, centrum ofcillationis inveniendum eft.

Sit virga, cum appenfo pondere, $\check{\AA} \mathrm{C}$, cujus longitudo dicatur $a$.

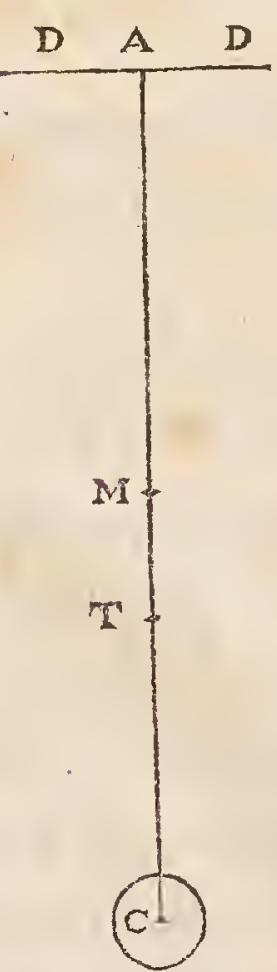

Intelligantur autem, tum virga ipfa, tum pondus appenfum $c$, in particulas minimas xquales divifa, earumque particularum virga habeat nume$\operatorname{rum} b$, pondus vero $c$ numerum $c$, ponendo nempe $b$ ad $c$, ficut gravitas virgx ad gravitatem appenfi ponderis. Longitudo igitur penduli fimplicis, dato ifochroni, habebitur, fi fumma quadratorum à diftantiis particularum omnium a puncto fufpenfionis $A$, dividatur per fummam earundem diftantiarum *. Secetur A $\mathrm{C}$ bifariam in $\mathrm{M}$; tum. vero in $T$, ut A $T$ fit dupla $T$ C. Quia ergo $M$ eft centrum gravitatis lineæ $\mathrm{A} C, \&$ A $\mathrm{T}$ fubcentrica cunei fuper ipfa abfcifli plano per $\mathbb{A} D$, perpendicularem ad $\AA \mathrm{C}$; qui cuneus hîc revera triangulum eft; erit fumma quadratorum, à diftantiis particularum virg $æ$ à puncto $\AA$, 
xqualis rectangulo $\mathrm{A} M \mathrm{~T}$, una cum quadrato $\mathrm{A} M$; hoc eft, rectan- DE CENIR

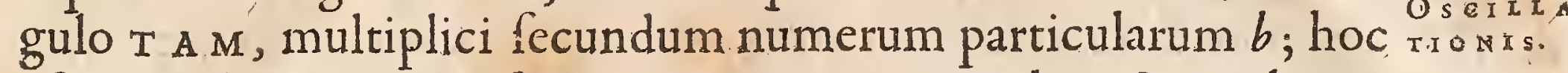
eft, $\frac{1}{3} a a b$; quia $\mathrm{M}$ A eft $\frac{1}{2} a, \& \& \mathrm{~T} A \frac{2}{3} a$, ac proinde rectangulum $\mathrm{T}$ $A M x \frac{1}{3}$ a $a$. Summa vero quadratorum, à diftantiis particularum ponderis $\mathrm{C}$ ab codem puncto $\mathrm{A}$, xquabitur quadrato $\mathrm{A} \mathrm{C}$, mulciplici fecundum numerum particularum ipfus ponderis; hoc eft, a a c. Adeoque fumma quadratorum omnium, tam à diftantiis particularum virgx, quam ponderis $c$, eric $\frac{1}{3} a b+a a c$.

Porro, diftantiæ omnes particularum virgx A $\mathrm{C}$ à puncto $A$, xquantur $\frac{1}{2} b a$; longitudini fcilicet virgx ipfius, quæ eft $a$, multiplici fecundum femiffem numeri particularum quas continet. Et diftantix omnes particularum ponderis $c$, ab eodem puncto $A$, funt a c. Ita ut fumma utrarumque diftantiarum fit $\frac{1}{2} a b+a c$ Per quam dividendo fummam quadratorum prius inventam, $-_{2} a a_{b}$ $+a a c$, fit $\frac{\frac{1}{3} a b+a c c}{\frac{3}{2} a b+a c}$ five $\frac{\frac{1}{3} a b+a c}{\frac{1}{2} b+c}$, longitudo penduli ifochroni. Quæ itaque habebitur, fi fiat, ut dimidia gravitas virgæ, una cum gravicate appenfi ponderis, ad trientem gravitatis virgx, una cum gravitate ejuldem appenfi ponderis, ita longitudo a $\mathrm{C}$ ad aliam. Oportet autem fumere longirudinem a c, à puncto fufpenfronis $A$ ad centrum gravitatis ponderis $C$; cum magnitudinis ejus ratio hic non habeatur, ac veluti minimum confideretur.

Quod fijam, præter pondus c, alterum infuper D virgæ inhæ$\therefore \quad$ rere intelligatur, cujus gravitas, feu particularum numehuic ita compofito ifochronum inveniacur, addenda funt ad fummam fuperiorem quadratorum, quadrata diftantiarum particularum ponderis $\mathrm{D}$ à puncto A, quæ quadrata apparet effe $d f f$. Adeo ut fumma omnium jam fic furura $\frac{1}{3} a a b+a a c+f f d$. Item, ad fummam diftanciarum, addendx diftantix particularum ponderis $D$, qux faciunt $d f$. Ac fumma proinde diltantiarum omnium erit ${ }_{2} b a+c a+d f$; per quam dividenda eft ifta quadrato-

(c) rum fumma, \& fit $\frac{\frac{1}{3} a a b+a a c+f f d}{\frac{3}{2} a b+a c+f d}$, longitudo penduli ifochroni.

Quod fi vero, hæc longitudo penduli ifochroni, daræ æqualis poltuletur, quæ fit $p$, \& reliqua omnia quæ prius data fint, præter 
DE CENTro diftantiam $A$ feu $f$, qux determinat locum ponderis $D$ : fitque OscrlaA- invenienda hæc diftantia, id fiet hoc modo. Nempe, cum poltu-
rons. letur $\frac{\frac{1}{3} a a b+a a c+f f d}{\frac{\pi}{2} a b+a c+f d}$ equale $p$, orietur ex hac æquatione ff so $p f-\frac{f}{6}$ $\frac{\frac{x}{2} a b p+c a p-\frac{1}{3} a a b-a a c}{d} \cdot$ Et $f>\frac{x}{2} p+v e l-V \frac{\frac{1}{4} p \frac{x+\frac{x}{2} a b p+c a p \cdot \frac{x}{3} a a b-a a c}{d}}{d}$ Vbi animadvertendum, duas effe veras radices, $f_{1} \frac{1}{2} a b p+c a p$ minus fit quam $\frac{x}{3} a b b+a a c$; hoc eft, $f_{1}$ longitudo $p$ minor fit quam $\frac{1}{3} a b+a c$

$\frac{3 b+a c}{\frac{1}{2} b \rightarrow c}$, quæ antea inventa fuit longitudo penduli ifochroni, five diftantia centri ofcillationis à fufpenfione, in pendulo compofito ex virga A C \& pondere C.

$V$ nde patet, fi velimus efficere, ut, applicato pondere $\mathrm{D}$, acce. leretur penduli motus; poffe duobus locis, inter a \& c, illud dif poni, quorum utroliber eadem celeritas pendulo concilietur: velut in $\mathrm{D}$ vel $\mathrm{E}$. Quæ loca æqualiter diftabunt à puncto $\mathrm{N}$, quod abeft $\mathrm{ab}$ A, femiffe longitudinis $p$, hoc eft, femiffe penduli fimplicis, cui compofitum hoc ifochronum poftulabatur. Apparet autem, quando hæc longitudo $p$ tantum exiguo minor ponitur quam $A \mathrm{C}$, etiam punctum $\mathrm{N}$ exiguo fuperius effe puncto medio virgæ A C.

Porro, ex æquatione fuperiori, $f x p+v e l-\sqrt{\frac{1}{4} p p^{+\frac{1}{2} a b p+a c p} \frac{1}{d}}$ habetur determinatio longitudinis $p$. Pater enim, $\frac{1}{4} p p+\frac{d}{\frac{d}{2} b p+a c p}$

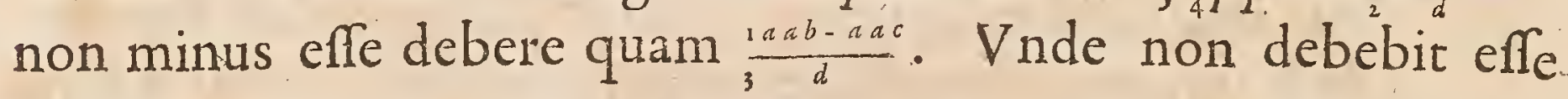
minor quam $\frac{a}{d} \sqrt{\frac{4}{3} b d+4 c d+b} \overline{b+4 b c+4 c c}-\frac{a b \cdot 2 a c}{d}$. Quod fi: $p$ xquetur huic quantitati, hoc eft, $\mathrm{f}_{\frac{1}{4}} p p+\frac{1 a b p+a c p}{2}$ fuerit $x-$ quale $\frac{\frac{1}{3} a b-a a c}{d}$, erit jam, in eadem fuperiori æquatione, $f$ > $\frac{1}{2} p$, hoc eft, $\frac{a}{2} \sqrt{\frac{4}{3} b d+4 c d+b b+4 b c+4 c c-\frac{a}{2 d}^{a b-2 a c}}$. Quo determinatur diftantia ponderis $\mathrm{D}$ à puncto $A$, ex qua maxime omnium acceleret motum penduli.

Atque hac ad horologiorum ufum fic porro adhibentur. Sit, exempli gratia, pendulum horologii, quod fingulis of cillationibus fcrupula fecunda notet. Virgx autem gravitas fit $\frac{1}{50}$ gravitaris appenfi ponderis in imo pendulo: $\&$, præter hoc, fit aliud exiguum pondus mobile fecundum virgælongitudinem, cujus gravitas ea- 
HOROLOG. OS C I L LA T OR.

dem ponatur quæ ipfius virgx. Quxritur jam, quo loco hoc virgæ $D_{\text {E CENTRO }}$ imponendum, ut uno fcrupulo primo acceleretur horologii mo- I I O I s. tus, fpatio 24 horarum. Item, ubi collocandum, ut duorum fcrupulorum primorum fit acceleratio; item, ut trium, quatuor, atque ita porro.

Duotis viginti quatuor horis fexagies, fiunt 1440, quot nempe fcrupula prima una die continentur. Ex his unum aufer, quando unius fcrupuli acceleratio quaritur : fuperfunt I439. Ratio autem 1440 ad 1439 duplicata, proxime eft ea qux 1440 ad 1438 . Ergo, $f_{1}$ penduli fimplicis, fecunda fcrupula notantis, longitudo divifa intelligatur in partes $æ$ quales 1440 , earumque 1438 alii pendulo tribuantur, hoc præceder alterum illud, in 24 horis, uno forupulo primo. A deo ur hic $p$ valeat partes 1438 .

Quia autem pendulum horologii, ex virga metallica \& pondere appenfo compofitum, ifochronum ponitur pendulo fimplici partium 1440 ; invenienda primum eft virgx illius longitu. do, ex æquatione fuperius pofita. Erat nempe $\frac{\frac{1}{3} a b+a c}{\frac{1}{2} b+c} x q u a l e$ longitudini penduli fimplicis, quod ifochronum compofito ex virga ha. bente longitudinem $a$, gravitatem $b, \&$ pondere affixo cujus gravitasc. Ergo fi longitudo penduli fimplicis ifochroni dicatur $\int$. Erit $\frac{\frac{1}{2} b f+c f}{\frac{\pi}{3} b+c} \infty$ a. pofitoque, uthic, $c \infty$ so; $b$ so 1 ; $\int \infty$ 1440; fiet $a x$ $\$ 444 \frac{4}{5}$, longitudo virgx.

Iam, quia erat $f x^{\frac{1}{2}} p+$ vel $-V \frac{\frac{1}{4} p p+\frac{\frac{1}{2} a b p+a c p-\frac{1}{3} a a b-a a c}{4}}{4}$, fiet $f x$ $\frac{1}{2} p+\mathrm{vel}-\sqrt{\frac{1}{4} p p+72962 p-105061210} \cdot$ Vnde porro, fi $p$ fit, uti diximus, partium 1438; invenietur $f \times 1331 \frac{1}{2}$, qualium nempe $\int$, feu pendulum fimplex, fecunda fcrupula of cillationibus defignans, continet 1440 . Cujus longitudo fi pedum trium ftatuatur, quos horarios vocavimus, habebit $f$ uncias $33, \& 3$ unciarum uncias, quas lineas vocant. Vel, auferendo hanc longitudinem $f^{\prime} \mathbf{a}$ tota trium pedum longitudine, fupererunt uncix dux, linex 9 , à centro ofcillationis penduli compofiti furfum fumendx, ut habeatur locus ponderis $D$, unius fcrupuli primi accelerationem præftans tempore 24 horarum. Eoden modo reliquas diftantias, quibus virga dividenda eft, calculo inveftigavimus, aliam atque aliam ponendo longitudinem $p$ : cafque fubjecta tabella exhibe. 
190 CHRISTIANI. HV.GENII

De CENTRO mus, fecundum cujus numeros etiam virga penduli divifa eft, qux

fuperius in defcriptione horologii fuit exhibita. Procedunt autem accelerationes diurnæ, ut jam illic advertimus, per is fcrupula fecunda, feu primorum fcrupulorum quadrantes. Ex. gr. fi, pondere mobili $\mathrm{D}$ hærente in parte 73,4 , inveniatur horologium tardius jufto incedere, in 24 horis, differentiâ 15 fecundorum fcrupulorum; oportebit furfum adducere pondus $D$, ufque ad numerum $8,6,6$, ut corrigatur.

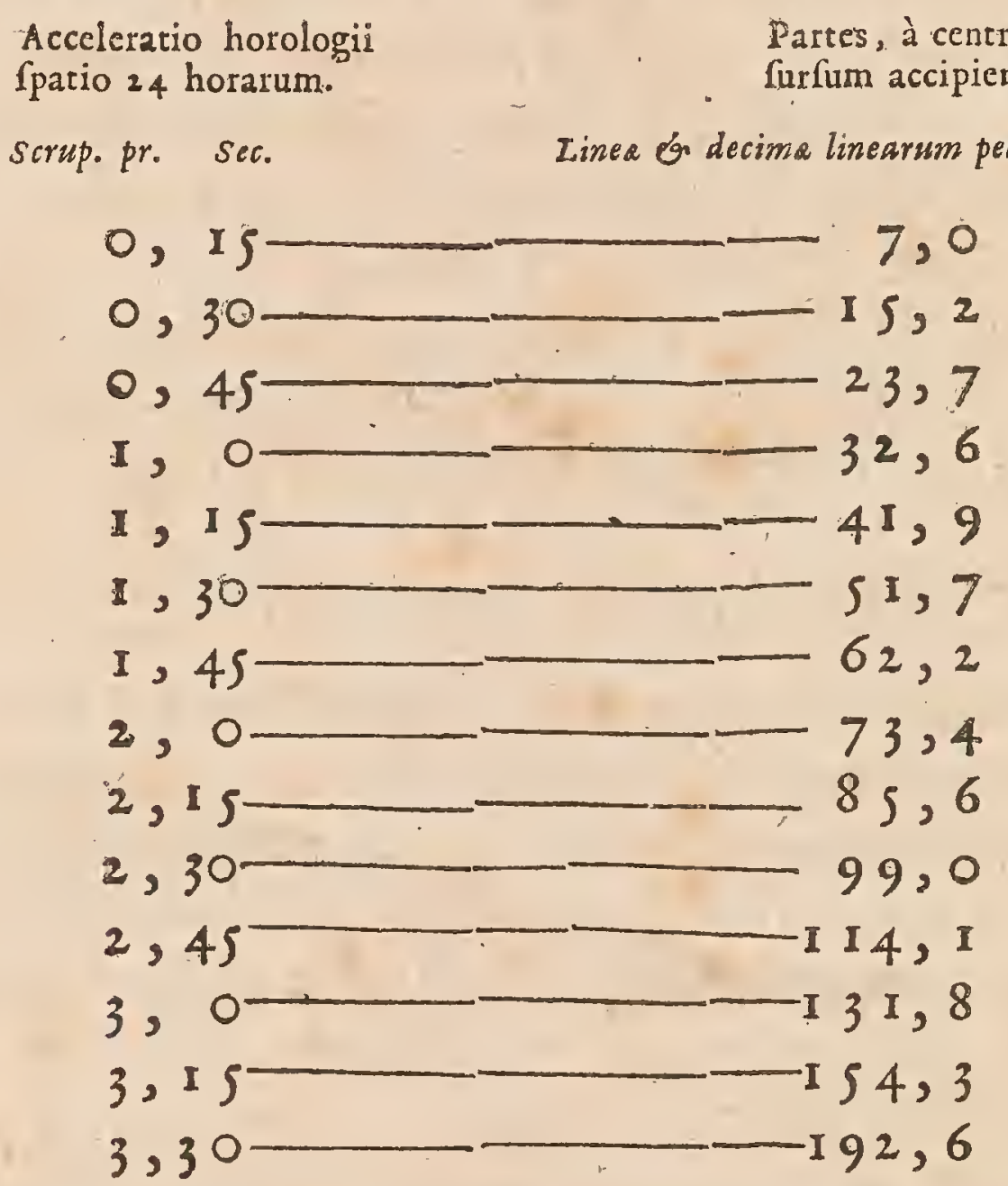

Centrum of cillationis altius eft centro gravitatis C partibus 1,4 .

\section{PROPOSITIO XXIV.}

Entri of cillationis rationem haberi non polfe, in pendulis inter Cycloides fupenfis; E' quomodo binc orta difficultas tollatur.

Si quis, fubtili examine, contuleric ea qux in fuperioribus, de pendulo inter cycloides fufpenfo, demonftravimus, cum his qux ad centrum of cillationis pertinent; videbitur ei deetfe aliquid ad perfectam illam, quam præferimus, of cillationum xqualitatem: Ac primo dubitabit, an, ad inveniendum circulum cycloidis genicorem, penduli longirudo accipienda fit à puncto fufpenfionis ad 
centrum gravitatis appenfi plumbi, an vero ad centrum of cilla- $D$ в CвNтRo tionis; quod, ab altero illo, fxpe fenfibili intervallo diftat, at- oscrizaque eo majore, quo major fuerit Pphra aut lens plumbea. Quid. enim, fi fphæræ diameter quartam, aut tertiam partem, penduli longitudinis $x q u e t$ ? Quod fi ad centrum of cillationis illam longitudinem accipiendam dicamus, non ramen expediet quo pacto ea, qux de centro of cillationis oftenfa funt, conveniant pendulo continue longitudinem fuam immutanti, quale illud quod inter cycloides movetur. Poffet enim videri, etiam centrum of cillationis mutari, ad fingulas diverfas longitudines; quod tamen hoc modo intelligendum non eft. Res fane explicatu difficillima, fi omnimodam áxpibfaw fectemur. Nam in demonftratione temporum æqualium in cycloide, mobile, per eam delatum, veluti punctum gravitate prxditum confideravimus. Sed, fi ad effectum fpectemus, non magni facienda eft difficultas hæc; cum ponderis, quo pendulum conftat, magnitudo in horologiis tanta non requiratur ( $\mathrm{etfi}$ quo majus eo melius) ut differentia centrorum gravitatis, \& ofcillationis, aliquid hic turbare polfit. Quod fi tamen effugere prorfus has tricas velimus, id ita confequemur, fi fphæram lentemve penduli, circa axem fuum horizontalem, mobilem efficiamus: axis extrema utrinque, virgæ penduli imæ, inferendo: quæidcirco ut bifida hac parte fic neceffe eft. Fit enim hoc modo, ex motus natura, ut eandem perpetuo pofitionem, refpectu horizontalis plani, fphæra penduli ferver, atque ita puncta ejus quævis, æque ac centrum ipfum, cycloides eafdem percurrant. Vnde ceffat hic jam centrorum of cillationis confideratio; nec minus perfectam temporum æqualitatem tale pendulum confequitur, quam fi puncto unico omnis ejus gravitas contineretur.

\section{P R O P OSITIO XXV.}

\section{(1) Emenfure univerfalis, Es perpetus, conftituenda ra- tione.}

Certa, ac permanens magnitudinum menfura, qux nullis cafbus obnoxia fit, nec temporum injuriis, aut longinquitate aboleri aut corrumpi poffit, res eft \& utiliffima, \& à multis pridem quxfita. Quæ fi prifcis temporibus reperta fuifet, non tam perplexæ nunc forent, de pedis Romani, Græci, Hebræique veteris modulo, difceptationes. Hæc vero menfura, Horologii noftri opera, facile conftituitur; cum fine illo nequaquam, aut ægre admodum, ha- 
52 CHRISTIANI HVGENII

DE CENTRO OSCIIIATIONIS.

beri poffit. Etfi enim, fimplici pendulorum of cillatione, hoc à quibufdam tentatum fuerit, numerando recurfus qui tota cæli con.verfione continentur, vel parte ejus cognita, per fixarum ftella. rum diftantias, fecundumafcenflonem rectam; nec certitudo eadem tioc modo, qua adhibiris horologiis, contingit, \& labor longe eft moleftiffimus ac txdiofiffimus, propter numerandi folicitudinem. Quia autem, præter horologia, aliquid, ad exactiflimam hiu. jus menfuræ in quifitionem, eriam centrorum of cillationis notitia confert ; ideo hic demum, poft eorum tractarionem, hanc determinationem fubjicimus.

Aptiffma huic rei funt horologia, quorum of cillationes fingulx fecunda fcrupula, vel eorum femiffes, notant, quxque indicibus etiam, ad ea demonftranda, inftructa funt: Poftquam enim, ad mediocrem dierum longitudinem, ejufmodi horologium, fixarum ftellarum obfervationibus, compofitum fuerit, methodo illa quam in horologii defcriptione oftendimus : aliud pendulum fimplex, hoc eft, fphæra plumbea, aut alia materia gravi conftans, ex tenui filo religata, juxtafufpendenda eft, moruque exiguo im: pellenda; ac tantifper producenda, aut contrahenda fili longitu-

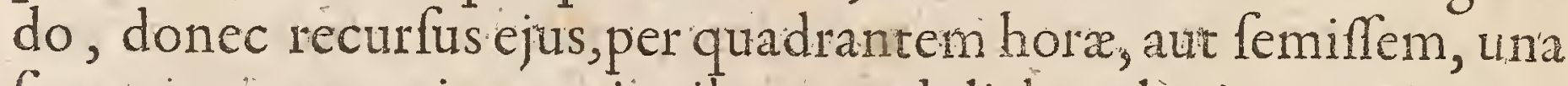
ferantur cum reciprocationibus penduli horologio aptati. Dixi autem exiguo motu impellendum pendulum, quia of cillationes exigux, pura s vel r partium, faris æqualia tempora habent, magnæ vero non item. Tunc, acceptâ menfurâ diftantia, à puncto fufpenfionis ad centrum of cillationis penduli fimplicis; eâque, $f$ recurfus finguli fcrupula fecunda valeant, in tres partes divisâ; fa. cient hæfingulæ longitudinem pedis, quem HoRARIum in fuperioribus vocavimus: quique, hoc pacto, non folum ubique gentium conftitui poflit, fed \& venturo xvo redintegrari. A deo ut \& moduli pedum omnium aliorum, femel ad hunc proportionibus fuis expreffi, certò quoque in pofterum cognofci poffint. Sicut jam fupra, pedem Parifienfem ad hunc horarium effe diximus, ut 864 ad 88r; quod idem eft ac fi, pofito prius pede Parifienfi, dicamus tribus hujufmodi pedibus, cum octo lineis \& dimidia, conItitui pendulum fimplex, cujus ofcillationes fcrupulis fecundis horariis refponfurx fint. Pes autem parifienfis ad Rhenanum; quo in patria noftra utuntur, fe haber ut ${ }_{144}$ ad $_{139}$; hoc eft, quinque lineis fuis diminutus, alterum illum relinquit. Atque ita \& hic pes, \& alii quilibet, perpetuo duraturas menfuras accipiunt.

Quomodo autem centrum of cillationis in f phæra, ex qualibet longitudine 
longitudine fufpenfa, inveniatur, infuperioribus demonftratum

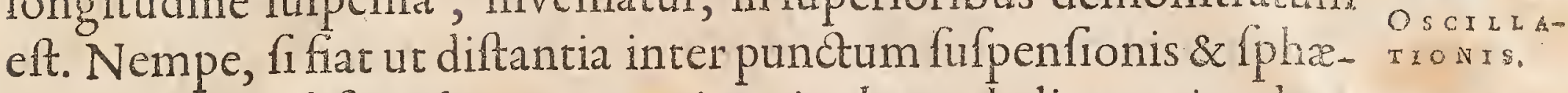
ræcentrum, ad femidiametrum ejus, ita hæc ad aliam; ejus duas quintas, à centro deorfum acceptas, terminari in quxitito ofcillationis centro. Facile autem apparet cur neceffaria fit hujus centri confideratio, ad accuratam pedis Horarii conftitutionem. Nam, fi à puncto fufpenfionis ad f phæræ centrum diftantia accipiatur, fphæræ autem magnitudo non definiatur proportione ad fili longitudinem, non erit certa menfura penduli cujus recurfus fecunda fcrupula metiantur; fed quo major erit ejus fphæra, hoc minor invenietur menfura illa, inter centrum fphæræ \&x punctum fufpenfronis intercepta. Quia in ifochronis pendulis, centra quidem ofcillationis à punctis fufpenfionum xqualiter diftant; amplius autem defcendit centrum of cillationis infra centrum fphæræ majoris, quam minoris.

Hinc neceffe fuit illis, qui, ante hanc centri of cillatorii determinationem, menfuræ univerfalis conftituendæ rationem inierunt; quod, jam inde à prima Horologii noftri inventione, nobilis illa Societas Regia Anglicana fibinegotium fumpfit, \& recentius doctiflimus Aftronomus Lugdunenfis, Gabriel Moutonus; his, inquam, neceffe fuit defignare globuli fufpenfi diametrum, vel proportione certa ad fili longitudinem, cujus nempe tricefimam vel aliam partem æquaret; vel menfura quadam cognita, ut digiti vel pollicis. Sed hoc pofteriore modo, ponitur jam certi aliquid, quod id ipfum eft quod quærendum eft: etfi fcio vix fenfibilem errorem fore, dummodo fphæræ iftam, quam jam dixi, magnitudinem non multum excedant. Priore autem poffet quidem aliquo pacto res explicari; fed ita, ut numerandarum of cillarionum labor fubeundus fit, calculoque etiam utendum. Quamobrem præitat, centra ofcillationis adhibendo, certam rationem fequi, nullifque præter neceffitatem legibus obligari. atque hic jam majoribus (phæris quam exiguis potius utendum, quod illæ occurfu aëris minus impediantur.

Cæterum, non fphæræ tantum ex filo fufpenfx, fed \& coni, cylindri, aliaque omnia folida, planaque, quorum centra ofcillationis fuperius exhibuimus, ad hanc menfuram inveftigandam apta funt; quoniam, à punč̃o fufpenfionis ad centrum of cillationis, certum idemque omnibus ifochronis pendulis eft intervallum. Neque etiam illa duntaxat horologia, quæ fecunda frupula aut eorum femiffes fingulis penduli recurfibus indicant, ad hæc ufur- 
Dr centro pare poffumus; fed \& aliâ quâcunque penduli longitudine inftructis propofitum obtinebitur, dummodo ex rotarum proportionibus, feu dentium numero, cognofcacur numerus of cillationum certo tempore peragendarum. Invento enim pendulo fimplici, cujus librationes fingulæ conveniant vel fingulis, vel binis ternifve recurfibus horologii, conftabit jam hinc, quot penduli illius vices horæ fpatio tranfigantur. Quarum numerus fi quadretur, erit ut quadracum è 3600 , numero fcrupulorum fecundorum horam unam efficientium, ad quadratum illius numeri, ita longitudo penduli fimplicis inventi, (quxlongitudo femper à puncto fufpenfionis ad centrum ofcillationis accipienda eft) ad longitudinem penduli il lius horarii tripedalis, quod diximus. Hoc enim inde conftat, quod duorum quorumvis pendulorum longitudines funt inter fe, ficut quadrata temporum quibus fingulæ of cillationes tranfeunt; ideoque contrariam rationem habent quadratorum à numeris, quos efficiunt of cillationes xqualibus temporum intervallis peractx. Nam, cum hactenus experientiâ tantum comprobatum fuerit Theorema illud, de pendulorum longitudinibus; eas nempe duplicatam habere rationem temporum, quibus ofcillationes fingulæ peraguntur; nunc ejus demonftratio ex fuperius traditis manifefta eft. Cum enim oftenderimus, fingulos recurfus penduli, inter cycloides fufpenfi, ad cafum perpendicularem, è dimidia penduli longitudine, certam rationem habere; eam fcilicet quam circumferentia circuliad diametrum fuam; facile hinc colligitur, tempora of cillationum in duobus pendulis effe inter $\mathrm{fe}$, ficut tempora defcenfus perpendicularis ex dimidiis eorum altitudinibus. Qux altitudines * Prop. 3. dimidix, five etiam totæ, cum habeant rationem duplicatam temporum, quibusipfæ defcenfu perpendiculari percurruntur*; exdem quoque duplicatam rationem habebunt temporum, qux of cillationes fingulas metiuntur. Ab of cillationibus autem minimis penduli,inter cycloides fufpenfi, non differunt fenfibiliter of cillationes minim $x$ penduli fimplicis, cujus eadem fit longitudo. Itaque $z$ pendulorum fimplicium longitudines, duplicatam rationem habebunt temporum, quibus of cillationes minimæ tranfiguntur.

Quod fiquis of cillationum numerandarum, quæ horæ aut femihoræ tempore tranfeunt, laborem non defugiat; horologiumque adfit, cujus index fecunda fcrupula demonftret; quacunque accipiatur penduli fimplicis longitudo, ejus numerus ofcillationum, quæ hora una continentur, hoc modo cognofcetur; atque indelongitudo penduli tripedalis, ad fecunda fcrupula, ut ancea, calculo prodibit. 


\section{P R O POS I T I O X X V.}

\section{( Patium definire, quod gravia, perpendiculariter caden. $\checkmark$ tia, dato tempore percurrunt.}

Hanc menfuram quicunque hactenus inveftigarunt, experimenta confulere neceffe habuerunt; quibus, prout hactenus inftituta fucre, non facile ad exactam decerminationem pervenitur, propter velocitatem cadentium, fub finem motus acquifitam. Ex noftra autem prop. 25 , de Defcenfu gravium, connitaque longitudine penduli ad fecunda fcrupula, abfque experimento, per certam confequentiam, rem expedire poffumus. Ac primo quidem fpatium illud inquiremus, quod unius fcrupuli fecundi tempore grave præterlabitur; ex quo quælibet alia deinde colligere licebit. Quia igitur penduli, ad fecunda fcrupula, longitudinem diximus effe pedum Horariorum 3 : tempus autem unius of cillatio. nis minima, eft ad tempus defcenfus perpendicularis ex dimidia penduli alticudine, ur circumferentia circuli ad diametrum; hoc eft, ut 355 ad 113 : fi fiat, ur numerus horum prior ad alterum, ita tempus unius fecundi fcrupuli, five fexaginta tertiorum, ad aliud; fient $19^{\prime \prime \prime} \frac{1}{10}$, tempus defcenfus per dimidiam pendulialtitudinem, qux nempe eft pedis unciarum 18 . Sicut autem quadrata temporum, ita funt fparia illis temporibus peracta, quemadmodum fuperiori propofitione fuit oftenfum. Ergo, fi fiat ut quadratum ex $19^{\prime \prime \prime} \frac{1}{10}$ ad quadratum ex $60^{\prime \prime \prime}$, hoc eft, ut $3648 \mathrm{rad}$ 360000 , ita 18 uncix ad aliud, fient ped. 1 4. unc. 9. lin. 6, altitudo defcenfus perpendicularis, tempore unius fecundi. Cum autem pes Horarius fit ad Parifienfem, ur 881 ad 864; erit eadem altitudo, ad hanc menfuram reducta, proximè pedum is $\&$ uncix unius. Atque hæc cum accuratiffimis experimentis noftris prorfus conveniunt. in quibus punctum illud temporis, quo cafus finitur, non aurium aut oculi judicio difcernitur; quorum neutrum hic fatis tutum eft; fed fparium defcendendo peractum, alio modo, quem hic exponere tentabimus, abfque ullo errore cognofcitur.

Penduli, ad parietem tabulamve erectam, fufpenfi dimidia ofcillatio moram temporis, cadendo abfumpti, indicat. Cujus fphærula, ut eodem momento ac plumbum cafui deftinatum dimittatur, utraque filo tenui connexa tenentur, quod admoto igne inciditur. Sed prius, cafuro plumbo, funiculus alius adnectitur, ejus longitudinis, ut, cum totus exierit à plumbo tractus, nondum ad pa- 
Da centro rietem illidatur pendulum. Funiculi ejus caput alterum, regulæ tem tabulamve applicaræ, ut trahentem funem facile fequi poffit, rectáque fecundum longitudinem fuam defcendere; eo loci tranfiens, quo pendulifphæra ad tabulam accidet. Abfumpro igitur funiculo toto, pars inluper regulæ deorfum trahitur à cadente plumbo, priufquam pendulumad tabulam pertingat. Quæ quanta fit pars, fphæra fuligine leviter infecta, regulamque præterlabentem fignans, indicat. Huc autem addita funiculi longitudine, fpatium cadendo emenfum certò definitum habetur.

Aëris autem occurfum, quafi nullus effet in his intelligimus, ut menfura cadentibus corporibus præfixa cum experimentis exa. cte confentiat. Nec fane tantus eft ille, ut in altitudinibus his, quò afcendere datur, fenfibile difcrimen inducere poffit; dummodo folidacorpora è metallo, aut, fi leviore materia conftent, mole grandiufcula accipiantur. Levitas enim materiæ, in iis quæ cadendo aërem fecant, ita magnitudine corporis penfatur, ut fphæra lignea, vel etiam è fubere formata, paria faciat cum plumbea: quando nimirum diameter harum ad plumbex diametrum eam rationem habuerit, quam gravitas plumbi propria ad ligni fuberifve gravitatem. Tunc enim gravitates fphærarum erunt inter fe ficut earum fuperficies. Veruntamen, ut æquali celeritate, quantum fenfu percipi poteft, decidant corpora , qux multum intrinfeca gravitate differunt, nequaquam opus eft ut proportio illa diametrorum fervetur. Poffunt enim inter fe xqualia effe, dummodo utraque fatis magna fint ; aut ex non nimia altitudine decidant. Etenim illud quoque hic animadvertendum eft, tantam vel altitudinem effe poffe; vel, in mediocri etiam altitudine, tantam projecti corporis levitatem; ut ob aëris renitentiam, acceleratio motus tandem ab illa, quam in fuperioribus demonftravimus, proportione plurimum receffura fit. Namque in univerfum, corpori cuiliber, per aërem aliudve liquidum labenti, certus celeritatis modus, pro ratione ponderis ac fuperficiei fux, conftitutus eft; quem excedere, aut potius ad quem pervenire nunquam poffic. Qux nempe celeritas ea eft, quam fi aër, aut liquor ille furfum tendens, haberet, fufpenfum corpus idem fibi innatans fuftinere poffet. Verum de his, alias fortaffe, pluribus agendi occafio erit.

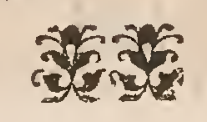




\section{HOROLOGII}

\section{OSCILLATORII}

\section{$P A R S Q U I N T A$.}

Confructionem aliam, è circulari pendulorum motu deduCtam, continens; ET Theoremata deVi Centrifuga.

$\mathrm{E}$

ST \& aliud Ofcillatorii motus genus, præter id quod hactenus pertractavimus. Ejufmodi nempe, quo, per circuli ambitum, pendulum pondus circumfertur. Vnde aliud quoque horologii commentum deduximus, eodem fere tempore quo prius illud; certoque itidem $x$ quabilitatis principio nixum; fed cujus ufus minus percrebuit, propter alterius illius conftructionem, quodammodo fimpliciorem facilioremque. Plura tamen hujus quoque generis de quo nunc loquimur, nec fine fucceffu, conftructa fuere : eftque in his fingulare illud, quod continuo atque æquabili motu circumferri cernitur index poftremus, qui fecunda fcrupula defignar; cum in priore noftro horologio, omnibufque aliis, fubfultim quafi feratur. Item hoc quoque, quod abfque ftrepitu, fonoque omni, moveantur hac ratione confructa automata. quanquam, ad obfervationes aftronomicas, fonus ad fingula fecunda fcrupula repetitus, utilitate non careat. Et conftitueram quidem, defcriptionem horum cum iis demun edere, qux ad motum circularem \& Vim Centrifugam, ita enim eam vocare liber, attinent; de quo argumento plura dicenda habeo, quam qux hoc tempore exequi vacet. Sed, ut nova nec inutili fpeculatione maturius fruantur harum rerum ftudiofi, neve cafu aliquo intercidat, hanc quoque partem, præter deftinatum, cæteris adjunxi, qua machinæ hujus fabrica breviter expo.. nitur, fimulque Theoremata traduntur, ad vim centrifugam pertinentia; demonftratione ipforum in aliud rempus dilata.

\section{Horologii fecundi confructio.}

Non neceffarium duxi, ut rotarum, quibuis interiora horologii conftant, difpofitionem hic exhiberem; cum ea ab artificibus fa- 

partis hic figura expreffa eft.

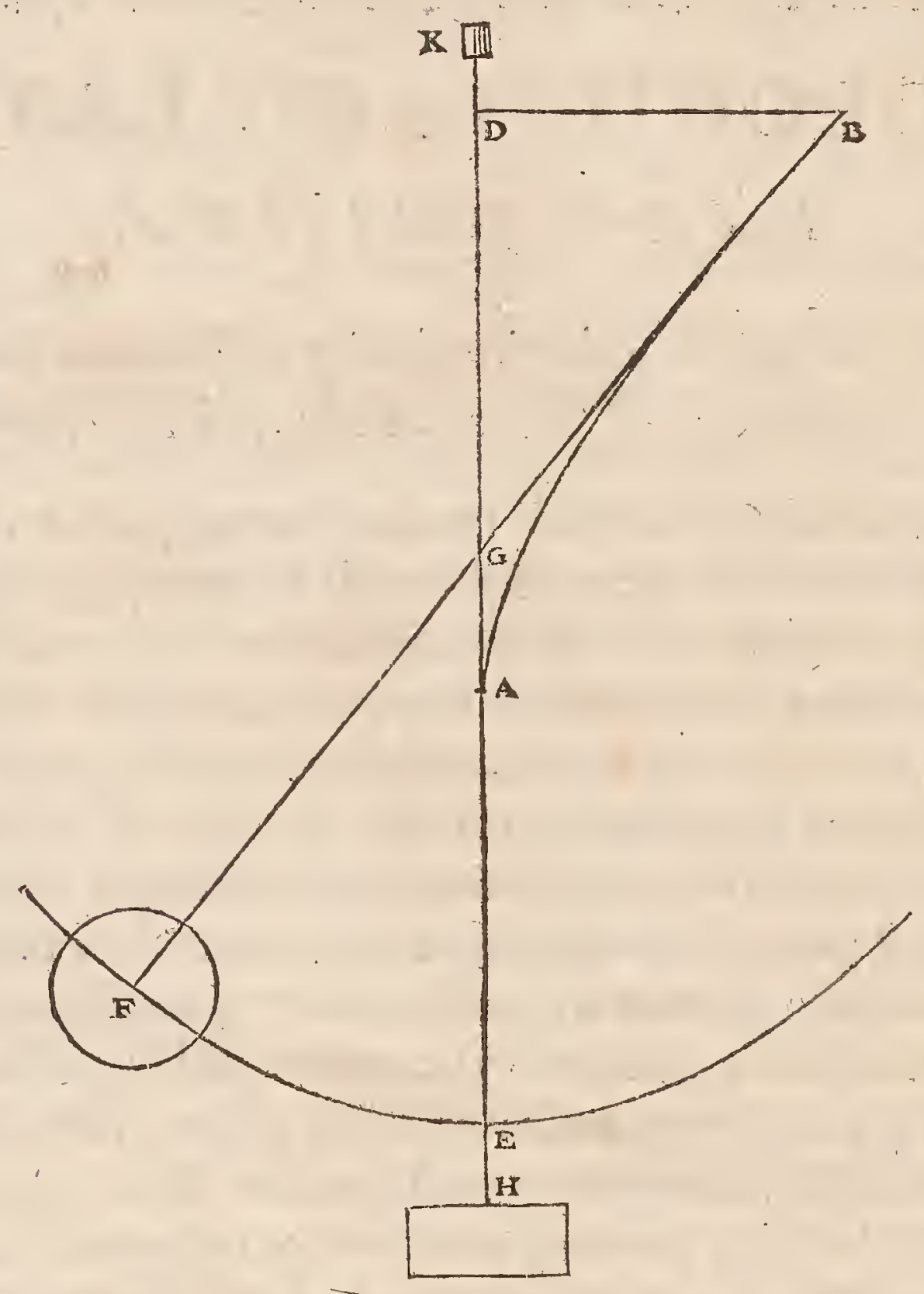

Axis D H ad horizontem erectus intelligendus eft, ac fuper polis duobus mobilis. Huic ad A affixa eft lamina, latitudine aliqua prædita, curvataque fecundum lineam A B; quæ eft paraboloides illa de qua oftendimus, propof. 8. partis 3, evolurione ejus, poftquam ipfi recta quædam juncta fuerit, defcribi parabolam. Ea recta bic eft A E; parabolam vero, ex evolutione totius B A E defcriptam, refert linea E F. Filum curvæ B A applicatum, cujus extremo puncto parabola defcribitur, eft B G F. Pondus illi affixum F. Dum autem axis $\mathrm{D} H$ in fefe vertitur, filum $\mathrm{B} G \mathrm{~F}$, in rectam lineam extenfum, fphærulam $\mathrm{F}$ una circumducit, ita ut circulos horizonti parallelos percurrat; qui majores minorefve erunt, prout majori aut minori viaxis $\mathrm{DH}$, ab rotis horologii in tympanidium $\mathrm{K}$ agentibus, incitabitur: fed ita, ut omnes in fuperficie conoidis parabolici contineantur. Atque hoc ipfo æqualia femper circuitus tempo- 
ra evadent, ut ex is, qux de hoc motu poftea dicemus, apparebit. S E C UND I

Quod fi circuicus fingulos, fecundorum fcrupulorum femiffes HOROIOGII $_{\text {OECRIOT. }}$ notare velimus, oportet latus rectum parabolæ E F effe 4 - unciarum pedis Horarii noftri, hoc eft dimidium longitudinis penduli, cujus fingula of cillationes femifcrupulum fecundum impenderent. Ex parabolæautem latere recto, pender magnitudo lateris reOti paraboloidis $A B$; quippe quod illius $\frac{27}{16}$ continer : atque item longirudo $A$ E, qua lateris recti parabolæ dimidium eft. Si vero fecunda frupula unoquoque circuicu expleri defideremus, quadrupla priorum accipienda funt, tum latera recta, tum linea $\mathrm{A}$.

Porro, etfi flum B G F veluti unicum ac fimplex hactenus defignavimus, fciendum tamen longe præftare ut parte fuperiori duplex fit, ac verfus $\mathrm{F}$ in angulum coeat, 20 vel 30 partium. In quem finem \& laminx A B latitudo ad B canta effe debet, quanta ifti filorum divaricationi fufficit, vel \& ipła bifida facienda. Hoc pacto enim mocus circularis ponderis.F, abfque alio ullo adminiculo, continuatur, ac filum utrumque fibi annexum in rectum extendit; quod non faceret, fi unico tantum filo teneretur. Vbitamen vim illam ab horologii rotis, vel pondere vel alia pocentia motis, ad continuationem hujus motus circularis requiri fciendum. Qux nempe vis per tympanidium $\mathrm{K}$ ad axem $\mathrm{K} \mathrm{H}$ pervenir, ac minimo nifu, motum fphæræ $\mathrm{F}$ femel inditum, confervat.

Hoc autem quo facilius poffit, liberrimam axis $\mathrm{K} H$ revolutionem effe oportet. Quod nulla ratione melius perfici compertum, quam fi, parte fui ima, durato chalybe conftet, fuppofitamque habeat adamantis fuperficiem planam; cujus minima quævis particula hic fufficit, fubter laminam perforatam collocanda.

Caterum in locum fili B G F, qua parte curva A B applicari debet, catenulam tenuem ex auro, aliove metallo, adhibere licebit, quo melius invariata fervetur longitudo. A tque hoc in priore quoque horologio, ubi pendulum inter cycloides fufpenfum eft, experti fumus. Sed ibi flexus catenulæ continuus, attritu annulorum, perexiguo licet, non parum impedit liberam penduli agitationem.

\section{E V I C E N T R I F V G A ex motu circulari, Theoremata.}

I.

S I mobilia duo equalia, aqualibus temporibus circumfe1 rentias inaquales percurrant; erit vis centrifug in ma- 
160

DE YICEN- jori circumferentia, ad eam qua in minori, ficut ip $\int e$ interfe circumferentie, vel earum diametri.

\section{I.}

Si duo mobilia aqualia, equali celeritate ferantur, in circumferentiis inequalibus; erunt corum vires centrifuge in ratione contraria diametrorum.

\section{I I.}

Si duo mobilia aqualia in circumferentiis aqualibus ferantur, celeritate inaquali, fed utraque motu aquabili, qua. lem in his omnibus intelligivolumus; erit vis centrifugavelocioris, ad vim tardioris, in ratione duplicata celeritatum.

\section{V.}

Si mobilia duo equalia, in circumferentiis inequalibus circumlata, vim centrifugam aqualem habuerint; erit tempus circuitus in majori circumferentia, ad tempus circuitus in minori, in fubdupla ratione diametrorum.

\section{$\mathrm{V}$.}

Si mobile in circumferentia circuli feratur ea celeritate, quam acquirit cadendo ex altitudine, que fit quarte parti diametri agualis; habebit virn centrifugam fun gravitail equalem; hoc eft, eadem vi funem quo in centro detinetur intendet, atque cum ex eo fuspenfum eft.

\section{$\mathrm{VI}$.}

In cava fuperficie conoidis parabolici, quod axem ad perpendiculum erectum babeat, circuitus omnes mobilis, circumferentias borizonti parallelas percurrentis, froe parve fue magne fuerint, aqualibus temporibus peraguntur: que tempora engula equantur binis of cillationibus penduli, cujus longitudo fit dimidium lateris recti parabole genitricis.

\section{I I.}

Si mobilia duo, ex flis inequalibus suppenfa, gyrentur ita ut circumferentias horif onti parallelas percurrant, capite altero fli immoto manente; fuerint autem conorum, quorum Juperficiem flla boc motu de cribunt, altitudines aquales; tempora quoque circulationum aqualia erunt. 
Si mobilia duo, utiprius, motw conico gyrentur, filis aquaIRIY UIGA libus vel inequalibus fupenfa; fuerintque conorum altitudines inaquales; erunt tempora circulationum in fubduplicata ratione ipfarum altitudinum.

\section{X.}

Sipendulum, motu conico latum, circuitus minimos faciats corum ingulorum tempora, ad tempus cafus perpendicularis ex dupla penduli altitudine, eam rationem habent, quam circumferentia circuli ad diametrum : ac proinde aqualia funt tempori duarum of cillationum lateralium, ejufdem penduli, minimarum.

X.

Si mobile in circumferentia feratur, circuitusque fingulos abfolvat eo tempore, quo penalulum, longitudinem femidiametri circumferentice ejus habens, motu conico circuitum minimum abfolveret, vel duplicem of cillationem minimam lateralem: habebitvim centrifugam fue gravitati aqualem.

\section{$\mathrm{X} \mathrm{I}$.}

Penduli cujuflibet, motu conico lati, tempora circuitus aqualia erunt tempori cafus perpendicularis, ex altitudine penduli flo equali; cum angulus inclinationis fli, ad planum borizontis, fuerit partium 2. Scrup. 54, proxime. Exacte vero, fo anguli dicti finus fuerit ad radium, ut quadratum circulo infcriptum ad quadratum à circumferentia ejus.

\section{I I.}

Si pendula duo, pondere aqualia, fed insquali fllorum longitudine, motu conico gyrentur, fuerintque conorum altitudines aquales; erunt vires, quibus flla fwa intendent, in eadem ratione que eft fllorum longitudinis.

\section{I I I.}

Sipendulum fimplex of cillatione laterali maxima agitetur, boc eft. fi per totum circuli quadrantem de cendat: ubi ad punctum imum circumferentix pervenerit, triplo majori vi filum funm trabet, quam fi ex illo smpliciter fupenfum foret. 


\section{CORRIGENDA.}

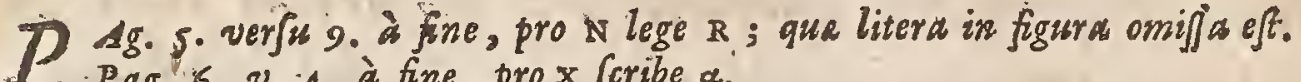
Lag. 6. v. 4. à fine, prox fcribe a.

Ibidem v. ult. pro $\mathrm{E}$ fribe $\varepsilon$. Et fic quoque pag. Sequ. verfu 2.

Pag. 7. v. 2. à fine, pro M $\mathrm{x} \int c r i b e \mathrm{x}$.

Pag. I6. $v$. I3. poft, tricefimamve, adde aut etiam minorem.

Pag. ead. v. 23. O 24. citantur literd $A, B, C$, que in figura omiffa funt. ubi linea bac eâdem 24. poft, à puncto autem $\mathrm{c}$, adde centro ofcillatioñis.

Pag. 26. v. 3. lege quadrato.

Pag. s6. v. 7. ̈̀ fine pro o $\Lambda$ lege s $\Lambda$.

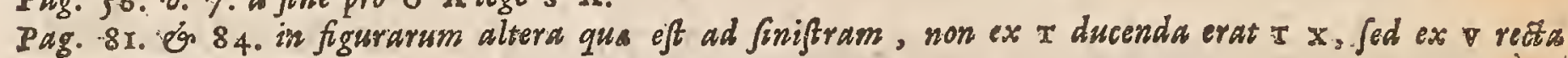
$\mathbf{v} \times$ parallela $\mathbf{I} \mathrm{K}$.

Pag. 8.5. v. II. à fine, post $\mathrm{K} M, \mathrm{I} \mathrm{N}$, adde, quarum hac major erit。

Pag. 86. $v$. I. pro a a $x$ lege a $x x$, bo dele so $y$.

Pag. 87. v. IO. à fine, pro F D fcribe B D.

Ibidem $v$. 2. aे fine, pro $\mathrm{F} \times$ Ccribe $\mathrm{A} \mathrm{R} \mathrm{I}$.

Item v. 3. à fine, lege continuati.

Pag. 9 \%. v. I. pro B. fcribe G.

Pag. ead. v. à fine s. lege volumus.

Pag. 99. v. 12. dele velut e.

Pag. TO4. v. I0.pro A D lege M.

Pag. 107. in fig. qua aid dextram, debebat punitum is effe ad alteram partem puncti

Pag. 'II. v. à fine 4. 6. É 7. pro $2 z \mathrm{~m}$ lege $2 x \mathrm{~m}$.

P.ig. 112. v. 2. pro $\frac{m m l l}{\theta}$, lege $\frac{m m-l l}{\theta}$.

RAg. 123. v. 20. pro \& H centrum gravitatis, lege, \& O H fubcentrica. 

qTS Huygens, Christian, 545 1629-1695.

$\mathrm{H} 98$

$\mathrm{RB}$

Christiani Hvgenii

MHT Horologivm Oscilla-. torivm.

Parisiis, 1673.

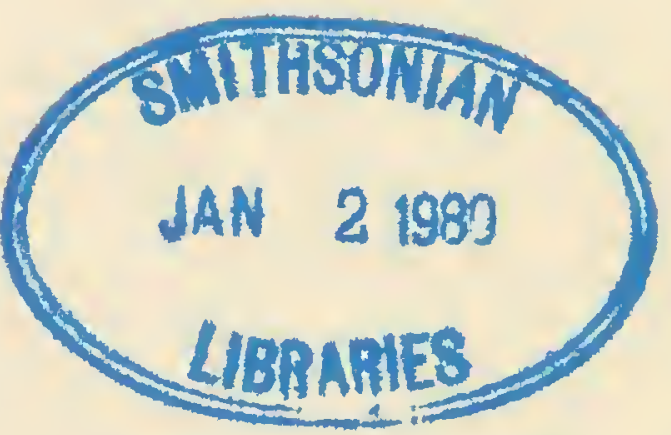





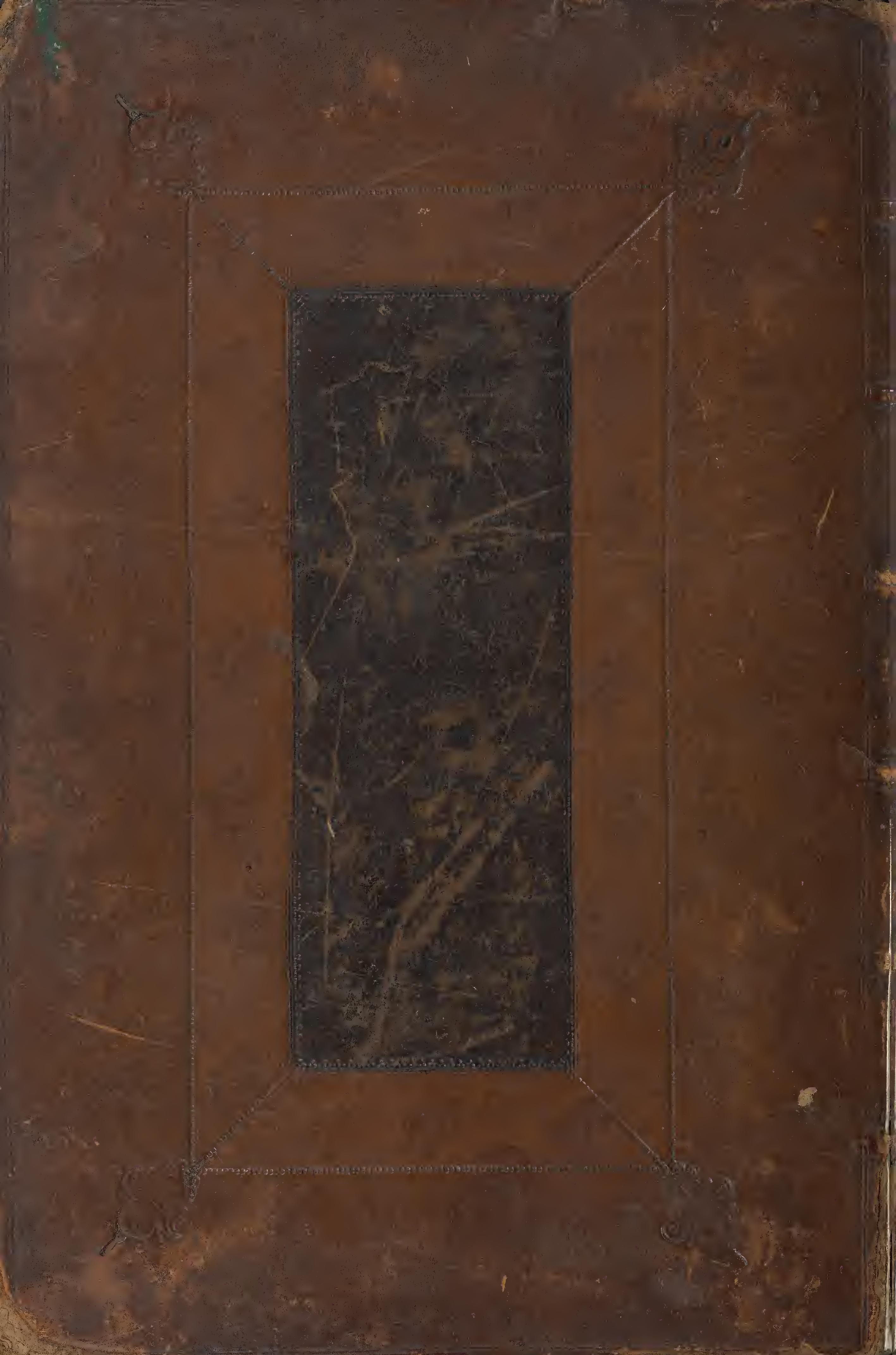

